

\title{
FRICTION MODELLING OF COATED SHEETS FOR
} FORMING APPLICATIONS

\author{
Meghshyam Prabhakar Shisode
}


This research was carried out under project number S22.1.14520b in the framework of the Partnership Program of the Materials innovation institute M2i (www.m2i.nl) and the Technology Foundation TTW (www.stw.nl), which is part of the Netherlands Organization for Scientific Research (www.nwo.nl).

Composition of the graduation committee:

Chairman and Secretary:

Prof. dr. ir. H.F.J.M. Koopman

University of Twente

Supervisor:

Prof. dr. ir. A.H. van den Boogaard University of Twente

Co-supervisor:

Dr. J. Hazrati

University of Twente

Members:

Prof. dr. ir. M.B. de Rooij

University of Twente

Prof. dr. ir. T. Tinga

University of Twente

Prof. dr. J.P. Ponthot

University of Liège

Prof. dr.-ing. A. Brosius

Technische Universität Dresden

Dr. ir. C.H.L.J. ten Horn

TATA Steel Europe

ISBN: - 978-94-641-9066-3

DOI: - 10.3990/1.9789464190663

1st printing October 2020

Keywords: asperity flattening, friction, multi-scale model, boundary lubrication, mixed lubrication, zinc coated sheet, sheet metal forming, surface texturing.

This thesis was prepared with LTEX by the author and printed by Gildeprint, Enschede, from an electronic document.

Copyright (C) 2020 by M.P. Shisode, Enschede, The Netherlands

All rights reserved. No parts of this thesis may be reproduced, stored in a retrieval system or transmitted in any form or by any means without permission of the author. Alle rechten voorbehouden. Niets uit deze uitgave mag worden vermenigvuldigd, in enige vorm of op enige wijze, zonder voorafgaande schriftelijke toestemming van de auteur. 


\title{
FRICTION MODELLING OF COATED SHEETS FOR FORMING APPLICATIONS
}

\section{DISSERTATION}

\author{
to obtain \\ the degree of doctor at the University of Twente, \\ on the authority of the rector magnificus, \\ Prof. dr. T.T.M. Palstra, \\ on account of the decision of the Doctorate Board \\ to be publicly defended \\ on Wednesday 28 October 2020 at 12.45 hrs
}

by

Meghshyam Prabhakar Shisode

born on 28 January 1986

in Sangamner, Maharashtra, India 
This dissertation has been approved by the supervisor:

Prof. dr. ir. A.H. van den Boogaard

and the co-supervisor:

Dr. J. Hazrati 
To Aai, Baba and Akshada. 

"[To] mechanical progress there is apparently no end: for as in the past so in the future, each step in any direction will remove limits and bring in past barriers which have till then blocked the way in other directions; and so what for the time may appear to be a visible or practical limit will turn out to be but a bend in the road."

- Osborne Reynolds 



\section{Summary}

The main challenges in the sheet metal forming industry are zero defect production, reducing the cost and lead time of new products. Finite element (FE) analysis is a standard tool for studying the formability of sheet metals in forming processes. Friction is a determining parameter which influences the simulation accuracy and reliability of these analyses. In the past, it has been verified that the coefficient of friction is not constant for given contacting surfaces during forming but varies with local contact conditions. Therefore, in forming processes the coefficient of friction is a transient phenomenon and changes from location to location. Nowadays, textured zinc coated steel sheets (GI) are widely used in forming applications to improve formability, corrosion resistance, durability and paint appearance. Therefore, an accurate description of friction for coated sheets is required in FE formability analyses.

Friction is a local phenomenon which depends on the local contact conditions at the tool-sheet metal interface. The contact condition is defined mainly by the real area of contact. Therefore, understanding asperity flattening mechanism is vital for a reliable modelling of friction. In a typical deep drawing process, the sheet metal is subjected to normal load, sliding and stretching. In this thesis, asperity flattening models are presented for normal loading, sliding and combined normal loading and stretching. The models account for the coating and substrate material behaviour and measured surface topography of the rough surface. In this study, an experimental setup is developed to investigate the effect of combined normal load and bulk strain on real area of contact. The experimental results are used to validate the normal load flattening model and to calibrate model parameters of combined normal load and bulk strain flattening model. The experimental investigation revealed that the surface deformation depends not only on the material behaviour and coating thickness but also on surface topography.

In deep drawing processes, the tribological system is defined by 
lubricant, surface topographies of tool and sheet metal and their materials. A boundary lubrication or mixed lubrication regime may occur at the tool-sheet metal contact depending on the lubricant amount, tool and sheet surface topographies and other process parameters. If the lubricant amount is not enough to fill the valleys of contacting surfaces, a boundary lubrication condition exists in which the total contact load at the interface is carried by asperity contacts. On the other hand, if the lubricant amount is enough, a hydrodynamic pressure may develop in the lubricant which shares some part of the contact load. Therefore, the coefficient of friction in the mixed lubrication regime is lower than in the boundary lubrication regime. In this thesis, the multi-scale friction model in the boundary and mixed lubrication regimes are presented for coated sheets. Measured surface topographies of sheet and tools are used as the input. The local contact locations and their sizes at the tool-sheet interface are determined for a given loading condition using the flattening models. The friction force at each contact patch is determined by adapting a single asperity micro-scale ploughing model from which the overall coefficient of friction is determined. A recently developed 3D elliptical paraboloid shaped single asperity ploughing model which accounts for 3D asperity shape, size, and orientation is used. The boundary friction model is implemented in an in-house FE code DiekA for forming simulations. The boundary friction model is coupled with the average Reynolds equation to describe friction in the mixed lubrication regime. The hydrodynamic pressure developed in the lubricant is determined by solving the average Reynolds equation in the FE domain. To account for the influence of surface topographies, flow factors are determined for measured surface topographies of tool and sheet which are used in the average Reynolds equation. Deep drawing experiments are performed to demonstrate the validity of the boundary and mixed lubrication friction model. The comparison of experiments and simulations shows good agreement.

Sheet surface texturing is critical in the steel industry since it influences the tribological performance, formability, and paint appearance of the sheet surface. In forming processes, variations in tribological systems due to tool wear and applied lubricant amount can lead to undesirable variation in friction behaviour. Designing a surface texture can be an option to control and improve the robustness in friction behaviour. Surfaces textured by electro-discharge textured (EDT) rolls are widely used in industry, resulting in semi-deterministic surface texture. Similarly, laser textured (LT) surfaces are gaining increasing attention due to its better control on resulting surface 
texture. In this thesis, the influence of surface texture parameters on friction behaviour is studied. For this purpose, surface generation algorithms are implemented to generate EDT and LT surfaces. The effect of change in tool roughness and lubricant amount on the coefficient of friction is studied to determine the surface texture parameters which result in the least variation in friction coefficient. Furthermore, a component level case study is presented to demonstrate the relation between surface texture and robustness in friction coefficient. The results show that the developed friction model can be used to design surface textures for forming processes under given process parameters for robust friction behaviour. 



\section{Samenvatting}

De grootste uitdagingen in de industriële plaatmetaal vervormingsprocessen zijn zero defect productie, reductie van de kosten en verkorten van de doorlooptijden van nieuwe producten. Eindige Elementen (EE) analyse is een standaard gereedschap om de vervormbaarheid van plaatmetaal in vervormingsprocessen te onderzoeken. Wrijving is een bepalende factor die de simulatie nauwkeurigheid en de betrouwbaarheid van deze analyses beïnvloed. In het verleden is aangetoond dat de wrijvingscoëfficiënt niet constant is voor oppervlakken die in contact zijn tijdens vervorming, maar varieert met lokale contactcondities. Daarom is, in vervormingsprocessen, de wrijvingscoëfficiënt een fenomeen dat varieert van locatie tot locatie. Tegenwoordig wordt getextureerd zink gecoat plaatstaal (GI) wijd gebruikt in vervormingstoepassingen om de vervormbaarheid, weerstand tegen corrosie, duurzaamheid en het uiterlijk van de verf te verbeteren. Daarom is een accurate beschrijving van de wrijving voor gecoate platen in de EE vervormbaarheidsanalyses noodzakelijk.

Wrijving is een lokaal fenomeen dat afhangt van de lokale contactcondities op het grensvlak tussen gereedschap en plaatmetaal. De contactconditie word voornamelijk bepaald door het werkelijk contactoppervlak. Daarom is inzicht in het afvlakken van de ruwheidstoppen essentieel voor het betrouwbaar modelleren van wrijving. In een typisch dieptrekproces, wordt het plaatmetaal onderworpen aan normaalbelasting, glijden en rek. In dit proefschrift worden modellen gepresenteerd voor het afvlakken van de ruwheidstoppen onder normaalbelasting, glijden en gecombineerde normaalbelasting en rek. De modellen beschouwen het materiaalgedrag van de coating en het substraat en de gemeten topografie van plaat en gereedschap. In dit onderzoek is een experimentele opstelling ontwikkeld om het effect van de gecombineerde normaalbelasting en de bulk-rek op het werkelijke contactoppervlak te onderzoeken. De experimentele resultaten worden gebruikt om het afplattingsmodel onder normaalbelasting te valideren en om de model parameters van het afplattingsmodel onder gecombineerde 
normaalbelasting en bulk-rek te kalibreren. Het experimentele onderzoek onthulde dat de oppervlakvervorming niet alleen bepaald wordt door het materiaalgedrag en de dikte van de coating, maar ook door de topografie van het oppervlak.

In het dieptrekproces wordt het wrijvingssysteem gedefinieërd door het smeermiddel, de topografieën van het oppervlak van gereedschap en plaatmetaal en hun materialen. Een grenssmeringsgebied of een gemengd gesmeerd gebied kan voorkomen op het contact tussen gereedschap en plaatmetaal afhankelijk van de hoeveelheid smeermiddel, de topografieën van gereedschap en plaatoppervlak en andere proces parameters. Als de hoeveelheid smeermiddel niet genoeg is om de valleien van de oppervlakken die in contact zijn op te vullen, dan bestaat er een grenssmeringsgebied waarin de totale contactbelasting op de interface gedragen wordt door contact van de ruwheidstoppen. Aan de andere kant, wanneer er genoeg smeermiddel is, kan er een hydrodynamische druk ontstaan in het smeermiddel dat een deel van de contactbelasting draagt. Daarom is de wrijvingscoëfficiënt in het gemengd gesmeerde gebied lager dan in het grenssmeringsgebied. In dit proefschrift zullen multi-scale wrijvingsmodellen voor het grenssmeringsen gemengd gesmeerde gebied gepresenteerd worden voor gecoate platen. Gemeten topografieën van plaatmetaal en gereedschap worden gebruikt als input. De lokale contact locaties en hun groottes op de gereedschapplaat interface zijn bepaald voor een gegeven belasting, gebruikmakende van de afplattingsmodellen. De wrijvingskracht op elke contact patch wordt bepaald op basis van een ploegmodel op microschaal van een enkele ruwheidstop waarop de totale wrijvingscoëfficiënt word bepaald. Een recent ontwikkeld ploegmodel met een enkele 3D elliptische parabool ruwheidstop, welke de 3D vorm van de ruwheidstop, grootte en oriëntatie meeneemt in de berekening, wordt gebruikt. Het grenssmeringsgebied is geïmplementeerd in een interne EE code voor vervormingssimulaties, DiekA. Het grenssmeringswrijvingsmodel is gekoppeld met een gemiddelde Reynoldsvergelijking om de wrijving te beschrijven in het gemengd gesmeerde gebied. De hydrodynamische druk die in het smeermiddel ontwikkelt wordt bepaald door de gemiddelde Reynolds-vergelijking op te lossen in het EE domein. Om rekening te houden met de invloed van topografieën, worden stromingsfactoren bepaald voor gemeten topografieën van gereedschap en plaat die worden gebruikt in de gemiddelde Reynolds-vergelijking. Er worden dieptrek-experimenten uitgevoerd om de validiteit van het grenssmeringsen gemengd gesmeerde wrijvingsmodel aan te tonen. De vergelijking van experimenten en simulaties laat een goede overeenkomst zien. 
Texturering van plaatoppervlakken is van cruciaal belang in de staalindustrie, aangezien het de tribologische prestatie, vervormbaarheid en het uiterlijk van de verf van het plaatoppervlak beïnvloedt. Bij vervormingsprocessen kunnen variaties in wrijvingssystemen als gevolg van gereedschapsslijtage en aangebrachte hoeveelheid smeermiddel leiden tot ongewenste variatie in wrijvingsgedrag. Het ontwerpen van een oppervlaktestructuur kan een optie zijn om de robuustheid in wrijvingsgedrag te beheersen en te verbeteren. Oppervlakken getextureerd door elektro-ontladen getextureerde (EDT) worden veel gebruikt in de industrie, wat resulteert in een semi-deterministische oppervlaktestructuur. Evenzo krijgen laser gestructureerde (LT) oppervlakken steeds meer aandacht vanwege de betere controle op de resulterende oppervlaktetextuur. In dit proefschrift wordt de invloed van oppervlaktestructuurparameters op wrijvingsgedrag bestudeerd. Voor dit doel worden algoritmen voor het genereren van oppervlakken geïmplementeerd om EDT- en LT-oppervlakken te genereren. Het effect van verandering in de ruwheid van het gereedschap en de hoeveelheid smeermiddel op de wrijvingscoëfficiënt wordt bestudeerd om de parameters van de oppervlaktetextuur te bepalen die resulteren in de minste variatie in wrijvingscoëfficiënt. Bovendien wordt een casestudy op componentniveau gepresenteerd om de relatie tussen oppervlaktetextuur en robuustheid in wrijvingsgedrag aan te tonen. De resultaten laten zien dat het ontwikkelde wrijvingsmodel kan worden gebruikt om oppervlaktestructuren te ontwerpen voor vervormingsprocessen onder gegeven procesparameters voor robuust wrijvingsgedrag. 



\section{Nomenclature}

Some of the symbols appear more than once, their meaning follows from their context.

\section{Greek symbols}

$\begin{array}{llr}\alpha & \text { fractional real area of contact } & {[-]} \\ \bar{\alpha} & \text { mean apparent contact area of asperity } & {\left[\mathrm{mm}^{2}\right]} \\ \beta & \text { asperity orientation angle w.r.t. sliding direction } & {[\mathrm{deg}]} \\ \delta & \text { local surface height from mean line } & {[\mathrm{mm}]} \\ \varepsilon & \text { strain } & {[-]} \\ \dot{\varepsilon} & \text { strain rate in bulk material } & {\left[\mathrm{s}^{-1}\right]} \\ \varepsilon_{\text {eq }} & \text { equivalent plastic strain } & {[-]} \\ \eta & \text { dynamic viscosity } & {[\mathrm{Pas}]} \\ \mu & \text { coefficient of friction } & {[-]} \\ \psi & \text { ploughing depth correction factor } & {[-]} \\ \rho_{\mathrm{a}} & \text { asperity density } & {\left[\mathrm{mm}^{-2}\right]} \\ \rho & \text { density } & {\left[\mathrm{kg}^{3} / \mathrm{m}^{3}\right]} \\ \rho_{\mathrm{LT}} & \text { dimple area density of LT surface } & {[\%]} \\ \rho_{\mathrm{EDT}} & \text { EDT event density } & {\left[\mathrm{mm}^{-2}\right]} \\ \sigma_{\mathrm{y}} & \text { yield strength } & {[\mathrm{MPa}]} \\ \tau_{\mathrm{BL}} & \text { shear strength of the interfacial boundary layer } & {[\mathrm{MPa}]} \\ \tau_{\text {visc }} & \text { lubricant viscous shear stress } & {[\mathrm{MPa}]} \\ \tau_{\text {lub1 }} & \text { shear stress at workpiece-fluid interface } & {[\mathrm{MPa}]} \\ \tau_{\text {lub2 }} & \text { shear stress at tool-fluid interface } & {[\mathrm{MPa}]} \\ \tau_{\text {tot }} & \text { total shear stress } & {[\mathrm{MPa}]} \\ \tau_{\text {solid }} & \text { nodal shear stress due to direct asperity contact } & {[\mathrm{MPa}]} \\ \Phi & \text { fan angle } & {[-]} \\ \Phi_{\mathrm{P}} & \text { pressure flow factor tensor } & {[-]} \\ \Phi_{\mathrm{S}} & \text { shear flow factor tensor } & {[-]} \\ \phi & \text { surface height distribution function } & {\left[\mathrm{mm}^{-1}\right]}\end{array}$




\section{Roman symbols}

\begin{tabular}{|c|c|c|}
\hline$A$ & contact (patch) area & {$\left[\mathrm{mm}^{2}\right]$} \\
\hline$A_{\text {nom }}$ & nominal area & {$\left[\mathrm{mm}^{2}\right]$} \\
\hline$A_{0}$ & fractional real area of contact due to normal load & {$[-]$} \\
\hline$A_{\mathrm{s}}$ & fractional real area of contact due to sliding & {$[-]$} \\
\hline B & hardness factor & {$[-]$} \\
\hline$D_{\mathrm{EDT}}$ & crater outer diameter of EDT event & {$[\mu \mathrm{m}]$} \\
\hline$d$ & normal displacement of tool & {$[\mathrm{mm}]$} \\
\hline$d$ & ploughing depth & {$[\mathrm{mm}]$} \\
\hline$d^{\prime}$ & ploughing depth corrected for pile-up effects & {$[\mathrm{mm}]$} \\
\hline$d_{\mathrm{EDT}}$ & crater inner diameter of EDT event & {$[\mu \mathrm{m}]$} \\
\hline$d_{\mathrm{LT}}$ & dimple diameter of LT surface & 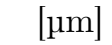 \\
\hline$F$ & force vector & {$[\mathrm{N}]$} \\
\hline$F_{a s p}$ & normal force on asperity & {$[\mathrm{N}]$} \\
\hline$F_{b h f}$ & blankholder force & {$[\mathrm{N}]$} \\
\hline$f_{\mathrm{d}}$ & material deposition factor & {$[-]$} \\
\hline$F_{\text {int }}$ & internal force & {$[\mathrm{N}]$} \\
\hline$F_{\text {friction }}$ & friction force vector & {$[\mathrm{N}]$} \\
\hline$F_{\mathrm{N}}$ & normal force & {$[\mathrm{N}]$} \\
\hline$F_{\mathrm{sh}}$ & total shear force & {$[\mathrm{N}]$} \\
\hline$H$ & hardness, contact pressure & {$[\mathrm{MPa}]$} \\
\hline$h$ & height of asperity & {$[\mathrm{mm}]$} \\
\hline$h$ & local fluid film thickness & {$[\mathrm{mm}]$} \\
\hline$h_{\text {avg }}$ & average fluid film thickness & {$[\mathrm{mm}]$} \\
\hline$h_{\mathrm{EDT}}$ & crater depth of EDT event & [1 $]$ \\
\hline$h_{\mathrm{LT}}$ & dimple depth of LT surface & [1 $]$ \\
\hline$h_{\mathrm{T}}$ & nominal surface separation & {$[\mathrm{mm}]$} \\
\hline$h_{\mathrm{t}}$ & transition height & {$[\mathrm{mm}]$} \\
\hline I & second order unit tensor & {$[-]$} \\
\hline$k$ & shear strength of workpiece & {$[\mathrm{MPa}]$} \\
\hline$k_{\alpha}$ & constant shear factor & {$[-]$} \\
\hline$K_{\mathrm{d}}$ & constant relating $d_{\mathrm{EDT}}$ and $D_{\mathrm{EDT}}$ & {$[-]$} \\
\hline$L$ & length of surface & {$[\mathrm{mm}]$} \\
\hline$l$ & mean half spacing between asperities & {$[\mathrm{mm}]$} \\
\hline$m$ & number of nodes & {$[-]$} \\
\hline$N$ & number of contacting asperities & {$[-]$} \\
\hline$\hat{\mathrm{n}}$ & outward normal unit vector & {$[-]$} \\
\hline$P_{0}$ & $\begin{array}{l}\text { ratio of contact pressure and fractional real area } \\
\text { of contact }\end{array}$ & $\mathrm{N} / \mathrm{a}$ \\
\hline
\end{tabular}


$P_{\text {lub }} \quad$ lubricant pressure

$$
\begin{array}{r}
{[\mathrm{MPa}]} \\
{[\mathrm{MPa}]} \\
{[\mathrm{MPa}]} \\
{\left[\mathrm{mm}^{2} / \mathrm{s}\right]} \\
{\left[\mathrm{mm}^{2} / \mathrm{s}\right]}
\end{array}
$$

nominal pressure

$P_{\text {sol }} \quad$ solid-solid contact pressure

$Q_{\text {rough }}$

flow through a pair of rough surfaces per unit

$Q_{\text {smooth }}$ width

$\mathrm{Ra}$

flow through a pair of smooth surfaces per unit width

$R_{\text {conj }}$

average $2 \mathrm{D}$ profile roughness

$R_{\text {min }}$

radius of conjoined EDT event

$R_{\text {maj }}$

semi-minor axis of asperity base

[um]

[mm]

$[\mathrm{mm}]$

semi-major axis of asperity base

[mm]

projected length of the asperity perpendicular to

$[\mathrm{mm}]$

the sliding direction

$R_{\mathrm{sm}}$

mean peak spacing

radius

$\mathrm{Sa}$

average surface roughness

$\mathrm{Sq}$

RMS surface roughness

RMS roughness of tool

$\mathrm{Sq}_{\mathrm{t}}$

$\mathrm{Sq}_{\mathrm{wp}}$

$\hat{\mathrm{t}}$

RMS roughness of initial untextured surface

tangential unit vector

velocity vector

uniform rise of non-contacting bars

velocity vector of lower surface

[um]

[mm]

[pm]

$[\mu \mathrm{m}]$

[um]

[um]

$U$

$u$

velocity vector of upper surface

sliding velocity

volume

$V \quad$ velocity parameter

lubricant volume

penetrated volume of tool asperity

$V_{\text {pen }}$

$\begin{array}{ll}v_{1} & \text { velocity vector of workpiece } \\ v_{2} & \text { velocity vector of tool }\end{array}$ $[\mathrm{mm} / \mathrm{s}]$

$\begin{array}{ll}v_{\mathrm{d}} & \text { downward velocity of deforming asperities } \\ v_{\mathrm{u}} & \text { upward velocity non-contacting surface }\end{array}$ $[\mathrm{mm} / \mathrm{s}]$

$v_{\mathrm{u}}$ punch speed

\section{Abbreviations}

BA bearing area

COF coefficient of friction

EDT electro-discharge textured 
FE finite element

FLD forming limit diagram

LHS left hand side

LT laser textured

MPM material point method

RFT rotating friction tester

RHS right hand side

RMS root mean square 


\section{Contents}

Summary ix

Samenvatting xiii

Nomenclature $\quad$ xvii

1 Introduction 1

1.1 Sheet metal forming $(\mathrm{SMF}) \ldots \ldots \ldots \ldots$

1.2 Sheet material and surface texturing . . . . . . . . . . . . 2

1.3 Friction in deep drawing . . . . . . . . . . . . . . . . . 3

1.4 Motivation . . . . . . . . . . . . . . . . 4

1.5 The objective of this research . . . . . . . . 5

1.6 Overview ....................... 6

2 Normal load flattening model for coated sheets 9

2.1 Introduction . . . . . . . . . . . . . . . . . 10

2.2 Flattening model . . . . . . . . . . . . . . . . . . 13

2.2.1 Single asperity FE model . . . . . . . . . . . . . 14

2.2.2 Multiple asperity flattening model . . . . . . . . . 18

2.2 .3 Analytical flattening model . . . . . . . . . . . 20

2.3 Experiments and model validation . . . . . . . . . . . 23

2.3.1 Height distribution measurement . . . . . . . . . . 23

2.3.2 Experimental setup . . . . . . . . . . . . . . . . . 25

2.3 .3 Results . . . . . . . . . . . . . . . . 26

2.3.4 Model results and validation . . . . . . . . . . . 29

2.4 Summary and conclusions . . . . . . . . . . . . 31

3 Effect of bulk strain on real area of contact 33

3.1 Introduction . . . . . . . . . . . . . . 34

3.2 Combined normal load and bulk strain experiments . . . . 36 
3.2 .1 Experimental setup . . . . . . . . . . . . . . . 36

3.2 .2 Sheet samples and test procedure . . . . . . . . 37

3.2 .3 Results . . . . . . . . . . . . . . . . . 39

3.3 Effect of different parameters on real area of contact . . . . 43

3.3 .1 FE modelling . . . . . . . . . . . . . . . . 43

3.3.2 Discussion . . . . . . . . . . . . . . . . 45

3.4 Analytical model to estimate real area of contact . . . . . 48

3.4.1 Description of rough surface . . . . . . . . . . . 48

3.4.2 Model description . . . . . . . . . . . . . . . . 49

3.4 .3 Model results and discussion . . . . . . . . . . 51

3.5 Summary and conclusions . . . . . . . . . . . . 52

4 Boundary friction model for coated sheets 55

4.1 Introduction . . . . . . . . . . . . . . . . 56

4.2 Asperity flattening step . . . . . . . . . . . . 57

4.3 Estimation of friction coefficient . . . . . . . . . . . . 58

4.3 .1 Single asperity model . . . . . . . . . . . . . . . 59

4.3.2 Multi-asperity friction model . . . . . . . . . . 62

4.3.3 Fitting the elliptical parabola to tool asperities . . . 63

4.3.4 Updating the real area of contact due to sliding . . . 64

4.4 Friction experiments . . . . . . . . . . . . . 65

4.4.1 Determining shear factor ' $k_{\alpha}$ ' . . . . . . . 68

4.4.2 Measurement of the friction coefficient and comparison with model predictions . . . . . . . . . . . 69

4.5 Application in deep drawing processes . . . . . . . . . . . . 70

4.5.1 Cup drawing experiments . . . . . . . . . . 70

4.5.2 Model implementation to forming simulations . . . . 72

4.5.3 Comparison of experiments and FE simulations . . . 74

4.6 Summary and conclusions . . . . . . . . . . . . . . 77

5 Mixed lubrication friction model $\quad 79$

5.1 Introduction . . . . . . . . . . . . . . 80

5.2 Formulation of the average Reynolds equation . . . . . . . 82

5.3 Determination of flow factors . . . . . . . . . . 83

5.3 .1 Pressure flow factor . . . . . . . . . . . . 84

5.3 .2 Shear flow factor . . . . . . . . . . . . . 86

5.3 .3 Solution scheme . . . . . . . . . . . . . . . 86

5.3.4 Finite difference scheme to determine flow factors . . 88

5.3.5 Deformed surface topography and film thickness . . 90

5.3.6 Results of the flow factor calculation . . . . . . . . 91 
5.4 Mixed lubrication friction for forming processes . . . . . 95

5.4.1 Coefficient of friction in mixed lubrication . . . . . 96

5.5 Experiments and validation . . . . . . . . . . . . . 99

5.5.1 Deep drawing experiments: cross-die . . . . . . . . 99

5.5.2 FE simulations using the new friction model . . . . 100

5.5.3 FE results and comparison with experiments . . . . 102

5.6 Summary and conclusions . . . . . . . . . . . . . 106

6 Modelling textured surfaces and study of friction $\quad 107$

6.1 Introduction . . . . . . . . . . . . . . . . . 108

6.2 Modelling LT surfaces . . . . . . . . . . . . . . . . . . . 109

6.3 Effect of LT surface parameters on friction . . . . . . . . . 112

6.3.1 LT surface: results and discussion . . . . . . . . . . 115

6.4 Modelling EDT surface . . . . . . . . . . . . . . . 117

6.4.1 EDT roll surface . . . . . . . . . . . . . . . . 118

6.4.2 Roughness transfer model . . . . . . . . . . . . . 119

6.5 Effect of EDT surface parameters on friction . . . . . . . . . 121

6.5.1 EDT surface: results and discussion . . . . . . . . 122

6.6 Robust friction behaviour: A case study . . . . . . . . . . . 124

6.7 Summary and conclusions . . . . . . . . . . . . . . 127

7 Conclusions and recommendations 129

A Linear friction test: GI sheet - sapphire 133

Research deliverables $\quad 135$ 



\section{Chapter 1}

\section{Introduction}

\subsection{Sheet metal forming (SMF)}

Sheet metal forming is a metalworking process of forming a flat sheet into a 3D metal part with plastic deformation without adding or removing material. The most common sheet metal forming processes are deep drawing, bending, stretching and spinning. Figure 1.1 illustrates the deep drawing process and typical car body parts manufactured by deep drawing. In deep drawing processes, a piece of sheet metal (blank) is placed on the die. The blank holder applies a compressive load on the blank to prevent wrinkling of the sheet and to control sliding of the sheet into the die cavity during drawing. The punch moves downward deforming the sheet plastically to its final shape. The punch force and blank holder force must be sufficient to deform a sheet to a desired final shape. The punch and the die together replicate the final or intermediate shape of the product. The stretching process is similar to the deep drawing process but in this case the blank is firmly clamped at its circumference and the punch is moved downward to induce a plastic deformation by stretching. In bending processes the punch is moved downward, bending the sheet metal around it to form the desired shape. The sheet metal in this case is free to move. The bending operation causes bending about one axis but a multiple bending sequence can be used to form a complex shape. The spinning process is also called spin forming which is used to form axisymmetric parts. In this process, a circular blank is rotated at a high speed and pressed against the die having an intended final product shape by a roller.

The deep drawing process can be used to manufacture products of complex geometries. In this case, the product is formed in multiple steps. The 

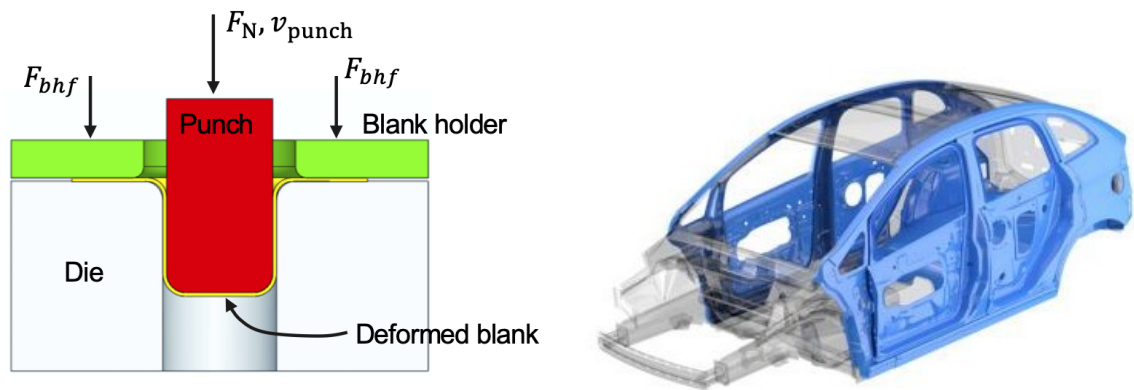

Figure 1.1 Illustration of the deep drawing process and typical car body side panels (blue parts) manufactured by deep drawing (source - TATA Steel website).

number of steps can sometimes be reduced by preheating the sheet material. The deep drawing process is widely used in the automotive, packaging, aerospace, construction equipment and home appliances industries. Considering this significant industrial relevance, the deep drawing process forms the main application basis of this thesis.

\subsection{Sheet material and surface texturing}

Sheet material has been evolving to meet ever increasing requirements such as material strength, formability, durability, corrosion resistance, paint

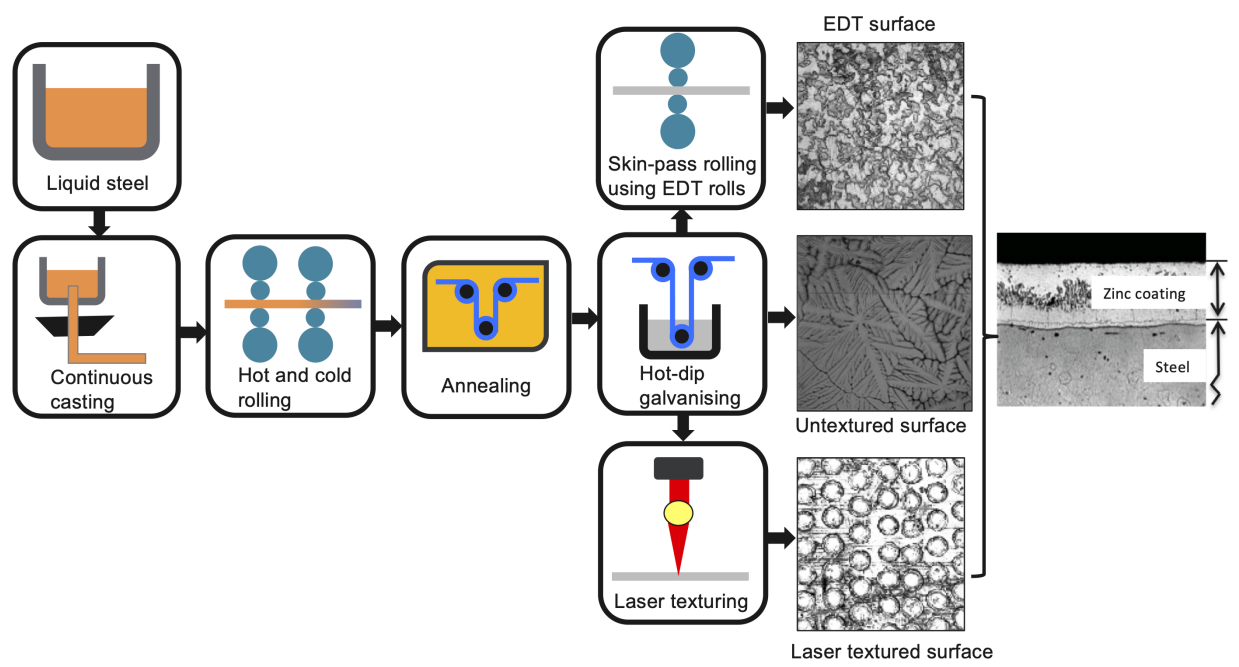

Figure 1.2 Production stages of galvanised steel (GI) sheet. 
appearance and cost. The most common sheet materials in industrial applications are steel and aluminium. Corrosion in steel sheet is a very serious issue which lowers the durability. Therefore, the steel sheets are often coated with zinc to prevent corrosion. In industry, hot-dip galvanising is the most widely used method due to its speed, simplicity and low operational cost. Figure 1.2 illustrates the typical stages involved in manufacturing of hot-dip galvanised steel sheet. In this process, a sheet is immersed in a bath of molten zinc at a temperature of around $445-455^{\circ} \mathrm{C}$. The blast furnace turns raw material (iron ore) into molten pig iron which is then treated to remove impurities and to control carbon content. The resulting molten metal is known as steel. The molten steel is converted to solid cast billets using a continuous casting process. The billets are rolled into thin sheets followed by annealing before hot-dip galvanising. The zinc coated steel sheet is commonly referred to as galvanised iron (GI) sheet. For typical automobile sheet metal parts, the zinc coating thickness of GI sheets is in the range of $\sim 7-20 \mu \mathrm{m}$.

Normally, the steel sheets are textured which offers better paint appearance and allows surface properties and tribological behaviour to be controlled. Nowadays, steel sheets textured by electro-discharge textured (EDT) rolls are widely used in industry. EDT is a commonly used technique in industry to produce sheets with a desired texture. In this process, the sheet is passed through the EDT rolls where it undergoes slight elongation $(<2 \%)$ called skin pass rolling. The negative of the texture roll is imprinted on the sheet. The resulting surface texture is semi-deterministic in nature. Deterministic texture can be produced on the sheet using a laser texturing method or by using textured rolls with deterministic pattern. Although there are no mass production techniques yet available using the laser texturing method which can compete with the EDT method, much better control on surface texturing offered by laser texturing has triggered huge motivation towards its implementation for mass-scale sheet metal production.

\subsection{Friction in deep drawing}

In deep drawing processes there are three main regions where friction occurs due to relative sliding between the tool and the sheet metal, as shown in Figure 1.3: blank holder area (region 1), die radius (region 2) and punch radius (region 3 ). The contact pressure in the blank holder region is small (1-10 MPa) while in the die radius region it is relatively high (20-100 MPa). 


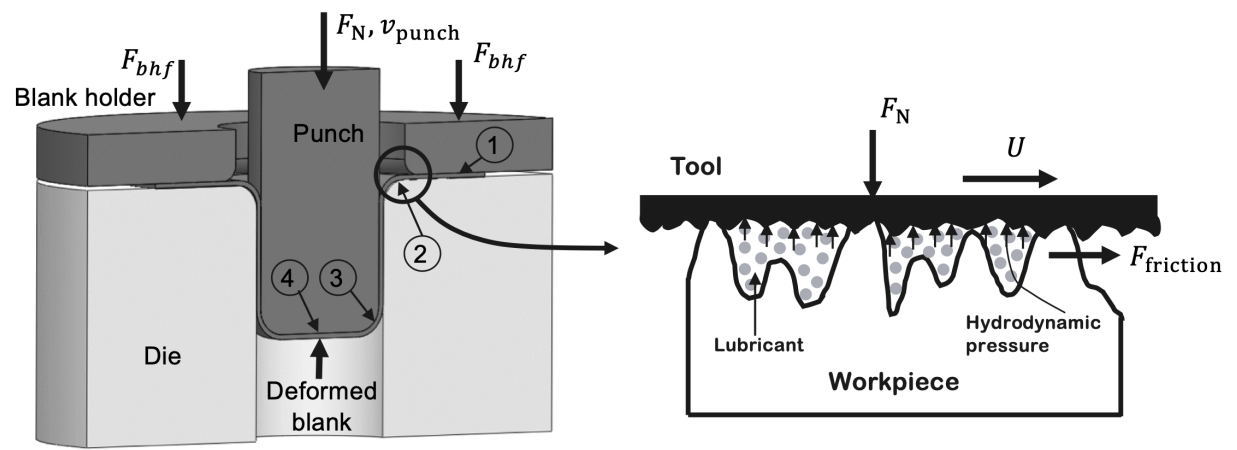

Figure 1.3 Deep drawing process illustration and tribological system.

In this region, the strain developed in the sheet is high and the sheet is bent and unbent as it slides over the die radius. On the punch side, the sheet comes in contact with the punch at the beginning of region 3 . The sheet is further stretched in this region. At the punch bottom (region 4), the contact pressure is limited and the friction in this region does not influence the deep drawing process much.

Figure 1.3 shows a typical tribological system at the tool-sheet metal interface. Normally the roughness of tooling is much less than that of sheet metal. Also, the sheet surfaces are usually lubricated. A boundary lubrication or mixed lubrication friction condition may occur at the toolsheet interface depending on the lubricant amount, tool and sheet surface topographies and process parameters. In the boundary lubrication regime, the sheet surface is lubricated but the lubricant amount is often not sufficient to fill the valleys in the sheet surface. Therefore, normal and tangential contact loads are carried only by the asperities on the sheet. In the mixed lubrication regime, the asperity deformations are governed by direct asperity contact and hydrodynamic pressure developed in the lubricant. The hydrodynamic pressure is influenced by surface topographies of the contacting surfaces in addition to lubricant properties and process parameters. The total friction force in this regime is due to the shear stress developed at direct asperity contact and lubricant viscous shear stress.

\subsection{Motivation}

The challenge in metal forming technology is to achieve zero defect production and to reduce the cost and lead time of new metal products. Effectiveness of forming processes depends on the understanding of material 
behaviour under forming conditions. Finite element (FE) analysis is a standard tool to study the formability of sheet metals in forming processes. Although the accuracy of material models in FE simulations has improved significantly over recent years, the Coulomb friction model is still used in the majority of simulations that make use of a constant coefficient of friction. However, from theoretical and experimental studies, it is known that this is not realistic. Friction is a determining process parameter in forming processes which typically varies from location to location and in time during forming. In forming processes, friction is a local phenomenon which is influenced by the contact loads, surface topographies of the contacting surfaces, material behaviour and the lubrication condition at the toolsheet metal interface. Additionally, the sheet metals have evolved from uncoated to textured coated sheets which brings additional complexities to understand the surface interactions. Furthermore, the lubrication and the surface texture together influence the tribological condition at tool-sheet metal contacts. To improve prediction accuracy of the forming simulations, understanding the surface interactions under forming conditions based on fundamental physics is crucial. Consequently, a reliable friction model for coated sheets accounting for surface texture effects under forming conditions is necessary. The surface texture is key parameter which can be used to control the friction condition. Therefore, an important step forward is to investigate the influence of different surface textures on friction. This will enable engineering of the sheet surfaces to achieve optimal throughprocess friction conditions, which is an important step towards defect free production.

\subsection{The objective of this research}

The objective is to develop a multi-scale friction model for coated sheets for two common lubrication regimes present in the sheet metal forming applications: boundary and mixed lubrication regimes. Developed models will be formulated such that they are computationally efficient to use in industrial-scale forming simulations. Furthermore, these models can be used to investigate the influence of different surface texture parameters (for example, parameters of laser textured (LT) surfaces) on friction coefficient. The results from this study will be used to draw conclusions on the optimized surface texture for a robust friction behaviour. The important aspects of this work can be summarized as:

- For reliable modelling of friction phenomenon, an accurate estimation of 
real area of contact is necessary at the tool-sheet metal interface. For this purpose, models of asperity flattening are required for the loading conditions that are common in forming processes. Flattening models will be developed for normal load, sliding and combined normal load and bulk strain. The models must account for a measured surface topography of the sheet metal and physical behaviour of the coating-substrate hybrid system.

- A multi-scale friction model for coated sheet will be developed for the boundary lubrication regime. In this model, a single asperity micro-scale ploughing model will be adapted at macro-scale. The developed model will use the measured surface topographies of sheet metal and tools.

- The boundary friction model will be extended to the mixed lubrication regime by including the effects of lubricant. In this model, the overall coefficient of friction due to lubricant effects and direct asperity contacts will be determined using a coupled friction model. The model will be implemented in a FE code (in-house FE code "DiekA") for forming simulations.

- Experiments will be performed to validate flattening models at different loading conditions and to determine the model calibration parameters. For this purpose, an experimental setup will be developed for combined normal loading and bulk strain flattening experiments. Furthermore, two types of experiments will be performed to validate the friction models: lab-scale friction experiments and component level deep drawing experiments.

- Using the developed friction models, the influence of different surface texture parameters (for example, dimple diameter, density and depth in LT surface) on friction coefficient will be studied. For this purpose, a surface generation algorithm is developed to generate surfaces of user defined texture parameters. This study will be used as a basis to determine the optimized surface for a robust friction condition under various uncertainties in deep drawing processes.

\subsection{Overview}

In Chapter 2, a newly developed flattening model for coated sheet under normal loading conditions is presented. Experiments are performed on uncoated and zinc coated steel sheets to validate the model. Combined normal load and bulk strain increases the evolution of real area of contact significantly in comparison with the normal load alone. The newly developed 
experimental setup for combined normal load and bulk strain experiments is presented in Chapter 3. Uncoated and zinc coated steel sheets with different coating thicknesses, surface topographies and substrate materials are used in the experimental study. Furthermore, an analytical flattening model for combined normal load and bulk strain is presented which is calibrated for coated sheets. In Chapter 4, the multi-scale friction model applicable for coated sheets in the boundary lubrication regime is presented. The model is implemented in FE code for simulations of deep drawing processes. Labscale friction tests and cup drawing experiments are performed on coated sheets to validate the model. The boundary friction model is extended to the mixed lubrication regime as described in Chapter 5. This model includes the effect of lubricant on the measured surface topographies of tool and sheet surfaces. The coupled friction model that accounts for direct asperity contact and lubricant effects is implemented in FE code which is validated using deep drawing experiments. In Chapter 6, surface generation algorithms for a LT and EDT surfaces are presented. The friction model is used to study the effects of different texture parameters on friction behaviour with the strip draw test as a model problem. Using the results, conclusions are made about the texture parameters for a robust friction condition under typical uncertainties in deep drawing processes such as evolution of tool roughness (due to wear) and lubricant amount. A case study is presented in which the deep drawing simulations are performed with an optimized surface to demonstrate the applicability of the optimization study. 



\section{Chapter 2}

\section{Flattening model for normal loading}

A normal load flattening or contact model developed for coated sheets is presented in this chapter. Friction is a local phenomenon that depends on the local contact condition between tool and sheet metal. The contact condition is defined mainly by the real area of contact between tool and sheet surface. Therefore, the first step for an accurate prediction of friction is to reliably estimate the real area of contact at different contact loads. A multi-scale flattening model is developed to predict deformation of asperities on rough uncoated and coated surfaces and thus to estimate the real area of contact under normal loading condition. The model accounts for the coating thickness and material behaviour of coating and substrate.

Section 2.2 describes the flattening model. A contact pressure database for ellipsoidal asperities of different aspect ratios is generated using FE simulations, as presented in Section 2.2.1. Section 2.2.2 describes the multiple asperity flattening model followed by its implementation procedure in Section 2.2.3. Section 2.3 presents an experimental setup developed for normal load flattening experiments. The experiments are performed on uncoated and zinc coated steel sheets. The results of the experiments are used to validate the flattening model presented in Section 2.3.4.

This chapter is based on the publication: M.P. Shisode, J. Hazrati, T. Mishra, M.B. de Rooij and A.H. van den Boogaard, "Semi-analytical contact model to determine the flattening behavior of coated sheets under normal load" Tribology International, 146, 106182, 2020 . 


\subsection{Introduction}

The real area of contact between two surfaces is determined by the resistance of the highest asperities to deformation mainly at the softer surface. Therefore, mechanical properties as well as geometry of the asperities or texture of the contacting surfaces govern the real area of contact. Furthermore, it is generally assumed that the real area of contact is dominated by plastic deformation of the asperities.

Reliable modelling of friction in sheet metal forming simulations is vital for the accuracy of the formability analyses [1]. The first step to have a reliable prediction of friction coefficient is to accurately estimate the real area of contact at the sheet metal-tool interface. The real area of contact is influenced by local contact pressure, surface topographies of the sheet metal as well as the forming tool, their material behaviour, lubricant condition and temperature in the sheet metal-tool contact [1-3].

The real area of contact is determined either numerically using finite element (FE) analyses or by analytical contact models. These two approaches can be understood respectively as the direct and indirect approaches. In the indirect approach, the rough surface is described by a statistical function which leads to an efficient modelling and analytical solution of the surface. Greenwood and Williamson [4], for example, used the elastic Hertz contact theory for the contact between rigid flat tool surface and elastic rough surface (GW model) . The rough surface asperities are described by a summit height-based stochastic parameter. The model assumed spherical asperities near their tips with all asperities having the same radii.

Following the GW model, Bush et al. [5] extended the elastic contact model by incorporating the variations in the radius, ellipticity ratio and the height. Furthermore, Chang et al. [6] proposed an elastic-plastic contact model. The model implements elastic-plastic deformation in the asperity, based on the critical indentation depth derived by equating the hardness of the material and maximum contact pressure derived from the Hertz contact theory on the spherical asperity. The model also takes into account the volume conservation in the asperity. The major shortcoming of this approach is that the contact load at the onset of plastic deformation is not continuous. According to their formulation, the contact pressure is allowed to increase at the onset of yielding. Another example of elastic-plastic contact models is proposed by Zhao et al. [7]. Though these statistical models are simple and computationally efficient, they are still limited to lightly loaded contacts as they do not account for material hardening, asperity interactions and accurate asperity geometry. Furthermore, the 
use of summit height-based statistical description is ambiguous due to its dependency on the scanning resolution of the surface. Westeneng [8] developed a fully plastic statistically based flattening model where the rough surface is modelled as measured height data represented by bars. The tool surface is assumed to be rigid and perfectly flat. Energy and volume conservation equations are solved to determine the indentation and rise of asperities. The model accounts for the hardening effects of the material but requires experimental results to calibrate the model. Furthermore, the model assumes a simple and constant relation between the material hardness and material yield strength $H=\mathrm{B} \sigma_{\mathrm{y}}$, where for metals $\mathrm{B} \approx 2.8$ [9]. The constant parameter that relates the hardness to yield strength is derived using hardness tests. However, this relation holds for approximately ideal-plastic materials [9]. Moreover, the constant relation is not always true and can vary based on the type of hardness test, indenter shape and size. Furthermore, there is no conclusive finding on the similarity between the indentation situation in the hardness test (rigid indenter on a polished surface) and a flat rigid tool upsetting soft asperities on a sheet surface.

In the direct approach, using the FE technique for example, a rough surface can be modelled explicitly and solved for the assumed nominal pressures $[10,11]$. Full scale FE modelling of rough surface can consider all the material and geometrical complexities such as material hardening, arbitrary shape of the asperities, their interactions and bulk straining of the substrate to predict the real area of contact. However, the major drawback of the full scale FE method is the excessive complexity in modelling the rough surfaces at the asperity level and the computational time.

Nowadays, coated steels are widely used in the automotive industry to improve the formability, corrosion resistance and paint appearance of the sheet metals. Although the coating would not directly alter the mechanical behaviour of steels, its frictional behaviour may change the strain path during the forming process and ultimately affect the formability of the sheet metal. Therefore, in the flattening model it is necessary to take the mechanical behaviour of the coating into account. Though there are various analytical and semi-analytical flattening models available for uncoated sheets, very few have been extended to coated sheets [12-15]. The major challenge in modelling the contact mechanics of the coated system is to capture the contribution from coating and substrate for the given load. This is done by defining the effective hardness of the coated system for which there are many empirical relations developed based on the hardness tests on coated sheets [12, 16-19]. For example, empirical relations proposed 
by Halling et al. [19] are a function of coating and substrate hardness, coating thickness and radius of the asperity. However, hardness results are derived from a typical indentation tests with spherical indenter on polished coated sheet. Moreover, the hardness result from the test depends on various parameters, such as the type and size of indenter, load and indentation depth. Nevertheless, determining the effective hardness makes it possible for coated systems to adapt the model developed for uncoated systems. Chang et al. [13] extended an elastic-plastic flattening model [6] to a coated surface. They also proposed a hardness relation for plastically deforming asperity with surface coating. However, the model is limited to spherical asperity which is far from the asperity geometry found on surfaces. Also, the model does not account for strain hardening in the material. Furthermore, based on plane strain upper bound method, Mulki and Mizuno [14] proposed an ideal plastic flattening model for GI sheet. However, the model makes simplifying assumptions about the material behaviour, asperity shape and their interaction. Also, the model is not suitable for a general 3D rough surface with asperities of random shapes and distribution. Chen et al. [12] proposed load independent effective hardness relations for a coated sphere. They used FE analyses to develop the relations for different coating thicknesses under realistic contact situation of a smooth rigid tool flattening the spherical asperities. The proposed relations are more reliable as they also consider the material hardening but are limited to spherical asperities. Recently, Shisode et al. [15] proposed a normal load flattening model for coated sheets which is an extension of the Westeneng's model [8]. The model allows input of the actual measured height data for coating and substrate material. The model also considers the material hardening effects. However, the limitations of Westeneng's model still exist in this model.

The goal of this study is to develop a normal load flattening model for a generalized rough surface which describes more accurately the mechanical behaviour of the asperity and the effect of coating-substrate material combination. For this purpose, the model uses a series of FE analyses of smooth ellipsoidal asperities of various sizes and aspect ratios to determine the contact pressure of a single asperity. Later, this database of contact pressures is used to determine the contact pressure of individual asperities on the rough surface. In this way, the deformation of the rough surface and thus real area of contact can be calculated. 


\section{$2.2 \quad$ Flattening model}

The resistance of the asperity on the rough surface against deformation depends on its material, shape and size. Hence it is necessary to include the effects of asperity geometry on its flattening behaviour. One way to account for this shape and size dependency is to determine the contact pressure of each asperity under a flattening condition by a virtual test using the FE method. However, the practical challenge with this approach is the necessity to perform large number of simulations with various sizes and shapes of asperities. Chen et al. [12] considered a spherical asperity and determined its effective hardness or contact pressure under a normal flattening load. In the current model, asperities on the rough surface are approximated by an ellipsoid, which provides the flexibility to better approximate the shape of asperities. FE simulations are performed on the ellipsoidal geometry by varying its size and aspect ratio (height to radius ratio) in a certain range. Contact pressure of each asperity under the flattening situation is determined and the contact pressure database is built as a function of the geometrical parameters of the asperity. The contact pressure is determined as the ratio of load carried by asperity and its contact area. Due to material hardening and evolution of the asperity shape with flattening, the contact pressure evolves with upsetting height. Hence the contact pressure is determined at different levels of flattening.

\section{Key assumptions}

1. The tool is assumed to be rigid and smooth. These are routine assumptions $[6,8]$ in normal load flattening models. In sheet metal forming processes, tool hardness is normally much higher than the workpiece hardness. Moreover, tool surface roughness is generally one order lower than the sheet metal roughness. To accord with these assumptions, in this study a polished sapphire notch is used as a tool in the experiments.

2. In the analytical flattening model, displaced material from the deformed asperities is redistributed uniformly in the non-contacting area $[8,20]$.

3. Frictionless slip contact condition is assumed between a single asperity and the rigid tool. This is on the basis that during normal loading of the surface there is a limited sliding between tool and a single asperity and therefore friction is not playing a significant role.

4. In FE analyses, the elastic-plastic response of the material is described 
by a $\mathrm{J}_{2}$ isotropic plasticity theory.

5. Coating thickness is assumed uniform and perfectly bonded to substrate. This is also confirmed by measuring coating thickness at different locations on the sheet surface using a DUALSCOPE FMP40 (Fischer) coating thickness measurement probe. The coating thickness varies by $\approx \pm 1.5 \mu \mathrm{m}$.

\subsubsection{Single asperity FE model}

A contact pressure database for different materials and coating thicknesses is built for ellipsoids of different sizes and aspect ratios. The base radius and height are varied from 10-100 $\mu \mathrm{m}$ and $0.8-5 \mu \mathrm{m}$ respectively. The range is decided by carefully observing the dimensions of the fitted ellipsoids on the samples used in this study at different tool contact planes. The base radii of $10,20,50,70$ and $100 \mu \mathrm{m}$ and heights of $0.8,1.5,3$ and $5 \mu \mathrm{m}$ are used to form 20 axisymmetric simulations for each substrate material and coating thickness combination corresponding to the samples used in the experimental validation (see Table 2.2).

\section{Material properties}

The stress-strain curves are available from uniaxial tensile tests for all the steel substrate materials, as shown in Figure 2.1. Flow curves from the tensile tests are extrapolated for higher values of strain using the biaxial tensile test data [21]. Song et al. [22] performed nano-indentation tests on various zinc grains of the GI sheet. The averaged stress-strain curve of the zinc coating was extracted from the measured load-depth curves as shown in Figure 2.1. The Young's modulus, Poisson's ratio and yield strength of the zinc coating $[22,23]$ and the steel substrates corresponding to materials used in the experiments are shown in Table 2.1.

Table 2.1 Material properties of the samples.

\begin{tabular}{|l|l|l|l|}
\hline Material & $\begin{array}{l}\text { Young's modulus } \\
(\mathrm{GPa})\end{array}$ & $\begin{array}{l}\text { Poisson's ratio } \\
(-)\end{array}$ & $\begin{array}{l}\text { Yield strength } \\
(\mathrm{MPa})\end{array}$ \\
\hline Zinc coating & 70 & 0.3 & 75 \\
\hline DX56 & 210 & 0.3 & 153 \\
\hline DC04 & 210 & 0.3 & 171 \\
\hline S220 & 210 & 0.3 & 220 \\
\hline
\end{tabular}




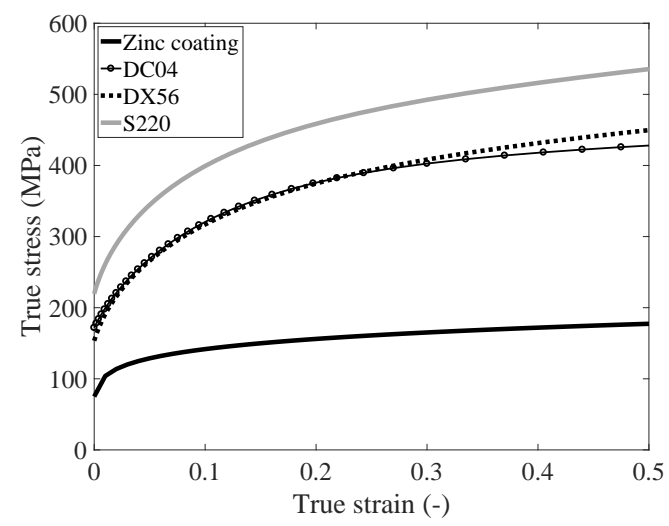

Figure 2.1 Material flow curves.

\section{FE modelling and post-processing}

Figure 2.2 shows the models of asperity for uncoated and coated specimens. For coated samples, the coating is modelled as a mean coating thickness. A commercial FE solver (MSC Marc) was used for non-linear, elastic-plastic axisymmetric FE simulations of ellipsoidal geometries. In the simulations, axisymmetric 4 node quadrilateral elements with full integration and constant dilatation are used. The FE mesh is divided into different mesh density zones. A finer mesh density is used in the asperity than in the other parts of the model. Sufficient model extent in the lateral direction and in the thickness direction $(>3 r)$ is considered. The bottom of the model is fixed in the vertical direction and the outer edges are free to expand. Material flow curves shown in Figure 2.1 are used. The tool is moved incrementally downward and at each increment, the results are postprocessed to determine the contact force, contact length and the asperity flattened volume. From the contact length a contact area is determined. The contact pressure is determined as the ratio of contact force and contact area and stored as a function of percentage of flattened volume with respect to total asperity volume. Once the contact pressure database is constructed for a specific set of coating-substrate material combination and coating thickness, it can be used to model the flattening behaviour of different surface textures and normal loads as long as the materials and mean coating thickness are unchanged.

Figure 2.3 shows some of the contact pressure results from the simulations as a function of flattened asperity volume (\%) for sample numbers 1,2 and 4, corresponding to a coating-substrate material combination and 

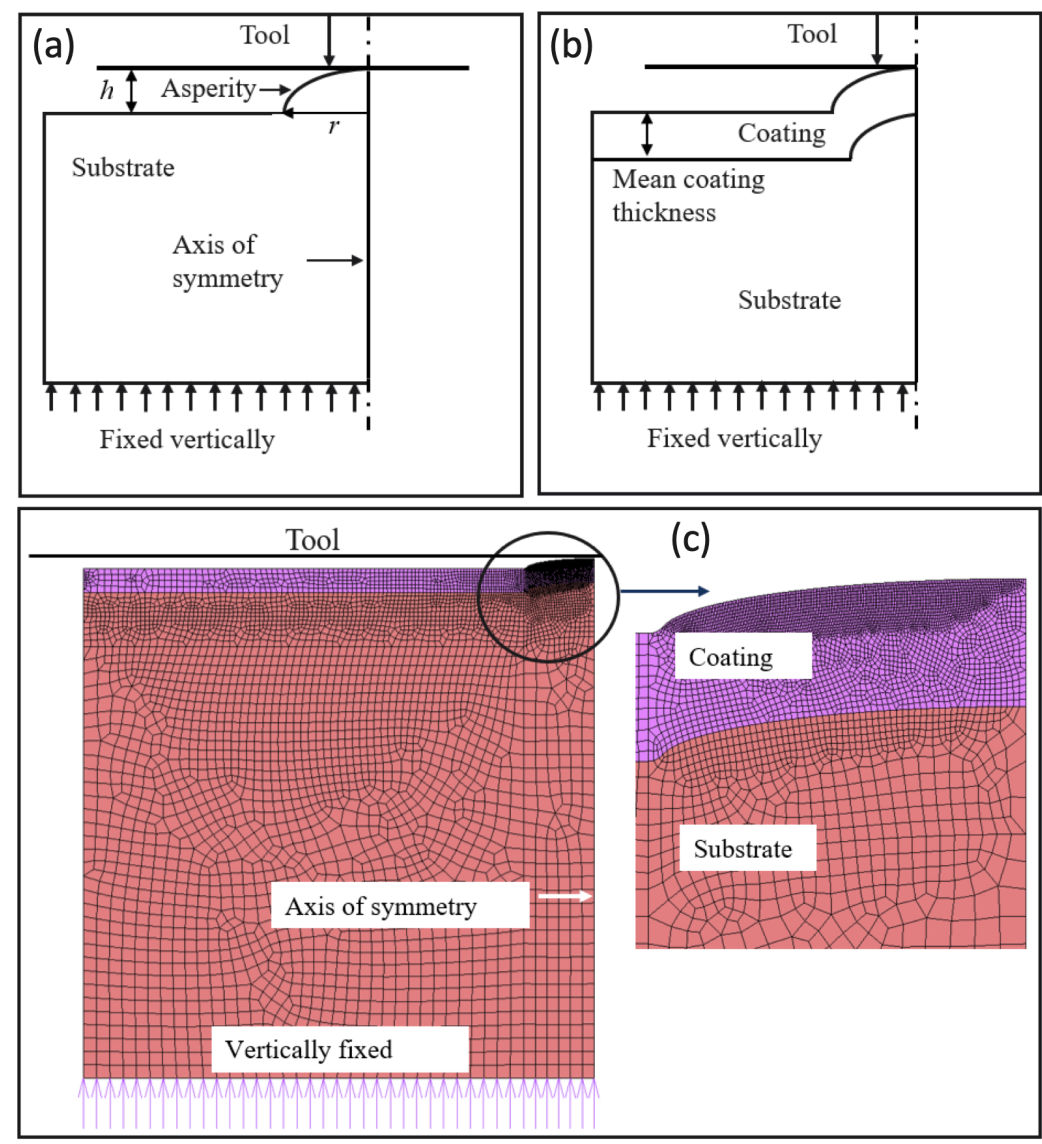

Figure 2.2 Single asperity model. (a) Uncoated system. (b) Coated system. (c) Axisymmetric FE model.

coating thickness as per Table 2.2. Hardness curves derived from FE analyses are smoothed out and used in the analytical contact model (Section 2.2.3). It is clearly seen that the contact pressure of an uncoated asperity is higher than that of the coated asperity and, as the coating thickness increases, the contact pressure decreases. For the coated asperities with a higher aspect ratio (at base radius of 10 and $20 \mu \mathrm{m}$ and height of $3 \mu \mathrm{m}$ ) the contact pressure initially increases; however, at larger indentations it decreases or remains almost constant afterwards. For the coated asperities of $10 \mu \mathrm{m}$ base radius and $3 \mu \mathrm{m}$ height, with the increase in tool displacement the rate at which contact area increases is higher than the rate of increase in the contact force, resulting in a decrease in the contact pressure. In the case of asperities with a $20 \mu \mathrm{m}$ of base radius, $3 \mu \mathrm{m}$ height, the rise in force 
is approximately equal to the increase in contact area. This leads to almost constant contact pressure. This trend is reversed for asperities with larger base radii. This can be explained by the deformation of the steel substrate in asperities with a larger base radius. Figure 2.4 depicts the plastic deformation of asperities with base radii of 10 and $50 \mu \mathrm{m}$ with height of $3 \mu \mathrm{m}$. It is found that, for asperities of larger base radii, the plastic zone can reach to the substrate for a given tool displacement. For smaller asperities, it does not reach the substrate due to lower contact load for the same tool
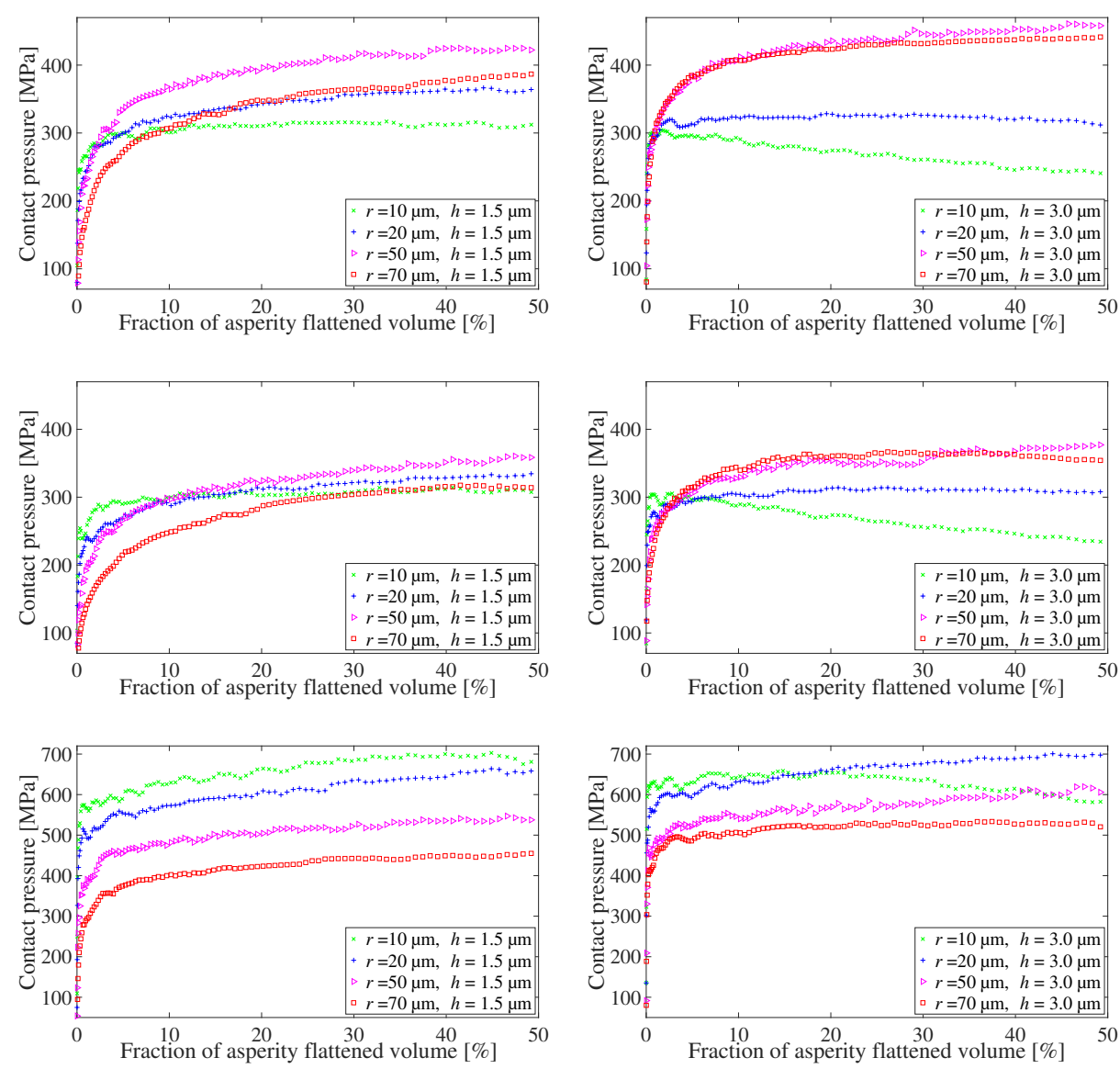

Figure 2.3 Ellipsoidal asperity contact pressure at different base radius and height. (top left and right) Material: DX56-GI, mean coating thickness $=7 \mathrm{\mu m}$. (middle left and right) Material: DX56-GI, mean coating thickness $=14 \mu \mathrm{m}$. (bottom left and right) Material: DC04 (uncoated). 
displacement. Hence for asperities with larger base radius the contribution of the substrate to the contact pressure of coating-substrate hybrid is larger.

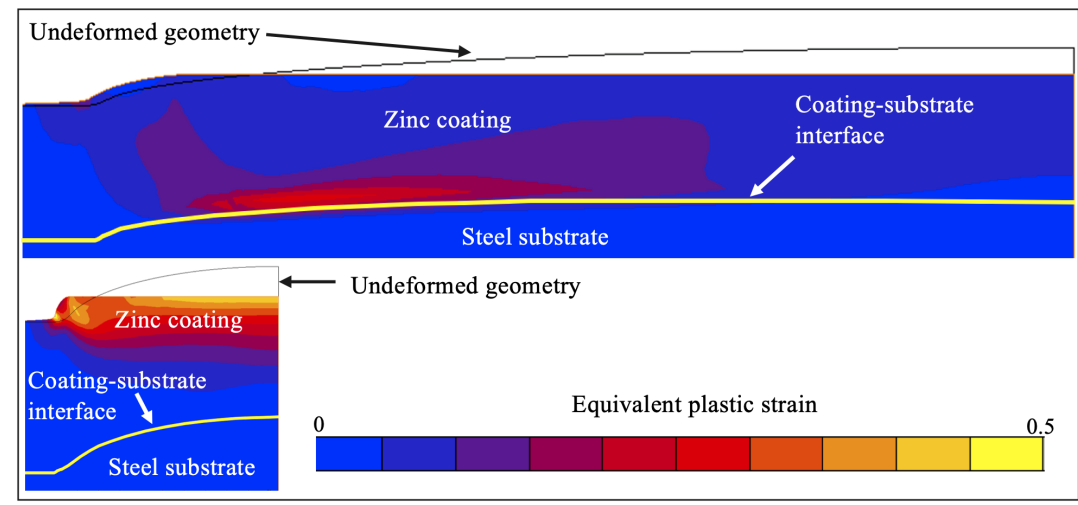

Figure 2.4 Equivalent plastic strain at upsetting height of $1.4 \mathrm{\mu m}$ for coated asperity (coating thickness : $7 \mu \mathrm{m}$, substrate material: DX56). (top) Asperity with base radius $=50 \mu \mathrm{m}$ and height $=3 \mu \mathrm{m}$. (bottom) Base radius $=10 \mu \mathrm{m}$ and height $=3 \mu \mathrm{m}$.

\subsubsection{Multiple asperity flattening model}

Asperities in contact with a flat tool on a rough surface at an assumed tool displacement are determined. Individual contacting asperities are fitted by an ellipsoidal shape and the geometrical parameters of the ellipsoid are determined for each asperity. The mechanical behaviour of each individual contacting asperity is modelled as the contact pressure of its equivalent ellipsoid derived from the contact pressure database. It should be noted that this is an approximation of the asperity but the derived shape and size dependent contact pressure is still expected to result in a better approximation of the asperity hardness in the flattening situation as compared with the constant relation proposed by Tabor [9]. Force balance and volume conservation equations are solved to determine the equilibrium position of the tool from which the real area of contact is determined.

A measured rough surface with a size equal to the representative area of $2 \times 2 \mathrm{~mm}$ is used in the model to determine the real area of contact. A strategy to determine the representative area is explained in Section 2.3.1. The rough surface is described as the measured surface points or pixels using confocal microscopy. This deterministic description of the surface is used to determine the real area of contact. Sheet surface is deformed by tool displacements in small increments $\left(5 \times 10^{-3} \mu \mathrm{m}\right)$. There are certain 
number of surface points or pixels that come into contact at an assumed position of the tool. The surface points which are in contact and adjacent form a cluster referred to as a contact patch, as shown in Figure 2.5. A contact patch is a cluster of pixels connected together by shared pixel edges or by shared pixel corner points. A procedure described by de Rooij [24] is followed to determine contact patches and the geometry of ellipsoids. The contact patches are identified by a binary image processing technique. Once the contact patches are determined, the base radius $r$ of the fitted ellipsoid is determined from the area $A$ of the contact patch. Knowing the base area $A$, the height $h$ of the ellipsoid is determined by equating the volume of the contact patch $(V)$ and half the ellipsoid volume using Equations (2.1) and $(2.2)$.

$$
\begin{gathered}
r=\left(\frac{A}{\pi}\right)^{1 / 2} \\
V=\frac{2}{3} \pi r^{2} h=\frac{2}{3} A h
\end{gathered}
$$

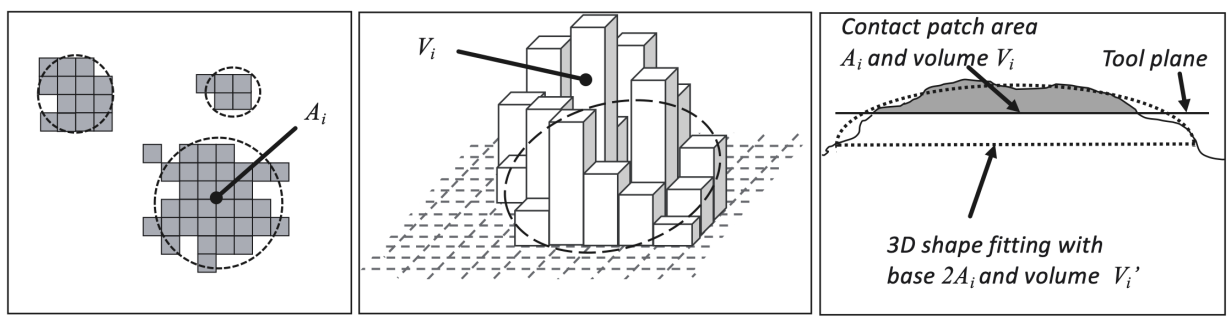

Figure 2.5 Contact patch and fitting. (left) Fitting the base area. (middle) Contact patch volume. (right) Fitting strategy.

It is expected that the asperity contact pressure is influenced by noncontacting material in its vicinity. However, if the ellipsoid is fitted at a tool position as shown in Figure 2.5 (right) with base area $A_{i}$, the contact pressure of the asperity cannot account for the adjacent material properly. The adjacency effect can be included by considering additional material adjacent to the contact patch while fitting an ellipsoid. However, considering too much adjacent material in the fitting stage can lead to a deviation in fitted geometry from the actual flattened asperity height data especially at the tip of the asperity. It is also expected that the effect of the adjacent material close to the flattened volume is the most significant and 
reduces with increasing distance from the flattened material. A sensitivity analysis on a single asperity FE simulation with a different amounts of adjacent material showed that the influence of adjacent material on contact pressure corresponding to a base area $\approx 2 A_{i}$ is a good approximation. Hence it is assumed that the contact pressure at a specific deformation level for the resulting contact patch (with contact area $A_{i}$ ) is better represented by an ellipsoid fitted on the height data with base area equal to two times the contact patch area $\left(2 A_{i}\right)$. The fitted ellipsoid on the asperity with base area of $2 A_{i}$ and contact area of $A_{i}$ is used to determine the contact pressure of asperity from the FE database. The schematic illustration of this strategy is shown in Figure 2.5 (right). This ensures the effect of adjacent material on asperity contact pressure with little effect on asperity fitting accuracy.

\subsubsection{Analytical flattening model}

To determine the fractional real area of contact $\alpha$ at a given nominal pressure $P_{\text {nom }}$, the tool is moved at small increments on the measured rough surface such that the separation between tool and rough surface decreases. Asperities in contact are determined. Force balance and volume conservation equations are solved to determine $\alpha$.

\section{Force balance equation:}

The total force $F_{\text {int }}$ carried by the contacting asperities is determined as follows:

$$
F_{\text {int }}=\sum_{i=1}^{N} H_{i} A_{i}
$$

The total force applied by the tool $F_{\text {ext }}$ on the rough surface is:

$$
F_{\text {ext }}=P_{\text {nom }} A_{\text {nom }}
$$

At equilibrium position of the tool:

$$
F_{\text {ext }}=F_{\text {int }}
$$

where $H_{i}$ is the contact pressure of each contacting asperity derived from the database based on asperity geometry, $A_{i}$ is the asperity contact area at the given tool position, $N$ is the total number of asperities in contact and $A_{\text {nom }}$ is the rough surface nominal area. 


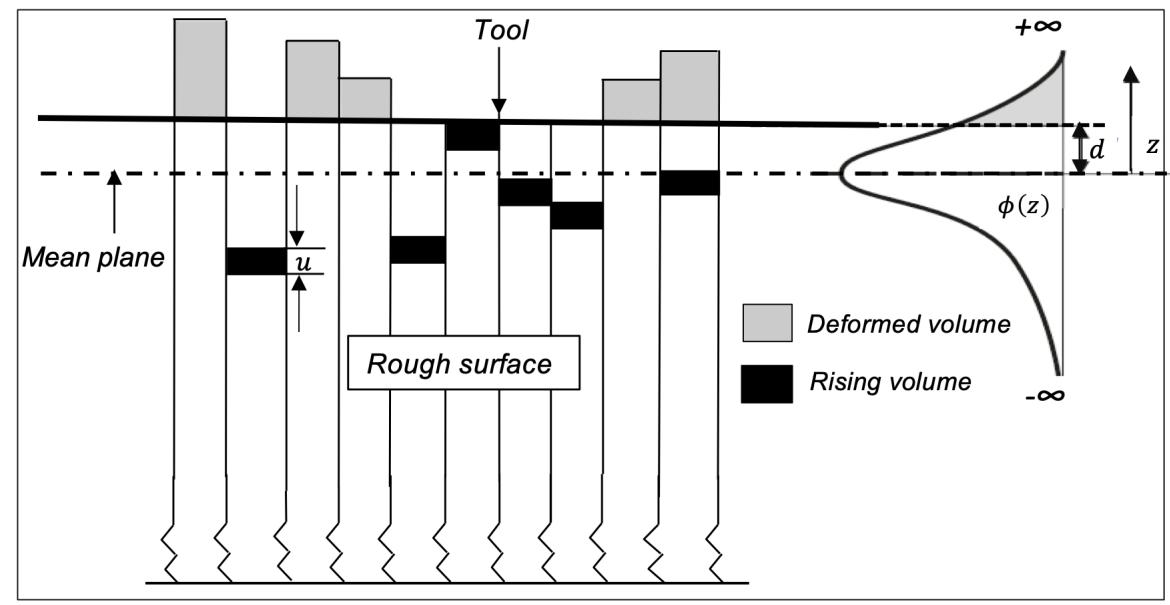

Figure 2.6 Deformation and uniform rise of asperities.

\section{Volume conservation:}

When the asperities deform, the displaced volume is distributed over the non-contacting area. This is taken into account in the contact pressure calculation stage using FE simulations but is also required to be included in the analytical model. In the analytical model it is assumed that the displaced volume is uniformly distributed over the non-contacting surface $[8,20]$, as shown in Figure 2.6. Due to the rise in non-contacting surface, some of the non-contacting surface points come into contact with the tool, increasing the real area of contact. The uniform rise $u$ in non-contacting surface points for a given tool position $d$ can be determined by balancing the flattened volume (left side of Equation (2.6)) to the rising volume (right side of Equation (2.6)), where, $\phi(z)$ is the normalized height distribution function of the measured surface (see Section 2.3.1 for more details on $\phi(z)$ ).

$$
\begin{gathered}
\int_{d-u}^{\infty}(z-d) \phi(z) \mathrm{d} z=u\left(1-\int_{d-u}^{\infty} \phi(z) \mathrm{d} z\right) \\
\alpha=\int_{d-u}^{\infty} \phi(z) \mathrm{d} z
\end{gathered}
$$

The contact pressure value for each of the contacting asperities is extracted from the contact pressure database generated by running offline FE simulations. At each increment, the bearing force contribution from each of the contacting asperities is determined using the contact pressure and the contact area at the asperity level (Equation (2.3)). Force balance 
(2.5) and volume conservation (2.6) equations are solved to determine the real area of contact.

\section{Solution scheme:}

A step by step solution scheme to determine real area of contact is summarized here.

Step 1: Start with tool displacement increment $d_{i}$. Determine the number of contact patches $N$ at tool plane $d_{i}$ on the measured height data. Determine the base area $A_{i}$ and volume $V_{i}$ for each contact patch, where, $V_{i}$ of the contact patch is determined as total volume of the surface points above the tool plane at $d_{i}$ and $A_{i}$ is the base area at tool plane $d_{i}$.

Step 2: Asperity fitting and contact pressure calculation for each contact patch

- Determine total fractional real area of contact $\alpha_{i}=\left(\sum_{i=1}^{N} A_{i}\right) / A_{\text {nom }}$ at tool plane $d_{i}$.

- Determine the position of an imaginary plane $d_{i}^{\prime}$ such that fractional real area of contact is equal to $2 \alpha_{i} . d_{i}^{\prime}$ is determined by solving Equation (2.8).

$$
2 \alpha_{i}=\int_{d_{i}^{\prime}}^{\infty} \phi(\mathrm{z}) \mathrm{d} z
$$

- Again determine the contact patches, $A_{i}^{\prime}$ and volume $V_{i}^{\prime}$ for each contact patch at plane $d_{i}^{\prime}$. Using equations 2.1 and 2.2 with $A=A_{i}^{\prime}$, $V=V_{i}^{\prime}$, determine base radius $r_{i}^{\prime}$ and height $h_{i}^{\prime}$ of the fitted ellipsoid for each contact patch.

- Read the contact pressure $H_{i}$ (interpolated value) from the contact pressure database for all the fitted ellipsoids with base radius $r_{i}^{\prime}$, height $h_{i}^{\prime}$ and fraction of flattened volume $V_{i} / V_{i}^{\prime}$. Note that the contact pressure for the contact patches at tool plane $d_{i}$ is determined for the fitted ellipsoids at a plane $d_{i}^{\prime}$ so as to consider the effect of neighbouring non-contacting material on contact pressure.

Step 3: Now for assumed tool plane at $d_{i}$, determine uniform rise in noncontacting surface points $u$ by solving Equation (2.6). Use $u$ and update the base area $A_{i}$ for all contact patches identified at assumed tool plane $d_{i}$. 
Step 4: Determine the force carried by each contact patch $F_{i}=H_{i} A_{i}$ and also the total force $F_{\text {int }}$, using Equation (2.3).

Step 5: Check the relative force unbalance ratio $=\left|\left(F_{\text {int }}-F_{\text {ext }}\right)\right| / F_{\text {ext }}$. If the ratio is less than the specified tolerance of $2 \%$, the equilibrium position of the tool is $d_{i}$ and the resulting fractional real area of contact $\alpha$ is determined using Equation (2.7). Otherwise add the next displacement increment in tool and repeat the process until the relative force unbalance ratio is less than the tolerance.

\subsection{Experiments and model validation}

Normal load flattening experiments are performed on coated and uncoated samples of steel with different substrate grades. The details of the samples are shown in Table 2.2. All the coated samples are zinc coated (GI) and electro-discharge textured (EDT) with different coating thicknesses. Coating thickness is measured at different locations on the sample using a Fischer FMP40 Dualscope coating thickness measurement probe which can measure the thickness of non-ferrous coating with an accuracy of $\pm 1 \mu \mathrm{m}$. A nominal contact pressure up to $60 \mathrm{MPa}$ is applied on the sheet surface. A Sensofar confocal microscope is used to measure the surface height data with a pixel resolution of $1.3 \mu \mathrm{m}$. The surface height data of the sample is measured before and after loading, from which the surface height distribution is derived.

Table 2.2 Summary of the samples.

\begin{tabular}{|l|l|l|l|}
\hline Sample \# & Steel grade & $\begin{array}{l}\text { Average coating } \\
\text { thickness }(\mu \mathrm{m})\end{array}$ & $\begin{array}{l}\text { Surface rough- } \\
\text { ness, Sa }(\mu \mathrm{m})\end{array}$ \\
\hline 1 & DX56-GI & 7 & 1.1 \\
\hline 2 & DX56-GI & 14 & 1.6 \\
\hline 3 & S220-GI & 23 & 1.0 \\
\hline 4 & DC04 & uncoated & 1.3 \\
\hline
\end{tabular}

\subsubsection{Height distribution measurement}

The measured height data using confocal microscopy is corrected for any missing points and unrealistic sharp peaks in the measurement which is often an error introduced during the measurement. The correction is done using the same procedure as described in [1]. A noise filter is used to remove 
sharp peaks from the measured data. A median filter is commonly used in the image or signal processing to remove noise. A median filter with kernel size of $(3 \times 3)$ is used to suppress the sharp peaks. The other type of correction required on the raw data is to remove the curvature or the tilt on the measured data. For this purpose, a $2^{\text {nd }}$ order polynomial function is fitted through the raw data. The raw data is shifted and straightened by subtracting it from the fitted function.

Furthermore, it is necessary to measure a sufficiently large area of the rough surface that is representative of the height distribution of the whole surface. It should be noted that a bigger measurement area increases overall computational time. Convergence of the height distribution data is used as a criterion to determine the size of representative area. For this purpose, height distribution density functions obtained from different sizes of the measurement areas are compared. The lowest measurement area at which the distribution smoothly converges is chosen as the representative area. Figure 2.7 (left) shows the result of this study with measurement size varies from $0.5 \times 0.5 \mathrm{~mm}$ up to $2.5 \times 2.5 \mathrm{~mm}$ at a resolution of $1.3 \mu \mathrm{m}$. It can be concluded from the results that a measurement area of $2 \times 2 \mathrm{~mm}$ can be chosen as the representative area. Therefore, all the measurements are carried out on a measurement area of $2 \times 2 \mathrm{~mm}$.
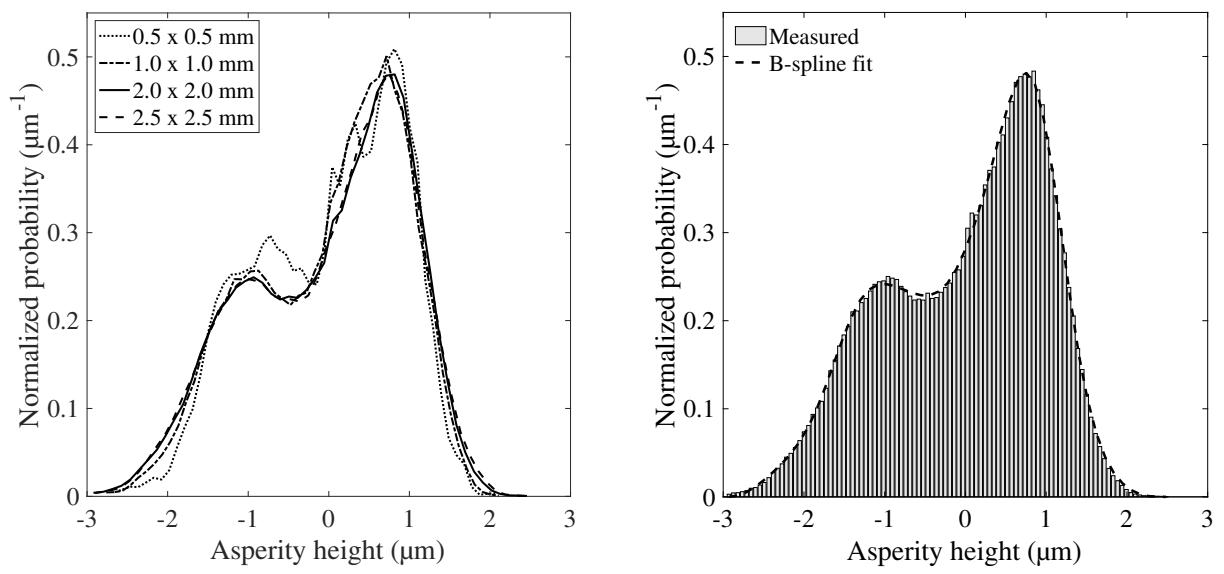

Figure 2.7 (left) Surface height distribution for different measurement areas. (right) Height distribution fit using the B-spline function. 


\section{Stochastic surface description}

In order to estimate the real area of contact, the rough surface is often modelled stochastically using a polynomial function or a normal distribution function. However, it is also observed that the height distribution function $\phi(\mathrm{z})$ can be non-normal or asymmetric. For example, EDT sheet surfaces generally have a bimodal height distribution, as shown in Figure 2.7. Such surfaces require flexible yet robust fitting function. Fourier series fit [1] or a B-spline fit [25] can be used for this purpose. The stochastic distribution facilitates an efficient translation from micro-scale contact modelling to macro-scale modelling of contact. The downside is that it eliminates the deterministic description of the surface texture and loses the adjacency information (spatial distribution of asperities) which is vital in the flattening modelling. However, a stochastic description can still be used in the equations of the solution scheme where the adjacency information is not required. In this study a B-spline function is used to fit the height distribution data. The accuracy of the fit depends on the order and number of splines. Figure 2.7(right) shows the height distribution data and its corresponding B-spline fit using 10 cubic splines. It can be concluded that the chosen fitting function represents the height distribution data well.

\subsubsection{Experimental setup}

Figure 2.8a shows the schematic of the experimental setup used in the normal load flattening experiments. The key components of the setup are a

(a)

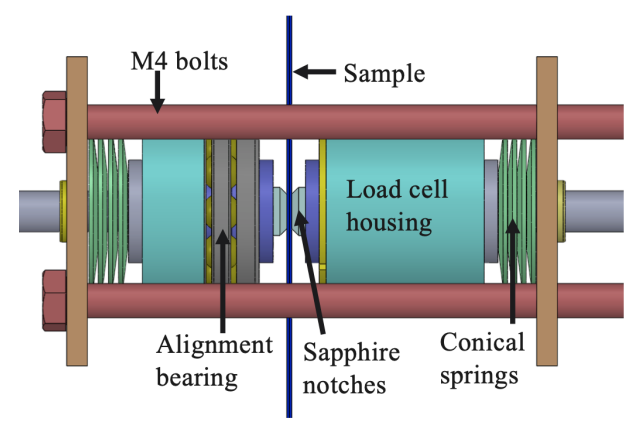

(b)

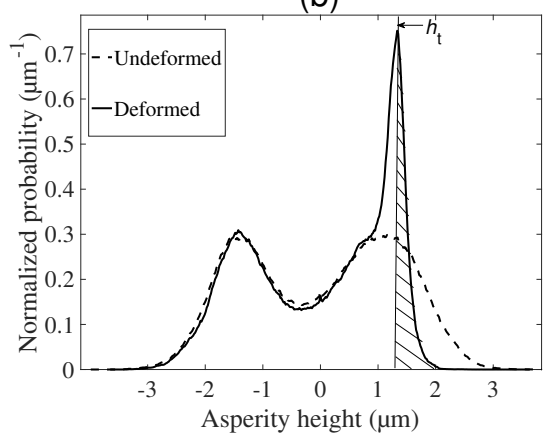

Figure 2.8 (a) Schematic of the experimental setup. (b) Transition height and real area of contact. 
pair of polished rectangular sapphire notches (surface roughness $\mathrm{Sa}<1 \mathrm{~nm}$ ), load cell, thrust bearing and fasteners. A sapphire notch can be considered rigid because its hardness is much higher than that of the sample material. A sheet sample of $5 \mathrm{~mm}$ width is placed between the pair of notches and loaded at the centre. The loading notches have a total rectangular contact area of $5 \times 7 \mathrm{~mm}$ with chamfers at the edges. The longer side $(7 \mathrm{~mm})$ ensures that the notches always cover the full width of the sample. A self-lubricating bushing is used to set a free sliding fit between the notch holder and the load cell housing. The notch holder slides freely in the load cell housing, thereby ensuring that the whole compressive load is delivered to the load cell which is sitting at the bottom of the housing. A miniature button load cell of $2 \mathrm{kN}$ is used. A thrust bearing is used for better alignment of the sapphire notch with the specimen during loading. The sample is marked at the centre with a square of $\approx 2.5 \times 2.5 \mathrm{~mm}$ to compare the asperity height data before and after loading. The bolts are tightened one by one in small increments while the applied load is continuously read during the loading until the total load reaches the desired nominal pressure.

\subsubsection{Results}

In this work, the real area of contact is determined using a height distribution function of the deformed rough surface [1, 8]. The height distribution functions of the deformed and undeformed sample is overlaid to visualize the difference. When the load is applied, the asperities deform and the height distribution profile shifts towards the left, giving rise to the local maximum value (Figure 2.8b). In an ideal situation, when a flat rigid surface is deforming a soft rough surface, all the taller asperities will attain the same transition height $h_{\mathrm{t}}$. However, due to elastic recovery and misalignment of any small degree the height distribution function does not show a perfect transition height (vertical line at the local maxima) but rather exhibits a steep slope (Figure 2.8b). In this study, asperity height corresponding to the local maxima is used as the transition height and the real area of contact $\alpha_{\mathrm{h}}$ is determined as follows:

$$
\alpha_{\mathrm{h}}=\int_{h_{\mathrm{t}}}^{\infty} \phi_{\mathrm{d}}(z) \mathrm{d} z
$$

where, $h_{\mathrm{t}}$ is the height of the asperity corresponding to local maximum peak and $\phi_{\mathrm{d}}(z)$ is the normalized height distribution data of the deformed surface. As mentioned in Table 2.2, four different samples are used for the flattening experiments. Flattening experiments are performed at four 
different nominal pressures: $15,30,45$ and $60 \mathrm{MPa}$ on four different samples with two repetitions. Figures $2.9-2.12$ shows the experimental results for each sample.

(a)

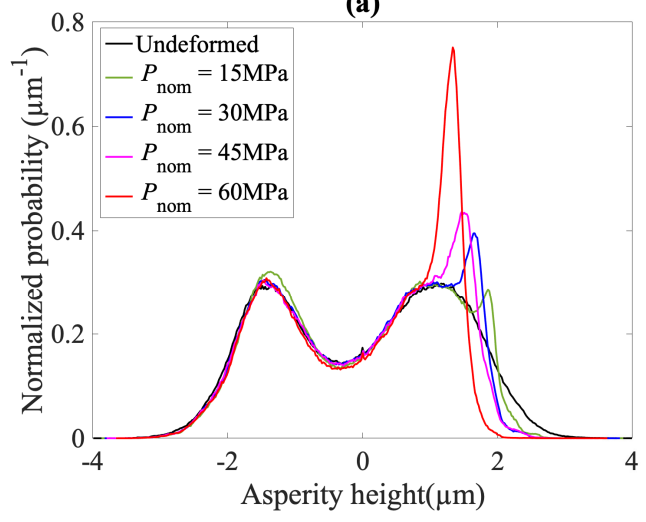

(b)

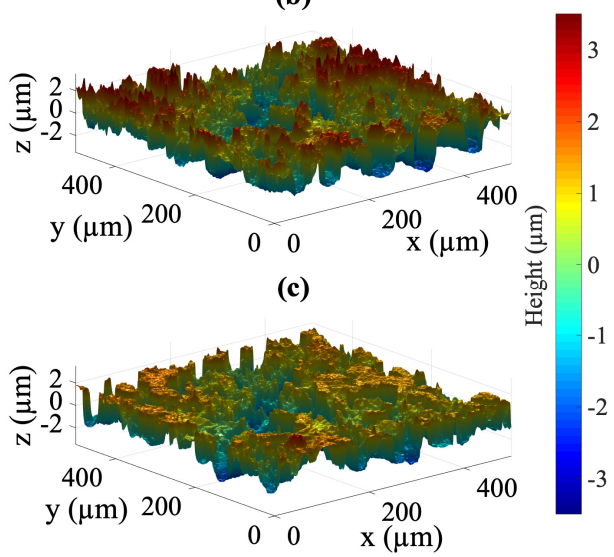

Figure 2.9 Sample 1: material DX56-GI. (a) Normalized surface height distribution of undeformed and deformed surfaces. (b) Undeformed sample. (c) Deformed at $P_{\text {nom }}=60 \mathrm{MPa}$.

(a)

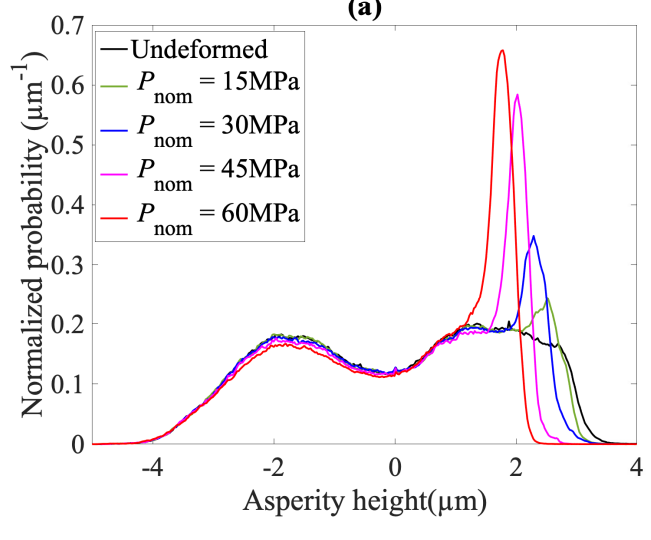

(b)

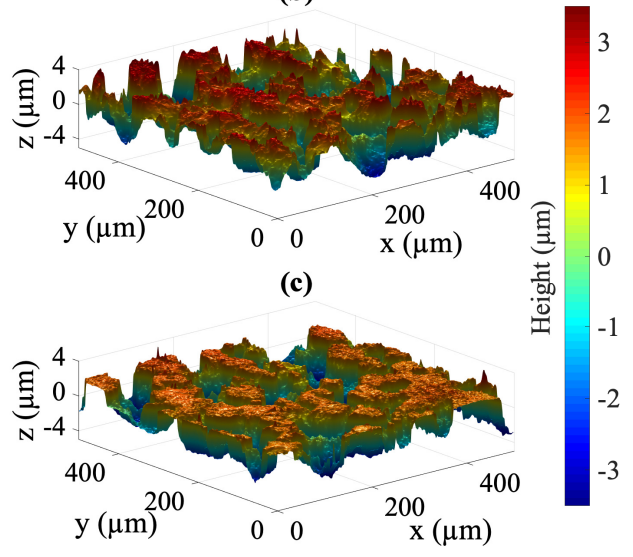

Figure 2.10 Sample 2: material DX56-GI. (a) Normalized surface height distribution of undeformed and deformed surfaces. (b) Undeformed sample. (c) Deformed at $P_{\text {nom }}=60 \mathrm{MPa}$. 
(a)

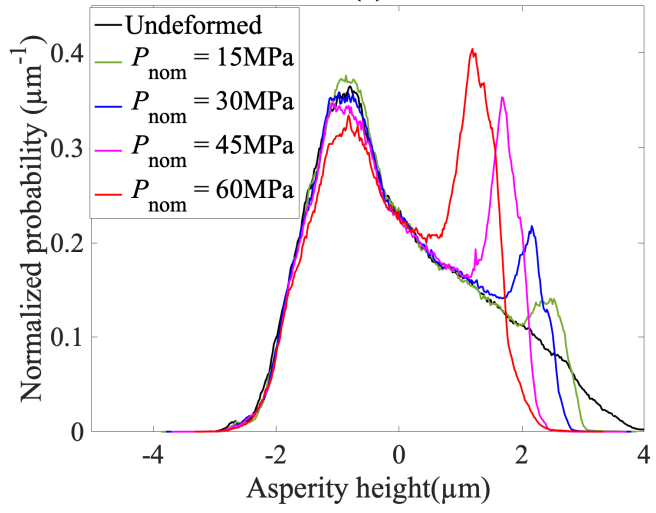

(b)

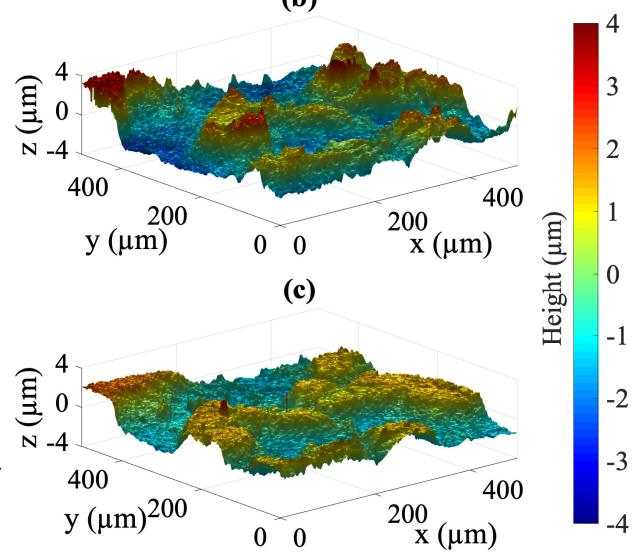

Figure 2.11 Sample 3: material S220-GI. (a) Normalized surface height distribution of undeformed and deformed surfaces. (b) Undeformed sample. (c) Deformed at $P_{\text {nom }}=60 \mathrm{MPa}$.

(a)

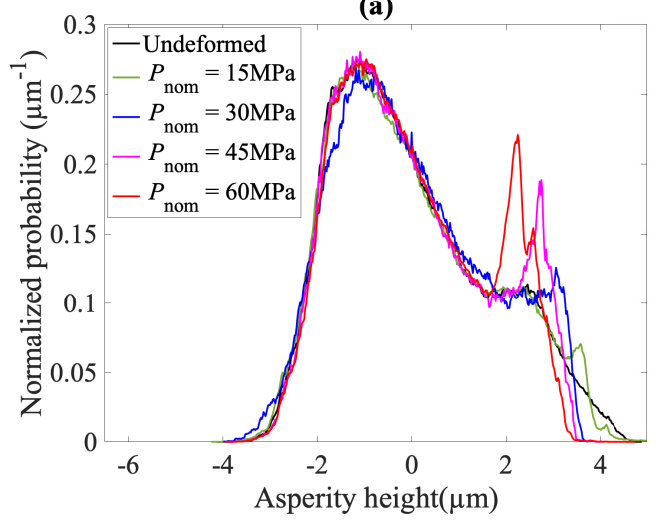

(b)

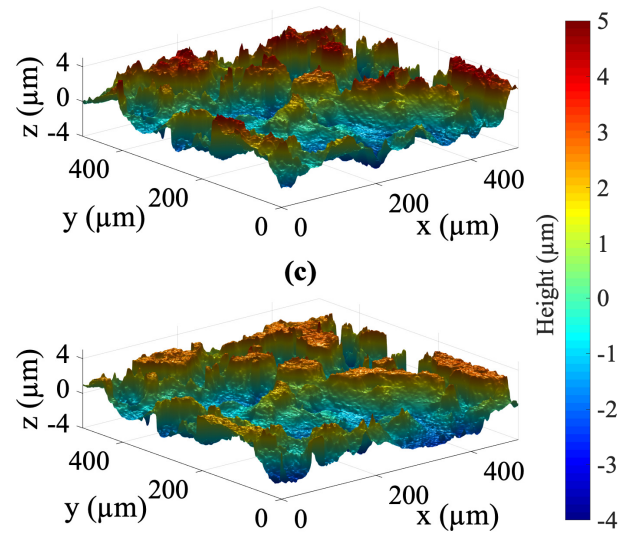

Figure 2.12 Sample 4: material DC04. (a) Normalized surface height distribution of undeformed and deformed surfaces. (b) Undeformed sample. (c) Deformed at $P_{\text {nom }}=60 \mathrm{MPa}$.

The 3D surface topography of the undeformed and deformed surfaces clearly show the flattening of the peak asperities with increasing applied pressure. The transition height $h_{\mathrm{t}}$ at local maxima is easily recognizable and is used to determine real area of contact using Equation (2.9). The 
results of the measurements for all samples are shown in Figure 2.13. The fractional real area of contact for all samples increases almost linearly with increase in nominal pressure. The real area of contact for uncoated material (sample 4) is smaller than that of the coated samples. This difference clearly demonstrates the effect of coating on asperity deformation. The difference in real area of contact for differently coated samples at low pressure is not clearly seen but for higher pressures the difference is clearly visible (Figure 2.13). The real area of contact for a higher coating thickness is higher. This can be attributed to reduction in effective hardness of the material with increase in zinc coating thickness. Sample 2 with average coating thickness of $14 \mu \mathrm{m}$ and sample 3 with average coating thickness of $23 \mu \mathrm{m}$ show similar results. This is because the substrate in sample 2 (S220) is stronger than that of sample 3 (DX56) (see Figure 2.1). The results show that the fractional real area of contact is proportional to applied load and that the coating material, its thickness and underlying substrate have an influence on the deformation of the asperities.

\subsubsection{Model results and validation}

The model is implemented in Matlab. Using the contact pressure database derived for each of the material combination and measured sample height data, the fractional real area of contact is determined at different nominal pressures. The model predictions for all the samples together with the experimental results are shown in Figure 2.13. The results show that model is able to predict the real area of contact for the nominal contact pressure range up to $60 \mathrm{MPa}$ very well. A real area of contact increases almost linearly with the rise in nominal pressure. This trend is consistent with the model results by Chang et al. [13]. This is because the rise in asperity contact pressure after initial yielding is limited for all asperity geometries and materials (see Figure 2.3). Furthermore, at each tool position, asperities of different sizes (hence different contact pressure) come into contact. Hence, the resulting effective contact pressure is an area averaged quantity of all the contacting asperities and depends on the distribution of asperity geometry. For example, Figure 2.14 shows the distribution of asperity base area and cut-off volume for sample 1 at equilibrium tool positions corresponding to $15 \mathrm{MPa}$ and $45 \mathrm{MPa}$. The number of asperities and their size increase with nominal pressure but there is always a contribution from a large range of asperities at each pressure level. The model is able to capture the trend and the magnitude of the fractional real area of contact as determined from the experiment. Coupling the single asperity FE simulation results 

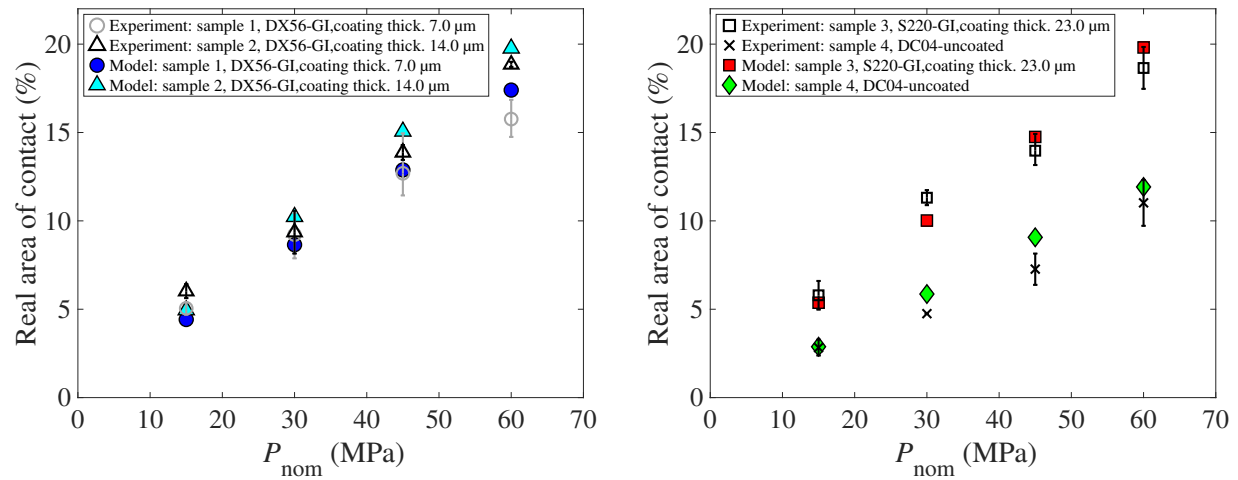

Figure 2.13 Fractional real area of contact: model vs. experiments. The error bars depict the maximum and minimum values.

with the analytical flattening model makes it possible to account for the coating-substrate material combination, material hardening, neighbouring non-contacting material effects and realistic asperity hardness.

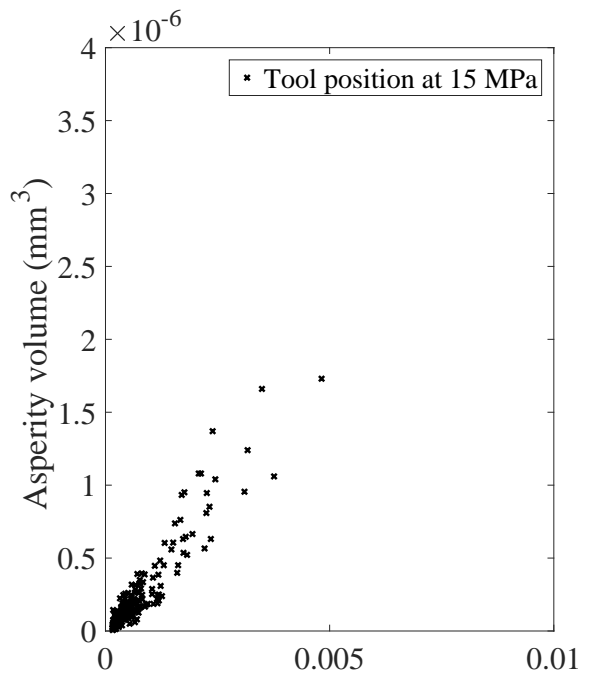

Asperity base area $\left(\mathrm{mm}^{2}\right)$

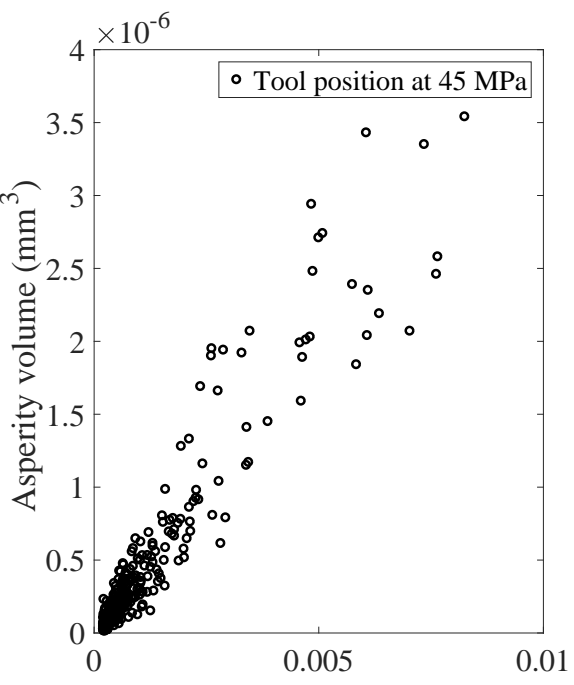

Asperity base area $\left(\mathrm{mm}^{2}\right)$

Figure 2.14 Asperity base area and volume at tool position of 15-45 MPa nominal pressure for sample 1 . 


\subsection{Summary and conclusions}

A semi-analytical normal load flattening model is proposed which accounts for the coating and substrate material behaviour, coating thickness and surface topography of the rough surface. Using the contact pressure under the flattening situation derived for ellipsoidal asperities of different sizes, an asperity deformation is modelled more accurately than in previous studies using a constant relation between yield strength and hardness [8]. The model is able to predict the influence of coating thickness, surface topography and coating-substrate material combination on real area of contact. Furthermore, the model does not require any fitting parameter. The rise of non-contacting material is included using volume conservation. The model predicts a monotonic increase in real area of contact for coated and uncoated systems.

Normal load flattening experiments are performed on uncoated and coated samples with different materials and coating thicknesses. For the samples analysed, the real area of contact increases approximately linearly relative to the applied load. The measured and calculated real area of contact for coated sheet is larger than that of the uncoated sheet. The real area of contact increases with the increase in coating thickness. The predictions from the proposed model show good agreement with the experimental results. 



\section{Chapter 3}

\section{Effect of bulk strain on real area of contact}

In a typical deep drawing process, the sheet surface evolves due to normal contact load, sliding and bulk strain in the sheet metal. Combined normal load and bulk strain increases the real area of contact significantly in comparison with the normal load alone. Experiments are performed to investigate the effect of a combined normal load and bulk strain on the real area of contact. Uncoated and zinc coated steel sheets (GI) with different coating thicknesses, surface topographies and substrate materials are used in the experimental study. Finite element (FE) analyses are performed on measured surface profiles to analyse the behaviour observed in the experiments and to understand the effect of surface topography and coating thickness on the evolution of the real area of contact. Finally, an analytical model to determine the real area of contact is presented for a combined normal load and bulk strain. The phenomena such as friction and wear can be modelled more accurately using the results of the analytical model.

In Section 3.2 an experimental setup developed for a combined normal load and bulk strain experiments is presented, followed by a test procedure and results. In Section 3.3 plane strain FE simulations are performed on measured 2D profiles of samples to investigate the effect of different parameters on the real area of contact. In Section 3.4 the modelling strategy to predict the real area of contact is presented followed by discussion and conclusions.

This chapter is based on the publication: M.P. Shisode, J. Hazrati, T. Mishra, M.B. de Rooij and A.H. van den Boogaard, "Evolution of real area of contact due to combined normal load and sub-surface straining in sheet metal" (Accepted in Friction). 


\subsection{Introduction}

Asperity flattening of rough surfaces at micro-scale is one of the key parameters for predicting friction and wear behaviour at the tool-workpiece interface. For example, friction models proposed by Bay [26, 27] and Wanheim [28] include real area of contact as an important parameter. Recently, Hol $[1,3]$ developed a multi-scale friction model for sheet metal forming applications where the real area of contact is used as a key parameter to determine the local coefficient of friction. The real area of contact is much lower than the nominal contact area at the tool-workpiece interface. Therefore, the local contact pressure developed at the asperity level is much higher than the nominal pressure, so it can plastically deform the asperities. The real area of contact for a given loading condition or a combination of loads is determined either by dedicated experiments or physics-based models. There are numerous models and experimental studies available for normal load flattening for uncoated [6-8] and coated sheets $[12-15,29]$. In a typical sheet metal forming process, the sheet surface is deformed due to the contact pressure (normal load), bulk strain in sheet metal and sliding of the tool over the sheet surface. A combination of these factors at the tool-workpiece contact interface influences the real area of contact. When straining is present, asperity flattening or roughening may occur. In the case of free surface straining, surface roughening is more likely to happen $[30,31]$. On the contrary, a normal load combined with bulk strain substantially increases the asperity flattening and real area of contact as confirmed by several experimental studies [8, 32-36]. In this case, plastic deformation of the bulk material reduces the effective hardness leading to easier asperity deformation. Wilson and Sheu [35] performed rolling experiments on aluminium alloy specimens which exhibit the combined normal load and subsurface straining. Specimens with triangular shaped asperities oriented parallel to the rolling direction were used. The width of the flattened asperity crests was measured on the deformed specimens to determine the real area of contact. Sutcliffe [34] performed biaxial experiments with combined normal contact loads and bulk tensile strain on copper specimens with triangular ridges aligned transversely to the bulk strain direction. Nielsen et al. [33] performed similar experiments on aluminium alloy specimens. The results from these experimental studies on different materials show that the real area of contact increases monotonically and reaches the nominal area asymptotically with increasing strain. All these studies provide good insights on the effect of subsurface straining. However, the experiments are limited to the specimens 
with uniformly spaced, ideal shaped asperities which are far from the realistic engineering surfaces. Westeneng [8] performed similar experiments on aluminium specimens with arbitrary shaped asperities under a combined normal load and longitudinal bulk strain. The results show a similar trend to that of specimens with ideal shaped asperities. So far, the experimental studies are limited to uncoated sheets. Nowadays, the zinc coated (GI) sheets textured by electro-discharge textured (EDT) rolls are widely used in deep drawing applications due to its corrosion resistance and better paint appearance. Hence, it is increasingly important to focus the study on textured coated sheets.

Modelling the combined effect of normal load and bulk strain on asperity deformation is complex. Simplified 2D models have been proposed in the past. For instance, Wilson and Sheu [35] and Sutcliffe [34] proposed models for ideal surfaces with uniform asperities oriented in parallel or perpendicular to the straining direction. They validated the models using dedicated experiments on ideal surfaces as mentioned above. However, the quantitative comparison of the model predictions and experiments showed that the model underestimates the real area of contact. Sutcliffe [34] used a slip-line analysis in a plane strain situation to predict asperity deformation. However, these 2D models are too simplified to accurately describe the surface deformation of the engineering surfaces. Westeneng [8] adapted these models to derive a model for arbitrary shaped asperities and height distributions assuming an ideal plastic material behaviour. The model requires a calibration parameter which can be determined either by $\mathrm{FE}$ simulations or experiments.

The goal of this study is to investigate the real area of contact due to asperity flattening under a combined normal load and bulk strain for uncoated and coated sheets. Combined normal load and bulk strain experiments are performed on samples of different surface topographies, coating thicknesses and substrate materials. Furthermore, Westeneng's [8] model is adapted to describe the surface deformation and to predict the real area of contact under a specific combination of normal load and bulk strain. The required model parameters are determined using the experimental results. 


\subsection{Combined normal load and bulk strain exper- iments}

\subsubsection{Experimental setup}

To mimic the sheet metal surface deformation during forming processes, the setup used for normal load flattening experiments (Chapter 2) is adapted to perform the combined normal load and bulk strain experiments. The setup enables application of an approximately constant nominal pressure
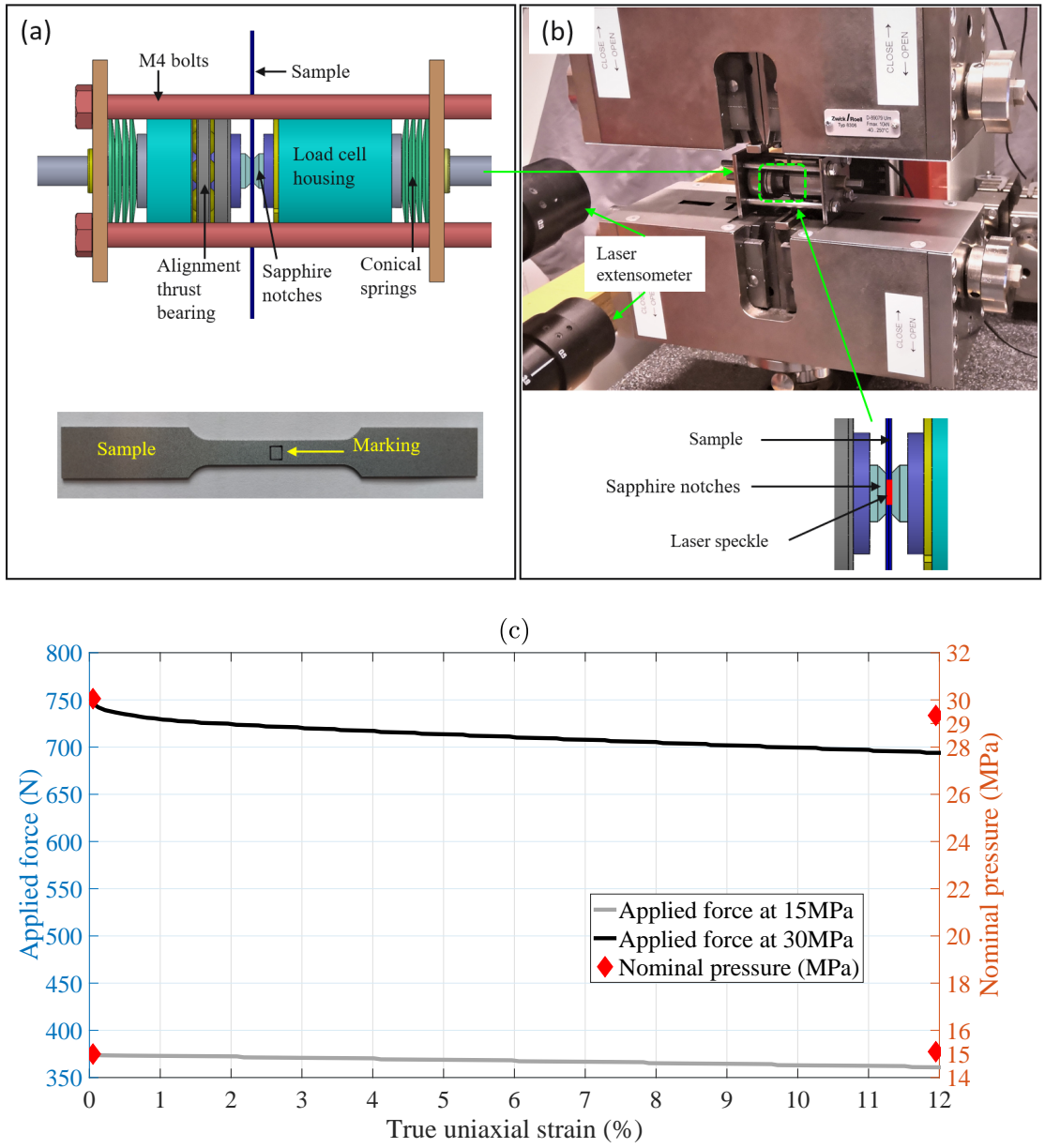

Figure 3.1 Experimental setup. (a) Bulk strain unit and sample geometry. (b) Test setup. (c) Evolution of normal force and nominal pressure vs. uniaxial strain (sample 1 in Table 3.1). 
on the sheet surface while the material is deformed in uniaxial tension. Figure 3.1a shows the setup and the sample geometry. Figure 3.1b shows the assembly of the setup on a tensile tester for a combined normal load and uniaxial tensile strain experiments. More details of the setup can be found in Chapter 2 (Section 2.3.2).

The specimen is loaded at the centre for a required nominal pressure using a pair of highly polished sapphire $\left(\mathrm{Al}_{2} \mathrm{O}_{3}\right)$ notches $(\mathrm{Sa}<1 \mathrm{~nm})$ with a contact area of $5 \times 7 \mathrm{~mm}$. The polished surfaces minimize the effect of notch asperities ploughing through the sheet surface during straining which can influence the real area of contact. To make the interpretation of the results easier, a constant nominal pressure is maintained on the surface of the specimen during the deformation. However, this might be affected during tensile straining of the sample because of the thickness and width reduction in the deformation zone. The decrease in thickness reduces the nominal pressure due to loss of clamping load at the notches. On the other hand, reducing the sample width increases the nominal pressure on the sample. To nullify these effects, a stack of conical springs is used to maintain a constant nominal pressure on the surface of the specimen. A design study is performed to determine the number of springs in the stack and their specifications. Reductions in width and thickness at a given longitudinal strain for each sample are determined using their plastic strain ratio (Lankford coefficients). Furthermore, the reduction in clamping load for the stack of springs is determined using the force vs. deflection curve of the stack of springs. Finally, the stack of springs is optimized such that the percentage loss in clamping force and nominal contact areas are equal so as to ensure a constant nominal pressure. Figure 3.1c shows an example of measured normal load by a load cell as the sample is strained. The initial and final nominal pressures determined from the measured normal load and nominal area are also plotted. The results show that the loss in nominal pressure is $<1 \mathrm{MPa}(<3.5 \%)$ for applied nominal pressure of $30 \mathrm{MPa}$.

\subsubsection{Sheet samples and test procedure}

Zinc coated (GI) and uncoated steel samples which are used in the normal load flattening study (Chapter 2) are used for the combined normal load and bulk strain experiments to investigate the influence of coating thicknesses and surface topography. Table 3.1 shows the sample details and Figure 3.2 shows the surface topographies of all samples. The sample numbers 1 through 4 in Figure 3.2 refer to samples prepared from four different sheets as in Table 3.1. Samples 1 and 2 have a similar surface topography with 
peaks separated by much lower spacing than in sample 3 (see $R_{\mathrm{sm}}$ in Table 3.1). All the samples are textured by electro-discharge textured (EDT) rolls.

Table 3.1 Summary of samples used in experiments.

\begin{tabular}{|l|l|l|l|l|}
\hline $\begin{array}{l}\text { Sample } \\
\#\end{array}$ & Steel grade & $\begin{array}{l}\text { Average coat- } \\
\text { ing thickness } \\
(\mu \mathrm{m})\end{array}$ & $\begin{array}{l}\text { Surface } \\
\text { roughness, Sa } \\
(\mu \mathrm{m})\end{array}$ & $\begin{array}{l}\text { Mean peak } \\
\text { spacing, } R_{\mathrm{sm}} \\
(\mu \mathrm{m})\end{array}$ \\
\hline 1 & DX56-GI & 7 & 1.1 & 66 \\
\hline 2 & DX56-GI & 14 & 1.6 & 76 \\
\hline 3 & S220-GI & 23 & 1.0 & 153 \\
\hline 4 & DC04 & uncoated & 1.3 & 95 \\
\hline
\end{tabular}

The test samples are prepared with a total length of $100 \mathrm{~mm}$, gauge length of $30 \mathrm{~mm}$ and width of $5 \mathrm{~mm}$ at the centre. A square mark of 2.5 $\times 2.5 \mathrm{~mm}$ is made on the sample (Figure 3.1a) where the surface height measurements are performed before and after the experiment to determine the real area of contact using a confocal microscopy. A sample is inserted between the loading notches making sure that the marked area is completely covered by the notches. The required normal load is applied using four M4 bolts (Figure 3.1a) to reach the desired nominal pressure. Once the required
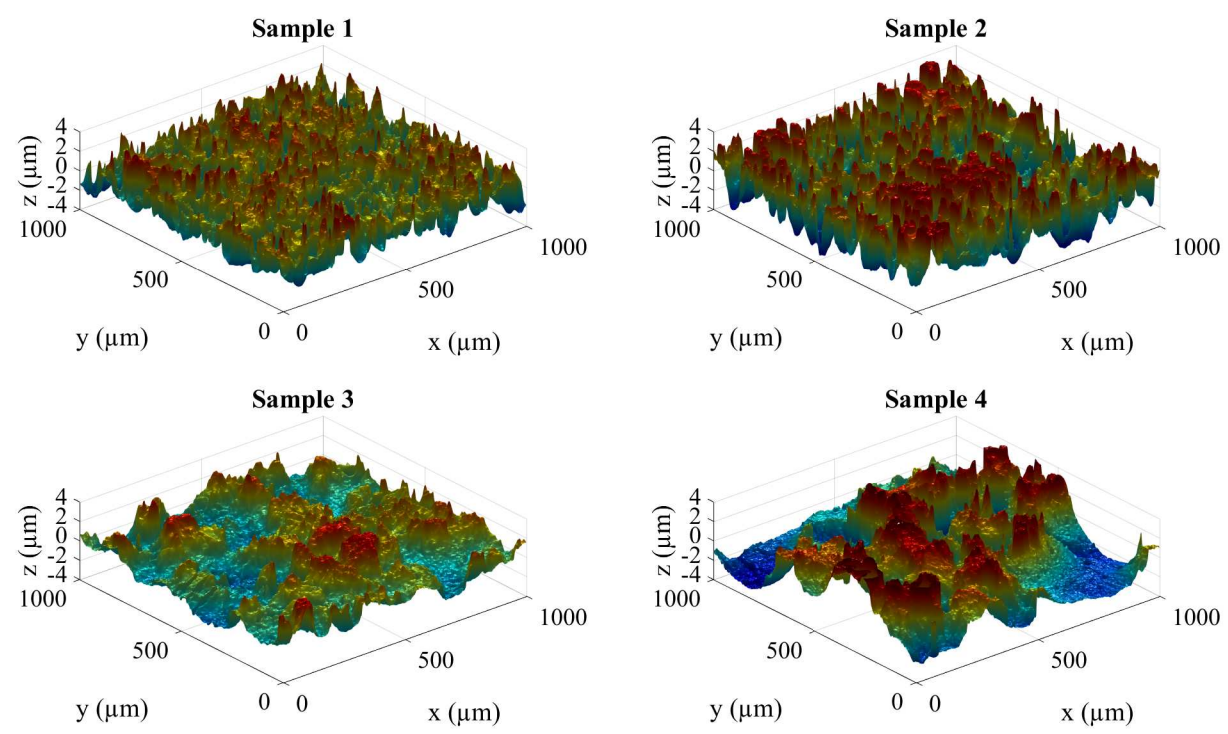

Figure 3.2 Height data of undeformed samples showing different surface textures. 
nominal pressure is reached, the setup is mounted on the tensile test machine for uniaxial tensile deformation. During straining, the setup moves along with the sample which helps to reduce the sliding effects between the sample and the sapphire notches. This also ensures that the same clamping area is subjected to normal load during straining. In addition, the surface of the samples is moistened with a small amount of Fuchs Anticorit PLS100T lubricant to further reduce the friction and the sliding effects between the sample and the sapphire notches. It can be safely assumed that the lubricant amount is not enough to completely fill the rough surface valleys. Therefore, no hydrostatic or lubricant squeeze effects are expected. Longitudinal strain is measured using a laser extensometer (see Figure 3.1b). For this purpose, a laser speckle pattern is projected on the thickness side of the sample between two notches. The sample is strained by $2 \%, 4 \%, 8 \%$ and $12 \%$ at constant nominal contact pressures of $15 \mathrm{MPa}, 30 \mathrm{MPa}$ and $45 \mathrm{MPa}$. The sample is strained at a rate of $2 \mathrm{~mm} / \mathrm{min}$. A new sample is used for each combination of strain and nominal pressure. After unloading the samples, the real area of contact of the deformed sample is determined using the surface height distribution function [8]. A representative measurement area of $2 \times 2 \mathrm{~mm}$ as determined in Chapter 2 (Section 2.3.1) is used to determine the height distribution function. An approach to determine the real area of contact is presented in Chapter 2 (Section 2.3.2).

\subsubsection{Results}

A separate sample is used for each combination of nominal pressure and strain. However, to visualize the progress of asperity deformation, additional experiments are performed on samples 2 and 3 using the same sample at constant nominal pressure of $15 \mathrm{MPa}$ and uniaxial tensile strains of $2 \%, 4 \%, 8 \%$ and $12 \%$. Small parts of the measured height data are shown in Figure 3.3 and 3.4 for samples 2 and 3 respectively. A decrease in asperity height due to flattening can be seen as the strain increases at constant nominal pressure. Height distribution functions derived from the measured height data of the undeformed and deformed surfaces are shown in Figure 3.5. Height distribution functions at nominal pressure of $30 \mathrm{MPa}$ and longitudinal strains up to $12 \%$ are plotted. Comparison of the undeformed and deformed distribution functions clearly shows the surface deformation. The real area of contact is determined by Equation (2.9) using the height distribution function of the deformed surface.

The fractional real area of contact as a function of longitudinal strain at a constant nominal pressure for all the samples are shown in Figure 3.6. 

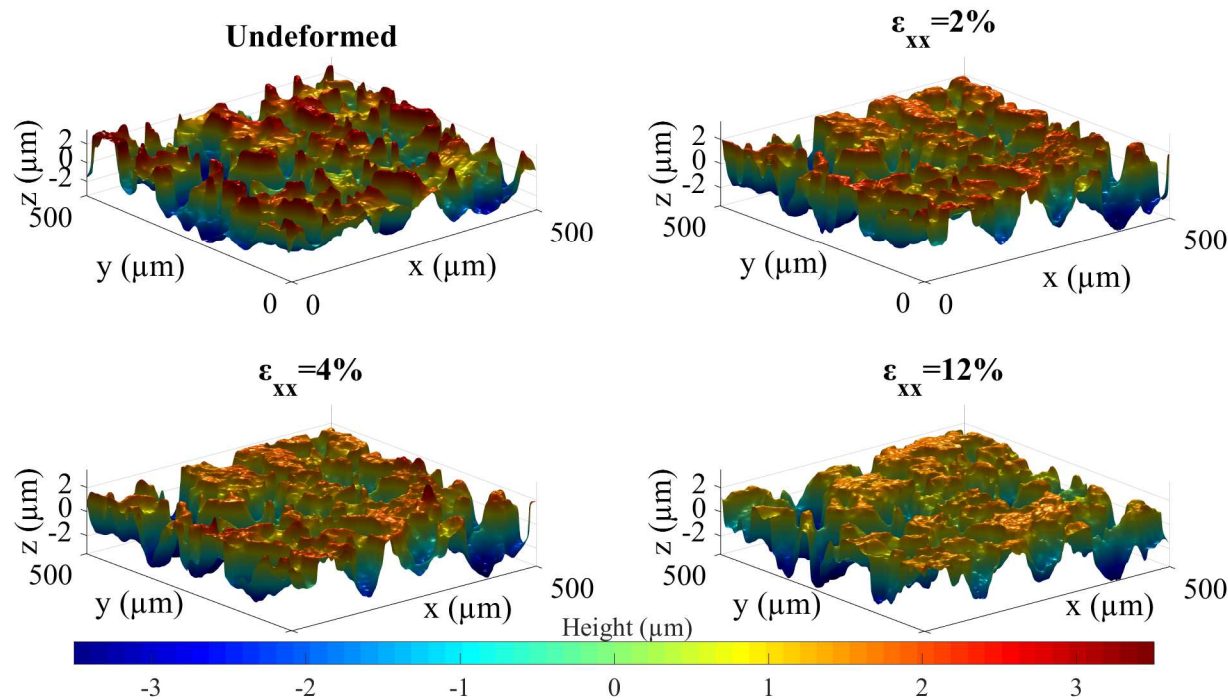

Figure 3.3 Evolution of surface topography due to a combined normal load (15 MPa) and longitudinal strain for sample 2 (the same sample is used for all experiments).
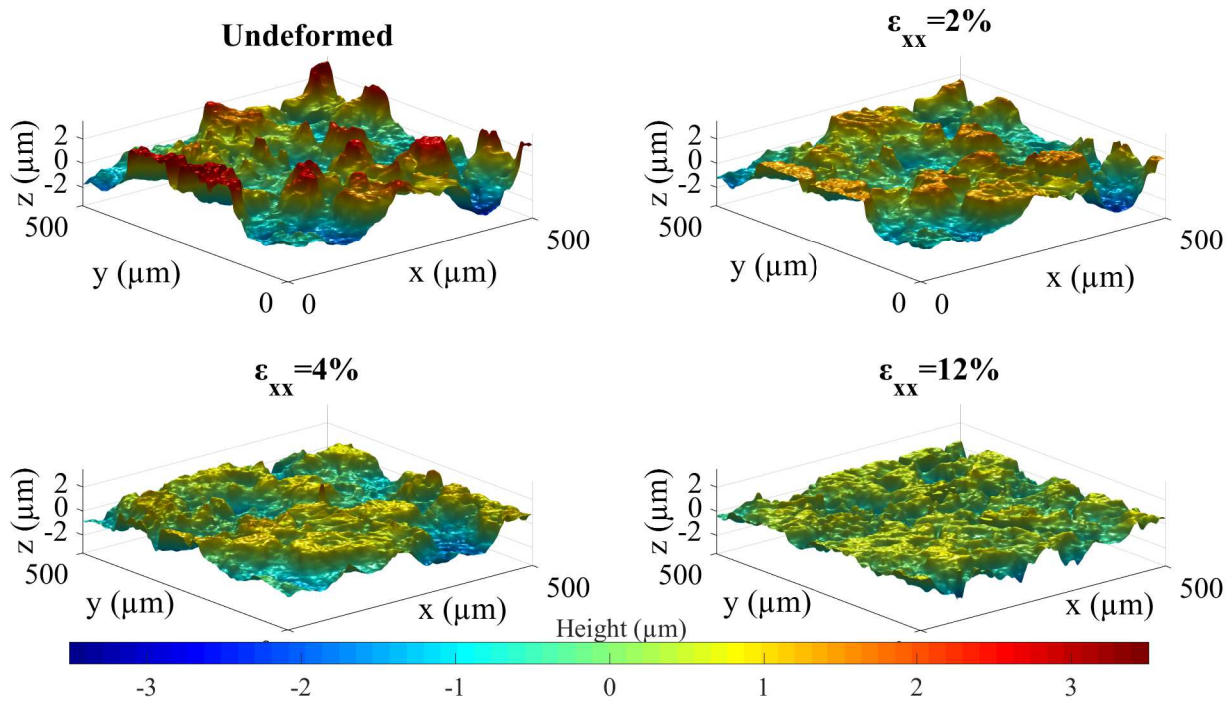

Figure 3.4 Evolution of surface topography due to a combined normal load (15 MPa) and longitudinal strain for sample 3 (the same sample is used for all experiments). 

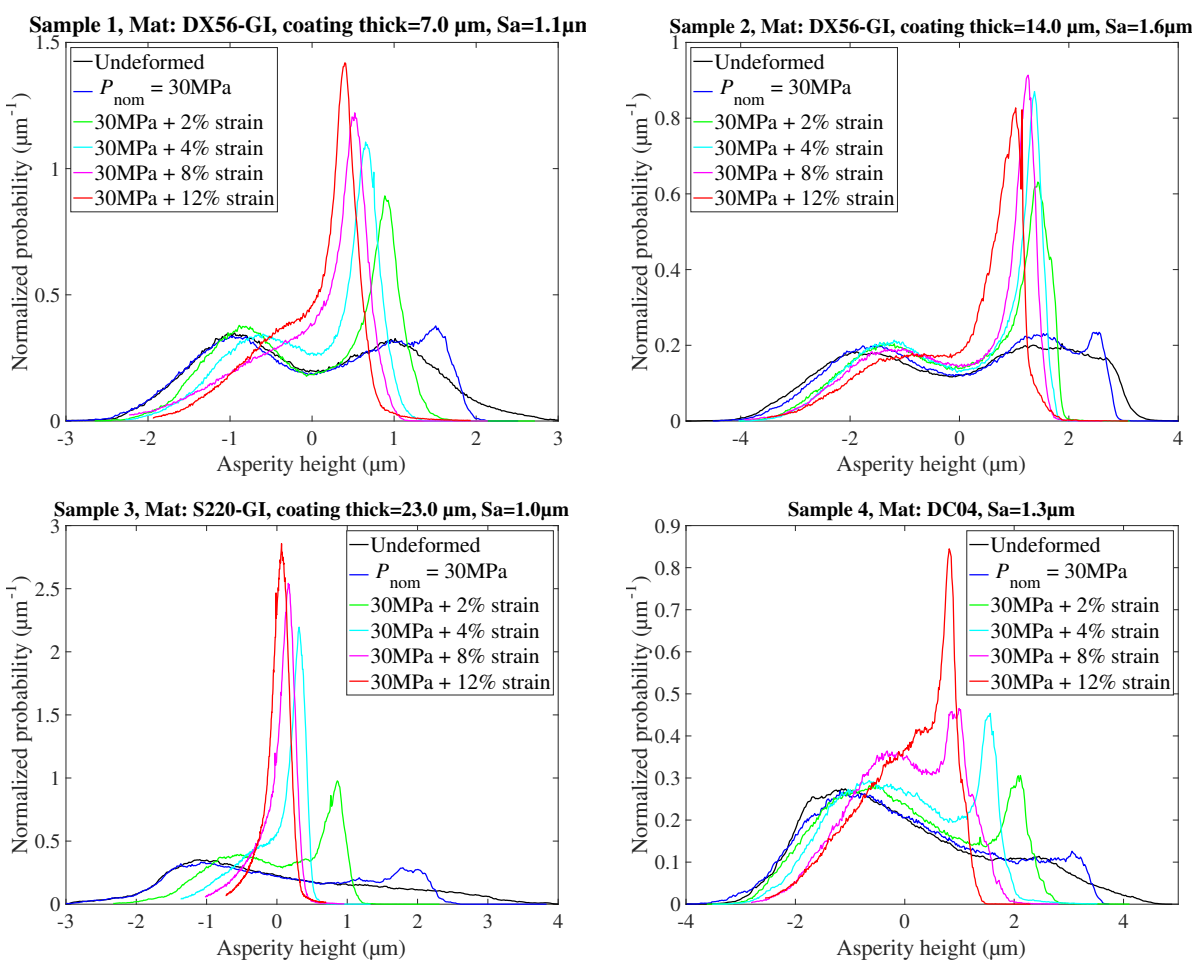

Figure 3.5 Surface height distribution functions of different samples before and after deformation.

The results show that the real area of contact increases monotonically with the increase in longitudinal strain at a constant pressure. The real area of contact shows a higher increase at the smaller strains. By increasing the strain, the skewness in height distribution of the samples increases rapidly, and the texture on the surface vanishes. Fading of the texture on the sheet metal can influence the frictional behaviour of the sheet metal. It can also affect the paint appearance of the sheet metal specifically for the areas which undergo large strains. The results show that the texture (roughness) of sample 3 is almost lost following $8 \%$ of strain at $30 \mathrm{MPa}$ (see Figure 3.5). It is noticeable that the real area of contact for GI samples is higher than that of uncoated DC04 sample. This is because the hardness of the GI sheet is lower than that of the uncoated sheet due to the softer zinc coating. Furthermore, the real area of contact is the highest for sample 3 (coating thickness $=23 \mu \mathrm{m}$ ), thereby demonstrating the influence of coating thickness. Also, the surface texture of sample 3 is very different (with higher $R_{\mathrm{sm}}$ value) 

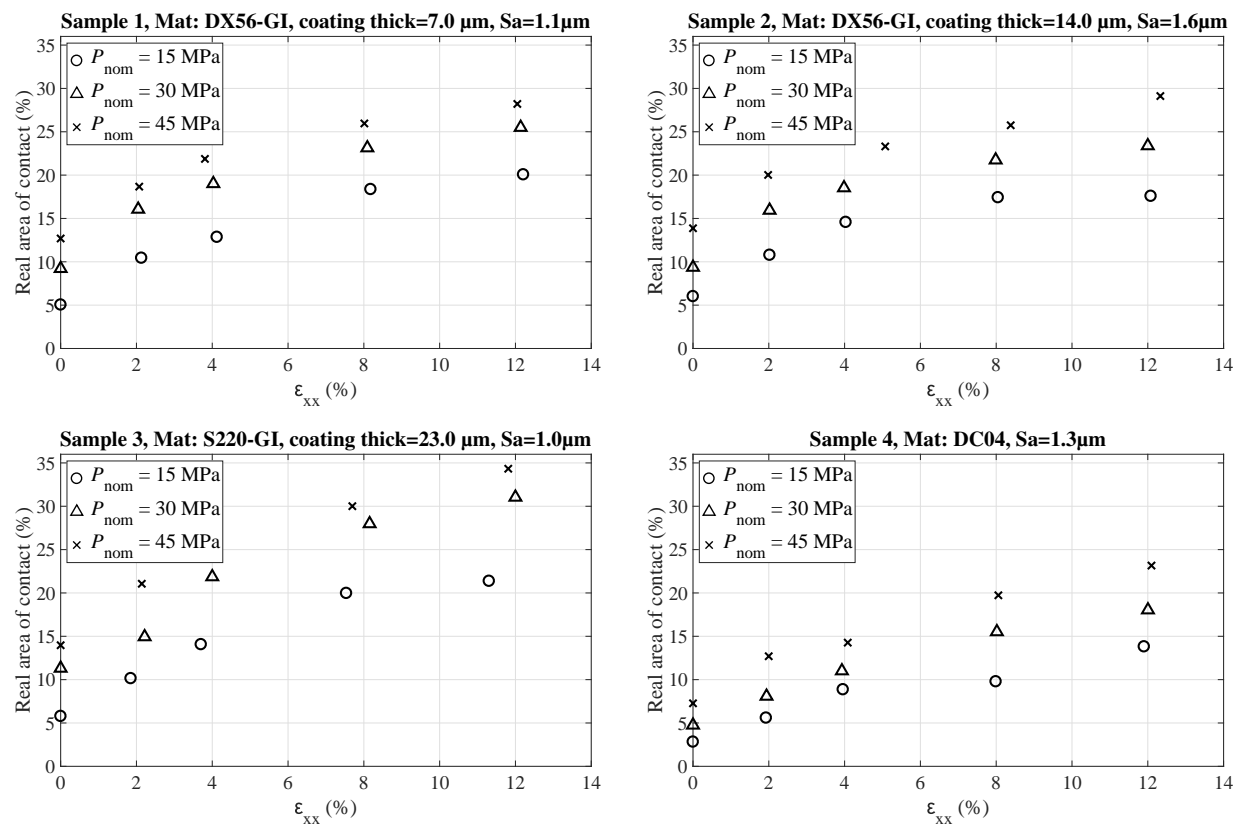

Figure 3.6 Experiments: real area of contact vs. uniaxial tensile strain at three different nominal pressures.

from that of samples 1 and 2 (see Figure 3.2). Moreover, the substrate in sample 3 is the strongest among all samples. This demonstrates the major influence of coating thickness in asperity deformation while the influence of substrate diminishes with the increase in coating thickness as concluded by Halling et al. [19]. The real contact areas of samples 1 and 2 are similar although sample 2 has a coating thickness twice that of the sample 1. However, sample 2 has a higher roughness than sample 1, which indicates that the surface roughness plays a significant role in asperity deformation as well. It should be noted that, despite a similar real area of contact, the resultant height distributions of the samples 1 and 2 after deformation are different (Figure 3.5). The results show that as the skewness of height distribution increases due to asperity deformation, the bimodal distribution reduces to almost a single peak in the case of sample 1 at high strains while it remains for sample 2. On the contrary, the bimodal distribution in sample 4 becomes more pronounced with the increase in strain.

For the samples investigated in this study, the coating thickness plays a significant role in asperity deformation while the effect of substrate is expected to be minor. In general, by increasing the surface deformation the 
shape of the height distribution profile changes and becomes more skewed. The results also suggest the influence of surface roughness and surface texture on asperity deformation but it is difficult to draw any conclusion using the available experimental data. Hence, 2D plane strain FE analyses are performed to understand the effect of each parameter on the real area of contact.

\subsection{Effect of different parameters on real area of contact}

Using FE simulations, it is possible to determine the influence of each individual parameter on the real area of contact under a combined normal load and bulk strain. 3D FE simulations can be done for more accurate predictions but modelling a 3D surface at the asperity level is complicated and computationally expensive. Hence, 2D plane strain FE simulations are chosen for sensitivity analysis of different parameters on the real area of contact. The parameters which are varied in this study are coating thickness, surface roughness and surface texture. The 2D profiles derived from GI samples (see Table 3.1 for specifications) are used. Figure 3.7 shows the 2D profiles of the undeformed samples 1, 2 and 3. Samples 1 and 2 have a similar surface texture and height distribution function which are different from sample 3. Hence, profiles of sample 1 (profile 1) and 3 (profile 3) are used for the numerical study by varying different parameters. To understand the influence of coating thickness, profile 1 with coating thickness of $7 \mu \mathrm{m}$ and $14 \mu \mathrm{m}$ are modelled. Furthermore, to investigate the influence of surface roughness, profile 1 with surface roughness of $1.1 \mu \mathrm{m}$ and with a scaled roughness of $1.6 \mu \mathrm{m}$ are modeled while maintaining the same coating thickness. Also, the results from profile 1 and 3 which have a similar surface roughness are compared so as to understand the effect of surface texture while maintaining the same coating thickness.

\subsubsection{FE modelling}

Figure 3.8 shows the details of a 2D plane strain model. The total profile length of $3 \mathrm{~mm}$ is modelled to include enough asperities to have a representative model. The substrate thickness is equal to $0.7 \mathrm{~mm}$. In the FE model, finer mesh is used in the coating with element edge length less than the surface height measurement resolution $(1.3 \mu \mathrm{m})$. Plane strain linear quadrilateral elements (full integration) are used. The mesh is gradually 
Sample 1 profile

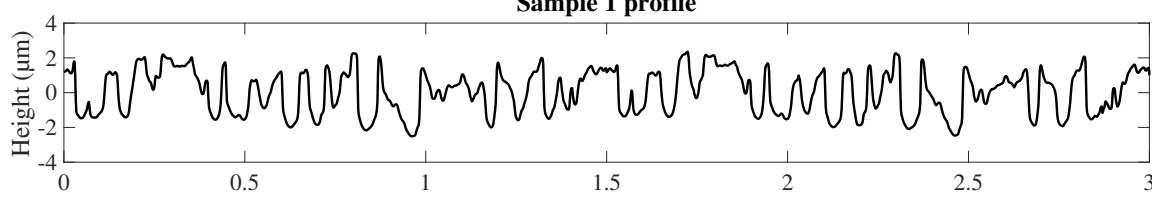

Sample 2 profile

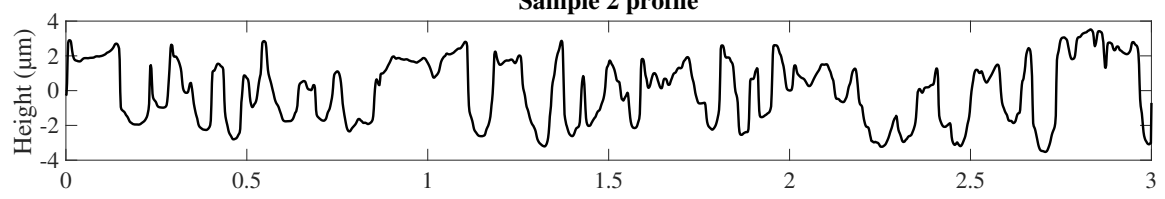

Sample 3 profile

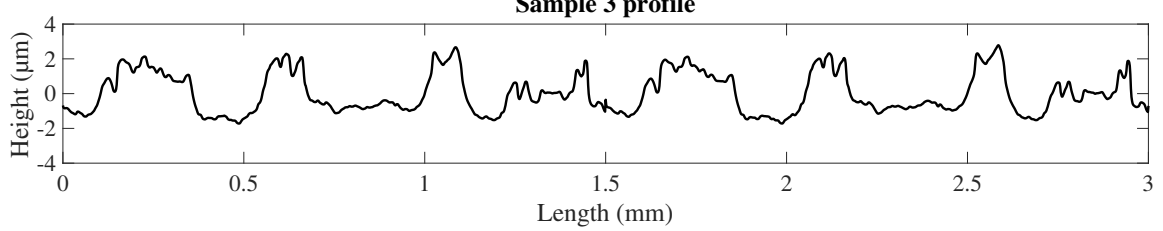

Figure 3.7 2D profiles derrived from samples 1 ( $R a=1.1 \mu \mathrm{m})$, $2(R a=1.6 \mu \mathrm{m})$ and $3(R a=1.0 \mu \mathrm{m})$.

coarsened in the substrate. The material properties of zinc coating and steel substrates presented in Chapter 2 (Section 2.2.1) are used in the simulations.

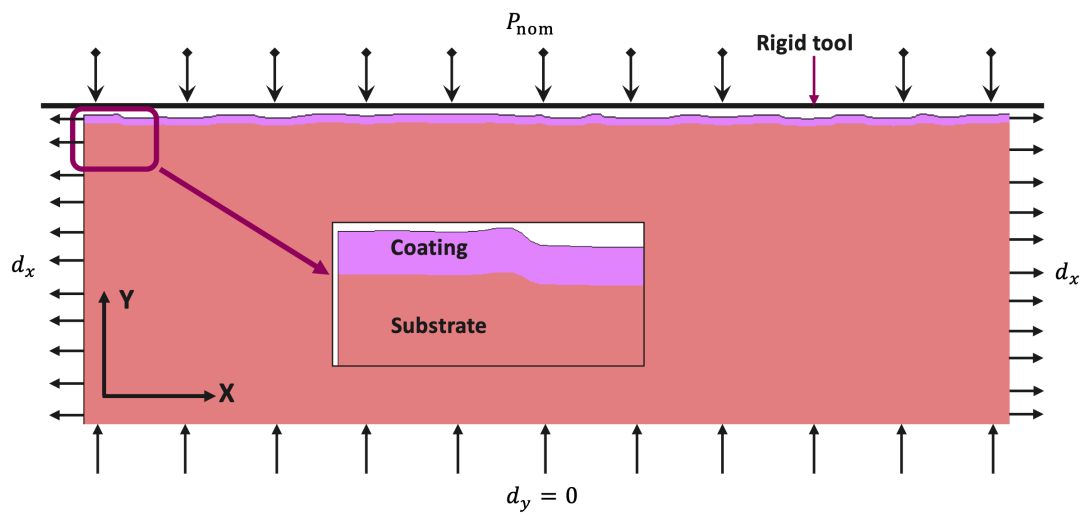

Figure 3.8 FE model details (profile 1).

\section{Key assumptions}

1. The tool is flat and rigid as the hardness of sapphire is much higher than that of the sample materials.

2. The coefficient of friction of 0.083 is used between the rough GI surface and the tool. The coefficient of friction between a mirror finished 
sapphire surface and GI sample is determined by a linear friction tester [37] (See Appendix A).

3. The coating thickness is uniform and bonded perfectly to the substrate.

4. Elastic-plastic material response of coating and substrate is modelled by $\mathrm{J} 2$ plasticity.

For simplicity, one type of substrate (DX56) with zinc coating is used in the FE analyses. This means that the sensitivity of the substrate material is not studied because the soft coating dominates the asperity flattening [19]. The material properties for other substrates are still required in the analytical model presented in Section 3.4. In the FE analysis, the tool is moved downward to apply a normal load corresponding to a nominal pressure of $15 \mathrm{MPa}$. Afterwards, a longitudinal strain is gradually applied by specifying lateral displacements on each side. As the material is strained, its nominal contact area with the tool increases, which reduces the nominal pressure at constant normal load. Hence the normal force is increased in the same proportion as the nominal contact area to keep the nominal pressure constant. Results are post-processed to determine the real area of contact at a nominal pressure of $15 \mathrm{MPa}$ and a longitudinal strain up to $10 \%$. The real area of contact is determined by identifying the nodes in contact with the tool, enabling the total contact length and the contact area to be determined.

\subsubsection{Discussion}

The fractional real area of contact of all profiles from FE simulations are shown in Figure 3.9. The evolution of real area of contact from plane strain FE simulations shows the same trend as in the experiments. The real area of contact for the profile with $14 \mu \mathrm{m}$ coating thickness is higher than that of the profile with $7 \mu \mathrm{m}$ coating thickness, which confirms the effect coating thickness on the real area of contact. On the other hand, a profile of higher roughness has a lower real area of contact for the same coating thickness, which means that the effect of coating thickness and surface roughness have opposite effects. This explains the similarity between the experimental results of samples 1 and 2. The surface texture or the profile shape also influences the asperity deformation. For example, profile 1 (bimodal height distribution and $R_{\mathrm{sm}}=66 \mu \mathrm{m}$ ) and profile 3 (Gaussian height distribution and $R_{\mathrm{sm}}=153 \mu \mathrm{m}$ ) have the same coating thickness and similar roughness but the real area of contact for profile 3 increases more rapidly after a certain 


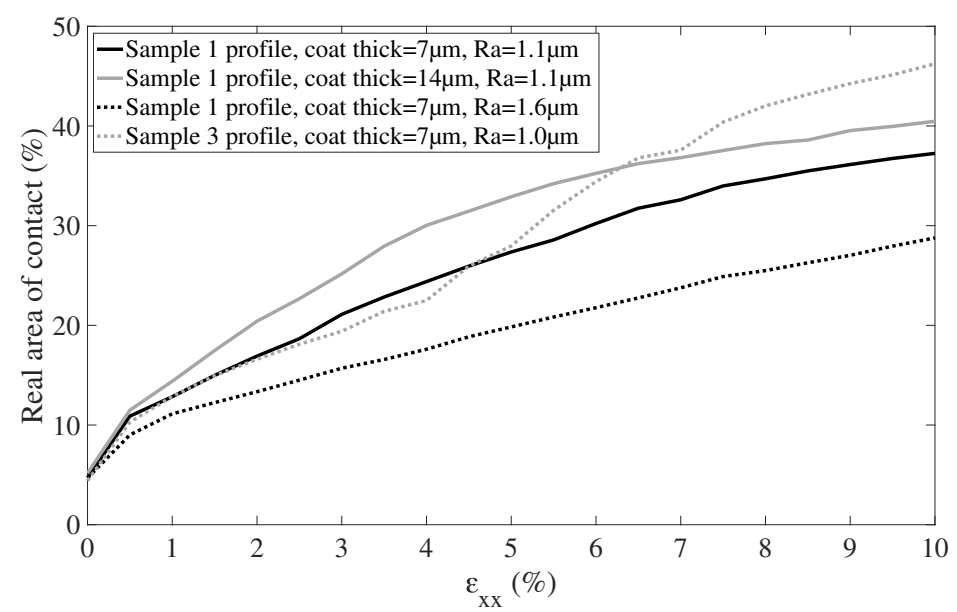

Figure 3.9 Effect of coating thickness, roughness and height distribution on real area of contact at nominal pressure of $30 \mathrm{MPa}$ obtained from $\mathrm{FE}$ results.

strain $(>5 \%)$ which can be attributed to the profile shape or the surface texture. In the case of profile 3 , the asperities deform gradually up to a strain of $5 \%$ but at higher strain, the asperities join together and the flat islands suddenly come into contact with the tool resulting in a sudden rise in the real area of contact.

A relation between different parameters and real area of contact can be explained by the distribution of stresses, strains and strain energy density in the coating layer. The scalar parameter strain energy density is chosen that combines the effect of stresses and strains. The total elemental strain energy density distribution is plotted for each profile as shown in Figures 3.10 and 3.11. The results show that as the coating thickness on profiles with the same roughness increases (Figure 3.10a), the total strain energy density distribution becomes more homogeneous throughout the coating (distribution with less spread) and the real area of contact is larger. This is because as the zinc coating thickness increases, it permits easy deformation of asperities and allows more homogeneous stress, strain and strain energy density distributions. Similarly, the profile with lower roughness results in a more homogeneous stress, strain and strain energy density distributions than the profile with higher roughness at constant coating thickness (Figure 3.10b). At constant normal load, the strain hardening is higher in the surface with higher roughness due to the taller asperities as compared to the smooth surface. This means a lower deformed volume and higher strain 
(a) $\varepsilon_{\mathrm{xx}}=10 \%$

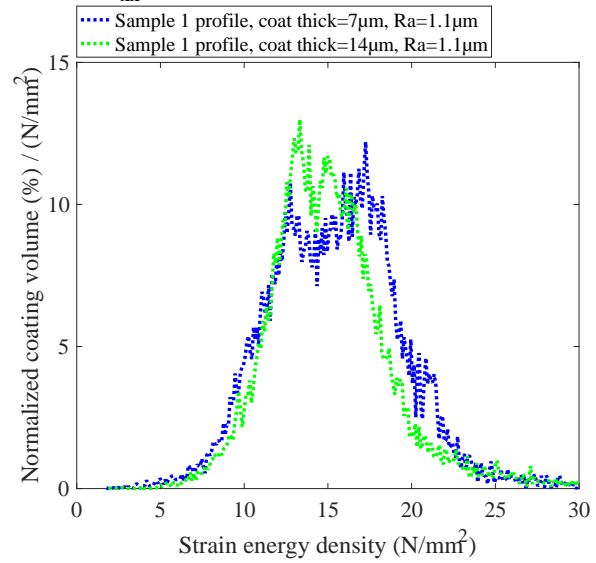

(b) $\varepsilon_{\mathrm{xx}}=10 \%$

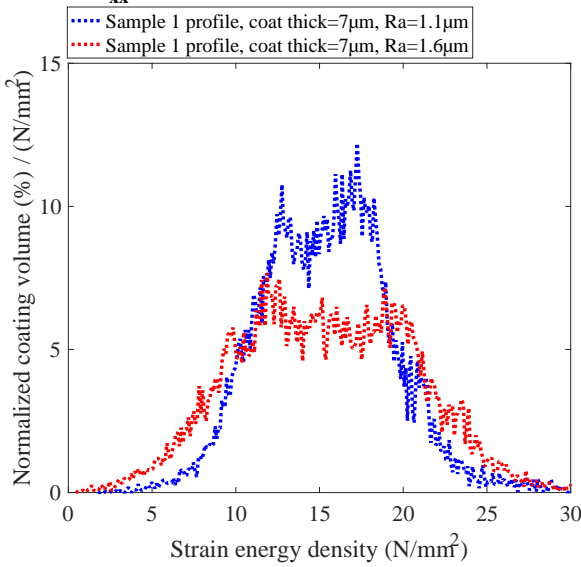

Figure 3.10 Total strain energy density distribution in coating at $P_{\text {nom }}$ of $15 \mathrm{MPa}$ and $\varepsilon_{x x}$ of $10 \%$. (a) Influence of coating thickness. (b) Influence of profile roughness.

energy density values than those of the surface with lower roughness (Figure $3.10 \mathrm{~b}$ ). Due to this, the real area of contact is smaller for a surface with higher roughness.

Figure 3.11 shows the effect of surface texture (profile shape) on the total strain energy density distribution in the coating at $5 \%$ and $10 \%$ longitudinal strains. A more homogeneous distribution and lower magnitude of strain

\section{(a) $\varepsilon_{\mathrm{xx}}=5 \%$}

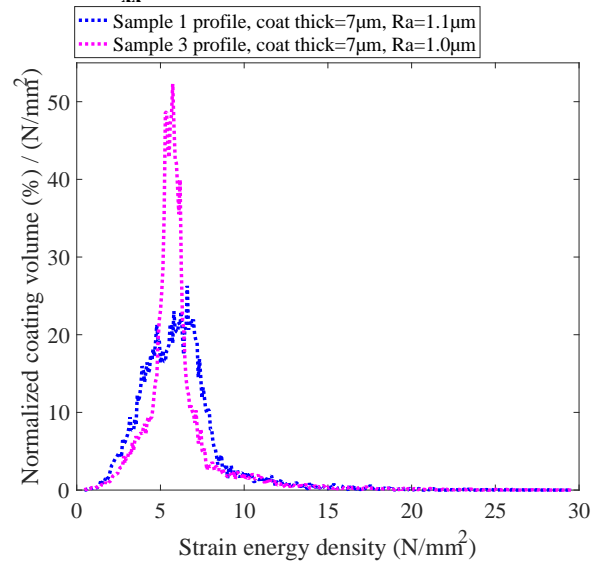

\section{(b) $\varepsilon_{\mathrm{xx}}=10 \%$}

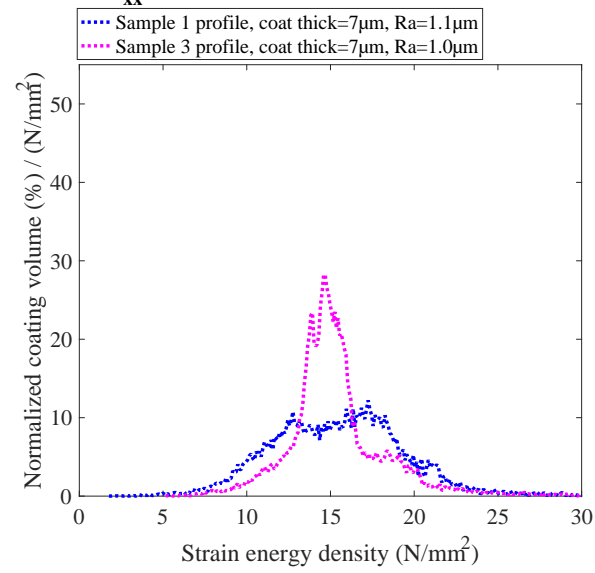

Figure 3.11 Total strain energy density distribution in coating at $P_{\text {nom }}$ of $15 \mathrm{MPa}$ and $\varepsilon_{x x}$ of $5 \%$ and $10 \%$ showing influence of profile shape. 
energy density can be seen in profile 3 than in profile 1 . This means that the load is more uniformly distributed resulting in lower strain hardening and higher real area of contact in profile 3 than in profile 1, especially at higher strains $(>5 \%)$. This is also observed in the experimental results in which the real areas of contact for samples 1 and 3 are similar at lower strains but the difference increases at higher strains.

\subsection{Analytical model to estimate real area of contact}

In deep drawing processes, the workpiece is subjected to a combined normal load and bulk strain. It is essential to estimate the real area of contact reliably and efficiently for such loading conditions for faster and more accurate friction and wear modelling. 2D models [34, 35] were proposed in the past for a combined effect of normal load and bulk strain. But these models are not suitable for randomly distributed and arbitrary shaped asperities. Westeneng [8] adapted the 2D models to include the effect of arbitrary shaped asperities and distribution by introducing a surface topography parameter called asperity density $\left(\rho_{a}\right)$. In this study, Westeneng model [8] is used to estimate the real area of contact for GI and uncoated steel sheets. The required asperity density parameter for each sample is determined using the experimental results.

\subsubsection{Description of rough surface}

The measured height data of the rough surface is modelled by bars [8, 29] as shown in Figure 3.12 (left). Each bar has a width equal to the measurement
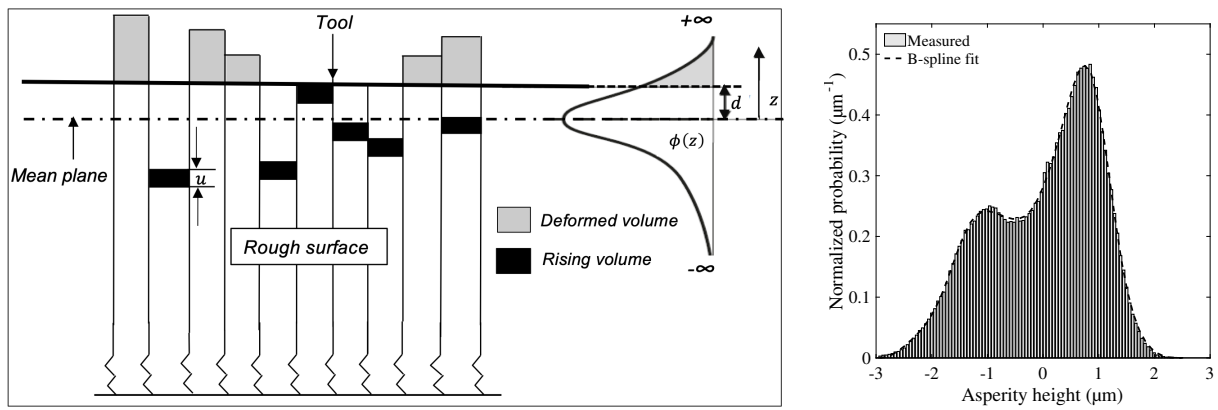

Figure 3.12 (left) Deformation and rise of asperities. (right) Fitting of height distribution data using the B-spline function. 
resolution $(1.3 \mu \mathrm{m})$ and height equal to the height of the measured surface point. The tool displacement due to crushing of bars is represented by tool position $d$ from the mean plane and the rise of non-contacting asperities is described by the uniform rise $u[8,25]$ based on the volume conservation. The height data of the measured surface is described by the height distribution function $\phi(z)$ based on B-spline function [25] using 10 cubic splines (Figure 3.12 (right)). The height distribution function is used in the analytical model to describe the rough surface.

\subsubsection{Model description}

Westeneng [8] derived the following analytical relation to determine the fractional real area of contact $\alpha_{\varepsilon}$ as a function of uniaxial strain $\varepsilon$ in the sheet. The model assumes a smooth and rigid tool plastically deforming soft asperities modelled as an ideal plastic material.

$$
\frac{\mathrm{d} \alpha_{\varepsilon}}{\mathrm{d} \varepsilon}=l V \frac{\mathrm{d} \alpha_{\varepsilon}}{\mathrm{d}\left(u_{\varepsilon}-d_{\varepsilon}\right)}
$$

$V$ is the velocity parameter, defined as

$$
V=\frac{v_{\mathrm{d}}+v_{\mathrm{u}}}{\dot{\varepsilon} l}
$$

where $v_{\mathrm{d}}$ is downward velocity of the deforming asperities and $v_{\mathrm{u}}$ is upward velocity of the non-contacting surface. Westeneng [8] approximated the velocity parameter using a relation proposed by Sutcliffe [34] for wedge shaped asperities deforming under a combined normal load and bulk strain. Sutcliffe [34] performed a slip-line analysis under a combined normal load and bulk strain assuming an ideal plastic material behaviour. A relation between the velocity parameter and the characteristic slip angle called fan angle $\Phi$ is derived from the slip-line analysis as follows:

$$
V=-0.184+1.21 \exp (1.47 \Phi)
$$

The fan angle [34] is defined as

$$
\Phi=\frac{H_{\mathrm{eff}}}{4 k}\left(1-\alpha_{\varepsilon}\right)
$$

where $H_{\text {eff }}=\frac{P_{\text {nom }}}{\alpha_{\varepsilon}}$ is the effective hardness and $k$ is the shear strength of the workpiece material. $k=\frac{H}{\mathrm{~B} \sqrt{3}}$ following the von Mises criterion under pure shear. $H=\mathrm{B} \sigma_{\mathrm{y}_{0}}$ is the initial hardness, $\sigma_{\mathrm{y} 0}$ is the initial yield strength of 
the sheet (zinc coating for GI sheet) material and B is the hardness factor equal to 2.8 for metals as determined by Tabor [9]. $l$ in Equation (3.1) is the mean half asperity spacing which is determined as [8]:

$$
\begin{aligned}
& l=\frac{\sqrt{\bar{\alpha}}}{2} \\
& \bar{\alpha}=\frac{1}{\rho_{a}}
\end{aligned}
$$

where $\bar{\alpha}$ is the mean apparent contact area of a single asperity and $\rho_{a}$ is the number of asperities in contact with tool per unit area. Definitions of $l$ and $\bar{\alpha}$ are true for uniformly distributed asperities of the same geometry as assumed by Sutcliffe [34]. Furthermore, $l$ changes during straining. This is because as the surface deforms, the asperities in contact with the tool increase, which increases the asperity density $\rho_{a}$ and reduces the mean half asperity spacing $l$. Hence, $l$ is a function of asperity density and $\alpha_{\varepsilon}$. Therefore, $\alpha_{\varepsilon}$ is introduced to account for the decrease in $l$ with an increase in real area of contact as follows [8]:

$$
l=\frac{1}{2 \sqrt{\rho_{\alpha} \alpha_{\varepsilon}}}
$$

The asperity density $\rho_{a}$ for any random surface is approximated by a fitting parameter. A relation to determine the asperity density $\rho_{a}$ and its parameters is described in Section 3.4.3. Equation (3.8) is used to determine the fractional real area of contact $\alpha_{\varepsilon}$.

$$
\alpha_{\varepsilon}=\int_{d_{\varepsilon}-u_{\varepsilon}}^{\infty} \phi(z) \mathrm{d} z
$$

where $\phi(z)$ is the height distribution function of the undeformed surface. Substituting Equation (3.8) in (3.1) yields

$$
\frac{\mathrm{d} \alpha_{\varepsilon}}{\mathrm{d} \varepsilon_{\text {total }}}=l V \phi\left(d_{\varepsilon}-u_{\varepsilon}\right)
$$

To determine $\alpha_{\varepsilon}$ at strain $\varepsilon_{\text {total }}$, an incremental solution scheme is used, as presented in Figure 3.13. $\alpha_{\mathrm{p}}$ is the real area of contact at nominal pressure $P_{\text {nom }}$ in the absence of bulk strain $(\varepsilon=0) ; d_{\mathrm{p}}$ and $u_{\mathrm{p}}$ are the corresponding tool position and uniform rise of asperity respectively. $\alpha_{\mathrm{p}}, d_{\mathrm{p}}$ and $u_{\mathrm{p}}$ are determined using the normal load flattening model. The normal load flattening model presented in Chapter 2 is used to determine the asperity deformation $d_{\mathrm{p}}$, uniform rise of non-contacting asperities $u_{\mathrm{p}}$ and real area of contact $\alpha_{\mathrm{p}}$ at applied nominal pressure $P_{\text {nom }}(\varepsilon=0)$ required as the input in Westeneg's model. 


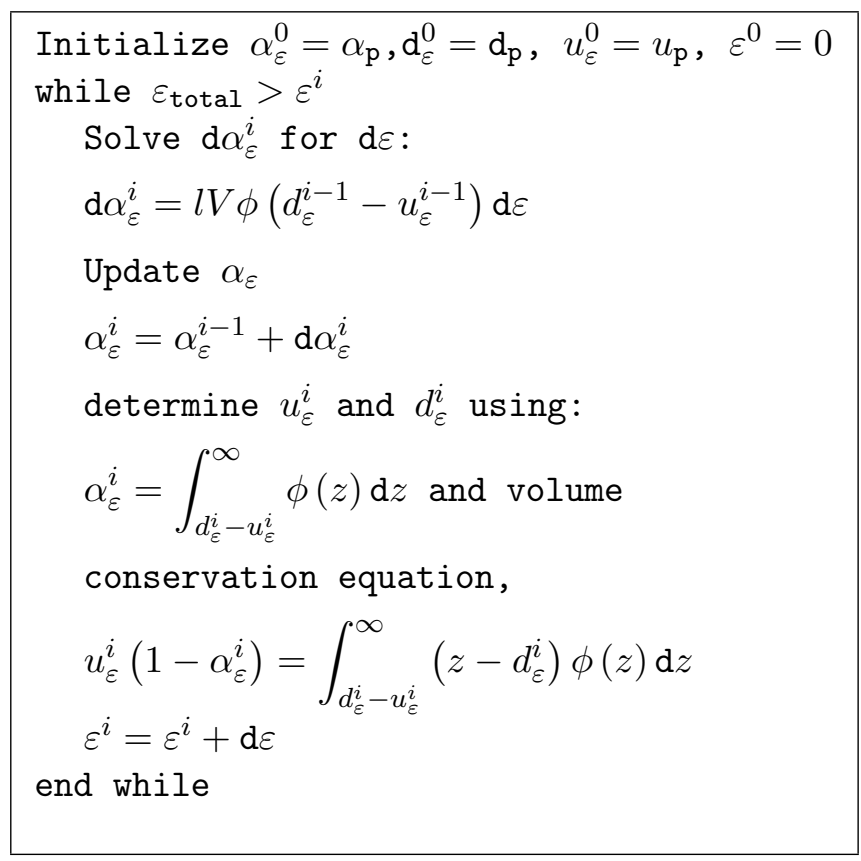

Figure 3.13 Solution scheme to determine $\alpha_{\varepsilon}$.

\subsubsection{Model results and discussion}

The model to determine the real area of contact under a combined normal load and bulk strain is implemented in Matlab. Asperity density $\rho_{a}$ which is necessary to determine the mean half asperity spacing $l$ in Equation (3.9) is unknown. $\rho_{a}$ can be determined using the 9-point summit rule [38] on measured surface height data. A summit is defined as the surface point with a height more than its surrounding points. However, the result is highly dependent on the resolution of surface measurement. Furthermore, $\rho_{a}$ increases with the real area of contact because the number of asperities in contact with the tool increases. Owing to the limitations and complexities, an asperity density is often calibrated for each specific surface. In this case, experimental results are used to calibrate asperity density. The asperity density is modelled by a power law function of the nominal pressure, $\rho_{a}=c P_{\text {nom }}^{n}$ [1]. Constants $c$ and $n$ are determined so as to reduce the difference in real area of contact between the model predictions and the experiments. For this purpose, a Matlab optimization algorithm fmincon is used to minimize the cumulative root mean square (RMS) error in real area of contact between the model predictions and the experiments at all 

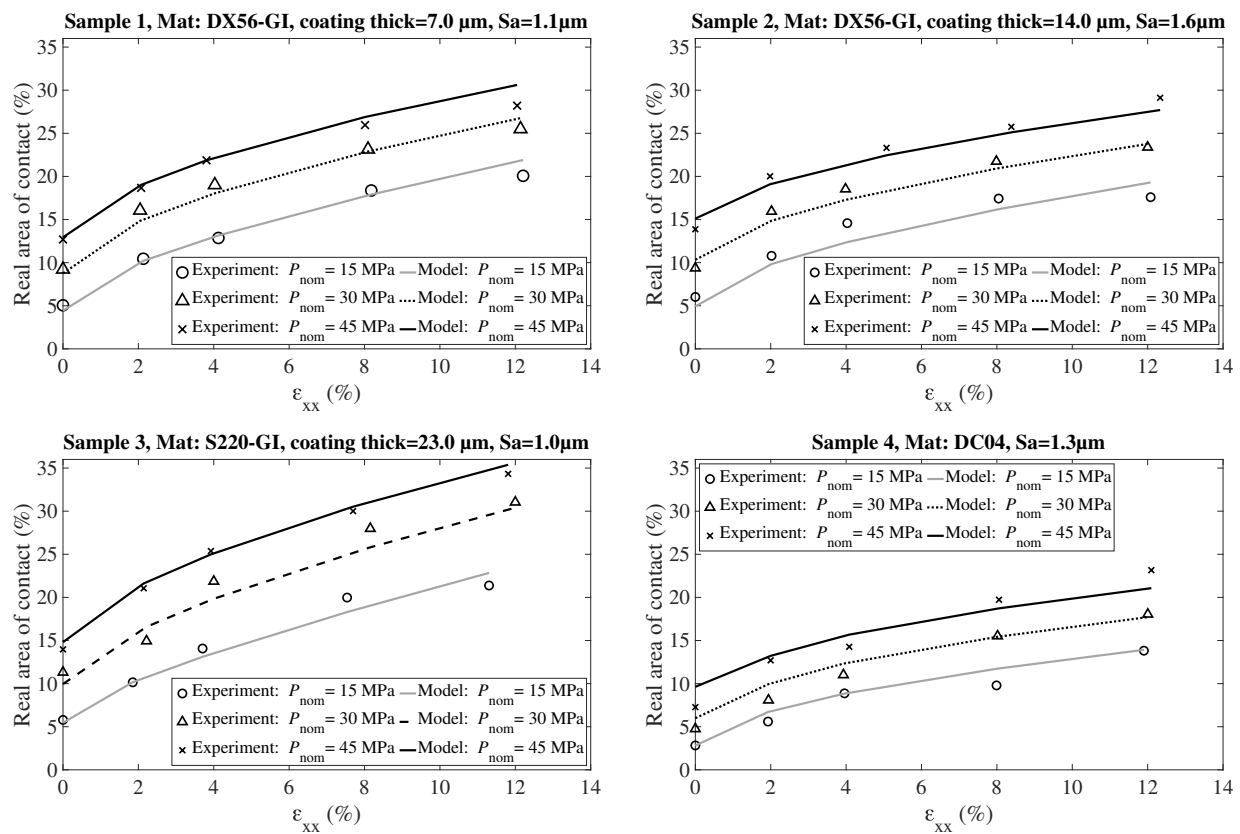

Figure 3.14 Real area of contact: experimental results vs. model predictions.

experimental data points. Constants $c$ and $n$ are optimized which results in an RMS error $<2 \%$ in the prediction of real area of contact. For sample 1 and 2: $c=5 \times 10^{4}, n=0.4$, for sample 3: $c=3.5 \times 10^{4}, n=0.23$ and for sample 4: $c=5.7 \times 10^{4}, n=0.47$. The model results using the adapted asperity density and experimental results are shown in Figure 3.14. The asperity density for samples 1 and 2 is the same; which might be due to having similar (bimodal) height distributions but no conclusion is made at this stage.

\subsection{Summary and conclusions}

GI samples of different surface topographies and zinc coating thicknesses are used to investigate the evolution of real area of contact under normal load and bulk strain. The real area of contact increases monotonically with strain for all the samples at constant nominal pressure with higher rate at lower strains than at higher strains. The plane strain FE simulations are performed to understand the trend observed in the experiments and the effect of different parameters. The real areas of contact determined using the FE simulations show the same trend as experiments. The influence 
of coating thickness, surface roughness and surface texture on real area of contact under a combined normal load and bulk strain is determined using FE simulations. From the experiments and FE simulations it can be concluded that the real area of contact under a combined normal load and bulk strain increases with coating thickness (soft coating on hard substrate) and decreases with surface roughness. The surface texture also has a significant influence on asperity deformation. For instance, the real area of contact is higher for surfaces with higher mean peak spacing $\left(R_{\mathrm{sm}}\right)$ while having the same surface roughness and coating thickness.

The Westeneng model originally developed for uncoated sheets to determine the real area of contact under a combined normal load and bulk strain is adapted for the coated sheets. The model is calibrated using the available experimental results. The calibrated model can be used for accurate modelling of friction and wear in sheet metal forming processes. 



\section{Chapter 4}

\section{Boundary friction model for coated sheets}

Friction is a local phenomenon which is influenced by the contact loads, surface topographies of the contacting surfaces, material behaviour and lubrication condition at the tool-sheet metal interface. In this chapter, a multi-scale friction model for coated sheets in the boundary lubrication regime is presented that accounts for the physical behaviour of the coatings. Measured surface topographies of sheet and tools are used as the input in the model to determine mechanical behaviour of the asperities and therefore the real area of contact. The contact patches are determined based on the flattening of asperities due to normal loading, sliding and bulk strain in the sheet metal. A single asperity micro-scale ploughing model is adapted at each contact patch to determine the friction force at each contact patch from which the overall coefficient of friction is determined. The friction model is validated using experiments on zinc coated (GI) steel sheets.

In Section 4.2 an asperity flattening step is described to determine the real area of contact. In Section 4.3 the single asperity ploughing model and multi-asperity friction models are presented. Two types of validation experiments are performed: lab-scale friction experiments (Section 4.4) and component level cup drawing experiments (Section 4.5). The implementation of the friction model in FE for forming simulations is described in Section 4.5. Finally, the conclusions are drawn from the study.

This chapter is based on the publication: M.P. Shisode, J. Hazrati, T. Mishra, M.B. de Rooij, C.H.L.J. ten Horn, J. van Beeck and A.H. van den Boogaard, "Modeling boundary friction of coated sheets in sheet metal forming" Tribology International, 153, 106554, 2020. 


\subsection{Introduction}

Coefficient of friction is one of the key parameters in the FE simulations of forming processes which can influence the prediction accuracy of these analyses. In sheet metal forming, different friction regimes may occur based on the lubricant amount and surface topographies of the tool and sheet metal. The boundary lubrication regime can prevail in sheet metal forming applications. In this regime, the sheet surface is lubricated but the lubricant amount is often not sufficient to fill the valleys of sheet surface. Hence, normal and tangential contact loads are carried only by the asperities on the sheet metal. This study is focused on the modelling and prediction of friction in the boundary lubrication regime. In a boundary friction regime, the coefficient of friction depends on the micro-scale asperity interactions between the contacting surfaces. During forming processes, coefficient of friction varies due to the spatial and time dependent evolution of the contact conditions at the tool-sheet interface. The topography of the contacting surfaces, contact loads and material behaviour influence the contact mechanics. Traditionally, a constant coefficient of (Coulomb) friction is used in the FE simulations which does not account for the evolving contact condition due to the change in contact loads during the forming process.

Challen and Oxley [39, 40], using the plane strain slip-line analysis, developed an analytical expression for the coefficient of friction accounting for the ploughing and the adhesion effects for the case of a single wedgeshaped rigid asperity ploughing through a softer material. Expressions for coefficient of friction are developed in cutting, wear and ploughing regimes based on the attack angle of the asperity relative to the sliding direction and the material behaviour of the substrate. Ma et al. [2] proposed a multiasperity macro-scale friction model for the aluminium extrusion process by adapting a wedge-shaped single asperity model [39] to determine the friction force at each tool-sheet metal contact patch, from which the overall coefficient of friction is determined. Similarly, Hol et al. [1] developed a multi-scale friction model for uncoated sheets in deep drawing applications by adapting the coefficient of friction expressions developed by Challen and Oxley [39]. The single asperity model developed by Challen and Oxley [39] is valid for a $2 \mathrm{D}$ wedge-shaped asperity ploughing through the substrate. Hence adapting such model for ploughing of arbitrary shaped 3D asperities requires model calibration using friction experiments [1]. Furthermore, such 2D models cannot consider the effect of the asperity geometrical orientation relative to the sliding direction on friction forces [41]. Mishra 
et al. [41] recently proposed an analytical model for an ellipsoidal and elliptical paraboloid-shaped asperities ploughing through a softer substrate. In this model, the asperity is assumed to be rigid and the substrate is considered to have an ideal plastic behaviour. The model also considers the asperity orientation relative to the sliding direction. The total shear force is determined as the contribution from ploughing of the substrate material and shearing of the lubricant boundary layer formed on the lubricated sheet surface. This new single asperity model is more realistic and considered more accurate for a macro-scale friction model.

The goal of this study is to develop a multi-scale friction model in the boundary lubrication regime. In the current model, the physical behaviour of the coating and its influence on the friction coefficient is considered as well. Figure 4.1 shows the modelling stages of the boundary friction model.

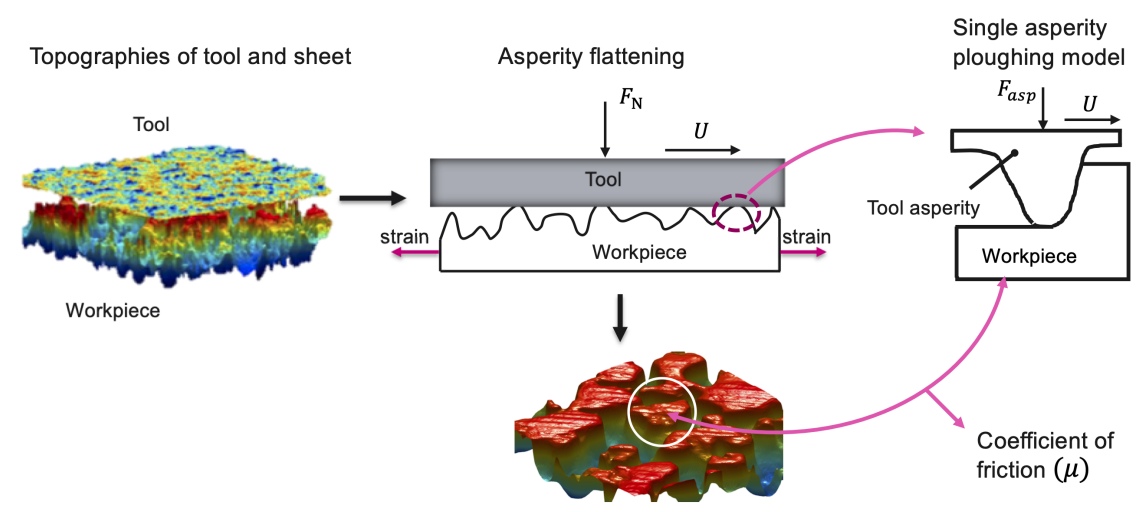

Figure 4.1 Modelling stages of multi-scale boundary friction model.

\subsection{Asperity flattening step}

The first step in the friction model is to estimate the real area of contact and therefore identifying the local contact locations at tool-sheet interface subjected to contact loads. For this purpose, flattening models are required to determine the workpiece asperity deformation. Asperities on the sheet metal surface are plastically deformed or flattened as the hard and smooth surface of the tool comes into contact with the comparatively soft and rough surface of the workpiece. In the forming process, the sheet metal is subjected to normal load, sliding and stretching. Asperity deformation under such loads is determined by the flattening models. Chapter 2 presents a newly developed normal load flattening model which is used in this study. The model accounts for the coating thickness, coating and substrate material 
behaviour and measured surface topography of the rough surfaces. The model also considers material hardening. The results of this model for the samples used in the friction experiments and its comparison with the experiments are presented in Section 4.4.

The surface roughness and therefore the real area of contact evolves as the sheet metal is strained. Chapter 3 presents a study of the effect of combined normal load and bulk strain on the evolution of real area of contact. Westeneng's [8] model is adapted for coated sheets to predict the real area of contact under a combined normal load and bulk strain. Experiments are performed on coated (GI) and uncoated sheets to determine the model parameter (asperity density). The current study is focused on GI sheets therefore, Westeneng's [8] model calibrated using the dedicated experiments is used to estimate the real area of contact under a combined normal load and bulk strain.

When sliding is present at the contact, the real area of contact increases further. According to Tabor [42], the real area must increase to accommodate the additional tangential load, as shown by experimental studies [1, 26, 43-48]. The increase in real area of contact due to sliding can be determined by an analytical expression proposed by Tabor [42]. However, sliding experiments are required to determine the model parameter called shear factor [1]. The asperity flattening due to sliding requires the coefficient of friction as an additional parameter to determine the tangential loads. The real area of contact and the coefficient of friction are solved iteratively. Therefore, this model is summarized in Section 4.3.4 after the description of multi-asperity friction model.

\subsection{Estimation of friction coefficient}

Having determined the real area of contact between sheet metal and tool using the flattening models, this section presents a new friction model for sheet metal forming applications of coated sheets in the boundary lubrication regime. In the boundary lubrication regime, the lubricant forms an interfacial boundary layer on the sheet surface due to chemical and physical adsorption. Therefore, friction force in the boundary lubrication regime is the result of shearing of the boundary layer and ploughing of sheet surface by the tool asperities. To account for these two effects, the single asperity ploughing model proposed by Mishra et al. [41] is adapted to determine the coefficient of friction. 


\subsubsection{Single asperity model}

Mishra et al. [41] proposed a single asperity analytical ploughing model to determine the ploughing forces on rigid ellipsoidal and elliptical paraboloid shaped asperities ploughing through an ideal plastic substrate. The single asperity model was validated by dedicated single asperity ploughing experiments [49]. The ploughing forces are due to the plastic deformation of the substrate and shearing of the lubricant boundary layer at the interface.

Figure 4.2 shows the schematic of the single asperity ploughing model. During sliding, only the frontal portion of the asperity (N-S in Figure 4.2 (right)) is in contact with the substrate. The contact surface of the asperity varies with the ploughing depth $d$ and orientation angle $\beta$. In their study, the ploughing depth $d$ is determined from the applied normal load $F_{a s p}$ and hardness $H$ of the ideal plastic substrate. The contact surface is divided into triangular elements. The forces are calculated on the elemental areas $\mathrm{d} A$. The contact pressure acts normal to $\mathrm{d} A$ with the unit normal vector $\hat{\mathrm{n}}$, whereas the shear stress at the interface acts in the tangential (or the plastic flow) direction $\hat{\mathrm{t}}$ to $\mathrm{d} A$. The total friction force $\mathrm{d} F$ due to ploughing and shearing of boundary layer acting over the contact area $\mathrm{d} A$ can be written as [41]:

$$
\mathrm{d} F=H \mathrm{~d} A \hat{\mathrm{n}}+\tau_{\mathrm{BL}} \mathrm{d} A \hat{\mathrm{t}}
$$

$\tau_{\mathrm{BL}}$ is the lubricant boundary layer shear strength. The elemental forces are integrated over the contact area to determine the total shear force from which the coefficient of friction is determined. $\tau_{\mathrm{BL}}$ is determined experimentally for a specific combination of lubricant and the sheet material. Mishra et al. [50] performed boundary layer shearing experiments on DX56-GI sheets with different types of lubricants. The details of the experiments can be found in [50]. The boundary layer shear strength is
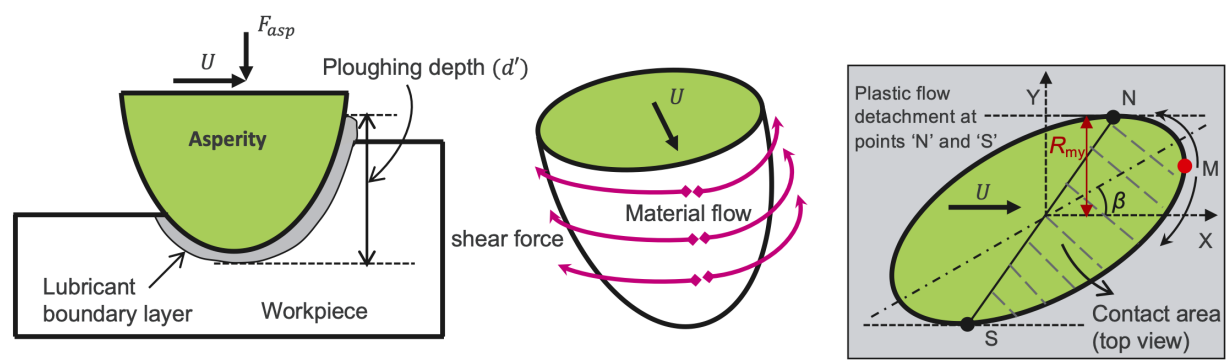

Figure 4.2 Schematic of single asperity ploughing model. 
determined at different nominal pressures and described as, $\tau_{\mathrm{BL}}=c_{0} P_{0}^{m}$ [50], where $c_{0}, m$ are constants and $P_{0}=\left(P_{\text {nom }} / \alpha\right)$ is the contact pressure based on the fractional real area of contact $(\alpha)$. In this study, DX56-GI sheet material lubricated with Fuchs Anticorit PLS100T lubricant is used for which $c_{0}=7.34$ and $m=0.78$ [50]. The model accounts for the change in magnitude and direction of the forces due to ploughing and shearing of the boundary layer based on the orientation, size and ploughing depth of the asperity. The results of the model are shown in Figure 4.3, where the influence of orientation angle and ellipticity ratio (ratio of major and minor axes) on the coefficient of friction are demonstrated. For this sensitivity study, rigid asperity is ploughing thorough DX56-GI sheet (lubricated with Fuchs Anticorit PLS100T). The hardness $H$ of the sheet is equal to $210 \mathrm{MPa}$ $\left(H=\mathrm{B} \sigma_{\mathrm{y} 0}\right)$, based on the yield strength of zinc coating $\sigma_{\mathrm{y} 0}(75 \mathrm{MPa})$ [22]. For the example shown in Figure 4.3a, an ellipsoidal asperity with ellipticity ratio of 2 , semi-major axis of $200 \mu \mathrm{m}$ in the base area is used to demonstrate the effect of the asperity orientation. Figure $4.3 \mathrm{~b}$ shows the effect of the ellipticity ratio on friction coefficient for an asperity with an orientation angle of zero. The applied normal load is $2 \mathrm{~N}$. The orientation angle $\beta$ is defined as the angle between the major axis of the asperity base and sliding direction (Figure 4.2).

During ploughing, the substrate material piles up in front of the asperity while it is displaced on either sides of the asperity. The material pile-up in front of the asperity increases the resistance to the ploughing which increases the total ploughing force. The model does not consider this effect. Mishra et al. [49] performed numerical simulations of single ellipsoidal asperities ploughing through an ideal plastic substrate to determine the coefficient of friction. Details of the simulations can be found in [51]. The results from the

(a)

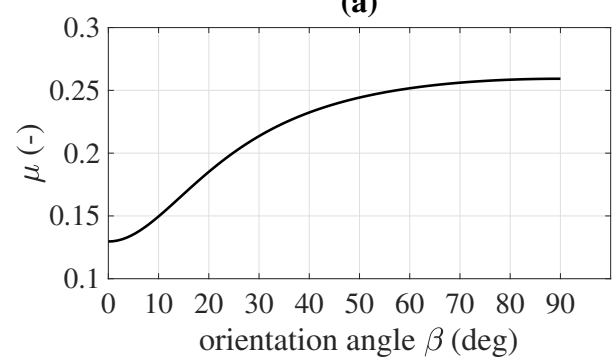

(b)

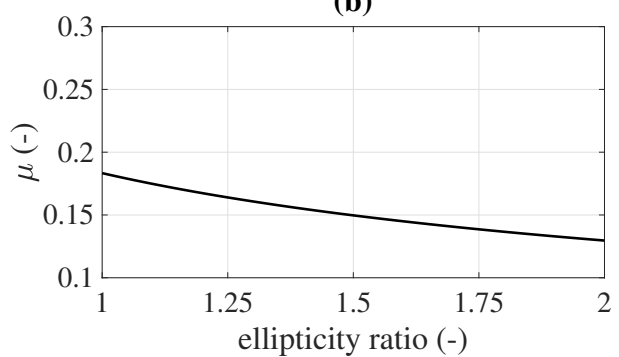

Figure 4.3 Coefficient of friction using single asperity model. (a) Effect of asperity orientation (at ellipticity ratio=2). (b) Effect of ellipticity ratio (at orientation angle $=0 \mathrm{deg}$ ). 

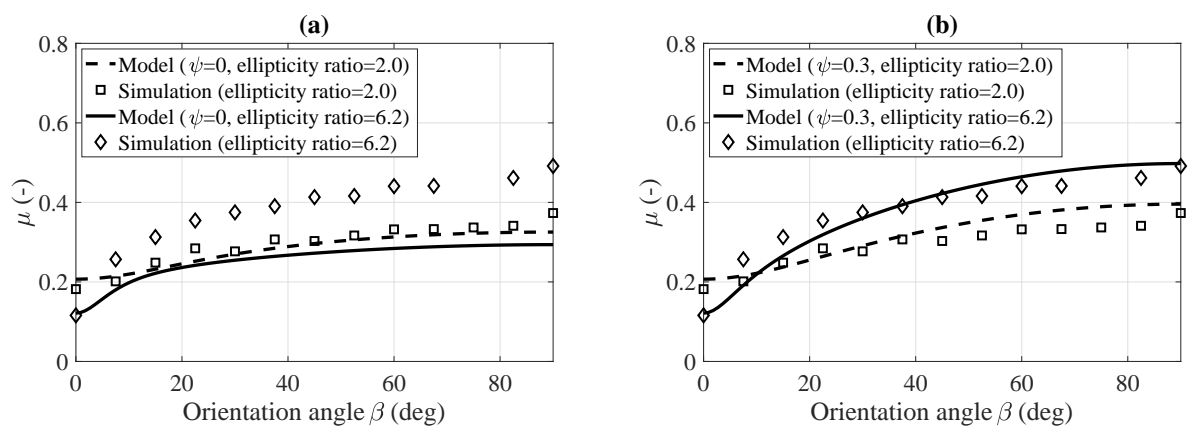

Figure 4.4 Coefficient of friction: simulations vs. the analytical model for ploughing of single asperity. (a) Model without correction, $\psi=0$. (b) Model with correction, $\psi=0.3$.

simulations are compared with the results of the analytical ploughing model. Consistent material properties, asperity geometry and normal load are used in the simulations and the analytical model. Figure $4.4 \mathrm{a}$ shows the results of the simulations performed using the material point method (MPM) [49] and the analytical model. The asperity is rigid with different ellipticity ratios ploughing through ideal plastic steel substrate at different orientation angles, where the asperity normal load $\left(F_{a s p}\right)$ is $1 \mathrm{~N}$, substrate hardness is $450 \mathrm{MPa}$ and the assumed boundary layer shear strength $\left(\tau_{\mathrm{BL}}\right)$ is $0.45 \mathrm{H}$. Mishra et al. [49] concluded that the analytical model and simulation results correlate well at lower ellipticity ratios and orientation angles but deviate as the ellipticity ratio increases. Figure $4.4 \mathrm{a}$ shows that for an asperity with ellipticity ratio of 2 , the results of the analytical model are in good agreement with simulations but deviate at an ellipticity ratio of 6.2. The deviations in the results come mainly from the effects of material pile-up which are explicitly considered in the MPM simulations. It is noticed that the pile-up effect is more pronounced for ellipsoids of higher ellipticity ratios and orientation angles [49].

As the orientation angle increases, the frontal projected area of the asperity increases. This increases the amount of displaced material and the average pile-up height. Hence a correction factor is introduced in the analytical model to include the rise in ploughing depth due to the material pile-up. The ploughing depth correction factor $\psi$ is proposed as follows:

$$
d^{\prime}=d\left(\frac{R_{\mathrm{my}}}{R_{\mathrm{min}}}\right)^{\psi}
$$

where $d^{\prime}$ is the corrected ploughing depth, $d$ is the initial ploughing 
depth, $R_{\mathrm{my}}$ is the projected length of the asperity perpendicular to the sliding direction and $R_{\min }$ is the semi-minor axis of the asperity (see Figure 4.2 (right)). Equation (4.2) shows that $\left(R_{\mathrm{my}} / R_{\mathrm{min}}\right)$ increases as the orientation angle increases, leading to a higher ploughing depth $\left(d^{\prime}\right)$ which results in a higher coefficient of friction as predicted by the numerical study. Similarly, at lower ellipticity ratios and orientation angles $d^{\prime} \approx d$, for which the model results and simulations correlate well. Therefore a geometrical correction factor $\psi=0.3$ is determined so as to calibrate the ploughing depth in the analytical model, as shown in Figure 4.4b. $\psi=0.3$ is used in the current study with DX54-GI sheet material.

\subsubsection{Multi-asperity friction model}

The single asperity ploughing model described in the previous section is adapted to determine the coefficient of friction at the macro-scale. The schematic of the macro-scale friction model is shown in Figure 4.5. For this step, the measured surface height of the workpiece and tool from confocal microscopy are used. The deformation of asperities and flattening of the workpiece surface is determined using the flattening models. The tool is assumed to be rigid and flat during this step.

The surface points of the deformed surface which are in contact with the tool and adjacent together form contact patches on the workpiece surface, as shown in Figure 4.6. Once the contact patches are determined, an elliptical

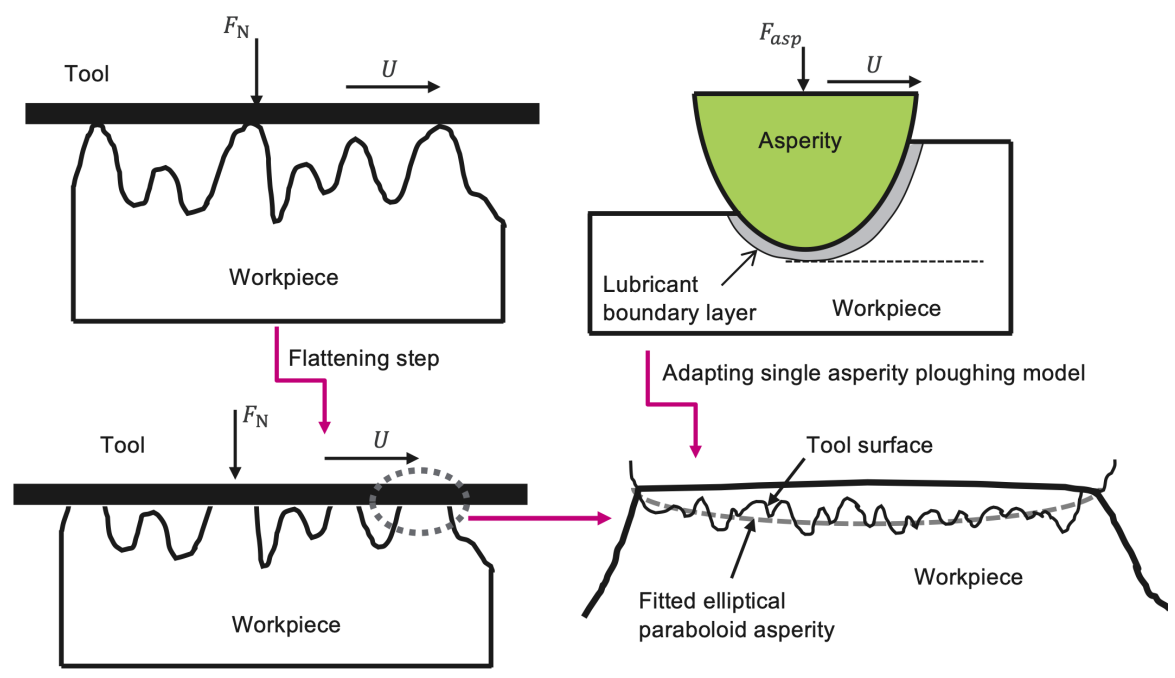

Figure 4.5 Adapting a single asperity ploughing model to macro-scale. 

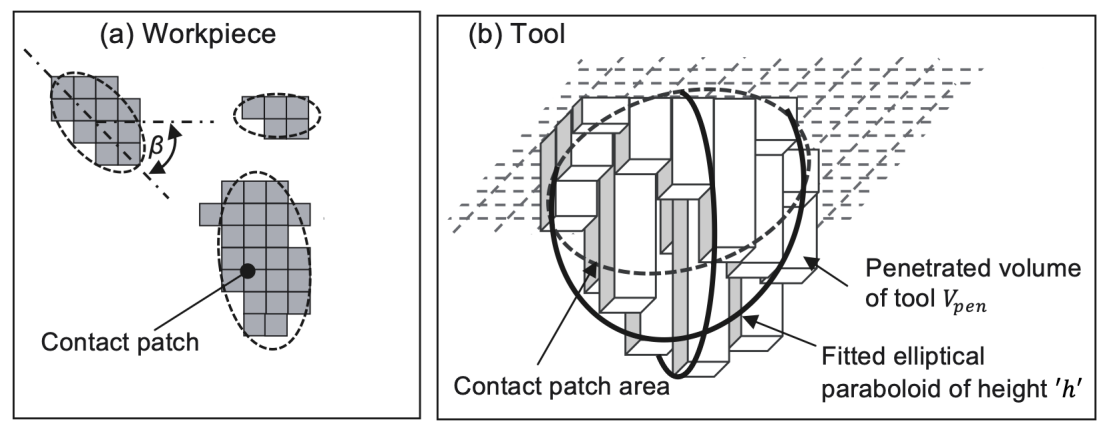

Figure 4.6 Contact patches and asperity fitting.

paraboloid shaped asperity is fitted through the penetrated tool height data at each contact patch (Section 4.3.3 describes the method). The single asperity ploughing model is then applied for each fitted asperity. The initial ploughing depth $d$ at the contact patch is set at the height $h$ of the elliptical paraboloid. The corrected ploughing depth $d^{\prime}$ is determined by Equation (4.2) using the geometrical parameters of the fitted elliptical paraboloid (asperity height, base area, ellipticity ratio and orientation angle). The friction force contribution from every contact patch is determined based on single asperity model from which the total friction force is calculated. Finally, the overall coefficient of friction $\mu$ is determined as follows:

$$
\mu=\frac{\sum_{i=1}^{n}\left(F_{\text {friction }}\right)_{i}}{F_{\mathrm{N}}}
$$

where $n$ is the total number of contact patches.

\subsubsection{Fitting the elliptical parabola to tool asperities}

A procedure described by de Rooij et al. [24] is followed to determine the geometry and orientation of the fitted elliptical paraboloid as shown in Figure 4.6. The base of the elliptical paraboloid is approximated by an ellipse with area equal to the area of the contact patch. The lengths of semi-major $\left(R_{\text {maj }}\right)$ and semi-minor $\left(R_{\text {min }}\right)$ axes and orientation angle $(\beta)$ are determined by having the same normalized second central moments as the contact patch.

To determine the height $h$ of the elliptical paraboloid, height data of the tool is required. Surface height data of the tool is overlaid on the deformed rough surface. The tool height data is lowered such that the total bearing area between the tool and the workpiece is equal to the total area of the 
contact patches. The height $h$ at each contact patch is determined by equating the penetrated volume $V_{p e n}$ and half of the elliptical paraboloid volume as follows:

$$
h=\frac{2 V_{\text {pen }}}{\pi R_{\mathrm{maj}} R_{\min }}
$$

\subsubsection{Updating the real area of contact due to sliding}

The real area of contact grows as the tool and sheet metal slide relative to each other. The first analytical expression to determine the real area of contact due to sliding was proposed by Tabor [42]. Tabor's analysis is based on understanding that the asperities which have been plastically deformed due to normal load should grow due to the additional tangential load from sliding. Cold junctions formed at the contacting points which grow due to the adhesion and ploughing of the tool asperities through the substrate referred as the junction growth (Figure 4.7). Assuming a perfectly plastic flow at the yielded contact points, the mean pressure at contact locations reduces to accommodate the additional shear stress to maintain a constant von Mises stress. The analytical expression proposed by Tabor [42] is as follows:

$$
1+k_{\alpha} \mu^{2}=\left(\frac{A_{\mathrm{s}}}{A_{0}}\right)^{2}
$$

where $A_{0}$ is the real area of contact due to normal load only and $A_{\mathrm{s}}$ is the real area of contact due to sliding, $\mu$ is the coefficient of friction and $k_{\alpha}$ is the shear factor constant [25]. During sliding, only the frontal area of the penetrating tool asperity is in contact with the substrate (see Figure 4.7(right)). Therefore, the real area of contact must grow by a factor approximately equal to 2 in order to satisfy the force equilibrium. However, due to the additional tangential load, $A_{\mathrm{s}}>2 A_{0}$. The theoretical value of $k_{\alpha}$ for simple 2D ideal plastic lightly loaded contacts is 3.0 [42]. However, there is no analytical solution available for 3D contact situations; friction

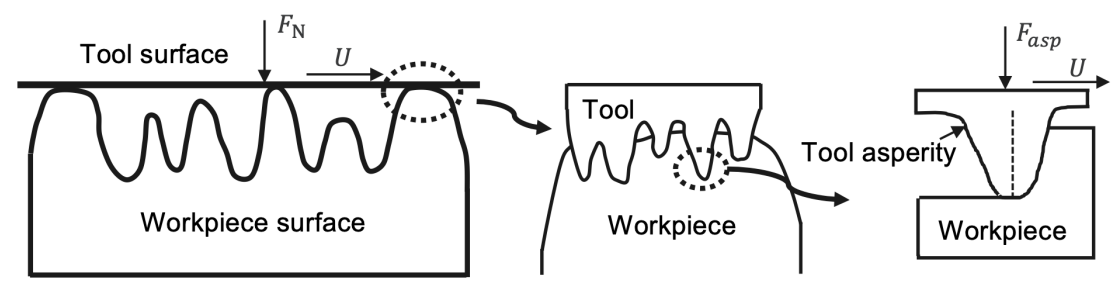

Figure 4.7 Junction growth and rise in contact area due to sliding. 
experiments are therefore required to determine $k_{\alpha}$. The value of $k_{\alpha}$ is expected to be higher for 3D contacts than for 2D contacts. In this study, shear factor $k_{\alpha}$ is determined using sliding experiments on GI sheet samples and presented in Section 4.4.1.

\subsection{Friction experiments}

Normal load and friction experiments are performed on two different GI sheets at different nominal pressures. Real areas of contact measured from normal load experiments are compared with the predictions of the flattening model. The friction experiments are used to determine the shear factor $k_{\alpha}$ required in the sliding model. Furthermore, the coefficient of friction measured from the friction experiments are compared with the predictions of the friction model. Two different samples of DX56-GI (CR4GI) grade with distinct surface roughness $\left(\mathrm{S}_{\mathrm{a}}=1.0 \mu \mathrm{m}\right.$ and $\left.1.3 \mu \mathrm{m}\right)$ are used. The material flow curves of DX56 steel substrate and zinc coating are presented in Chapter 2 (Section 2.2.1). Both samples are textured by electro-discharge textured (EDT) rolls. The sheet thickness is $0.7 \mathrm{~mm}$ and the mean coating thickness is $7 \mu \mathrm{m}$ for both samples. Table 4.1 shows the parameters of the experiments. The samples are lubricated with a small amount of lubricant $\left(0.6 \mathrm{~g} / \mathrm{m}^{2}\right)$. The lubricant amount is not enough to completely fill the surface valleys, thereby ensuring the boundary friction regime in the friction experiments.

Figure 4.8 shows the schematic of the rotating friction tester (RFT) developed at TATA Steel Europe for normal load and sliding experiments. The setup consists of a stationary punch and a rotating sample holder. The punch includes 3 highly polished flat notches $\left(S_{a}=27 \mathrm{~nm}\right)$ which are located

Table 4.1 Parameters of normal load and sliding experiments.

\begin{tabular}{ll}
\hline Sample geometry & $120 \mathrm{~mm} \times 120 \mathrm{~mm}$ \\
Notch size & $10 \mathrm{~mm} \times 10 \mathrm{~mm}$ \\
Nominal pressure & $10,20,30,45,60 \mathrm{MPa}$ \\
Sliding speed & $100 \mathrm{~mm} / \mathrm{s}$ \\
Sliding angle & $120^{\circ}$ \\
Lubricant & Fuchs Anticorit PLS100T $\left(0.6 \mathrm{~g} / \mathrm{m}^{2}\right)$ \\
& Dynamic viscosity $\left(\eta_{40^{\circ}}\right)=90 \mathrm{mPas}$ \\
\hline
\end{tabular}




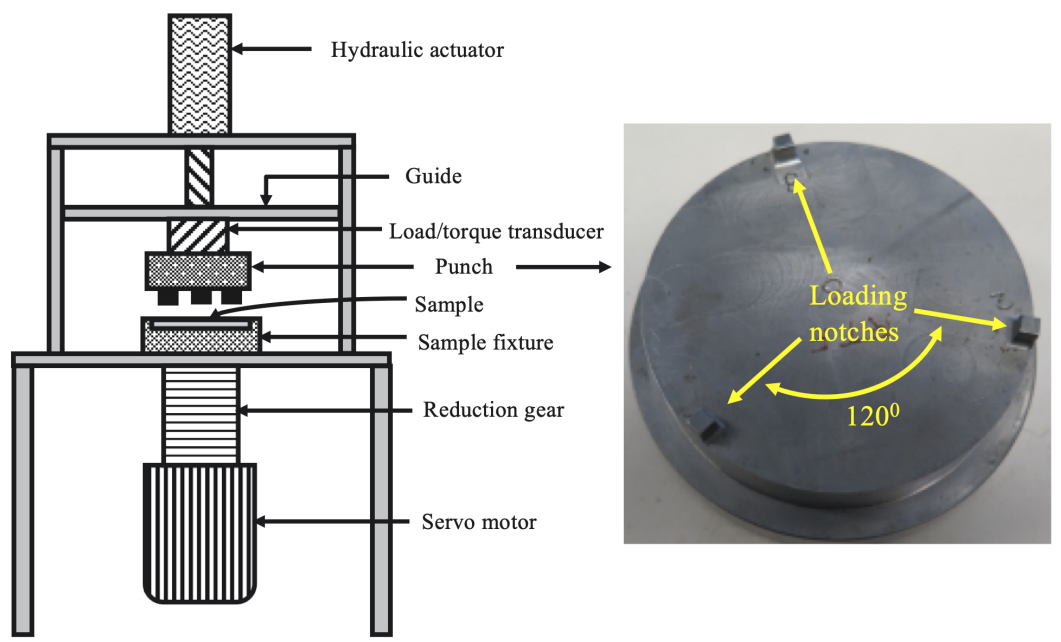

Figure 4.8 Schematic of rotating friction tester (RFT).

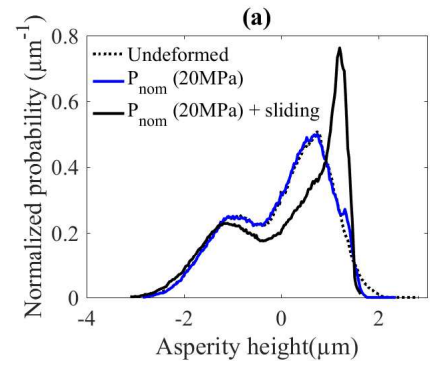

(c)

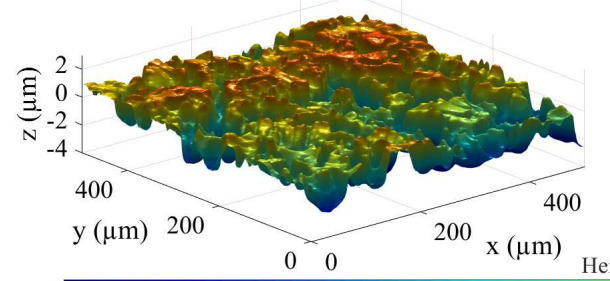

(b)

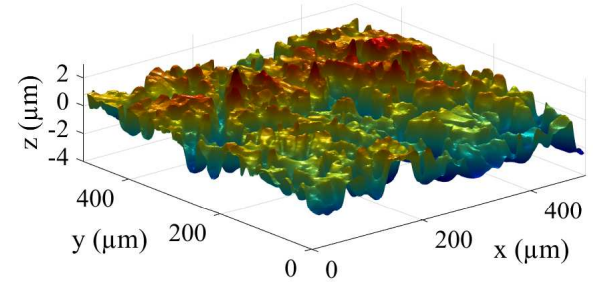

(d)

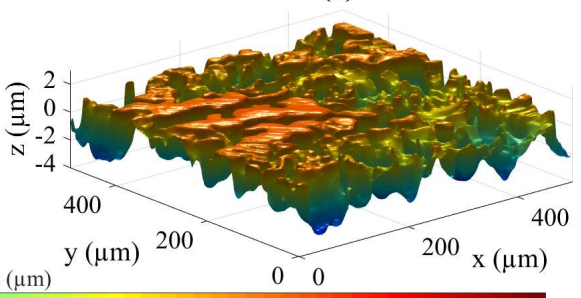

$\begin{array}{lll}-4 & -3 & -2\end{array}$

Figure 4.9 (a) Sample 1 normalized surface height distribution of undeformed and deformed surfaces. (b) Surface topography of undeformed sample 1. (c) Deformed at $P_{\text {nom }}=20 M P a$. (d) Deformed at $P_{\text {nom }}=20 M P a+$ sliding.

equidistant from the centre of the punch. For the normal load experiments, the punch is moved slowly downward by a hydraulic actuator and pressed against the fixed sample to reach the desired nominal pressure. 
The surface height measurement of the sample under the notch is performed using confocal microscopy before and after the loading. The real area of contact of the deformed sample is determined by analysing the surface height data. Surfaces of deformed and undeformed samples are measured on an area of $2 \times 2 \mathrm{~mm}$ at a pixel resolution of $1.3 \mu \mathrm{m}$. The surface height distribution function is plotted as shown in Figure 4.9a, from which the real area of contact is determined as described in Chapter 2 (Section 2.3.3). Figure 4.9 shows sample $1\left(\mathrm{~S}_{\mathrm{a}}=1.0 \mu \mathrm{m}\right)$ surface topographies and height distribution functions of undeformed and deformed surfaces at $20 \mathrm{MPa}$ after normal load only and friction test (tool sliding on sheet surface). The measured real areas of contact for samples 1 and 2 at different nominal pressures are shown in Figure 4.10. Normal load flattening model presented in Chapter 2 is used to determine the real area of contact

Sample 1, Mat:DX56-GI, Sa=1.0 $\mu \mathrm{m}$

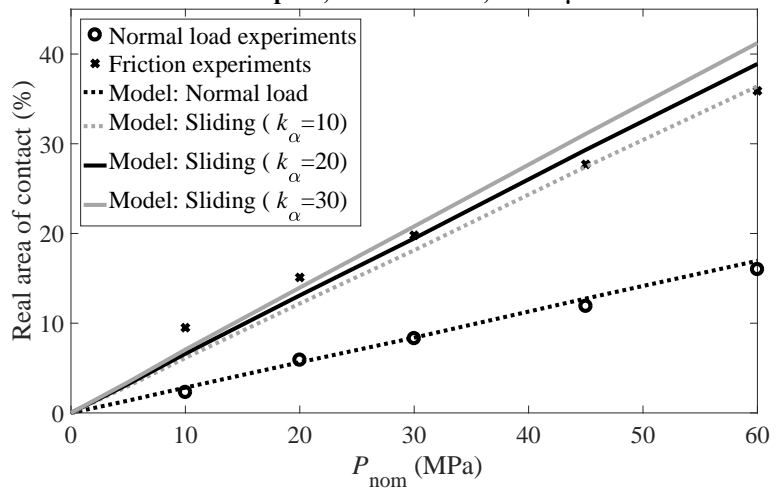

Sample 2, Mat:DX56-GI, Sa=1.3 $\mu \mathrm{m}$

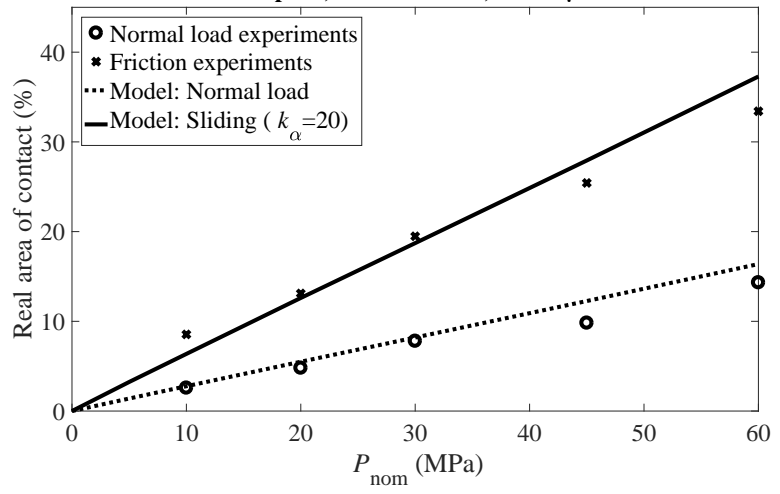

Figure 4.10 Experimental results vs. model predictions: real area of contact due to normal load and sliding. The top figure shows the sensitivity analysis of the model relative to $k_{\alpha}$. 
for samples 1 and 2. The results (Figure 4.10) show that the model can predict very well the real area of contact due to normal load. The real area of contact after sliding is used to determine the shear factor $k_{\alpha}$.

For the friction experiments, first the required nominal pressure is applied and afterwards the sample holder is rotated at a predefined sliding speed and rotation angle. The resultant torque due to sliding is measured, from which the coefficient of friction is determined.

\subsubsection{Determining shear factor ' $k_{\alpha}$ '}

The real areas of contact measured after sliding are used to determine the shear factor $k_{\alpha}$ in Equation (4.5). The real areas of contact due to normal load $A_{0}$ is used in Equation (4.5) from the normal load flattening model. To determine $A_{\mathrm{s}}$, the shear factor $k_{\alpha}$ and the coefficient of friction $\mu$ are required. $k_{\alpha}$ is determined by minimizing the difference between the measured real areas of contact due to sliding and the real areas of contact $A_{\mathrm{s}}$ determined by Equation (4.5) (see Figure 4.10). The iterative scheme is shown in Figure 4.11. The optimized value of the shear factor $k_{\alpha}$ from this study is 20 , for which the cumulative root mean square (RMS) error in real

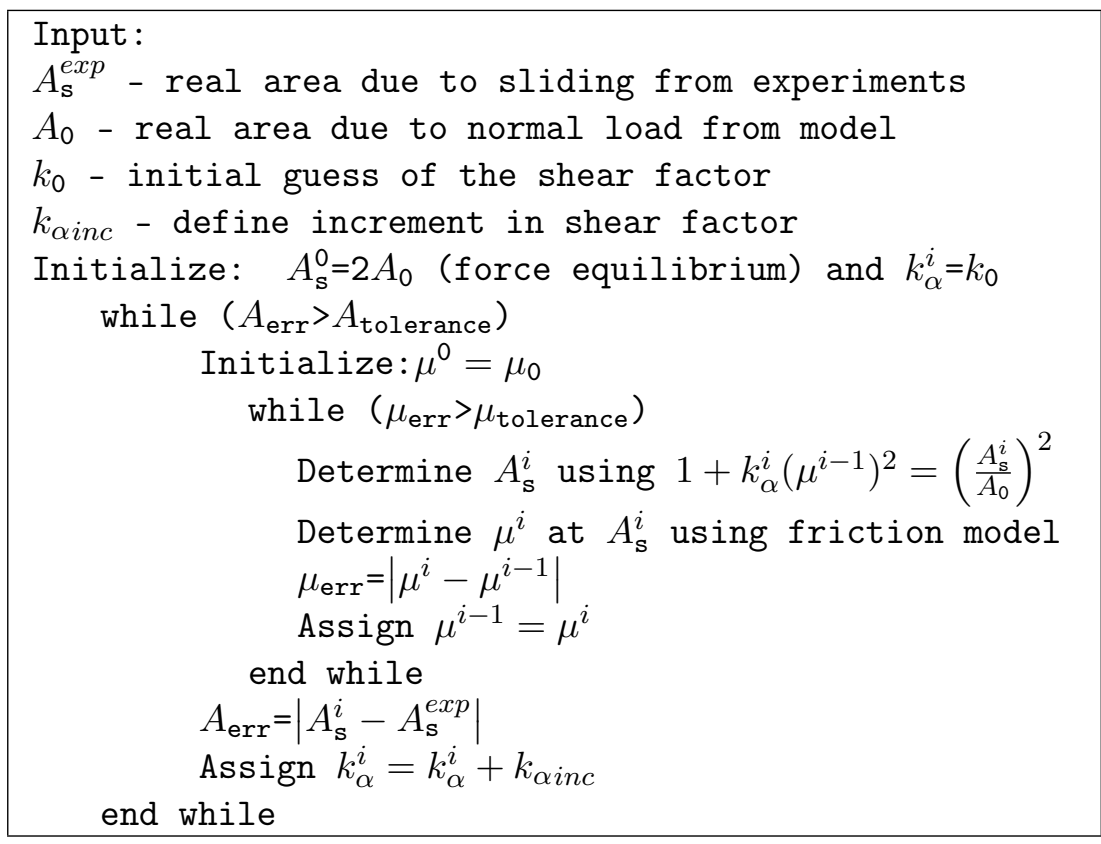

Figure 4.11 Solution scheme to determine $A_{s}, k_{\alpha}$ and $\mu$. 
area of contact due to sliding is $<1.5 \%$ for both samples.

\subsubsection{Measurement of the friction coefficient and compari- son with model predictions}

The coefficient of friction is determined using the measured torque during sliding and the applied nominal pressure. The coefficient of friction vs. the sliding angle is plotted at different nominal pressures in Figure 4.13a. The coefficient of friction shows a decreasing trend with the increase in nominal pressure; this is in agreement with previous observations [1, 8]. The coefficient of friction during the start is high due to the transition from static friction to dynamic friction, after which it becomes stable. For comparison with the friction model, the coefficient of friction averaged over the stable part of the curve (40-80 deg) is used.

Figure 4.12 describes the implementation of the friction model. The coefficient of friction determined from the experiments and the model for samples 1 and 2 at different nominal pressures are shown in Figure 4.13b. The comparison between the experiments and the model shows that the model is able to predict very well the trend and the magnitude of the coefficient of friction.

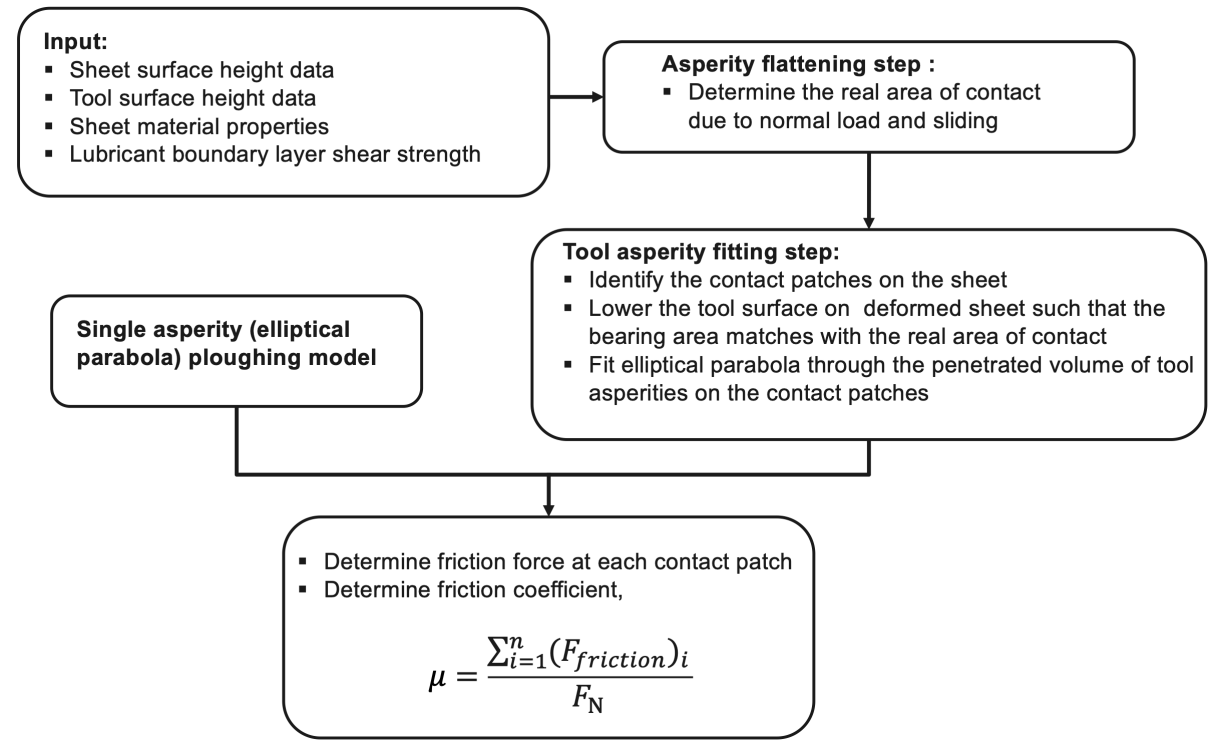

Figure 4.12 Algorithm of boundary friction model. 
(a) Sample 1 : experiments

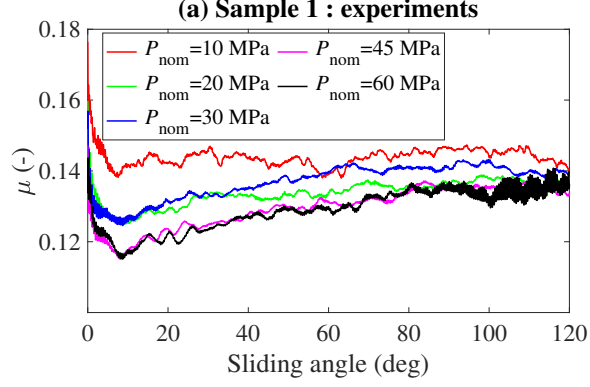

(a) Sample 2 : experiments

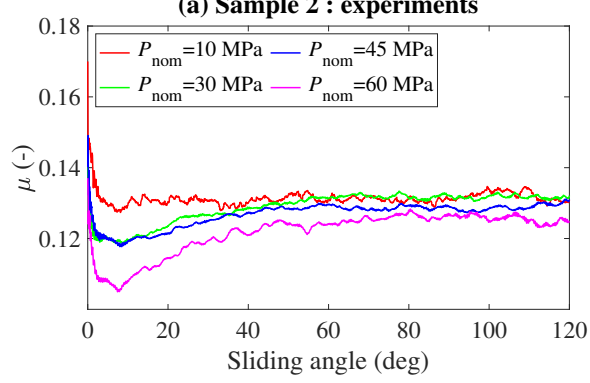

(b) Sample 1: model vs. experiments

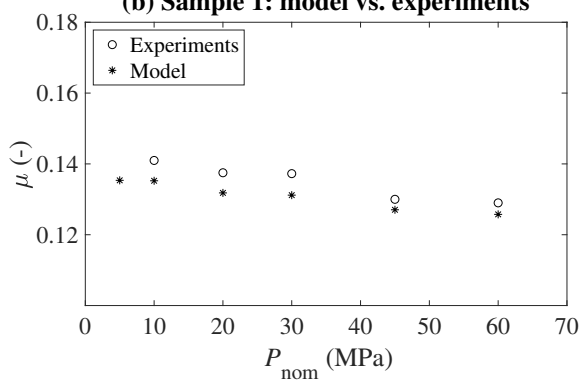

(b) Sample 2: model vs. experiments

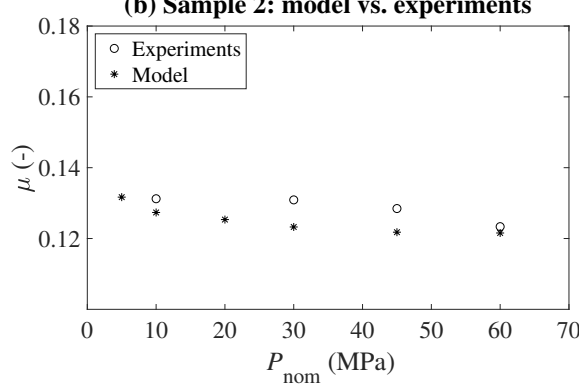

Figure 4.13 RFT results vs. the model predictions for samples 1 and 2.

\subsection{Application in deep drawing processes}

The boundary friction model is implemented for FE simulations of deep drawing processes. Cup drawing experiments are performed on GI sheet to validate the boundary friction model for sheet metal forming processes. Implementation of the boundary friction model for forming simulations is discussed and followed by the comparison of different parameters between the experiments and the simulations.

\subsubsection{Cup drawing experiments}

The process parameters of cup drawing experiments are shown in Table 4.2. The cup is drawn using a deep drawing press available at TATA Steel Europe. Figure 4.14 shows the schematic of the setup and the product. The experiments are performed at three different blank holder forces: $10 \mathrm{kN}$, $30 \mathrm{kN}$ and $50 \mathrm{kN}$. The blank is lubricated on either side with a lubricant amount of $0.3 \mathrm{~g} / \mathrm{m}^{2}$. The lubricant amount is so small that it falls well within the boundary friction lubrication regime. The surface roughness and topography are different at different locations of the tooling. Therefore, 
surface height measurement is performed on tools at key locations to be used in the friction model. Figure 4.14 shows the surface roughness of the blank and tools at different locations. For repeatability, experiments are repeated three times at each blank holder force. Figure 4.16 shows the punch force vs. punch displacement at different blank holder forces.

Table 4.2 Parameters of cup drawing experiments.

\begin{tabular}{ll}
\hline Blank material & DX54-GI \\
Tool material & DIN 1.2379 \\
Blank geometry & Circular with dia. $=140 \mathrm{~mm}$ \\
& Sheet thickness $=0.67 \mathrm{~mm}$ \\
& Coating thickness $=7 \mu \mathrm{m}$ \\
Lubricant & Fuchs Anticorit PLS100T \\
& Amount $=0.3 \mathrm{~g} / \mathrm{m}^{2}$ \\
& Dynamic viscosity $\left(\eta_{40^{\circ}}\right)=90 \mathrm{mPas}$ \\
Blank holder force $\left(F_{\text {bhf }}\right)$ & $10 \mathrm{kN}, 30 \mathrm{kN}$ and $50 \mathrm{kN}$ \\
Punch velocity $\left(v_{\text {punch }}\right)$ & $15 \mathrm{~mm} / \mathrm{s}$ \\
Punch stroke & $32 \mathrm{~mm}$ \\
\hline
\end{tabular}

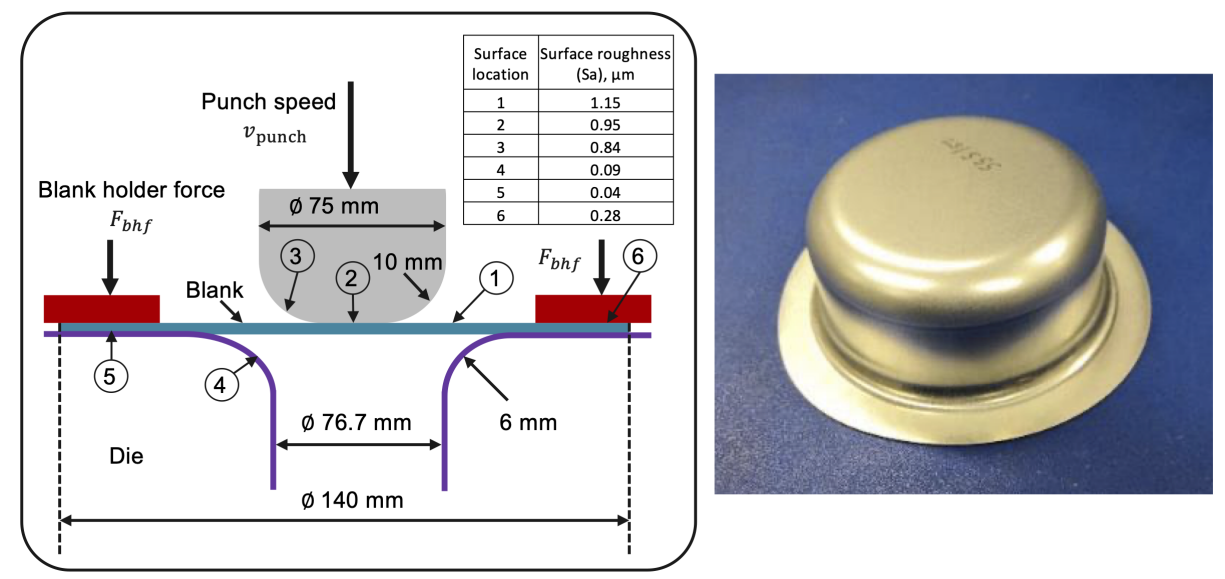

Figure 4.14 Schematic of the deep drawing setup and actual product. 


\subsubsection{Model implementation to forming simulations}

During the forming processes, sheet surface is subjected to different types of loads such as normal load, sliding and stretching, which vary at each time increment. This means that the sheet surface evolves continuously during the process. In the FE simulation, contact pressure and equivalent plastic strain at each node of the blank mesh for each time increment can be determined. With these inputs and using the flattening models it is possible to determine the local contact conditions (asperity deformation and real area of contact). Furthermore, the coefficient of friction at each node can be determined using the multi-asperity friction model discussed in Section 4.3.2. However, running the friction model at each node of the blank mesh for each time increment is computationally expensive. Therefore, an offline look-up table is generated which consists of the coefficient of friction and real area of contact for the range of nominal pressures (including the effects of sliding) and strains. The look-up table is supplied to the simulation as an input. During the simulation, the nominal contact pressure and the equivalent plastic strain at each node of the blank mesh are extracted from the FE model to determine the real area of contact for a combined normal load (including the effects of sliding) and bulk strain. The coefficient of friction at each contacting node is determined using the look-up table and the nodal contact loads. In this way, the coefficient of friction at each contacting node is applied in the forming simulation. It should be noted that, the look-up table is generated for each tool surface to account for different tool topographies at different parts of the die, punch and blank holder.

The blank is meshed with three node triangular discrete Kirchhoff shell elements. Due to symmetry, one quarter of the cup is modelled. Tools are assumed to be rigid. Vegter yield model [52] is used to describe the yield surface of the sheet metal. The hardening behaviour is described by the Bergström-Van Liempt relation [53]. Table 4.3 shows the parameters of the yield surface and Table 4.4 shows the parameters used in the hardening relation. Simulations are performed at blank holder forces of 10, 30 and $50 \mathrm{kN}$. Figure 4.15 shows the results of the simulation for the punch side and die side of the blank at the punch displacement of $32 \mathrm{~mm}$ and blank holder force of $30 \mathrm{kN}$. On the punch side of the blank, the contact pressure is maximum at the punch corner region. The real area of contact is high at the punch corner region due to a high contact pressure. In the blank holder region, the real area of contact is high due to a high equivalent strain. The coefficient of friction in the punch corner region is higher than that in the 
blank holder region. This is because the tool roughness in the punch corner region is higher than in the blank holder region (see Figure 4.14). On the die side of the blank, the contact pressure and the equivalent strain are maximum in the die corner region resulting in a large real area of contact. Moreover, within the die corner region, the coefficient of friction is high at low contact pressure and vice versa which is consistent with the results of the friction experiments (see Figure 4.13).

Table 4.3 Vegter yield locus parameters for DX54.

\begin{tabular}{llll}
\hline Parameter & $0^{\circ}$ & $45^{\circ}$ & $90^{\circ}$ \\
\hline$R$-value & 2.438 & 1.763 & 2.661 \\
Uniaxial factor $\left(f_{\mathrm{un}}\right)$ & 1.0000 & 1.036 & 0.990 \\
Plane-strain factor $\left(f_{\mathrm{ps}}\right)$ & 1.272 & 1.271 & 1.268 \\
Plane-strain ratio $(\alpha)$ & 0.616 & 0.600 & 0.630 \\
Pure shear factor $\left(f_{\mathrm{sh}}\right)$ & 0.538 & 0.557 & 0.538 \\
Equi-biaxial factor $\left(f_{\mathrm{bi}}\right)$ & 1.151 & & \\
Equi-biaxial ratio $\left(\rho_{\mathrm{bi}}\right)$ & 0.916 & & \\
\hline
\end{tabular}

Table 4.4 Bergström-Van Liempt hardening parameters for DX54.

\begin{tabular}{lll}
\hline Material parameter & Value & Unit \\
\hline Initial static stress $\left(\sigma_{0}\right)$ & 88.28 & $\mathrm{MPa}$ \\
Stress increment parameter $\left(\Delta \sigma_{\mathrm{m}}\right)$ & 267.04 & $\mathrm{MPa}$ \\
Linear hardening parameter $(\beta)$ & 0.5 & \\
Hardening exponent $(n)$ & 0.5 & \\
Remobilization parameter $(\omega)$ & 5.81 & \\
Max. dynamic stress $\left(\sigma_{0}^{*}\right)$ & 1000 & $\mathrm{MPa}$ \\
Initial strain $\left(\varepsilon_{0}\right)$ & 0.005 & \\
Initial strain rate $\left(\dot{\varepsilon}_{0}\right)$ & $10^{8}$ & \\
Temperature $(T)$ & 293 & $\mathrm{~K}$ \\
Dynamic stress power $(m)$ & 3.18 & \\
Activation energy $\left(\Delta G_{0}\right)$ & 0.8 & $\mathrm{~J}$ \\
Boltzmann's constant $\left(\kappa_{\text {Bolz }}\right)$ & $8.617 \times 10^{-5}$ & $\mathrm{eV}$ \\
\hline
\end{tabular}


(a) Punch side of the workpiece

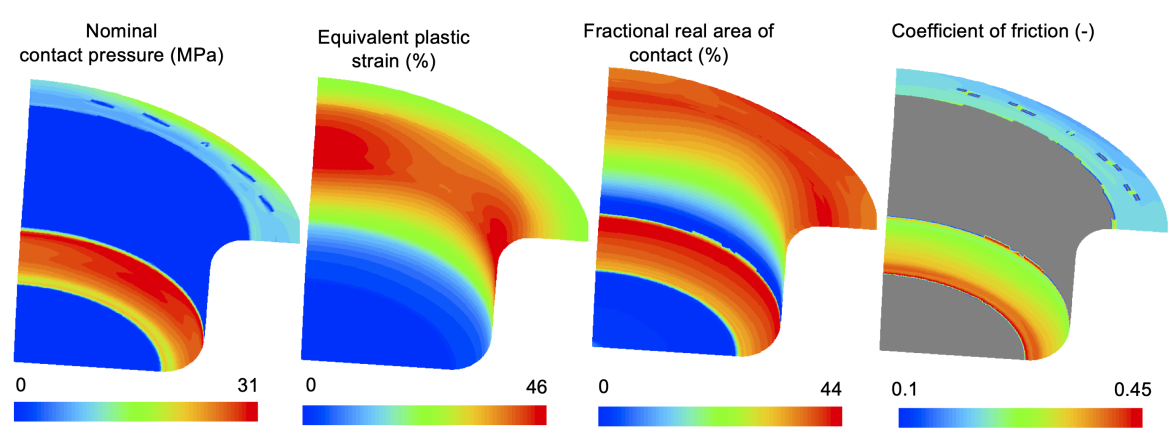

(b) Die side of the workpiece

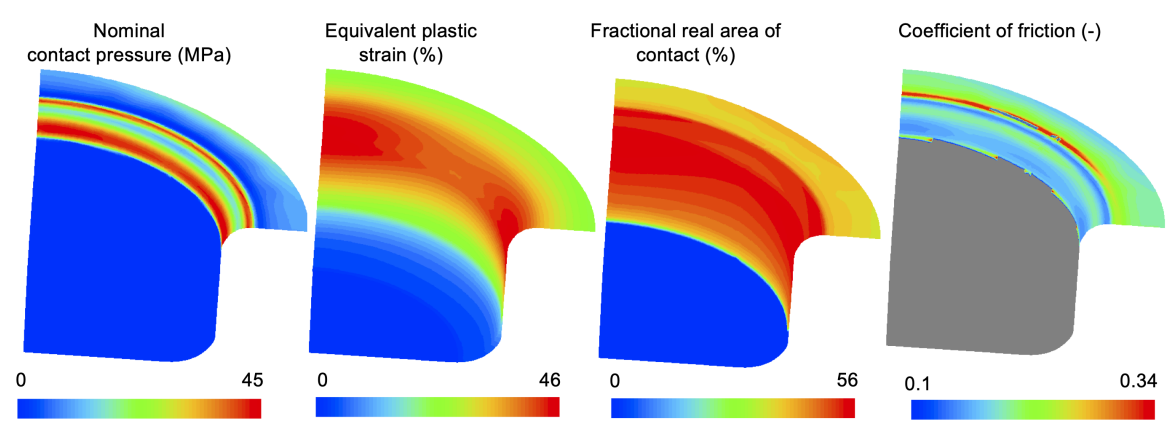

Figure 4.15 Cup drawing simulation results at blank holder force of $30 \mathrm{kN}$ and punch displacement of $32 \mathrm{~mm}$.

\subsubsection{Comparison of experiments and FE simulations}

Punch force vs. punch displacement, real area of contact and sheet draw-in are used to compare the results of the FE simulations and experiments. Figure 4.16 shows the punch force vs. punch displacement comparison between simulation results using multi-scale friction model and experiments. At the blank holder forces of $30 \mathrm{kN}$ and $50 \mathrm{kN}$, the simulation results correlate well with the experiments but the simulation underestimates the punch force at the blank holder force of $10 \mathrm{kN}$. For the blank holder force of $10 \mathrm{kN}$, traces of wrinkling were observed on the edges of the cup while the wrinkling cannot be captured in the current FE simulations. This explains the deviation between the experimental force-displacement curves and the FE results at $10 \mathrm{kN}$ blank holder force. Furthermore, Figure 4.17 shows that for a blank holder force of $10 \mathrm{kN}$ the blank in the die side loses the contact 


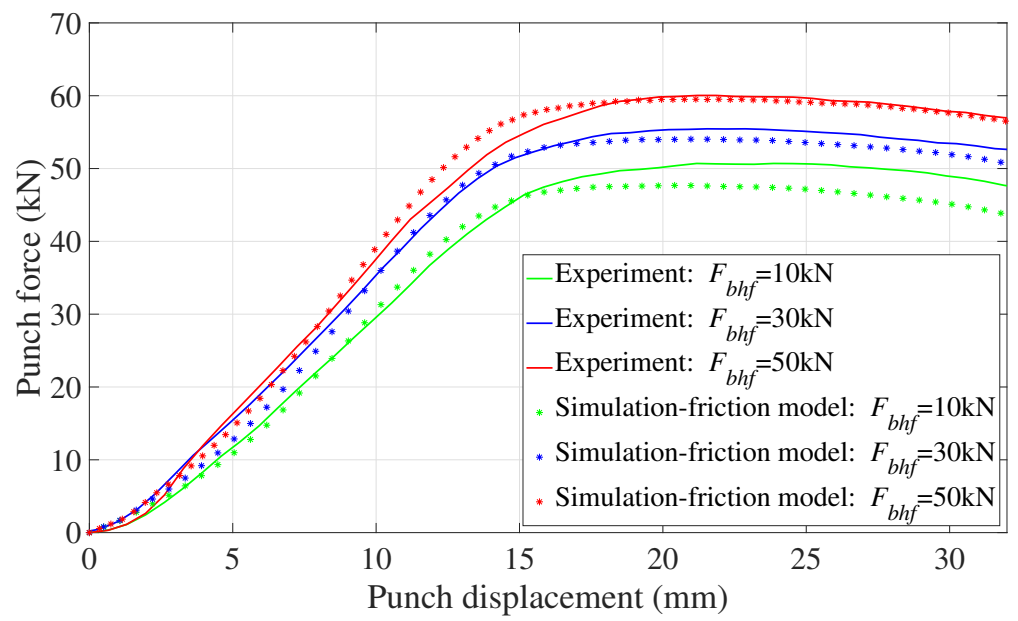

Figure 4.16 Experiments vs. model: punch force vs. punch displacement at different blank holder forces.
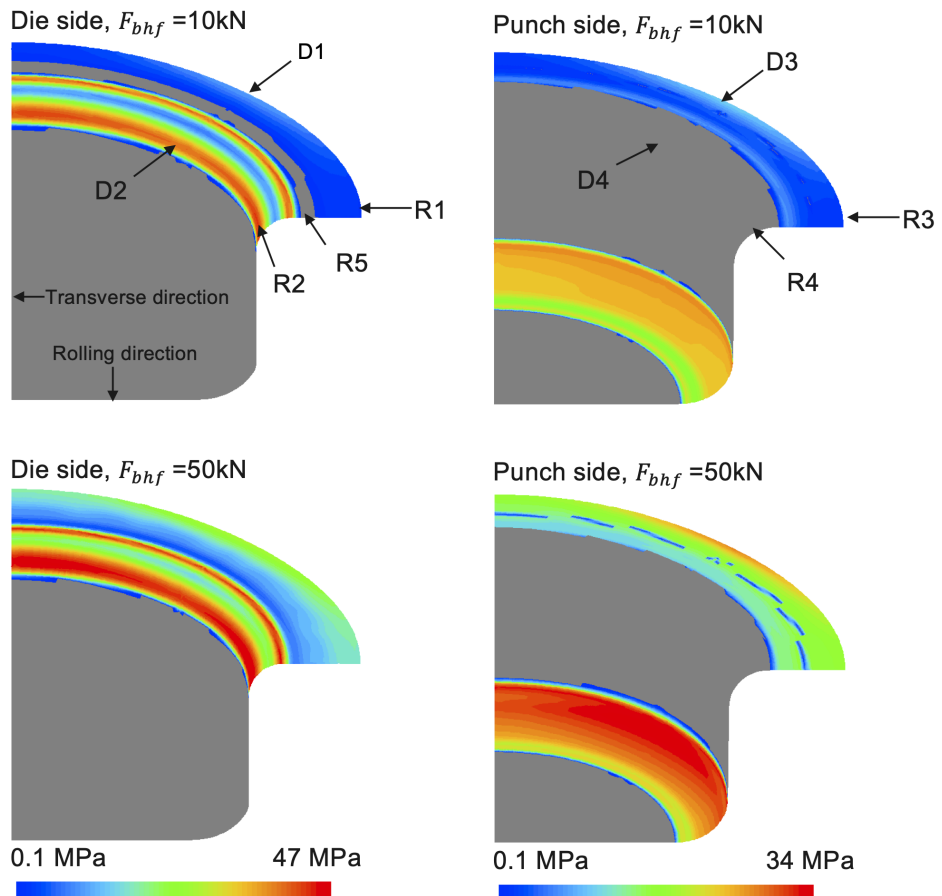

Figure 4.17 Contact pressure at blank holder force of $10 \mathrm{kN}$ and $50 \mathrm{kN}$ at punch displacement of $32 \mathrm{~mm}$. 
(region R5) but it remains in contact at a blank holder force of $50 \mathrm{kN}$. This might result in free surface roughening at region $\mathrm{R} 5$ at low blank holder force. This would slightly increase the punch force in the experiments as well. The free surface roughening effects are not captured in the current FE simulations.

As an additional validation case, the real area of contact is measured on the die side of the cup at different locations. The results are compared with the simulations as shown in Table 4.5. The real area of contact correlates well in the blank holder region (R1, D1) at blank holder forces of $30 \mathrm{kN}$ and $50 \mathrm{kN}$. Elastic recovery of deformed asperities on the measured surfaces is one of the reasons for deviation but it is expected to be low as the plastic deformation is dominant. However, the results are not favourable at a blank holder force of $10 \mathrm{kN}$; the large difference between measured and predicted real area of contact at location D1 $(30 \%)$ is mainly due to wrinkles formed at the cup edges. Furthermore, the real area of contact measurements at R1 are not reliable due to wrinkling at $10 \mathrm{kN}$ blank holder. In the die corner region (location R2 and D2), the simulations overpredict the real area of contact. But the difference reduces at higher blank holder forces. Overall, the predicted real area of contact at blank holder forces of $30 \mathrm{kN}$ and $50 \mathrm{kN}$ correlate well with the measurements.

Draw-in of the blank is measured and compared with the simulations as well. The material behaviour and coefficient of friction influence draw-

Table 4.5 Simulations vs. experiments: real area of contact on die side.

\begin{tabular}{llll}
\hline Location & $\begin{array}{l}\text { Blank holder } \\
\text { force }(\mathrm{kN})\end{array}$ & $\begin{array}{l}\text { Real area }(\%) \\
\text { (simulations) }\end{array}$ & $\begin{array}{l}\text { Real area }(\%) \\
\text { (experiments) }\end{array}$ \\
\hline \multirow{3}{*}{$\mathrm{R} 1$} & 10 & 34 & roughening \\
& 30 & 37 & 35 \\
& 50 & 39 & 41 \\
\hline \multirow{2}{*}{ D1 } & 10 & 38 & 29 \\
& 30 & 41 & 39 \\
& 50 & 43 & 42 \\
$\mathrm{R} 2$ & 10 & 55 & 38 \\
& 30 & 56 & 46 \\
& 50 & 57 & 47 \\
\hline \multirow{2}{*}{ D2 } & 10 & 53 & 38 \\
& 30 & 54 & 42 \\
\hline
\end{tabular}




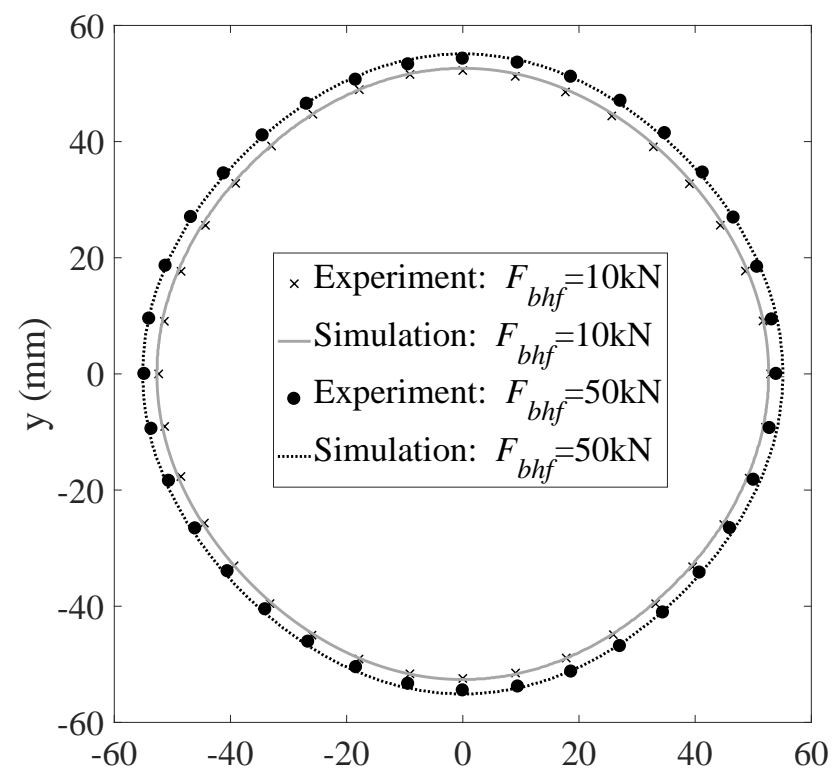

Figure 4.18 Experiments vs. simulations: draw-in of blank at blank holder force of $10 \mathrm{kN}, 50 \mathrm{kN}$ and punch displacement of $32 \mathrm{~mm}$.

in. For instance, the higher the coefficient friction higher the resistance to sliding which results in less draw-in. Figure 4.18 compares the measured and FE predicted draw-in values at blank holder forces of $10 \mathrm{kN}$ and $50 \mathrm{kN}$. The results show a good correlation between the simulations and the measurements. The measured draw-in also shows the earing phenomenon in the rolling and transverse directions due to the material anisotropy, which is predicted well by the simulations.

\subsection{Summary and conclusions}

A multi-scale boundary lubrication friction model for coated sheets is developed. The model considers the influence of contact loads on the evolution of the sheet surface topography and friction. The measured workpiece and the tool surfaces are used as the input to determine the coefficient of friction. The contact patches between the tool and the workpiece at normal load, sliding and combined normal load and bulk strain are determined using the flattening models. A single asperity ploughing model is applied at each contact patch from which the coefficient of friction is determined. The model uses the elliptical paraboloid single asperity 
ploughing model to determine the shear forces due to the ploughing of substrate and shearing of the interfacial lubricant boundary layer. The friction model is validated using the lab-scale friction experiments. The predictions from the proposed model show good agreement with the experiments. The model is implemented in FE analyses of deep drawing applications. Offline friction look-up tables are generated for the measured workpiece and tool surfaces. The friction look-up table indexes the coefficients of friction as a function of nominal contact pressure and strain. The look-up tables are supplied to the FE simulation as an input to determine the coefficient of friction at each node in FE mesh at each increment. The coefficient of friction at each node is determined based on the tool surface in contact, the nodal contact pressure and the nodal equivalent plastic strain. The cup drawing experiments are performed on GI sheet at different blank holder forces. The results from the experiments and simulations show good agreement for punch force vs. punch displacement, blank draw-in and real area of contact. This demonstrates the applicability of the developed model for the industrial-scale forming simulations. 


\section{Chapter 5}

\section{Mixed lubrication friction model}

In a typical deep drawing process, mixed lubrication friction condition may occur at the tool-sheet interface depending on the lubricant amount and process parameters. In this regime, asperity deformations are governed by direct asperity contact and hydrodynamic pressure developed in lubricant. The sheet surface texture may influence the distribution of lubricant pressure. Therefore, it is necessary to model the friction behaviour considering the surface texture effects. In this study, a multi-scale friction model is developed in the mixed lubrication regime which includes the effects of lubricant as well as the measured surface topographies of the tool and the sheet surfaces. The overall friction due to lubricant pressure and direct asperity contact is determined using a coupled hydrodynamic and boundary friction model. The model is implemented in an FE code for forming simulations. In the FE simulations, an average Reynolds equation is solved on the global FE domain to determine the lubricant pressure from which the load shared by the lubricant and the direct asperity contact are determined. The flow factors required in the average Reynolds equation are determined separately using measured tool and sheet surface topographies. Deep drawing experiments are performed on steel sheets at different lubricant amounts to demonstrate utilization of the friction model.

In Section 5.2, formulation of the average Reynolds equation applicable for high fractional real area of contacts is presented. The approach to

This chapter is based on the publication: M.P. Shisode, J. Hazrati, T. Mishra, M.B. de Rooij and A.H. van den Boogaard, "Mixed lubrication friction model including surface texture effects for sheet metal forming" (Under review). 
determine the flow factors for the measured surface topographies of the contacting surfaces is described in Section 5.3. Here, typical contact conditions relevant to forming conditions will be considered including deformation of contacting and rise of non-contacting asperities. In Section 5.4, the mixed lubrication friction model is described which couples the boundary friction model and the effects of lubricant pressure. In Section 5.5, the model is implemented in FE software code and validated using deep drawing experiments.

\subsection{Introduction}

In sheet metal forming processes, sheet surface is often lubricated; this changes the contact interaction between the tool and sheet metal. A mixed lubrication regime may exist depending on the lubricant amount and surface topographies of the contacting surfaces. Unlike the boundary lubrication regime where the contact load is completely carried by the direct asperity contacts, the contact load in the mixed lubrication regime is shared by the direct asperity contacts and the lubricant. The Reynolds equation is solved to determine the hydrodynamic pressure distribution from which lubricant viscous shear stresses are determined.

The lubrication regime is classified based on the ratio of fluid film thickness $h$ and combined root mean square (RMS) surface roughness Sq of the contacting surfaces. In the thick film lubrication regime $h / \mathrm{Sq}>10$, in the thin film lubrication regime $3<h / \mathrm{Sq}<10$ and in the mixed lubrication regime $h / \mathrm{Sq}<3$ [54]. In the mixed lubrication regime, there exists a frequent solid to solid contact (boundary lubrication) at asperity level but some portion remains supported by fluid film. In this regime, the influence of roughness or surface texture on the fluid flow is significant, a fact that must be considered while solving the Reynolds equation.

The major challenge in the numerical simulations of rough surfaces is the modelling of surface topography which is at a much smaller scale in comparison with the global domain. Therefore the direct method, in which the chosen mesh size is fine enough to account for the surface roughness, is intractable. Hence, other methods known as indirect or stochastic methods are gaining increasing attention. All these methods follow an approach of averaging the state variables on the solution domain. For example, solving Reynolds equation using the homogenization method in which the local effects due to surface roughness are averaged and included in the global Reynolds equation. This method was first proposed by Elrod [55] as a 
way to include the roughness effects. However, this method is limited to non-contact situations. Christensen and Tonder [56-58] have developed stochastic Reynolds equation for transverse and longitudinal surfaces which is applied for slider and journal bearings. However, the stochastic Reynolds equation is limited to surfaces with uni-directional roughness lays where one-dimensional ridges are oriented either transversely or longitudinally with respect to the sliding direction. Patir and Cheng [59] proposed a formulation of the average Reynolds equation ( $\mathrm{P} \& \mathrm{C}$ method) applicable to any general 3D surface topography. The method was used to investigate the effect of roughness on the performance of a finite slider bearing using the average Reynolds equation [60]. The average Reynolds equation accounts for local roughness effects using correction factors called flow factors. Flow factors are determined by comparing the fluid flow through the pair of rough surfaces and the flow through their equivalent smooth counterpart [59-63]. Two types of flow factors are defined: pressure and shear flow factors. The pressure flow factor accounts for the change in mean flow due to the surface roughness for a pressure gradient induced flow. The shear flow factor accounts for the fluid transport due to the rough contacting surfaces which are sliding relative to each other. It is necessary to mention that the average Reynolds equation proposed by Patir and Cheng [59] is suitable only for non-contacting and lightly loaded surfaces and becomes unstable for high fractional real area of contact situations such as in forming applications. Later, a few formulations $[61,64,65]$ were proposed to overcome this limitation. One such formulation is proposed by Wilson and Chang [66] which is suitable for the contact conditions having a high fractional real area of contact. Wilson and Marsault [67] adapted the flow factor relations proposed in [59, 61, 62] for numerically generated surfaces with Gaussian surface height distributions. In the current study, metal sheets textured by electro-discharge textured (EDT) rolls are used which often have a nonGaussian height distribution. Therefore, the measured surface height data is used to determine the flow factors using the formulation proposed by Wilson and Chang [66].

In the mixed lubrication regime, direct asperity contacts and lubricant pressure contribute to the total friction force. The possible approach to account for these effects in forming simulations is to solve a fluidstructure interaction problem by coupling the structural FE mesh with the discretized form of the average Reynolds equation. Booker and Huebner [68] first introduced this approach for rotor bearings. Later, Hu and Liu [69] implemented this coupled approach for sheet rolling processes and Yang 
and Lo [70] used it for axisymmetric cup stretching processes. Recently, Hol et al. [71] successfully implemented the coupled formulation for deep drawing applications. However, in this implementation the effects of surface roughness on lubricant pressure distribution are not considered. This may lead to inaccurate prediction of the lubricant pressure and the load carried by lubricant which in turn results in an unreliable estimation of the friction coefficient.

The goal of this study is to develop a mixed lubrication friction model applicable to forming simulations. The model must account for the measured surface topographies of tool and sheet metal to determine the lubricant pressure distribution. Lubricant pressure distribution is used to estimate the load carried by direct asperity contacts and lubricant in order to calculate the overall coefficient of friction. The new mixed lubrication friction model is utilized in FE simulations of sheet metal forming processes.

\subsection{Formulation of the average Reynolds equation}

The Reynolds equation is a partial differential equation governing the pressure distribution of viscous fluids. The 2D Reynolds equation for Newtonian, incompressible fluid in tensorial form can be written as [72],

$$
\nabla \cdot\left(\frac{h^{3}}{12 \eta} \nabla P\right)=\nabla \cdot\left(\frac{h\left(U_{1}+U_{2}\right)}{2}\right)+\frac{\partial h}{\partial t}
$$

where $\nabla=(\partial / \partial x, \partial / \partial y), P(x, y)$ is the local fluid pressure, $h$ is the local fluid film thickness, $\eta$ is the dynamic viscosity of the fluid and $U_{1}, U_{2}$ are the surface velocities, as shown in Figure 5.1. Patir and Cheng [59] proposed an average Reynolds equation to account for the surface roughness of the nominally separated contacting surfaces. The average Reynolds equation accounting for the roughness effects can be written as follows [59, 69]:

$$
\nabla \cdot\left(\frac{h_{\mathrm{T}}^{3}}{12 \eta} \Phi_{\mathrm{P}} \cdot \nabla \bar{P}\right)=\nabla \cdot\left(\frac{h_{\mathrm{avg}}\left(U_{1}+U_{2}\right)}{2}+\Phi_{\mathrm{S}} \cdot \frac{\mathrm{Sq}\left(U_{1}-U_{2}\right)}{2}\right)+\frac{\partial h_{\mathrm{avg}}}{\partial t}
$$

where $\Phi_{\mathrm{P}}=\left[\begin{array}{ll}\Phi_{\mathrm{P} x x} & \Phi_{\mathrm{P} x y} \\ \Phi_{\mathrm{P} y x} & \Phi_{\mathrm{P} y y}\end{array}\right]$ and $\Phi_{\mathrm{S}}=\left[\begin{array}{ll}\Phi_{\mathrm{S} x x} & \Phi_{\mathrm{S} x y} \\ \Phi_{\mathrm{S} y x} & \Phi_{\mathrm{S} y y}\end{array}\right]$ are pressure and shear flow factor tensors, $\bar{P}(x, y)$ is the average local fluid pressure, $h_{\mathrm{T}}$ is the nominal surface separation of undeformed surfaces and $h_{\text {avg }}$ is the average fluid film thickness (separation) which is equal to area averaged surface pockets volume between the contacting surfaces (see Section 5.3.5). 


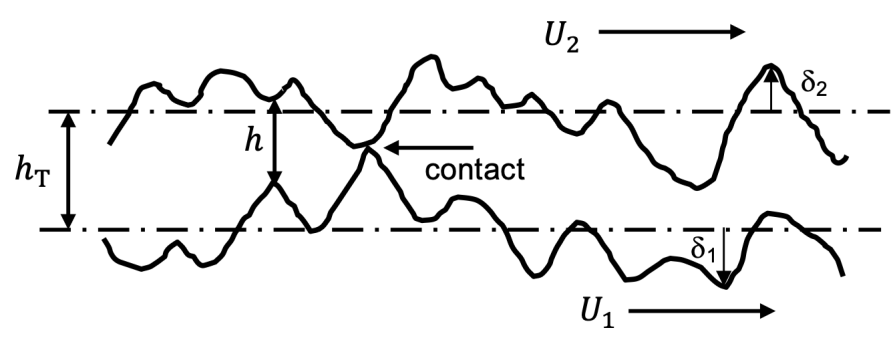

Figure 5.1 Rough surfaces in contact.

$\mathrm{Sq}=\sqrt{\mathrm{Sq}_{1}^{2}+\mathrm{Sq}_{2}^{2}}$ is the combined RMS surface roughness of the contacting surfaces. It should be noted that, when $\Phi_{\mathrm{P}}=[\mathrm{I}]$ and $\Phi_{\mathrm{S}}=[0]$, the average Reynolds Equation (5.2) reduces to the standard Reynolds Equation (5.1). The formulation proposed by Patir and Cheng [59] is suitable for non-contacting and lightly loaded surfaces $\left(h_{\mathrm{T}} / \mathrm{Sq}>3\right)$. This formulation becomes unstable for high fractional real area contact $\left(h_{\mathrm{T}} / \mathrm{Sq}<<3\right)$, especially in a real area of contact $>50 \%$ when the mean separation $h_{\mathrm{T}}$ may become negative. In forming processes, the fractional real area of contact can be high, therefore this formulation is not suitable. The formulation proposed by Wilson and Chang [66] is applicable in a high real area of contact. They used consistent fluid film thickness $h_{\text {avg }}$ in Poiseuille (LHS term in Equation (5.1)) and Couette terms (first RHS term in Equation (5.1)) of the equation. They proposed an alternative form by modifying Equation (5.2) as follows:

$$
\nabla \cdot\left(\frac{h_{\mathrm{avg}}^{3}}{12 \eta} \Phi_{\mathrm{P}} \cdot \nabla \bar{P}\right)=\nabla \cdot\left(\frac{h_{\mathrm{avg}}\left(U_{1}+U_{2}\right)}{2}+\Phi_{\mathrm{S}} \cdot \frac{\mathrm{Sq}\left(U_{1}-U_{2}\right)}{2}\right)+\frac{\partial h_{\mathrm{avg}}}{\partial t}
$$

This formulation is more stable because the ratio $h_{\mathrm{avg}} / \mathrm{Sq}>0$ over a wide range of contact conditions. Therefore, in the current study, this formulation is used to determine the lubricant pressure in the mixed lubrication regime.

\subsection{Determination of flow factors}

Patir and Cheng $[59,60]$ described a method (P\&C method) to determine the flow factors. The method is suitable for determining the diagonal terms of the flow factor tensors $\left(\Phi_{\mathrm{P} x x}, \Phi_{\mathrm{P} y y}, \Phi_{\mathrm{S} x x}, \Phi_{\mathrm{S} y y}\right)$. This is true for random and isotropic surfaces $[61,67,73,74]$. For directional surfaces with 
surface topography oriented in a specific direction, the off-diagonal terms may appear in flow factor tensors due to surface roughness anisotropy. For such surfaces, the pressure gradient in one direction can produce a flow in the other direction. However, for any surface a principal coordinate system exists for which $\Phi_{\mathrm{P}}$ and $\Phi_{\mathrm{S}}$ are diagonal [61,67]. The problem reduces to an eigenvalue problem, which means if the coordinate system is chosen in the eigen directions such that it aligns with the roughness lay direction, the $\mathrm{P} \& \mathrm{C}$ method can be used to determine the diagonal terms of the flow factors. For random and isotropic surfaces, $\Phi_{\mathrm{P} x x}=\Phi_{\mathrm{P} y y}, \Phi_{\mathrm{S} x x}=\Phi_{\mathrm{S} y y}$ and $\Phi_{\mathrm{P} x y}, \Phi_{\mathrm{P} y x}, \Phi_{\mathrm{S} x y}, \Phi_{\mathrm{S} y x}=0$ and for directional surfaces with coordinate system aligned in the principal directions, $\Phi_{\mathrm{P} x x} \neq \Phi_{\mathrm{P} y y}, \Phi_{\mathrm{S} x x} \neq \Phi_{\mathrm{S} y y}$ and $\Phi_{\mathrm{P} x y}, \Phi_{\mathrm{P} y x}, \Phi_{\mathrm{S} x y}, \Phi_{\mathrm{S} y x}=0[61,73]$. The current study is focused on metal sheets textured by EDT rolls for which the surface topography is random. Since for random (or isotropic) surfaces the flow factors $\Phi_{\mathrm{P}}$ and $\Phi_{\mathrm{S}}$ are diagonal and independent of the coordinate system, the flow factors reduce to, $\Phi_{\mathrm{P}}=\left[\begin{array}{cc}\Phi_{\mathrm{P} x x} & 0 \\ 0 & \Phi_{\mathrm{P} x x}\end{array}\right]$ and $\Phi_{\mathrm{S}}=\left[\begin{array}{cc}\Phi_{\mathrm{S} x x} & 0 \\ 0 & \Phi_{\mathrm{S} x x}\end{array}\right]$. The pressure and shear flow factors are determined by solving the Reynolds equation on a pair of contacting rough surfaces from which the flow is determined. This flow is compared with the mean flow of its equivalent pair of smooth surfaces separated by mean fluid film thickness. It is assumed that the Reynolds equation is applicable for the flow through rough surfaces. This requires asperities of small slopes, which is generally valid for most of the engineering surfaces [75]. In the current study, an area averaged fluid film thickness $h_{\text {avg }}$ is used. This is required to be consistent with the average Reynolds Equation (5.3), making it possible to calculate the flow factors for a high fractional real area of contact. The effect of surface roughness on pressure driven flow (Poiseuille term) to determine $\Phi_{\mathrm{P}}$ and sliding driven flow (Couette term) to determine $\Phi_{\mathrm{S}}$ can be analyzed separately, because the flow according to the Reynolds equation is a linear combination of pressure gradient induced flow and sliding driven flow.

\subsubsection{Pressure flow factor}

The pressure flow factor reflects the impedance to flow due to roughness. The flow through the pair of rough surfaces is determined by solving the standard Reynolds equation with a predefined pressure gradient $\left(P_{B}-\right.$ $\left.P_{A}\right) / L_{x}$ on a control volume. The calculated flow is compared with the flow through a pair of equivalent smooth surfaces separated by the average fluid film thickness $h_{\text {avg. }}$. For simplicity, both pressure and shear flow factors are 
determined in the $x$ direction $\left(\Phi_{\mathrm{P} x x}, \Phi_{\mathrm{S} x x}\right)$. Figure 5.2 shows the control volume and required boundary conditions to determine the pressure flow factor. A no-flow boundary condition $[59,76,77]$ on the edges of the control volume in the $y$ direction is used. The pressure flow factor $\Phi_{\mathrm{P} x x}$ in the $x$

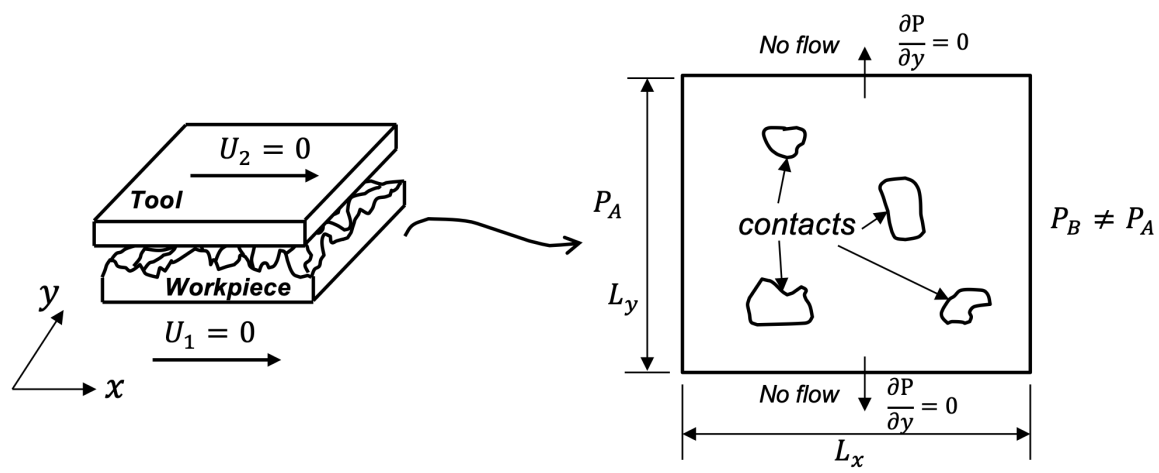

Figure 5.2 Boundary conditions for pressure flow factor calculation.

direction (direction of applied pressure gradient) is determined as

$$
\Phi_{\mathrm{P} x x}=\frac{Q_{\text {rough }}}{Q_{\text {smooth }}}
$$

where $Q_{\text {rough }}$ is the flow through a pair of rough surfaces and $Q_{\text {smooth }}$ is the flow through an equivalent pair of smooth surfaces per unit width under a pressure gradient of $\left(P_{B}-P_{A}\right) / L_{x}$. Patir and Cheng [59] used a flow averaged over the boundary to determine $Q_{\text {rough }}$ from the pressure distribution. $\mathrm{Hu}$ and Zheng [78] concluded that averaging the flow over a complete area gives better estimation of the flow. In the current study, $Q_{\text {rough }}$ is determined by averaging the flow over a bearing area using the estimated pressure field. Furthermore, to reduce the effects of boundary conditions the flow is calculated on a central area of $0.8 L \times 0.8 L[79] . Q_{\text {rough }}$ and $Q_{\text {smooth }}$ are determined as follows:

$$
\begin{gathered}
Q_{\text {smooth }}=\left(\frac{h_{\mathrm{avg}}^{3}}{12 \eta}\right)\left(\frac{P_{B}-P_{A}}{L_{x}}\right) \\
Q_{\text {rough }}=\frac{1}{0.8^{2} L_{x} L_{y}} \int_{0.1 L_{x}}^{0.9 L_{x}} \int_{0.1 L_{y}}^{0.9 L_{y}} \frac{-h_{x, y}^{3}}{12 \eta} \frac{\partial P}{\partial x} \mathrm{~d} x \mathrm{~d} y
\end{gathered}
$$

The flow factor in $y$ direction $\left(\Phi_{\mathrm{P} y y}\right)$ can be determined using the same method. In that case, the pressure gradient is applied in the $y$ direction and the no-flow boundary condition in the $x$ direction. 


\subsubsection{Shear flow factor}

The shear flow factor accounts for the sliding induced additional fluid flow. In this case the fluid entrapped in the surface pockets of the rough surfaces is transported. The mean flow per unit width is determined for the conditions of equal and opposite velocities of the contacting surfaces without any applied pressure gradient. In this case, $U_{1}=-U_{2}=U_{\mathrm{s}} / 2$ where $U_{\mathrm{s}}=U_{1}-U_{2}$ is the sliding velocity and $U_{\mathrm{r}}=U_{1}+U_{2}$ is the rolling velocity which is set to zero $[60,76,77]$. The corresponding boundary conditions are shown in Figure 5.3.

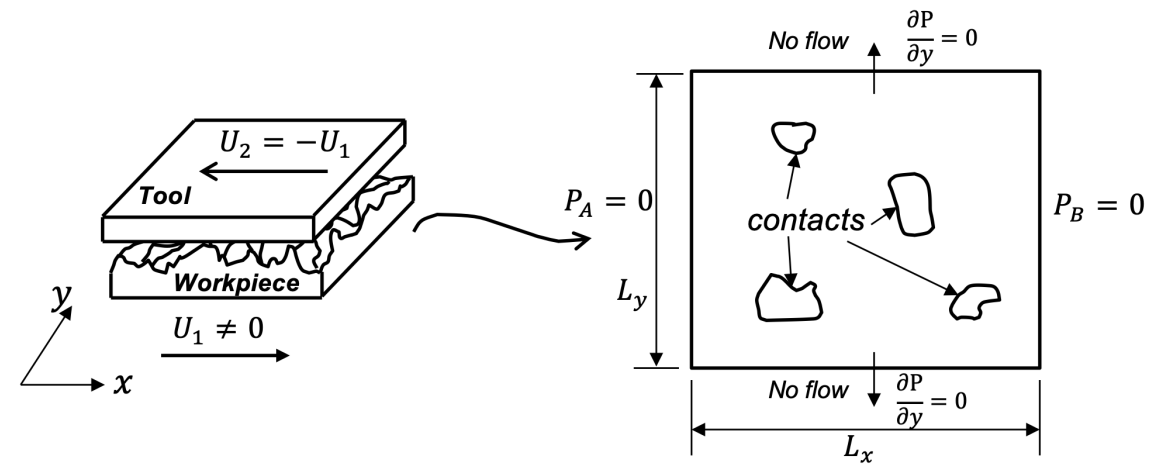

Figure 5.3 Boundary conditions for shear flow factor calculation.

The shear flow factor $\Phi_{\mathrm{S} x x}$ in the sliding direction is determined similarly to $\Phi_{\mathrm{P} x x}$ using Equation (5.4) for which $Q_{\text {rough }}$ is determined using Equation (5.6). Referring to Equation (5.3), since the mean pressure gradient and the rolling velocity are zero, $\Phi_{\mathrm{S} x x}$ can be determined as follows:

$$
\Phi_{\mathrm{S} x x}=Q_{\text {rough }}\left(\frac{2}{\mathrm{Sq} U_{\mathrm{s}}}\right)
$$

$\Phi_{\mathrm{P} x x}$ and $\Phi_{\mathrm{S} x x}$ depend strongly on local fluid film thickness $h$ and are independent of lubricant viscosity $\eta$, applied pressure gradient (in the case of $\Phi_{\mathrm{P} x x}$ ) and sliding velocity $U_{\mathrm{s}}$ (in the case of $\Phi_{\mathrm{S} x x}$ ) [75].

\subsubsection{Solution scheme}

The Reynolds equation (5.1) is solved over the control volume with boundary conditions shown in Figures 5.2 and 5.3. In the case of pressure flow factor, the RHS of Equation (5.1) is zero because the surfaces are stationary $\left(U_{1}=U_{2}=0\right)$ and $\partial h / \partial t=0$. Rewriting Equation (5.1) in the 
2D Cartesian coordinate system and setting RHS equal to zero,

$$
\frac{\partial}{\partial x}\left(\frac{h^{3}}{12 \eta} \frac{\partial P}{\partial x}\right)+\frac{\partial}{\partial y}\left(\frac{h^{3}}{12 \eta} \frac{\partial P}{\partial y}\right)=0
$$

where $h$ is the local fluid film thickness as shown in Figure 5.1. In the case of shear flow factor calculation, the relative sliding is introduced in the absence of a pressure gradient. The problem reduces to pure sliding of two nominally parallel surfaces. Therefore, Equation (5.1) takes the following form:

$$
\frac{\partial}{\partial x}\left(\frac{h^{3}}{12 \eta} \frac{\partial P}{\partial x}\right)+\frac{\partial}{\partial y}\left(\frac{h^{3}}{12 \eta} \frac{\partial P}{\partial y}\right)=\frac{\partial h}{\partial t}
$$

Due to the relative velocity, the position of surface points changes with time therefore the fluid film thickness is a function of time. To solve Equation (5.9), a displacement $\Delta x$ is assumed for a time increment of $\Delta t$ such that each surface moves by a displacement of $\Delta x$ during that time. Here, $x$ is the coordinate in sliding direction and $\Delta x$ represents the difference in position. Since each surface moves with a velocity of $U_{\mathrm{s}} / 2$, they are related as

$$
\frac{U_{\mathrm{s}}}{2}=\frac{\Delta x}{\Delta t}
$$

The bottom surface moves to the right and the top surface moves to the left; therefore, for a fixed spatial position the RHS of Equation (5.9) can be written as

$$
\frac{\partial h}{\partial t}=\frac{h(x, y, t+\Delta t / 2)-h(x, y, t-\Delta t / 2)}{\Delta t}
$$

Substituting $\Delta t$ from Equation (5.10),

$$
\frac{\partial h}{\partial t}=\frac{U_{\mathrm{s}}}{2 \Delta x}[h(x, y, t+\Delta t / 2)-h(x, y, t-\Delta t / 2)]
$$

$\Delta x$ is chosen as equal to the resolution of measured surface height data (pixel size). $U_{\mathrm{s}}$ is chosen arbitrarily and the time interval $\Delta t$ is determined using Equation (5.10). Referring to Figure 5.1, $h=h_{\mathrm{T}}+\delta_{1}+\delta_{2}$ is the local fluid film thickness. The expression for local fluid film thickness $h(x, y, t+\Delta t / 2)$ and $h(x, y, t-\Delta t / 2)$ can be written as [75],

$$
\begin{array}{r}
h(x, y, t+\Delta t / 2)=\left(h_{\mathrm{T}}+\delta_{1-}+\delta_{2+}\right) \\
h(x, y, t-\Delta t / 2)=\left(h_{\mathrm{T}}+\delta_{1+}+\delta_{2-}\right) \\
\delta_{1-}=\delta_{1}(x-\Delta x / 2, y, t), \delta_{1+}=\delta_{1}(x+\Delta x / 2, y, t) \\
\delta_{2-}=\delta_{2}(x-\Delta x / 2, y, t), \delta_{2+}=\delta_{2}(x+\Delta x / 2, y, t)
\end{array}
$$




\subsubsection{Finite difference scheme to determine flow factors}

The finite difference method is widely used to solve the Reynolds equation [60, 80-82]. Equation (5.8) is solved for the case of pressure flow factor and Equation (5.9) for the case of shear flow factor. The pressure field is determined from which the mean flow is estimated using Equation (5.6). Equations (5.8) and (5.9) are discretized over the area $\Delta x \Delta y$ as shown in Figure 5.4. The lengths $\Delta x$ and $\Delta y$ are chosen as equal to the resolution of measured surface in $x$ and $y$ directions. For the pressure flow factor case,

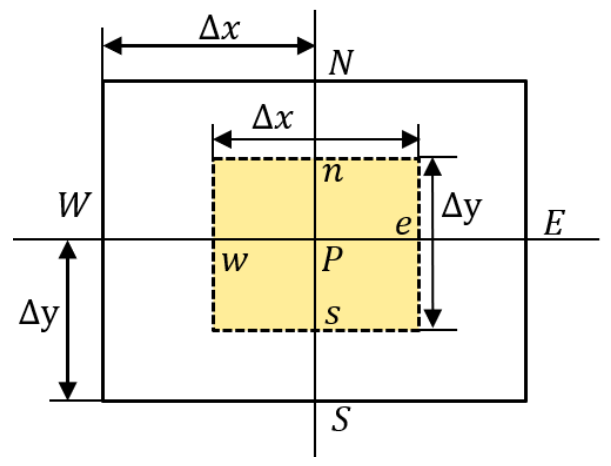

Figure 5.4 Position of grid points in cell with four control walls.

the finite difference approximation of Equation (5.8) for the control volume can be written as

$$
A_{i_{N}} P_{i_{N}}+A_{i_{S}} P_{i_{S}}+A_{i_{E}} P_{i_{E}}+A_{i_{W}} P_{i_{W}}-A_{i_{P}} P_{i_{P}}=0, i=1,2, \ldots, m
$$

where $m$ is the total number of nodes in the grid with unknown pressures (excluding nodes with prescribed pressures as boundary condition). The coefficients $A_{i}$ are determined as

$$
\begin{gathered}
A_{i_{N}}=k_{i_{n}} \frac{\Delta x}{\Delta y}, A_{i_{S}}=k_{i_{s}} \frac{\Delta x}{\Delta y}, A_{i_{E}}=k_{i_{e}} \frac{\Delta x}{\Delta y}, A_{i_{W}}=k_{i_{w}} \frac{\Delta x}{\Delta y} \\
A_{i_{P}}=A_{i_{N}}+A_{i_{S}}+A_{i_{E}}+A_{i_{W}}
\end{gathered}
$$

To determine the coefficients $A_{i_{N}}, A_{i_{S}}, A_{i_{E}}, A_{i_{W}}$ values of $k_{i_{n}}, k_{i_{s}}, k_{i_{e}}$, $k_{i_{w}}$ are not known. The values of $k_{i_{n}}, k_{i_{s}}, k_{i_{e}}, k_{i_{w}}$ are determined using values of $k$ at adjacent control nodes indicated by $N, S, E, W$ in Figure 5.4. There are different approximations proposed in the literature, for example harmonic mean or arithmetic mean based on $k$ values of adjacent nodes. When a uniform mesh is used $(\Delta x=\Delta y)$, Payvar and Salant [83] 
and Patankar [84] suggested using harmonic mean as an approximation to calculate the coefficients as follows:

$$
\begin{array}{r}
k_{i_{n}}=\frac{2}{\left(\frac{1}{k_{i_{N}}}+\frac{1}{k_{i_{P}}}\right)}, k_{i_{s}}=\frac{2}{\left(\frac{1}{k_{i_{S}}}+\frac{1}{k_{i_{P}}}\right)} \\
k_{i_{e}}=\frac{2}{\left(\frac{1}{k_{i_{E}}}+\frac{1}{k_{i_{P}}}\right)}, k_{i_{w}}=\frac{2}{\left(\frac{1}{k_{i_{W}}}+\frac{1}{k_{i_{P}}}\right)} \\
k_{i_{N}}=h_{i_{N}}^{3}, k_{i_{S}}=h_{i_{S}}^{3}, k_{i_{E}}=h_{i_{E}}^{3}, k_{i_{W}}=h_{i_{W}}^{3}, k_{i_{P}}=h_{i_{P}}^{3}
\end{array}
$$

For the shear flow factor case the RHS term in Equation (5.9) is not zero hence the discretized form of Equation (5.9) takes the following form,

$$
A_{i_{N}} P_{i_{N}}+A_{i_{S}} P_{i_{S}}+A_{i_{E}} P_{i_{E}}+A_{i_{W}} P_{i_{W}}-A_{i_{P}} P_{i_{P}}=B_{i_{P}}, i=1,2, \ldots, m
$$

where the expressions for coefficients $A_{i}$ remain the same and the additional term $B_{i_{P}}$ is determined (see Equation (5.9)) as follows:

$$
B_{i_{P}}=12 \eta\left(\frac{\partial h}{\partial t}\right)_{i_{P}}, i=1,2, \ldots, m
$$

where $(\partial h / \partial t)_{i_{P}}$ is determined from Equations (5.12) and (5.13). The coefficients are calculated for each node in the grid from which a set of linear equations is formed. The number of equations is equal to the number of nodes $m$ in the grid with unknown pressures. The assembly of Equations (5.14) and (5.19) can be written in the matrix form,

$$
\underset{(m \times m)(m \times 1)}{[C]} \underset{(m \times 1)}{[A]}=\underset{(B]}{[m \times 1)}
$$

where $C$ is the coefficient matrix, $A$ is the matrix containing unknown grid point pressures. Matrix $B$ contains the values related to known applied boundary pressures for assembly of Equation (5.14) (in the pressure flow factor case) and additionally, the coefficients $B_{i_{P}}$ for assembly of Equation (5.19) (in the shear flow factor case).

At contact points, $h=0$ (see Figure 5.1) will result in terms with division by zero (see Equations (5.17) and (5.18)). There is no flow at contact points, therefore the value of $h$ is assigned a very low value $(\omega=0.5 \mathrm{~nm})$ $[75,85]$ at contact points to avoid instability in the numerical solution. The flow at contact points is set to zero in the flow factor calculation after the pressure solution is obtained. Furthermore, if the grid point is surrounded by four contact points, from Equation (5.14) $A_{i_{P}}=4 \omega^{3}$, which can make 
the matrix $C$ ill-conditioned. But the pressure value at such grid points is not required for flow factor calculation since the flow is zero. Hence, in such cases the value of $A_{i_{P}}$ is set to a very high value [75]. This will automatically decouple the equations corresponding to such grid points from the assembly of equations which will also result in zero pressure at such grid points. Most of the terms in matrix $C$ are zero, therefore matrix $C$ is highly sparse in nature hence the matrix elements are stored in sparse form. Equation (5.21) is solved using linear equation solver for sparse matrices in Matlab to determine the pressure at each grid point.

\subsubsection{Deformed surface topography and film thickness}

The flow factors are determined at different levels of mean separations between the tool and the sheet surface. When the tool comes in contact with the sheet, the sheet surface topography changes due to asperity deformation. Hence, it is necessary to determine the surface topography in deformed condition to account for the asperity deformation in the flow factor calculation. The surface topography and average fluid film thickness $\left(h_{\text {avg }}\right)$ at a given position of the tool is determined assuming a smooth and rigid tool. During this step, the tool surface is modelled as a flat surface positioned at its mean plane. This is a reasonable assumption because generally the surface roughness of the tool is much less (in forming processes) than that of the workpiece. Note that the real tool surface topography is still considered in the solution of the Equations (5.8) and (5.9) to determine the flow factors. When the tool moves downward, the asperities deform, thereby redistributing the volume over the non-contacting area. It is assumed that the total deformed volume is uniformly distributed over the non-contacting area $[8,20]$. Figure 5.5 shows the schematic of the surface height data represented as bars where each bar represents a measured surface point. The uniform rise $u$ in non-contacting surface points for a given tool position $d$ can be determined by equating the flattened volume (LHS of Equation (5.22)) to the rising volume (RHS of Equation (5.22)) [1]. In this equation, $\phi(z)$ is the normalized height distribution function of the measured sheet surface [29].

$$
\int_{d-u}^{\infty}(z-d) \phi(z) \mathrm{d} z=u\left(1-\int_{d-u}^{\infty} \phi(z) \mathrm{d} z\right)
$$

The local fluid film thickness $h_{\text {avg }}$ is determined using a stochastic description of the rough surface and position of the tool $d$. The total lubricant volume trapped in the surface pockets is determined (see Equation 


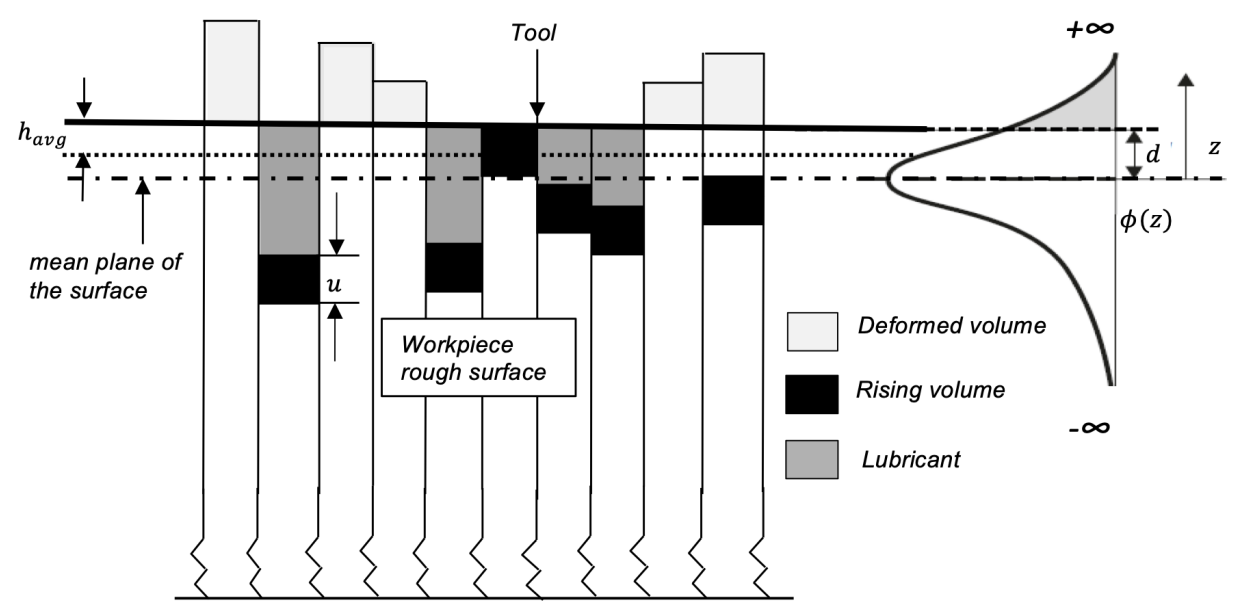

Figure 5.5 Estimation of fluid film thickness $\left(h_{\text {avg }}\right)$ and deformed workpiece surface topography.

(5.23)) and averaged over the total area $\left(A_{\text {nom }}\right)$ to determine the average fluid film thickness $h_{\text {avg }}$.

$$
h_{\mathrm{avg}}=\frac{V_{\mathrm{lub}}}{A_{\mathrm{nom}}}=\frac{A_{\mathrm{nom}} \int_{-\infty}^{d-u}(d-u-z) \phi(z) \mathrm{d} z}{A_{\text {nom }}}
$$

\subsubsection{Results of the flow factor calculation}

In the literature, the effects of surface topography and different surface statistical parameters $[67,75,86]$ on flow factors are studied, such as the ratio of correlation lengths in $x$ and $y$ directions, surface roughness, skewness and kurtosis. It was concluded that the flow factors depend on surface height data and its statistical properties. Patir [75] determined the flow factors for skewed surfaces and showed a significant difference from the Gaussian surfaces. Similarly, the results from Cho et al. [86] showed that the flow factors are sensitive to the value of kurtosis. Nowadays, sheet surfaces textured by electro-discharge textured (EDT) rolls are commonly used in the automotive and packaging industries. However, such surfaces often have bimodal (non-Gaussian) height distributions. In this study, two types of measured surfaces with different height distribution functions are analysed: bimodal and Gaussian surfaces. In order to study the effect of surface height distributions, the surfaces are chosen to have similar surface roughness. Furthermore, a representative measured surface area is used that 
includes a sufficient number of asperities that the surface height distribution is representative of the complete surface. A study on different sizes of measured surfaces (Section 2.3) showed that an area of $2 \times 2 \mathrm{~mm}$ is enough to statistically represent the sheet surface based on the convergence of the surface height distribution function. Therefore, a measured area of $2 \times 2 \mathrm{~mm}$ with resolution $=3 \mu \mathrm{m}$ is used in $x$ and $y$ directions in this study. The total grid size is $666 \times 666$ which is larger than used by [75, 79] in the flow factor study. Figure 5.6 shows the surface topographies and height distributions of the measured surfaces. The RMS roughness of the bimodal surface is $1.60 \mu \mathrm{m}$ and that of Gaussian surface is $1.56 \mu \mathrm{m}$.

The flow through contacting rough surfaces depends on the mean separation between the surfaces. Therefore, flow factors are determined at different values of $h_{\text {avg }} / \mathrm{Sq}$. For simplicity, the results are derived for a combination of rough workpiece surface (bottom surface) and rigid flat tool surface (top surface). A tool is moved in normal downward direction on the rough surface at certain displacement increments starting from a non-contacting situation. The surface topography of the deformed workpiece surface is determined using Equation (5.22). The average fluid film thickness $h_{\mathrm{avg}}$ is determined using Equation (5.23), from which $\left(h_{\mathrm{avg}} / \mathrm{Sq}\right)$ is determined at a given tool position. The pressure distribution
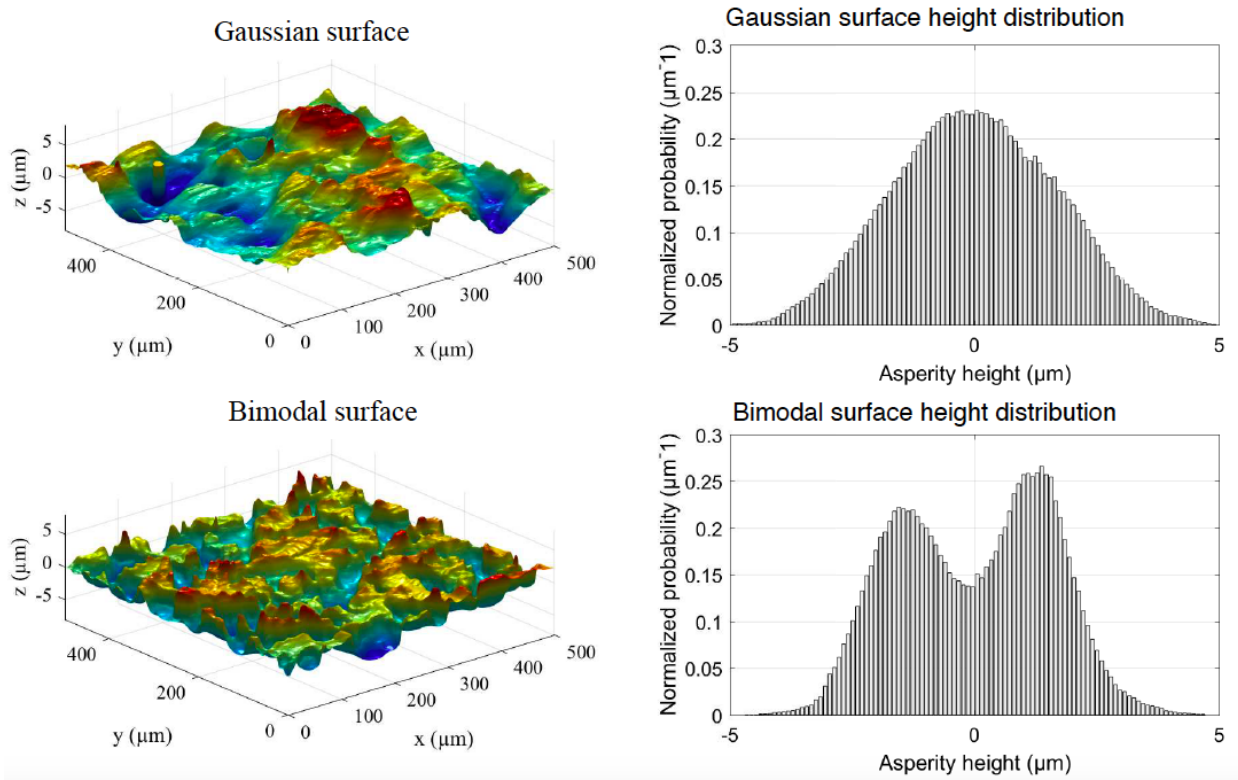

Figure 5.6 Surface topography and surface height distribution of measured Gaussian and bimodal surfaces. 
is determined for the boundary conditions shown in Figures 5.2 and 5.3, from which the pressure $\left(\Phi_{\mathrm{P}}\right)$ and shear $\left(\Phi_{\mathrm{S}}\right)$ flow factors are determined using Equations (5.4)-(5.7).

Figure 5.7 shows the surface topographies and pressure distributions at non-contacting $\left(h_{\mathrm{avg}} / \mathrm{Sq}=6\right)$ and contacting situations $\left(h_{\mathrm{avg}} / \mathrm{Sq}=1.5\right.$ and 0.8). Fluid pressure distributions are shown for the boundary conditions corresponding to the pressure flow factor case (see Figure 5.2). The fluid pressures of $0.1 \mathrm{MPa}$ and $1 \mathrm{MPa}$ are applied on the left and right edges respectively. It is also assumed that the lubricant amount is always enough to fill the gap between the surfaces. The difference in surface topographies is clearly visible. The maximum asperity height for the contacting situation is smaller than in the non-contacting situation due to asperity deformation. For the non-contacting situation, the pressure distribution is smoother than in the contacting situation, indicating less influence of surface roughness on the flow. For the contacting situation, the fluid pressure is zero (black patches in Figure 5.7d and 5.7f) at the surface points which are in contact with the tool (black patches in Figure 5.7c and 5.7e). In this case, the fluid flows through open and connected channels. As the asperity deformations increase, the flow channels start to become isolated and inactive, which reduces the flow. Therefore, in the contacting situation, the effect of roughness is higher.

The results of pressure and shear flow factors are plotted as a function of $h_{\mathrm{avg}} / \mathrm{Sq}$ in Figure 5.8 for measured Gaussian and bimodal surfaces. $\Phi_{\mathrm{P}}$ (in this case $\Phi_{\mathrm{P} x x}$ ) approaches unity at higher mean separation of contacting surfaces (see Figure 5.8a). This is because at higher mean separation the influence of roughness on flow is less, which means $Q_{\text {rough }}$ approaches $Q_{\mathrm{smooth}}$. It is interesting to note that for a bimodal surface, $\Phi_{\mathrm{P}}$ is more uniform for $h_{\mathrm{avg}} / \mathrm{Sq}>3$ and decreases sharply for the contacting situation $\left(h_{\mathrm{avg}} / \mathrm{Sq}<3\right)$. However, for a Gaussian surface the transition is smooth between the contacting and non-contacting situations. This clearly shows the dependency of flow factors on surface topography and surface height distribution. The rate of increase in surface contact points with an increase in tool displacement is more gradual for the Gaussian surface than for the bimodal surface. This can be understood from the surface height distribution shown in Figure 5.6: note the slope of the height distribution curves on the right side. Consequently, $Q_{\text {rough }}$ and hence the flow factors decrease more sharply for the bimodal surface than for the Gaussian surface for contacting situations $\left(h_{\mathrm{avg}} / \mathrm{Sq}<3\right)$. This also suggests that the open flow channels start to disappear more quickly in the bimodal surface than 

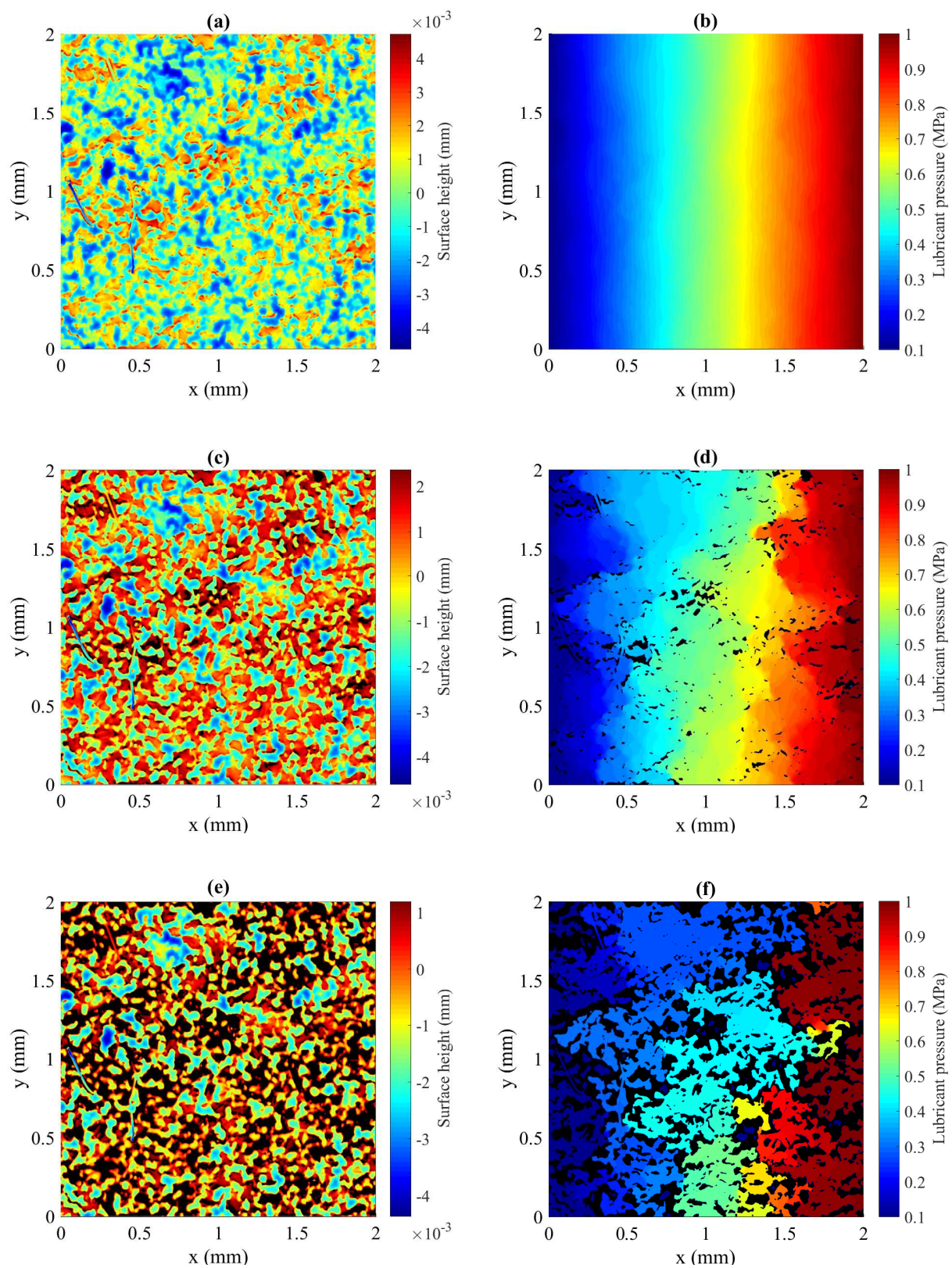

Figure 5.7 Surface topography and fluid pressure distribution for measured bimodal surface under pressure flow factor boundary conditions at (a,b) $h_{\text {avg }} / S q=6.0$ (c,d) $h_{\text {avg }} / S q=1.5$ (e,f) $h_{\text {avg }} / S q=0.8$ 
(a)

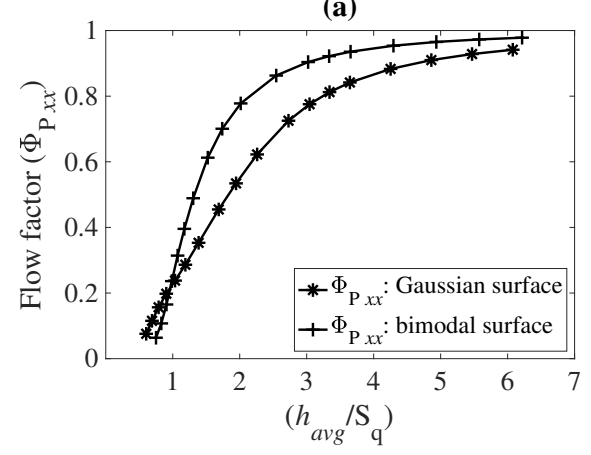

(b)

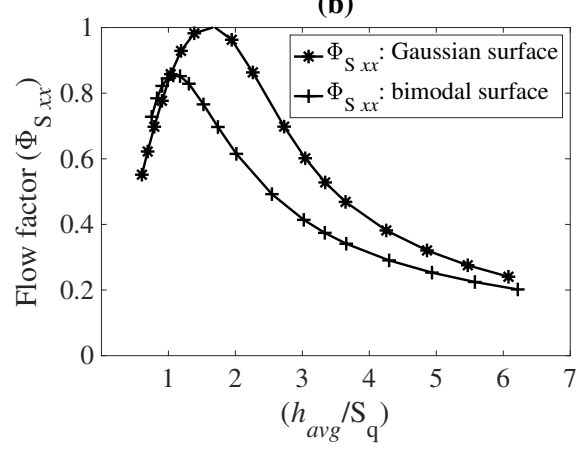

Figure 5.8 Pressure $\left(\Phi_{\mathrm{P} x x}\right)$ and shear $\left(\Phi_{\mathrm{S} x x}\right)$ flow factors for a measured Gaussian and bimodal surfaces.

for the Gaussian surface.

Similarly to the pressure flow factor, the effect of surface topography and height distribution on the shear flow factor $\Phi_{\mathrm{S}}$ (in this case $\Phi_{\mathrm{S} x x}$ ) is shown in Figure 5.8b. For both surfaces, $\Phi_{\mathrm{S}}$ approaches slowly to zero as $h_{\mathrm{avg}} / \mathrm{Sq}$ increases. There is a rise in $\Phi_{\mathrm{S}}$ as $h_{\mathrm{avg}} / \mathrm{Sq}$ decreases up to a certain value of $h_{\mathrm{avg}} / \mathrm{Sq}$ and then it decreases rapidly. This trend matches well with the results obtained by $[60,67,86]$. At lower $h_{\mathrm{avg}} / \mathrm{Sq}$, the sudden drop in $\Phi_{\mathrm{S}}$ is due to the increasing number of contact points. Contact points permit no flow, hence the shear flow factor decreases because of the sudden change in the available flow area.

\subsection{Mixed lubrication friction for forming pro- cesses}

In forming processes, the sheet surfaces are usually lubricated. Consequently, the contact condition at the tool-workpiece interface may fall in the mixed lubrication regime. In the mixed lubrication regime, the total friction force depends on the contribution from direct asperity contact and the viscous shear stresses developed in the lubricant. The topographies of the tool and workpiece surfaces, contact loads, materials and lubricant influence the contact conditions and coefficient of friction. The shear stress contribution from direct asperity contact is determined using the boundary friction model. These solid-solid contact shear stresses are coupled with the viscous shear stresses due to a hydrodynamic pressure in the lubricant to determine the total shear stress and overall coefficient of friction. 


\subsubsection{Coefficient of friction in mixed lubrication}

The boundary friction model is used to determine the friction forces due to direct asperity contact. The first step in the boundary friction model is to determine the deformed state of the workpiece during forming from which the real area of contact and contact patches are determined using the asperity flattening models. Refer to Chapters 2-4 for details on the flattening models for different loading conditions and the approach to determine the contact patches. The shear force at each contact patch is determined by adapting a single asperity friction model. For this purpose, the rigid single asperity model of elliptical paraboloid shape ploughing through a softer substrate proposed by Mishra et al. [41] is used. The model accounts for realistic 3D shapes of an asperity and asperity orientation relative to the sliding direction. Chapter 4 describes the multiscale boundary lubrication regime friction model by adapting the single asperity model. In this study, this model is used to determine the shear stress contribution and therefore the coefficient of friction from direct asperity contact.

The mixed lubrication friction model is implemented in an FE code which is used for forming simulations. The coefficient of friction due to direct asperity contact depends on the contact loads such as contact pressure and equivalent strain $[1,87]$. In the FE simulation, the contact loads change at each time increment which means that the coefficient of friction also evolves. However, running a friction model at each $\mathrm{FE}$ node for each time increment is computationally expensive. Therefore, a look-up or interpolation table is generated which is a database of shear stress values due to direct asperity contact for a range of contact pressures and equivalent plastic strains. To account for the effect of lubricant pressure, the average Reynolds Equation (5.3) is solved over the full $\mathrm{FE}$ domain. The inputs required to solve the average Reynolds equation are lubricant properties (viscosity), relative velocities of the tool and workpiece, $h_{\mathrm{avg}}, \Phi_{\mathrm{P}}$ and $\Phi_{\mathrm{S}}$ at each node of the FE mesh. The nodal values of $h_{\mathrm{avg}}, \Phi_{\mathrm{P}}$ and $\Phi_{\mathrm{S}}$ depend on the deformed state of the workpiece and vary during each time increment. Therefore, $h_{\text {avg }}$ is also determined for a range of contact pressures and equivalent strains. This is possible because the deformed state of the workpiece and real area of contact can be determined using the flattening models for range of contact pressures and equivalent strains. Using a deformed state of the workpiece, $h_{\text {avg }}$ is determined as described in Section 5.3.5. Furthermore, the flow factors $\Phi_{\mathrm{P}}$ and $\Phi_{\mathrm{S}}$ are determined at different values of $h_{\mathrm{avg}} / \mathrm{Sq}$ using offline flow factor simulations as described in Section 5.3. The real area of contact 
$(\alpha), h_{\mathrm{avg}}, \Phi_{\mathrm{P}}$ and $\Phi_{\mathrm{S}}$ are also stored in the look-up table for a range of contact pressures and equivalent strains.

The look-up table is passed on to the FE simulation as an input. A coupling approach used by Hol et al. [71] is adapted in the FE code. In the mixed lubrication regime, the total contact pressure $P_{\text {nom }}$ is shared between the solid-solid asperity contact pressure $P_{\text {sol }}$ and lubricant pressure $P_{\text {lub }}$. The lubricant pressure is determined for each node at each FE increment by solving the average Reynolds equation. $P_{\text {sol }}$ is determined at each node by subtracting $P_{\text {lub }}$ from the total contact pressure $P_{\text {nom }}$ which is read from FE results.

$$
P_{\text {sol }}=P_{\text {nom }}-P_{\text {lub }}
$$

It should be noted that $P_{\text {lub }}$ from the previous increment is used to determine $P_{\text {sol }}$ for the current increment. This means the fluid film thickness $h_{\text {avg }}$ and velocity vectors of workpiece $v_{1}$ and tool $v_{2}$ are used from the previous increment as well. This is considered a reasonable assumption for a small FE increment.

The nodal shear stress $\tau_{\text {solid }}$ due to direct asperity contact at nodal contact pressure $P_{\text {sol }}$ and equivalent plastic strain $\varepsilon_{\mathrm{eq}}$ is determined using a look-up table by linear interpolation. The lubricant viscous shear stress $\tau_{\text {visc }}$ at each node is obtained from the lubricant pressure field of the previous iteration. The viscous shear stress developed in the Newtonian fluid is determined as [72]

$$
\tau_{\text {visc }}=\eta \frac{\partial v}{\partial z}=\eta \frac{\left(v_{2}-v_{1}\right)}{h_{\mathrm{avg}}}+\frac{\left(2 z-h_{\mathrm{avg}}\right)}{2} \Delta P_{\mathrm{lub}}
$$

where $\tau_{\text {visc }}$ is the shear stress at height $z$ from the surface. The shear stress at workpiece-fluid interface $\tau_{\mathrm{lub}_{1}}$ and tool-fluid interface $\tau_{\mathrm{lub}_{2}}$ can be determined as

$$
\begin{aligned}
& \tau_{\text {lub }_{1}}=\eta \frac{\left(v_{2}-v_{1}\right)}{h_{\text {avg }}}-\frac{h_{\text {avg }}}{2} \Delta P_{\text {lub }} \\
& \tau_{\text {lub }_{2}}=\eta \frac{\left(v_{2}-v_{1}\right)}{h_{\text {avg }}}+\frac{h_{\text {avg }}}{2} \Delta P_{\text {lub }}
\end{aligned}
$$

The total shear stress $\tau_{\text {tot }}$ at workpiece FE node due to viscous shear stress $\tau_{\text {lub }_{1}}$ and shear stress from direct asperity contact $\tau_{\text {solid }}$ is determined:

$$
\tau_{\text {tot }}=\alpha_{\text {sol }} \tau_{\text {sol }}+\left(1-\alpha_{\text {sol }_{1}}\right) \tau_{\text {lub }_{1}}
$$

where $\alpha_{\text {sol }}$ is the fractional real area of contact and $\left(1-\alpha_{\text {sol }}\right)$ is the fluid film area. The nodal value of $\alpha_{\text {sol }}$ is interpolated from the look-up table at 
nodal contact pressure $P_{\text {sol }}$ and equivalent plastic strain $\varepsilon_{\mathrm{eq}_{\mathrm{pl}}}$. Finally, the local nodal coefficient of friction $\mu_{\text {tot }}$ combining the effects of direct asperity

Do $i=1: n$ (total number of $\mathrm{FE}$ increments)

if $i=1$

$$
\left(h_{\mathrm{avg}}\right)_{i},\left(v_{1}\right)_{i},\left(v_{2}\right)_{i},\left(P_{\mathrm{lub}}\right)_{i}=0
$$

else

$$
\left(h_{\mathrm{avg}}\right)_{i}=\left(h_{\mathrm{avg}}\right)_{i-1},\left(v_{1}\right)_{i}=\left(v_{1}\right)_{i-1},\left(v_{2}\right)_{i}=\left(v_{2}\right)_{i-1}
$$

end if

step1: solve for $\left(P_{\text {nom }}\right)_{i},\left(P_{\text {sol }}\right)_{i},\left(P_{\text {lub }}\right)_{i},\left(\tau_{\text {lub }}\right)_{i}$

- determine $\left(P_{\mathrm{nom}}\right)_{i},\left(\varepsilon_{\mathrm{eq}_{\mathrm{pl}}}\right)_{i}$ from FE contact algorithm

$-\operatorname{read}\left(\Phi_{\mathrm{P}}\right)_{i-1},\left(\Phi_{\mathrm{S}}\right)_{i-1}$ at $\left[\left(h_{\mathrm{avg}}\right)_{i-1} / \mathrm{Sq}\right]$

- solve Equation (5.3) for $\left(P_{\text {lub }}\right)_{i}$ using $\left(\Phi_{\mathrm{P}}\right)_{i-1},\left(\Phi_{\mathrm{S}}\right)_{i-1},\left(h_{\mathrm{avg}}\right)_{i-1},\left(v_{1}\right)_{i-1},\left(v_{2}\right)_{i-1}$

- determine $\left(\tau_{\text {lub }_{1}}\right)_{i}$ using Equation (5.26)

- determine $\left(P_{\text {sol }}\right)_{i}=\left(P_{\text {nom }}\right)_{i}-\left(P_{\text {lub }}\right)_{i}$

step2: determine $\left(\tau_{\mathrm{sol}}\right)_{i}$ using boundary friction model at $\left(P_{\mathrm{sol}}\right)_{i}$ and $\left(\varepsilon_{\mathrm{eq}_{\mathrm{pl}}}\right)_{i}$

step3: determine $\left(\tau_{\text {tot }}\right)_{i}$ and $\left(\mu_{\text {tot }}\right)_{i}$ using Equations (5.28) and (5.29)

step4: update variables for next increment

- update variables $\left(v_{1}\right)_{i}$ and $\left(v_{2}\right)_{i}$ from the results of $\mathrm{FE}$ contact algorithm

- update variables $\left(h_{\text {avg }}\right)_{i}$ (interpolated from look-up table at $\left(P_{\mathrm{sol}}\right)_{i}$ and $\left.\left(\varepsilon_{\mathrm{eq}}\right)_{i}\right)$

$$
i=i+1
$$

end do

Figure 5.9 FE solution scheme for mixed lubrication friction model. 
contact and lubricant pressure is determined.

$$
\mu_{\mathrm{tot}}=\frac{\tau_{\mathrm{tot}}}{P_{\mathrm{nom}}}
$$

$h_{\text {avg }}, v_{1}$ and $v_{2}$ are updated to be used for the next increment. An algorithm that describes the solution scheme of the mixed lubrication friction model is presented in Figure 5.9.

FE implementation of the mixed lubrication friction model is adapted from [71] to include the roughness effects. 3D wedge-shaped 9-node interface contact element with displacement degrees of freedom $(x, y, z)$ at corner nodes (6 nodes) and pressure degree of freedom $\left(P_{\text {lub }}\right)$ at mid-side nodes $(3$ nodes) is used to make a coupling between the structural and hydrodynamic part of the model [71]. The lubricant pressure distribution within the element is described by the pressure degrees of freedom.

\subsection{Experiments and validation}

Cross-die deep drawing experiments are performed with different lubricant amounts to demonstrate the applicability of the mixed lubrication friction model for metal forming processes and to validate it. The FE simulations are performed in which friction behaviour is modelled using the mixed lubrication friction model. Punch force vs. punch displacement data and strain field of the formed part are compared between the experiments and the simulations.

\subsubsection{Deep drawing experiments: cross-die}

Cross-die experiments are performed using a setup available at TATA Steel Europe. The schematic of the deep drawing setup and the product are shown in Figure 5.10. Table 5.1 shows the process parameters of the cross-die experiments. Three different lubricant amounts are chosen to investigate the influence of lubricant amount: $0.6,1.0$ and $2.0 \mathrm{~g} / \mathrm{m}^{2}$. The blank is lubricated on both sides. The surface topographies of tooling are different at different locations (punch/die). To account for this, surface height measurements are performed at different positions of the tooling to be used in the friction model. Figure 5.10 shows the surface roughness of workpiece and tools at different positions. The measured punch force vs. punch displacement is shown in Figure 5.13 for three different lubricant amounts. 
Table 5.1 Parameters of cross-die experiments.

\begin{tabular}{ll}
\hline Blank material & DC04 \\
Tool material & DIN 1.2379 \\
Blank size & $260 \times 260 \mathrm{~mm}$ \\
& Sheet thickness $=0.82 \mathrm{~mm}$ \\
Lubricant & Anticorit RP $4107 \mathrm{~S}$ \\
& Amount $=0.6,1.0$ and $2.0 \mathrm{~g} / \mathrm{m}^{2}$ \\
& Dynamic viscosity $\left(\eta_{40^{\circ}}\right)=32 \mathrm{mPas}$ \\
& Density $\left(\rho_{25^{\circ}}\right)=0.896 \mathrm{~g} / \mathrm{cm}^{3}$ \\
Blank holder force $\left(F_{b h f}\right)$ & $100 \mathrm{kN}$ \\
Punch velocity $\left(v_{\text {punch }}\right)$ & $60 \mathrm{~mm} / \mathrm{s}$ \\
Punch stroke & $58 \mathrm{~mm}$ \\
\hline
\end{tabular}
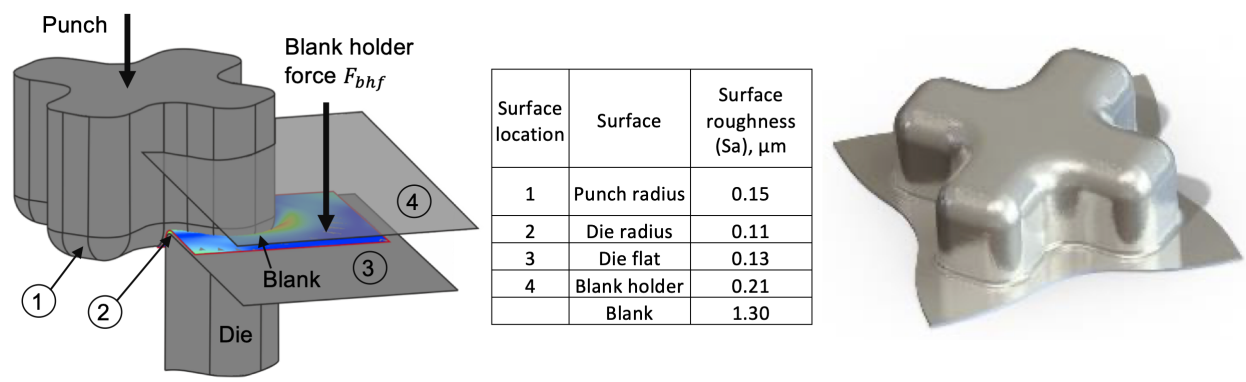

Figure 5.10 Schematic of the cross-die setup [1] and actual product.

\subsubsection{FE simulations using the new friction model}

The blank is meshed with 3 node triangular discrete Kirchhoff shell elements. The contact elements are attached on both sides of the blank mesh. The contact elements are used to couple the solution of average Reynolds equation with the boundary friction part. Due to symmetry, only a quarter of the cross-die product is modelled. The tools are assumed to be rigid. The yield surface of DC04 sheet metal is described by Vegter yield model [52] (see Table 5.2 for parameters) and the hardening behaviour is described by the Bergström-Van Liempt hardening relation [53] (see Table 5.3 for parameters).

As discussed in Section 5.4, a look-up table is used in the FE simulation as input for a computationally efficient FE simulation. Note that the tool 
Table 5.2 Vegter yield locus parameters for DC04.

\begin{tabular}{llll}
\hline Parameter & $0^{\circ}$ & $45^{\circ}$ & $90^{\circ}$ \\
\hline$R$-value & 1.92667 & 1.49433 & 2.21133 \\
Uniaxial factor $\left(f_{\mathrm{un}}\right)$ & 1 & 1.0310 & 0.9885 \\
Plane-strain factor $\left(f_{\mathrm{ps}}\right)$ & 1.248 & 1.2401 & 1.265 \\
Plane-strain ratio $(\alpha)$ & 0.599354 & 0.587015 & 0.608288 \\
Pure shear factor $\left(f_{\mathrm{sh}}\right)$ & 0.543471 & 0.56135 & 0.5398 \\
Equi-biaxial factor $\left(f_{\mathrm{bi}}\right)$ & 1.132 & & \\
Equi-biaxial ratio $\left(\rho_{\mathrm{bi}}\right)$ & 0.8988 & & \\
\hline
\end{tabular}

Table 5.3 Bergström-Van Liempt hardening parameters for $\mathrm{DCO} 4$.

\begin{tabular}{lll}
\hline Material parameter & Value & Unit \\
\hline Initial static stress $\left(\sigma_{0}\right)$ & 114.8 & $\mathrm{MPa}$ \\
Stress increment parameter $\left(\Delta \sigma_{\mathrm{m}}\right)$ & 250.34 & $\mathrm{MPa}$ \\
Linear hardening parameter $(\beta)$ & 0.25 & \\
Hardening exponent $(n)$ & 0.75 & \\
Remobilization parameter $(\omega)$ & 8.1014 & \\
Max. dynamic stress $\left(\sigma_{0}^{*}\right)$ & 600 & $\mathrm{MPa}$ \\
Initial strain $\left(\varepsilon_{0}\right)$ & 0.005 & \\
Initial strain rate $\left(\dot{\varepsilon}_{0}\right)$ & $10^{8}$ & \\
Temperature $(T)$ & 300 & $\mathrm{~K}$ \\
Dynamic stress power $(m)$ & 2.2 & \\
Activation energy $\left(\Delta G_{0}\right)$ & 0.8 & $\mathrm{~J}$ \\
Boltzmann's constant $\left(\kappa_{\text {Bolz }}\right)$ & $8.617 \times 10^{-5}$ & $\mathrm{eV}$ \\
\hline
\end{tabular}

topography is different at different locations, which affects the frictional behaviour. Therefore, look-up tables are generated separately for the different tool topographies that are measured at key locations of the die, punch and blank holder (see Figure 5.10). The workpiece topography is the same for all tool positions. The boundary friction model is run separately for each tool-workpiece surface combination. Similarly, the flow factors are determined separately for each tool-workpiece surface combination. The results for all tool-workpiece combinations are stored in the separate lookup tables. At each FE increment, the positions of the tool in contact with the blank nodes are identified to use a correct look-up table corresponding 
to the identified tool and its position. The effect of lubricant amount is considered in the simulations. The nodal average fluid film thickness $h_{\text {avg }}$ is compared with the available fluid film thickness $h_{\text {inp }}$ determined based on the lubricant amount per unit sheet surface area. For, $h_{\text {inp }}>=h_{\text {avg }}$, the available lubricant amount is enough to fill the surface pockets of the sheet surface therefore, the mixed lubrication condition prevails and the overall coefficient of friction is determined as described in Section 5.4.1 and applied to a workpiece node. For, $h_{\text {inp }}<h_{\text {avg }}$, the lubricant starvation condition occurs. In this case, the total friction force is determined based on the boundary friction model only and $P_{\text {lub }}$ is set to zero. In this study, the squeeze term $\left(\partial h_{\mathrm{avg}} / \partial t\right)$ is neglected during the solution of the average Reynolds equation, because a quasi-static situation is assumed during a forming process. Furthermore, a lubricant can permeate through the micro gaps present between the tool and the workpiece surface, thereby reducing the lubricant squeeze effect.

\subsubsection{FE results and comparison with experiments}

The simulations are performed for lubricant amounts of $0.6,0.1$ and $2.0 \mathrm{~g} / \mathrm{m}^{2}$. Figures 5.11 and 5.12 show the results of the simulations for the die side of the blank for lubricant amounts of 0.6 and $2.0 \mathrm{~g} / \mathrm{m}^{2}$ respectively at a punch displacement of $58 \mathrm{~mm}$. It should be noted that the lubricant amount of $0.6 \mathrm{~g} / \mathrm{m}^{2}$ is too low to fill the surface pockets of the rough workpiece. Therefore, a boundary lubrication regime exists. For a lubricant amount of $1.0 \mathrm{~g} / \mathrm{m}^{2}$, a combination of boundary and mixed lubrication regimes exists. However, the lubricant amount $2.0 \mathrm{~g} / \mathrm{m}^{2}$ is enough to fill the surface pockets, which ensures a mixed lubrication regime. This is validated by checking the lubricant starvation condition $\left(h_{\mathrm{inp}}<h_{\text {avg }}\right)$ at each node, therefore no lubricant pressure develops in the case of $0.6 \mathrm{~g} / \mathrm{m}^{2}$. In this case, the coefficient of friction is determined using only the boundary friction model.

The friction force due to direct asperity contact is the sum of friction force due to ploughing of the tool asperities through the sheet and the friction force due to shearing of the lubricant boundary layer formed on the lubricated sheet surface [41]. The lubricant boundary layer shear strength $\left(\tau_{\mathrm{BL}}\right)$ is required in the boundary friction model. Dedicated experiments are required to determine the boundary layer shear strength for any specific combination of lubricant and workpiece material. It is often described as $\tau_{\mathrm{BL}}=c_{0} P_{0}^{m}$ [50], where $P_{0}=\left(P_{\text {nom }} / \alpha\right), \alpha$ is the real area of contact and $c_{0}$, $m$ are constants. The boundary layer shear strength for the lubricant used in the experiments is not available. Therefore, the parameters $c_{0}=11.2$ and 

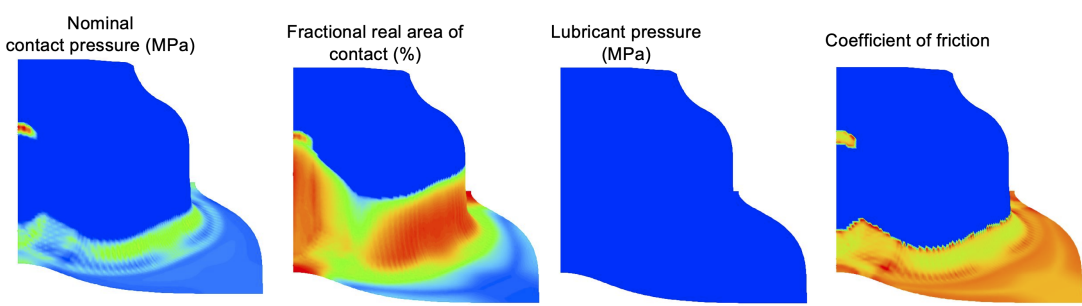

0

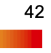

0

$32 \quad 0$

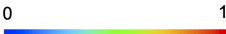

0.1

0.18

Figure 5.11 Cross-die simulation results (die side) for lubricant amount of $0.6 \mathrm{~g} / \mathrm{m}^{2}$ and punch displacement of $58 \mathrm{~mm}$.
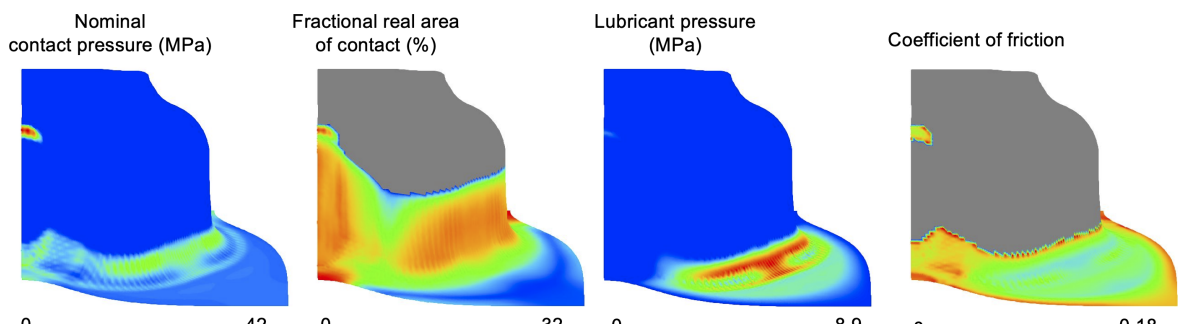

0

0

8.9

0

0.18
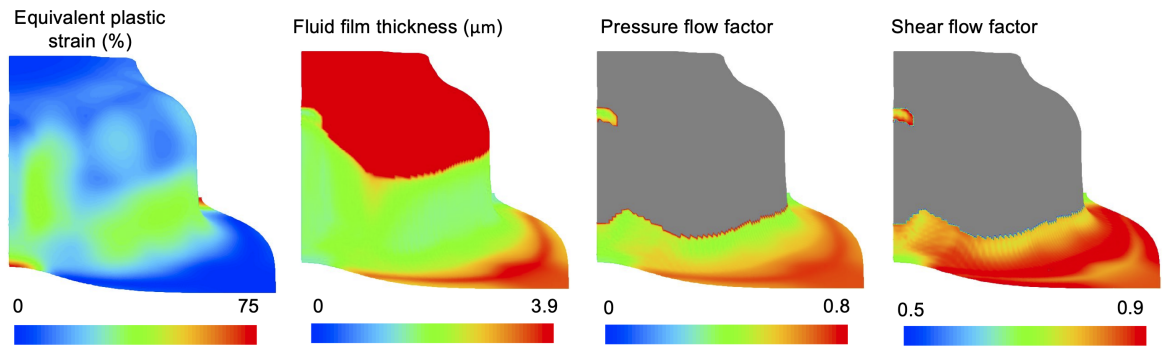

Figure 5.12 Cross-die simulation results (die side) for lubricant amount of $2.0 \mathrm{~g} / \mathrm{m}^{2}$ and punch displacement of $58 \mathrm{~mm}$.

$m=0.75$ are fitted for the case of $0.6 \mathrm{~g} / \mathrm{m}^{2}$ by minimizing the difference in punch force vs. displacement curve as shown in Figure 5.13. Note that the parameters are fitted only for a lubricant amount of $0.6 \mathrm{~g} / \mathrm{m}^{2}$ and maintained at the same value for a lubricant amounts of $1.0 \mathrm{~g} / \mathrm{m}^{2}$ and $2.0 \mathrm{~g} / \mathrm{m}^{2}$.

The real area of contact is high in the die corner region due to high contact pressure and strain, which results in a higher asperity deformation and smaller mean separation $\left(h_{\mathrm{avg}} / \mathrm{Sq}\right)$ between the tool and the workpiece. 
Consequently, the effect of surface roughness is higher, which is indicated by the smaller pressure flow factor $\left(\Phi_{\mathrm{P}}\right)$ (see Figure 5.12). For lubricant amounts of $1.0 \mathrm{~g} / \mathrm{m}^{2}$ and $2.0 \mathrm{~g} / \mathrm{m}^{2}$, the lubricant pressure is developed. The lubricant pressure developed is due to the wedge effects at the toolworkpiece contacts [71] and roughness effects. The wedge formation occurs due to the inhomogeneous distribution of contact loads resulting in nonuniform deformation of the workpiece asperities. Furthermore, the surface texture offers an additional resistance to the flow which is captured by the average Reynolds equation. A maximum lubricant pressure is developed around the die corner region (see Figure 5.12). Due to the developed lubricant pressure for lubricant amounts of $1.0 \mathrm{~g} / \mathrm{m}^{2}$ and $2.0 \mathrm{~g} / \mathrm{m}^{2}$, the coefficient of friction is less than in the results of $0.6 \mathrm{~g} / \mathrm{m}^{2}$ lubricant amount especially in the die corner region.

The punch force vs. punch displacement data is extracted from the simulations and compared with the experiments, as shown in Figure 5.13. The model is able to capture the influence of lubricant amount. The punch force is lower for the lubricant amounts of $1.0 \mathrm{~g} / \mathrm{m}^{2}$ and $2.0 \mathrm{~g} / \mathrm{m}^{2}$ than for the lubricant amount of $0.6 \mathrm{~g} / \mathrm{m}^{2}$ which is captured fairly well by the model. The maximum deviation is observed at a punch displacement of $25-35 \mathrm{~mm}$. During the process, the contact pressure in the die corner region increases with the increase in punch displacement and achieves a maximum at a punch

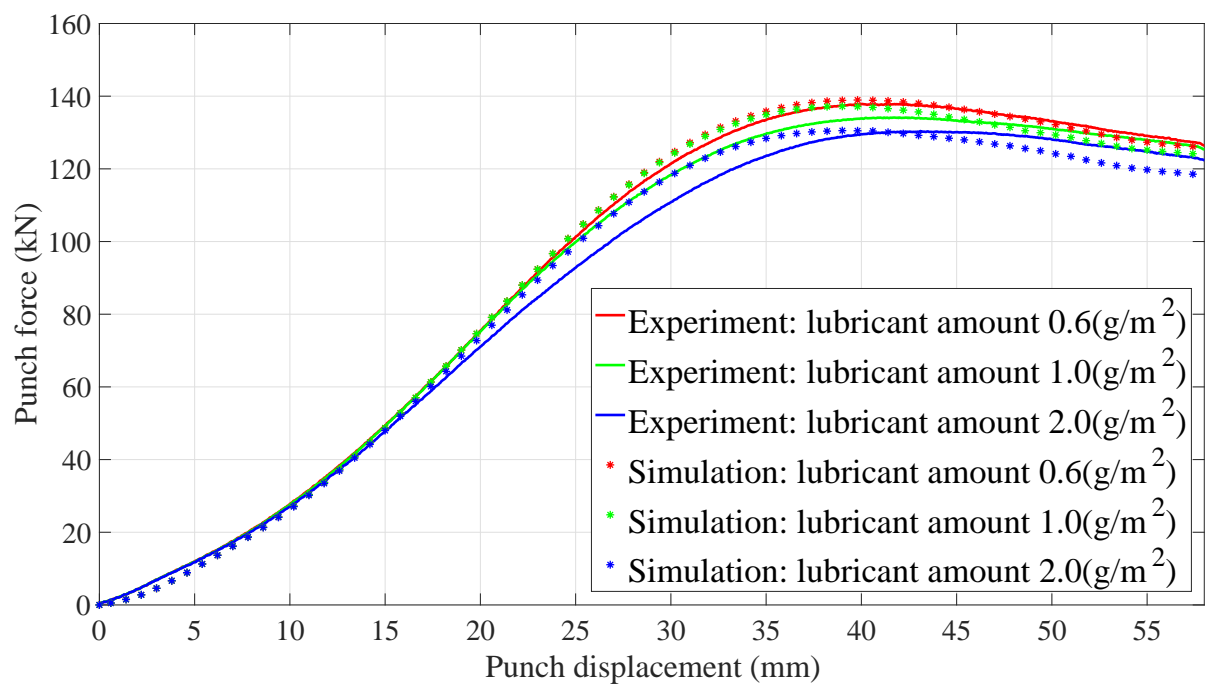

Figure 5.13 Experiments and friction model: punch force vs. punch displacement. 
Experiment

(a) Punch displacement $=40 \mathrm{~mm}$

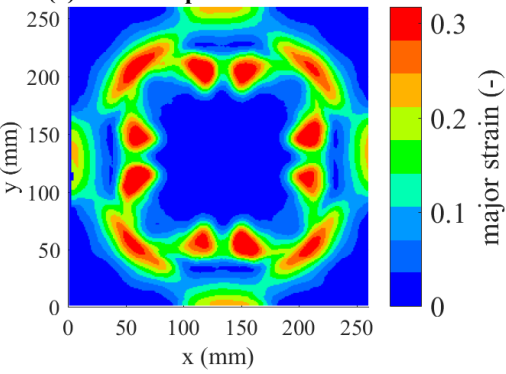

(c) Punch displacement $=40 \mathrm{~mm}$

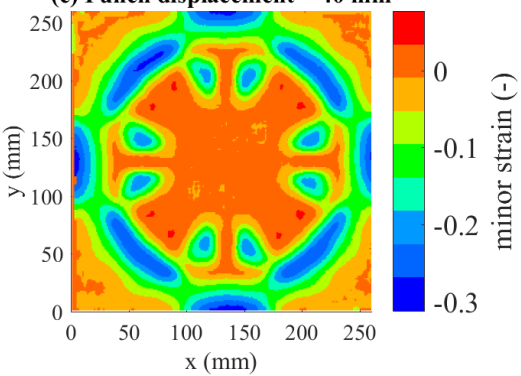

(e) Punch displacement $=\mathbf{5 8} \mathrm{mm}$

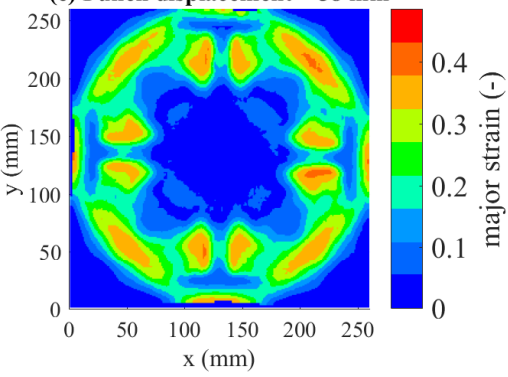

(g) Punch displacement $=58 \mathrm{~mm}$

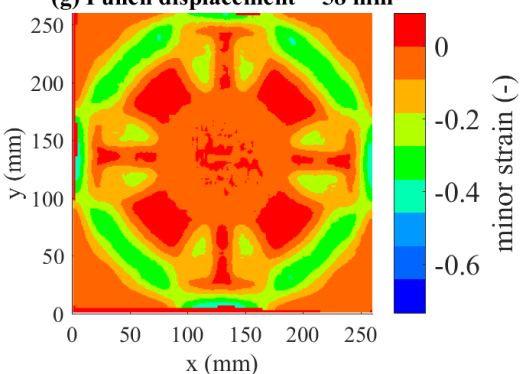

Simulation

(b) Punch displacement $=40 \mathrm{~mm}$

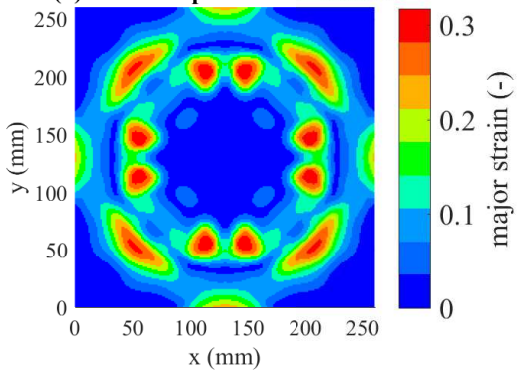

(d) Punch displacement $=40 \mathrm{~mm}$

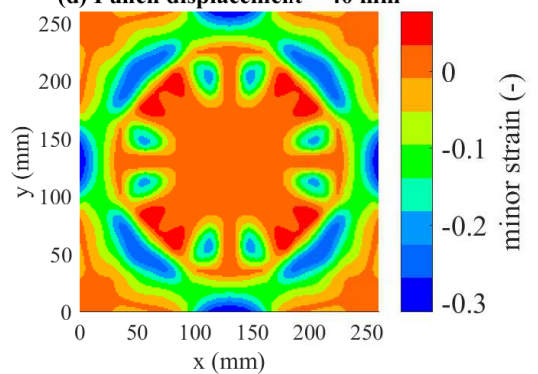

(f) Punch displacement $=58 \mathrm{~mm}$

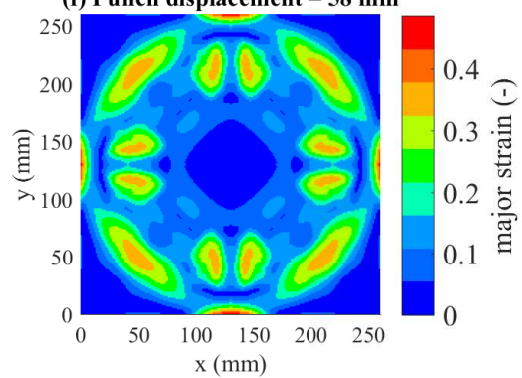

(h) Punch displacement $=58 \mathrm{~mm}$

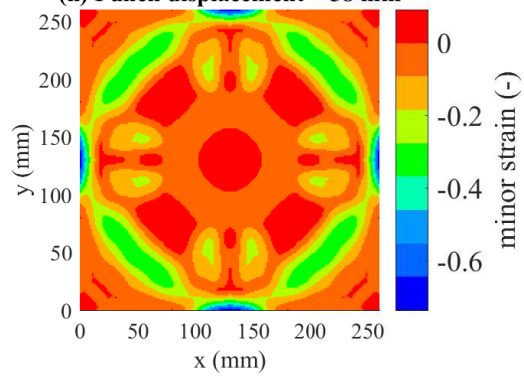

Figure 5.14 Comparison of major and minor strain distributions between the exepriments and simulations. $(a, b, c, d)$ Punch displacement $=$ $40 \mathrm{~mm}$. (e,f,g,h) Punch displacement $=58 \mathrm{~mm}$. 
displacement of around $35 \mathrm{~mm}$, after which it stabilizes. Due to this, the mean separation between the tool and the workpiece decreases quite quickly up to a punch displacement of $35 \mathrm{~mm}$, allowing less time for the lubricant to escape. Therefore, the squeeze effect may become significant at a punch displacement of $25-35 \mathrm{~mm}$ but later (at a higher punch displacement) the effect dies out as the contact pressure stabilizes.

The full-field optical strain measurements were performed on a formed product at a lubricant amount of $1.0 \mathrm{~g} / \mathrm{m}^{2}$ [88]. Before forming, the blank was electrochemically etched to create a grid pattern. The major and minor strains are measured at punch displacements of $40 \mathrm{~mm}$ and $58 \mathrm{~mm}$. The measured strain distributions are mapped to the undeformed configuration and compared with the results from simulations. Figure 5.14 shows the comparison in an undeformed configuration. The results show that the strain distribution predicted by the simulation correlates very well with the experiments, demonstrating the accuracy and applicability of the coupled friction model. Overall, the friction model offers a good potential to include the effects of lubricant type, lubricant amount and surface texture. This study also shows the applicability of the developed model for industrial-scale forming simulations.

\subsection{Summary and conclusions}

A mixed lubrication friction model including roughness effects is developed. Measured surface topographies of tools and sheet surfaces are used to predict the friction behaviour. The results show that surface roughness has a significant effect on lubricant pressure distribution at the contact situations. The coefficient of friction based on local contact conditions and the tribological system is determined by the mixed lubrication model. The effects of direct asperity contact and lubricant pressure are coupled to determine the coefficient of friction in the mixed lubrication regime. The roughness effects are accounted for by solving the average Reynolds equation for which the flow factors are determined on measured sheet and tool surfaces. The model is implemented in an (in-house) FE code for forming simulations. The results show that the proposed model is able to capture the effect of the lubricant amount. The applicability of the model for FE forming simulations is demonstrated by comparing the simulation results with experiments. 


\section{Chapter 6}

\section{Modelling textured surfaces and study of friction}

Sheet surface texture has a direct relationship with paint appearance and its tribological performance in forming. In forming processes, variations in tribological systems due to tool wear and inhomogeneous distribution of lubricant can lead to an undesirable variation in friction. In this chapter, the influence of surface texture parameters on friction is analysed. Surfaces textured by electro-discharge textured (EDT) rolls and laser textured surfaces (LT) are considered. For different surface textures, the change in coefficient of friction (COF) due to variation in tool roughness at different lubricant amounts is studied. For this purpose, textured surfaces are generated numerically by varying different texture parameters. The results show that it is possible to determine the surface texture parameters to reduce the variation in COF within a specific range of tool roughness and lubricant amount. Furthermore, a case study is presented in which deep drawing simulations using generated EDT sheet surfaces of different textures are performed to understand the robustness in friction relative to tool roughness at different lubricant amounts.

Section 6.2 describes the model to generate a LT surface for given texture parameters. Section 6.3 describes a virtual strip-draw test used to estimate the coefficient of friction (COF) of generated LT surfaces. The influence of texture parameters on COF and robustness in friction is discussed in Section 6.3.1. In a similar way to the study of LT surfaces, the modelling

This chapter is based on the publication: M.P. Shisode, J. Hazrati, T. Mishra, M.B. de Rooij and A.H. van den Boogaard, "Design of EDT surface texture for robust friction behavior" (In preparation). 
of EDT surfaces is described in Section 6.4 followed by the discussion on $\mathrm{COF}$ and robustness in friction in Section 6.5. To confirm the relationship between EDT surface texture parameters and robustness in friction, FE simulations of cross-die products are performed using different EDT surfaces as presented in Section 6.6.

\subsection{Introduction}

Sheet surface texturing is critical in steel industry because it affects its tribological performance [85, 89, 90], product formability and paint appearance [91, 92]. There are different methods of applying texture, such as electro-discharge texturing (EDT) [93, 94], electron beam texturing (EBT) [90] and laser texturing (LT) [95, 96]. Of all these methods EDT is commonly used in industry. The resulting surface texture has a semideterministic topography. Recently, deterministic surface textures produced by LT processes $[95,96]$ gained increasing attention because this allows better control of resulting surface topography and hence better prediction of tribological performance. LT method is not yet implemented for mass production but, the controlled surface topography offered by this method has triggered a huge motivation to develop mass production techniques.

The surface statistical parameters such as roughness, waviness and peak count are important considerations that influence the paint appearance and tribological performance. These parameters are maintained within a certain range determined based on past experience and customer requirements. The friction behaviour of textured surface is an important aspect in surface texturing. In literature, the friction behaviour of deterministic surfaces has been investigated to understand the influence of different texture parameters on COF [85, 97-100]. However, most of the modelling and experimental work focuses on the full film lubrication regime. Also, studies have been performed on EDT surfaces $[85,101,102]$ but these are not specifically aimed at understanding the influence of texture parameters. Boundary and mixed lubrication regimes are present in forming processes. Therefore, it is necessary to understand the friction behaviour of textured surfaces in these regimes. The tribological system at the tool-sheet metal interface varies between the product batches and sometimes between consecutive components. The tribological system in this case consists of lubricant (type and amount), the surface topographies of tool and sheet metal and their materials. Normally, the sheet surfaces are lubricated with a predefined amount of lubricant. However, the lubricant distribution may 
become inhomogeneous due to lubricant migration over time. The tool surface topography also evolves due to tool wear, thereby changing the friction at tool-sheet metal contacts. Furthermore, the temperature rise in tooling during production influences the friction. All these variations affect the friction, which may lead to part-to-part variation and sometimes failure. Controlling the friction under such variations is one of the important factors for improving the productivity. It is very well understood that the surface texture plays an important role in friction. For instance, the surface pockets of the LT surface can act as a lubricant reservoir where hydrodynamic pressure can build up resulting in low COF. Therefore, it is important to understand the influence of texture parameters on friction under realistic deep drawing conditions. Therefore, the surface texture which is less sensitive to the inevitable uncertainties in tribological systems is desired. This ensures that the tribological system is robust enough to minimize part-to-part variations and defects.

In this chapter, a methodology to generate LT and EDT surfaces is presented. A practical range of texture parameters is chosen such that the resulting sheet surface topographies are realistic, as used in forming applications. Numerical experiments are designed to give an understanding of the influence of texture parameters on friction using generated surfaces. The study is performed at different lubricant amounts and tool surface topographies (roughness) to determine the robustness of textured surface in friction. For this purpose, a virtual strip-draw test is simulated using $\mathrm{FE}$ analysis to estimate the COF. The FE simulation is able to account for boundary and mixed lubrication regimes. The friction look-up table required as input for FE simulation is generated for each surface. The flow factors required for the mixed lubrication regime are generated using the method described in Chapter 5. The COF estimated from the strip-draw test is presented as a function of texture parameters. Furthermore, a case study is used to analyse robustness in the friction of EDT surfaces with respect to tool roughness at different lubricant amounts using FE simulations of the cross-die product. The forming limit diagrams (FLD) are constructed using simulation results. The difference in FLDs with respect to tool roughness is used as a measure for robust friction behaviour.

\subsection{Modelling LT surfaces}

In LT method, material is removed from the surface using high-energy laser pulses. Laser sources are available as ultrashort and nanosecond pulse 
laser. The ultrashort pulse laser sources of femtosecond and picosecond pulse duration offer higher texture accuracy and low processing time in comparison with the nanosecond pulse laser source.
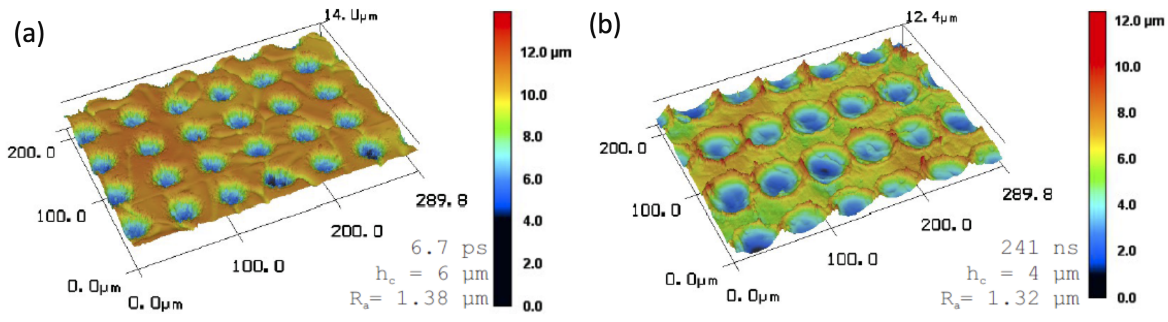

Figure 6.1 Surface topography of LT surface using (a) 6.7 picosecond laser (b) 241 nanosecond laser [96].

Figure 6.1 shows the surface topographies of LT surfaces manufactured by (a) picosecond and (b) nanosecond pulse laser. The surface textured by nanosecond pulse laser has a distinguishing ring present at the edge of cavity or dimple [96]. However, the ring does not appear for the ultrashort (femtosecond, picosecond) pulse laser. In this study, surfaces textured using an ultrashort pulse laser source are modelled to study their friction behaviour. In the steel industry, the GI sheet is further processed to apply texture after removing it from the zinc bath. The RMS surface roughness (Sq) of untextured GI sheet is normally $\leq 0.5 \mu \mathrm{m}$ [103]. The surface topography of untextured GI sheet has a unique dendritic morphology and generally has Gaussian surface height distribution. Figure 6.2 shows the surface topography and surface height distribution of measured untextured
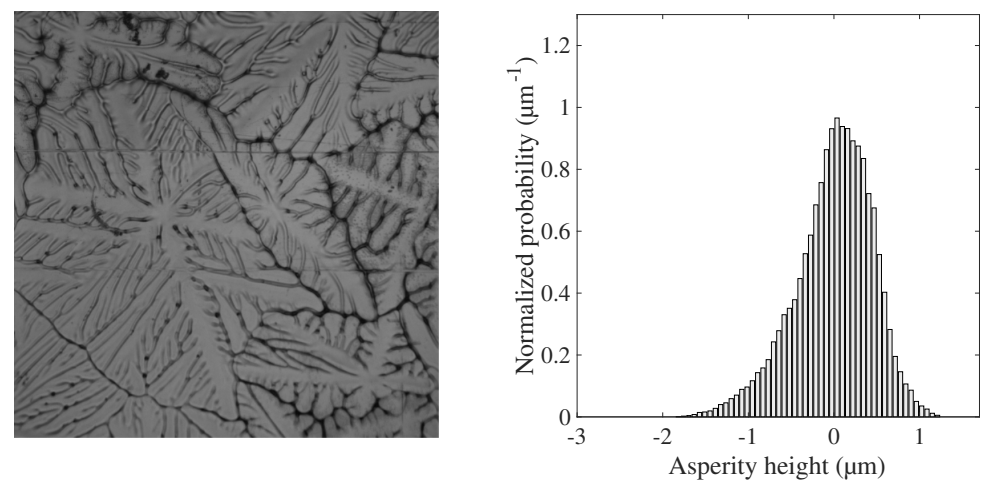

Figure 6.2 Untextured GI sheet $(2 \times 2 \mathrm{~mm})$ and its surface height distribution. 
GI sheet. In this study, the texture pattern is generated on the actual untextured surface of GI sheet obtained from confocal measurement. The texture parameters of LT surface are dimple diameter $\left(d_{\mathrm{LT}}\right)$, dimple density $\left(\rho_{\mathrm{LT}}\right)$ and dimple depth $\left(h_{\mathrm{LT}}\right)$. The dimples are assumed circular and the density is defined as the fraction of area covered by dimples.

To generate a LT surface, first a texture pattern on a flat surface is modelled. The circular dimples with a required depth are modelled as shown in Figure 6.3. The height data of each individual dimple $h_{\mathrm{LT}}(x, y)$ in a local coordinate system with origin at the centre of the dimple is determined using Equation (6.1) [104].

$$
\begin{gathered}
h_{\mathrm{LT}}(x, y)=\left\{\begin{array}{l}
0 \forall R_{\mathrm{LT}}^{2} \geqq 1 \\
\frac{d_{\mathrm{LT}}}{2}\left(\left(\frac{1}{4 \xi_{\mathrm{d}}}-\xi_{\mathrm{d}}\right)-\sqrt{\left(\xi_{\mathrm{d}}+\frac{1}{4 \xi_{\mathrm{d}}}\right)^{2}-R_{\mathrm{LT}}^{2}}\right) \forall R_{\mathrm{LT}}^{2}<1
\end{array}\right. \\
\xi_{\mathrm{d}}=\frac{h_{\mathrm{LT}}}{d_{\mathrm{LT}}}, X=\frac{2 x}{d_{\mathrm{LT}}}, Y=\frac{2 y}{d_{\mathrm{LT}}}, R_{\mathrm{LT}}=\sqrt{X^{2}+Y^{2}}
\end{gathered}
$$

Based on the required dimple diameter and dimple density, the number of dimples are determined for a given surface area; these dimples are then distributed uniformly on the surface. An exact required dimple density may not be possible at the assumed dimple diameter, in which case the closest possible density is chosen. The texture pattern is transferred to the measured untextured surface with roughness $(\mathrm{Sq})$ of $0.5 \mu \mathrm{m}$ to generate the LT surface. Figure 6.4 shows some examples of generated LT surfaces (surface height data and height distribution). The surface height distribution of the resultant LT surfaces changes from Gaussian to nonGaussian as a result of texturing.

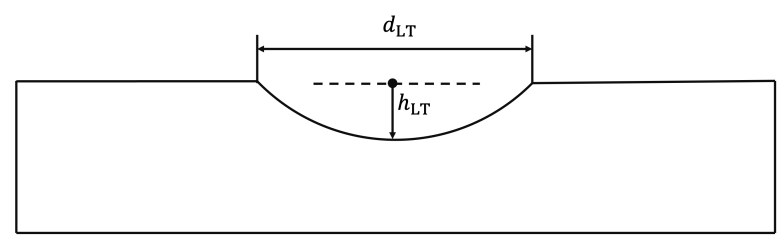

Figure 6.3 Modelled geometry of a single dimple in LT surface. 

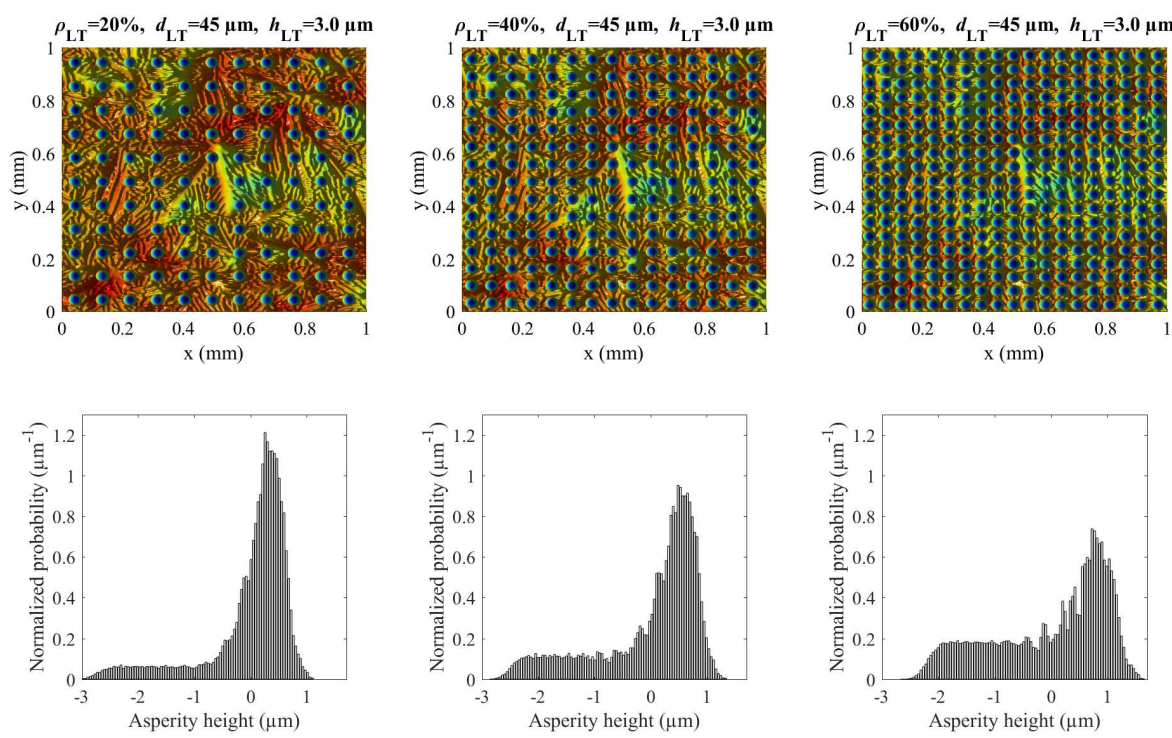

Figure 6.4 Surface height data and height distributions of the generated LT surfaces.

\subsection{Effect of LT surface parameters on friction}

The texture parameters used to generate LT surfaces are shown in Table 6.1. Two roughness levels $\left(\mathrm{Sq}_{\mathrm{wp}}=0.3\right.$ and $\left.0.5 \mu \mathrm{m}\right)$ are used for the initial untextured surface of which the surface with $\mathrm{Sq}_{\mathrm{wp}}=0.5 \mu \mathrm{m}$ is the actual measured GI surface. The surface of $\mathrm{Sq}_{\mathrm{wp}}=0.3 \mu \mathrm{m}$ is derived by scaling the surface height data of the measured GI surface. For this study, GI sheets with a coating thickness of $7 \mu \mathrm{m}$ and DX54 substrate is used.

To study the influence of texture parameters on friction, a virtual strip-draw friction test is simulated using an in-house FE code (DiekA).

Table 6.1 Texture parameters for LT surface DOE.

\begin{tabular}{lll}
\hline Parameter & Values & Unit \\
\hline Untextured sheet surface roughness $\left(\mathrm{Sq}_{\mathrm{wp}}\right)$ & $0.3,0.5$ & $\mu \mathrm{m}$ \\
Dimple diameter $\left(d_{\mathrm{LT}}\right)$ & $30,45,60$ & $\mu \mathrm{m}$ \\
Dimple area density $\left(\rho_{\mathrm{LT}}\right)$ & $20,40,60$ & $\%$ \\
Dimple depth $\left(h_{\mathrm{LT}}\right)$ & $1,3,5$ & $\mu \mathrm{m}$ \\
\hline
\end{tabular}



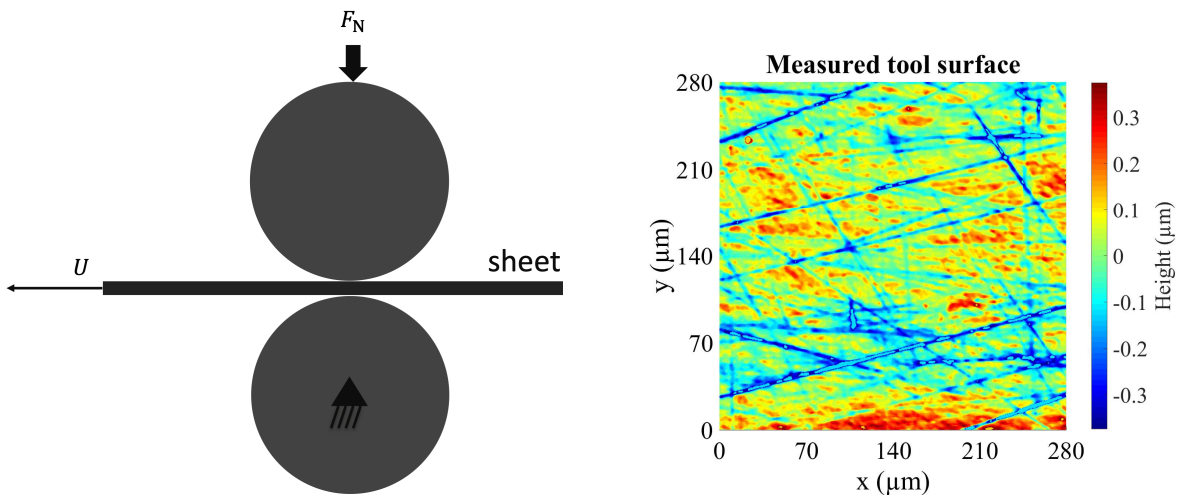

Figure 6.5 Schematic of the virtual strip-draw test and surface topography of the measured tool surface.

The schematic of the strip-draw test is shown in Figure 6.5. Besides the sensitivity analysis of different texture parameters, the effects of tool roughness and lubricant amount on friction of the textured surfaces are investigated. For this purpose, the tool height data measured at a die corner radius having roughness $\mathrm{Sq}_{\mathrm{t}}=0.1 \mu \mathrm{m}$ (see Figure 6.5 right) from the cup drawing setup (Section 4.5) is used and its measured height data is scaled to generate three different tool roughnesses $\left(\mathrm{Sq}_{\mathrm{t}}=0.04 \mu \mathrm{m}, 0.07 \mu \mathrm{m}\right.$ and $0.1 \mathrm{\mu m}$ ). The friction look-up table is generated for each LT surface of $2 \times 2 \mathrm{~mm}$ for three different tool roughnesses using the boundary friction model (Chapter 4). Different lubricant amounts are considered to realize boundary and mixed lubrication conditions in the simulations. Therefore, two different amounts of PLS100T lubricant -0.2 and $2.0 \mathrm{~g} / \mathrm{m}^{2}$ are used. The properties of PLS100T lubricant can be found in Table 4.2. The flow factors for each surface are determined separately at different deformation levels using the method described in Chapter 5. The flow factors are required as input to solve the average Reynolds equation to determine lubricant pressure in the mixed lubrication regime. The cylindrical rolls of $20 \mathrm{~mm}$ diameter are assumed rigid in FE simulations. The bottom roll is fixed while a normal load of $100 \mathrm{~N}$ is applied on the top roll. The normal load is chosen such that the maximum nominal contact pressure on the sheet is realistic as observed in typical deep drawing applications. The surface topography of top and bottom roll is assumed the same. After application of normal load, the GI sheet of thickness $1 \mathrm{~mm}$, length $15 \mathrm{~mm}$ and width $2 \mathrm{~mm}$ is pulled at a velocity of $100 \mathrm{~mm} / \mathrm{s}$ up to a total sliding length of $10 \mathrm{~mm}$. The blank is meshed with three node triangular Kirchhoff shell elements 
with an element edge length of $40 \mu \mathrm{m}$ in length direction and $80 \mu \mathrm{m}$ in width direction. The 9-node wedge shaped interface contact elements with displacement and pressure degrees of freedom [71] are attached on both sides of the shell elements. The total number of generated surfaces using a full factorial approach for the parameters given in Table 6.1 is 54. A total of six simulations are performed for each surface (three tool roughness and two lubricant amounts). The COF for each surface for assumed tool roughness and lubricant amount is determined using the ratio $\left(F_{\mathrm{sh}} / 2 F_{\mathrm{N}}\right)$, where $F_{\mathrm{sh}}$ is the total shear force.

The COF results of one such surface at different tool roughnesses and lubricant amounts are shown in Figure 6.6a. The results clearly show the influence of tool roughness and lubricant amount on COF. At a lower lubricant amount, a boundary lubrication regime is most likely to occur because the lubricant amount is not sufficient to fill rough surface valleys. Therefore, in this case a lubricant pressure is not developed. On the other hand, for a higher amount of lubricant a mixed lubrication regime is possible. In this case, a lubricant pressure is developed (see Figure $6.6 \mathrm{~b}$ ), therefore the COF is lower. The fluctuations at the beginning of the curve is observed at a lubricant amount of $2.0 \mathrm{~g} / \mathrm{m}^{2}$. This is because at the beginning the deformation of sheet surface resembles the curvature of roll with maximum deformation at the centre of the roll bite. As the sliding distance increases, the sheet surface passes through maximum contact pressure (centre of roll) and achieves maximum deformation. Therefore, the surface on the left the of roll centre has a higher deformation than on the right side. It requires certain sliding distance for deformation to stabilize. The lubricant fluid film thickness is determined from the deformed

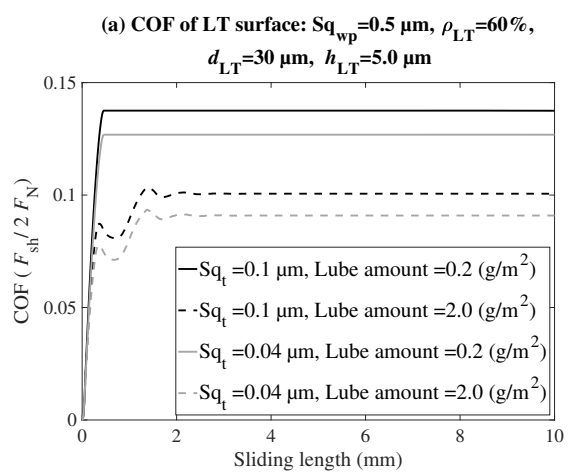

(b)

Total nominal pressure (MPa)

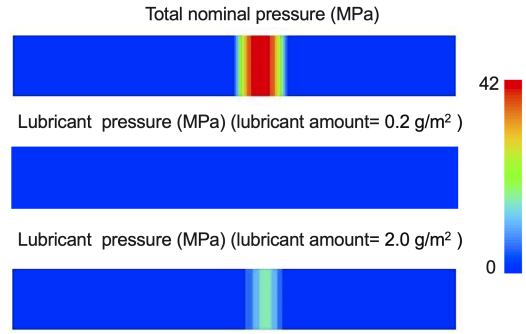

Figure 6.6 Simulation results. (a) COF of LT surface at different lubricant amounts and tool roughness. (b) Nominal and lubricant pressure at different lubricant amounts. 
state of the surface. Therefore, the developed lubricant pressure distribution stabilizes after a certain sliding distance which causes the initial fluctuation in Figure 6.6a. The COF is determined from the stable part of the curve and is used for further comparison.

\subsubsection{LT surface: results and discussion}

It should be noted that the friction model used in this study is validated for EDT sheets (See Chapter 4) and assumed to be applicable for LT surfaces. The COF results of all generated surfaces at different tool roughnesses and lubricant amounts are shown in Figure 6.7.

Figures $6.7 \mathrm{a}$ to $6.7 \mathrm{c}$ show COF results at different tool roughness, constant $\mathrm{Sq}_{\mathrm{wp}}=0.3 \mu \mathrm{m}$ and lubricant amount of $0.2 \mathrm{~g} / \mathrm{m}^{2}$. For surfaces with dimple depth $h_{\mathrm{LT}}=1 \mu \mathrm{m}$, the lubricant amount of $0.2 \mathrm{~g} / \mathrm{m}^{2}$ is enough to fill surface valleys, hence a mixed lubrication condition prevails and the COF is lower. With an increase in tool roughness, a rise in COF can be observed although the rise is not significant in the mixed lubrication regime. This can be seen in Figures 6.7d to $6.7 \mathrm{f}$ for which most of the surfaces are in mixed lubrication regime due to a higher amount of lubricant. However, the surfaces with $h_{\mathrm{LT}}=5 \mu \mathrm{m}, \rho_{\mathrm{LT}}=60 \%$ have a higher COF than other surfaces. This is because, the lubricant amount of $2.0 \mathrm{~g} / \mathrm{m}^{2}$ is still not enough for mixed lubrication regime to exist in full contact width at the tool-sheet interface. For these surfaces, the lubricant amount is enough only for the part of the contact area where the surface asperity deformation is high (high real area of contact). At such contact areas, the lubricant amount may be enough to fill the surface valleys as the asperity deformation reduces the surface roughness. The information about the real area of contact as a function contact loads (contact pressure and equivalent strain) is included in the friction look-up table (see Chapter 4 for more details). Hence, these surfaces have lubricant pressure developed only for the part of contact area. Therefore, the COF of these surfaces is higher than that of other surfaces. All surfaces in Figures $6.7 \mathrm{~g}$ to $6.7 \mathrm{i}$ are in the boundary lubrication regime because of low lubricant amount and high $\mathrm{Sq}_{\mathrm{wp}}=0.5 \mu \mathrm{m}$, which results in higher surface roughness than the surfaces with $\mathrm{Sq}_{\mathrm{wp}}=0.3 \mu \mathrm{m}$. It is interesting to note that in the boundary lubrication regime the influence of texture parameters is minor. However, in general the COF increases with increase in roughness of the tool and the initial untextured workpiece. The robustness of the $\mathrm{COF}$ with respect to the change in tool roughness is estimated by determining the maximum difference in $\mathrm{COF}$ at the constant lubricant amount, i.e. the difference in $\mathrm{COF}$ at tool roughness of $0.1 \mu \mathrm{m}$ 
(a) COF : $\mathrm{Sq}_{\mathrm{wp}}=0.3 \mu \mathrm{m}, \mathrm{Sq}_{\mathrm{t}}=0.04 \mu \mathrm{m}$, Lubricant amount $=0.2\left(\mathrm{~g} / \mathrm{m}^{2}\right)$ (b) $\mathrm{COF}: \mathrm{Sq}_{\mathrm{wp}}=0.3 \mu \mathrm{m}, \mathrm{Sq}_{\mathrm{t}}=0.07 \mu \mathrm{m}$, Lubricant amount $=0.2\left(\mathrm{~g} / \mathrm{m}^{2}\right)$ (c) $\mathrm{COF}: \mathrm{Sq}_{\mathrm{wp}}=0.3 \mu \mathrm{m}, \mathrm{Sq}_{\mathrm{t}}=0.1 \mu \mathrm{m}$, Lubricant amount $=0.2\left(\mathrm{~g} / \mathrm{m}^{2}\right)$

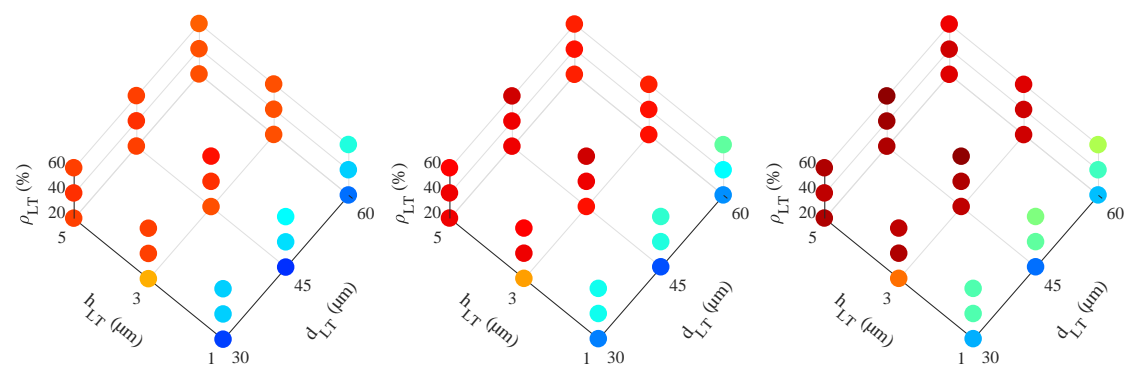

(d) COF : $\mathrm{Sq}_{\mathrm{wp}}=0.3 \mu \mathrm{m}, \mathrm{Sq}_{\mathrm{t}}=0.04 \mu \mathrm{m}$,

Lubricant amount $=2.0\left(\mathrm{~g} / \mathrm{m}^{2}\right)$

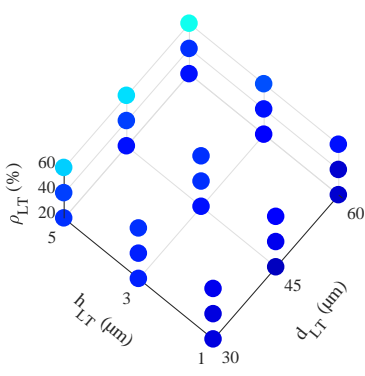

(g) $\mathrm{COF}: \mathrm{Sq}_{\mathrm{wp}}=0.5 \mu \mathrm{m}, \mathrm{Sq}_{\mathrm{t}}=0.04 \mu \mathrm{m}$,

Lubricant amount $=0.2\left(\mathrm{~g} / \mathrm{m}^{2}\right)$

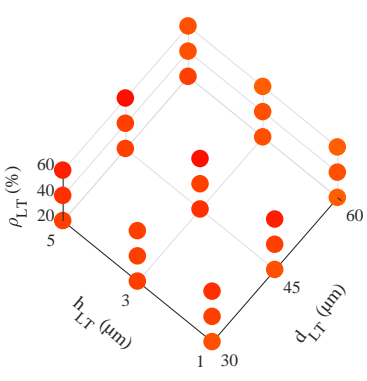

(j) COF : $\mathrm{Sq}_{\mathrm{wp}}=0.5 \mu \mathrm{m}, \mathrm{Sq}_{\mathrm{t}}=0.04 \mu \mathrm{m}$,

Lubricant amount $=2.0\left(\mathrm{~g} / \mathrm{m}^{2}\right)$ (e) $\mathrm{COF}: \mathrm{Sq}_{\mathrm{wp}}=0.3 \mu \mathrm{m}, \mathrm{Sq}_{\mathrm{t}}=0.07 \mu \mathrm{m}$,

Lubricant amount $=2.0\left(\mathrm{~g} / \mathrm{m}^{2}\right)$ (f) $\mathrm{COF}: \mathrm{Sq}_{\mathrm{wp}}=0.3 \mu \mathrm{m}, \mathrm{Sq}_{\mathrm{t}}=0.1 \mu \mathrm{m}$, Lubricant amount $=2.0\left(\mathrm{~g} / \mathrm{m}^{2}\right)$

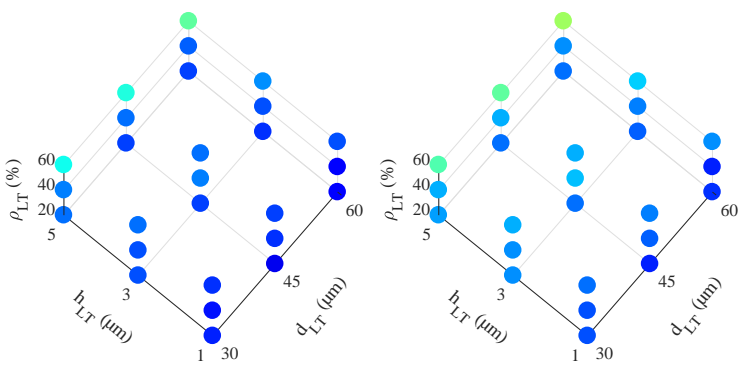

(h) COF : $\mathrm{Sq}_{\mathrm{wp}}=0.5 \mu \mathrm{m}, \mathrm{Sq}_{\mathrm{t}}=0.07 \mu \mathrm{m}$,

Lubricant amount $=0.2\left(\mathrm{~g} / \mathrm{m}^{2}\right)$

(i) $\mathrm{COF}$ : $\mathrm{Sq}_{\mathrm{wp}}=0.5 \mu \mathrm{m}, \mathrm{Sq}_{\mathrm{t}}=0.1 \mu \mathrm{m}$,

Lubricant amount $=0.2\left(\mathrm{~g} / \mathrm{m}^{2}\right)$

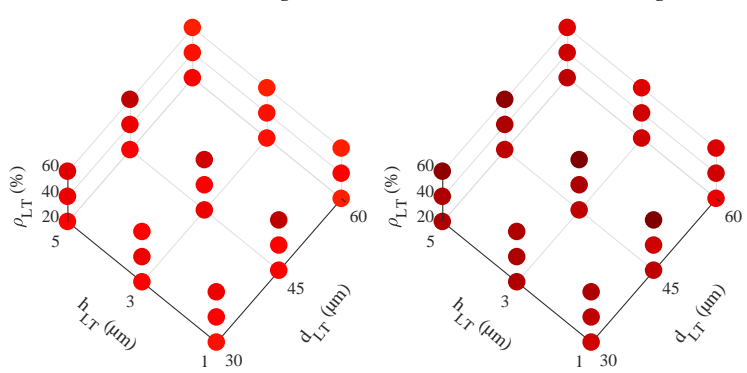

(k) COF : $\mathrm{Sq}_{\mathrm{wp}}=0.5 \mu \mathrm{m}, \mathrm{Sq}_{\mathrm{t}}=\mathbf{0 . 0 7} \mu \mathrm{m}$,

(l) $\mathrm{COF}: \mathrm{Sq}_{\mathrm{wp}}=0.5 \mu \mathrm{m}, \mathrm{Sq}_{\mathrm{t}}=0.1 \mu \mathrm{m}$,

Lubricant amount $=2.0\left(\mathrm{~g} / \mathrm{m}^{2}\right)$
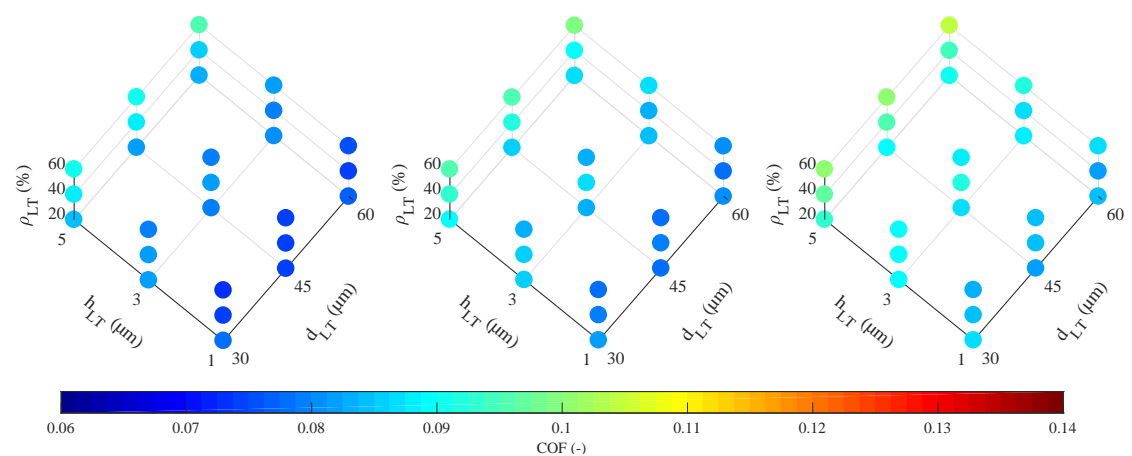

Figure 6.7 COF of LT surfaces for different texture parameters. 
(a) $\mathrm{COF}_{\text {range }}\left(\mu_{\text {max }}-\mu_{\text {min }}\right): \mathrm{Sq}_{\mathrm{wp}}=0.5 \mu \mathrm{m}$, Lubricant amount $=0.2\left(\mathrm{~g} / \mathrm{m}^{2}\right)$

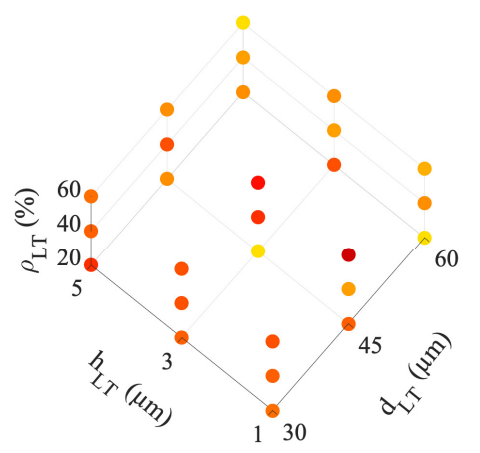

(b) $\mathrm{COF}_{\text {range }}\left(\mu_{\text {max }}-\mu_{\text {min }}\right): \mathbf{S q}_{\mathrm{wp}}=0.5 \mu \mathrm{m}$,

Lubricant amount $=2.0\left(\mathrm{~g} / \mathrm{m}^{2}\right)$

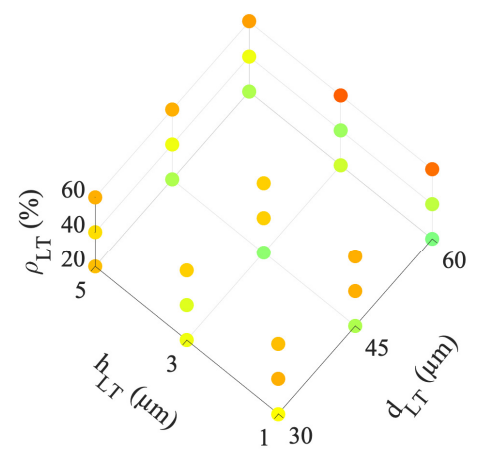

0 0.002

0.004

0.006

COF range

0.012

0.014

Figure 6.8 LT surface: range of COF with respect to tool roughness at lubricant amounts of (a) $0.2 \mathrm{~g} / \mathrm{m}^{2}$ (b) $2.0 \mathrm{~g} / \mathrm{m}^{2}$.

and $0.04 \mu \mathrm{m}$. Figure $6.8 \mathrm{a}$ and $6.8 \mathrm{~b}$ shows the results at a lubricant amount of $0.2 \mathrm{~g} / \mathrm{m}^{2}$ and $2.0 \mathrm{~g} / \mathrm{m}^{2}$ respectively. The results show that for a smaller amount of lubricant the effect of tool roughness is slightly higher. Therefore, surfaces are more robust in the mixed lubrication regime. Furthermore, it can also be concluded that the robustness is less sensitive to texture parameters.

\subsection{Modelling EDT surface}

In the steel industry, it is a common practice that the GI sheet is passed through textured rolls to apply texture. This stage is also called skin pass or temper rolling. The resulting texture depends on the texture pattern on the rolls, and process settings such as rolling force, sheet material and condition of rolls (fresh or worn). The surfaces textured by EDT rolls [94] are widely used in mass production due to their effectiveness and simplicity. Wentink et al. [105] presented a model to generate an EDT surface that consists of modelling steps resembling the actual process. First, a surface topography of EDT roll is generated. The roughness transfer model based on a bearing area (BA) approach is used to print EDT roll texture on the sheet surface. In the current study, the surface generation model proposed by Wentink et al. [105] is used. 


\subsubsection{EDT roll surface}

In electro-discharge texturing of a roll surface, an electrode which is moving radially and axially is placed near the rotating roll in the presence of conductive fluid [106]. An electric current forms a spark (discharge pulse) between the electrode and the roll surface which causes local melting of the roll surface to form a crater. During this EDT event, a fraction of the molten material evaporates and the remaining liquid metal solidifies on the crater edge. Repetition of this action and continuous rotation of the roll surface creates many craters to provide a textured roll surface. Figure $6.9 \mathrm{a}$ shows two adjacent EDT events and Figure $6.9 \mathrm{~b}$ shows a $2 \mathrm{D}$ height profile of a single EDT event measured at the centre of a crater [105]. The EDT roll surface is the result of many such individual events. Therefore, it can be described by geometry of the single event, event density and distribution. Wentink et al. [105] assumes the geometry of the single crater to be axisymmetric. The measured 2D height profile is parametrized using Equation (6.2) [105]. The resulting parametrized curve of an EDT event is shown in Figure 6.9c.

$$
h_{\mathrm{EDT}}(r)=\left\{\begin{array}{l}
-h_{\mathrm{EDT}} \cos \left(\frac{\pi r}{d_{\mathrm{EDT}}}\right) \quad \forall 0 \leq r \leq d_{\mathrm{EDT}} / 2 \\
-\left(\frac{2 f_{\mathrm{d}} h_{\mathrm{EDT}}(\pi-2) d_{\mathrm{EDT}}^{2}}{\pi\left(d_{\mathrm{EDT}}^{2}-D_{\mathrm{EDT}}^{2}\right)}\right) \sin \left(\frac{2 \pi\left(r-d_{\mathrm{EDT}} / 2\right)}{D_{\mathrm{EDT}}-d_{\mathrm{EDT}}}\right) \\
\forall d_{\mathrm{EDT}} / 2<r \leq D_{\mathrm{EDT}} / 2 \\
0 \forall r>D_{\mathrm{EDT}} / 2
\end{array}\right.
$$

where $h_{\mathrm{EDT}}(r)$ is the crater depth at radius $r, d_{\mathrm{EDT}}$ and $D_{\mathrm{EDT}}$ are inner and outer crater diameters and $f_{\mathrm{d}}$ is the material deposition factor which

(a)

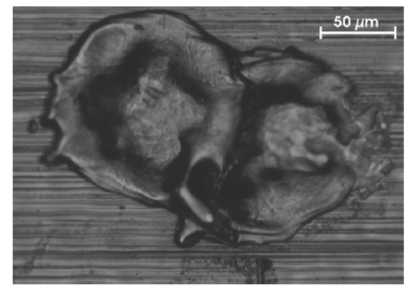

(b)

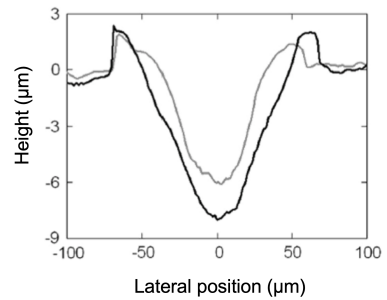

(c)

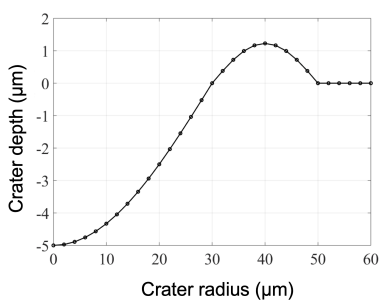

Figure 6.9 (a) Optical microscopy image of a conjoined EDT events. (b) Height profile of an isolated EDT crater. (c) Parametrized profile of an EDT crater [105]. 
is equal to the fraction of total crater volume deposited at the crater edge. A fixed relation is assumed between the outer and inner diameters of the crater based on the ratio of rim annulus area to crater cross-sectional area, therefore $K_{\mathrm{d}}=\left(D_{\mathrm{EDT}}^{2}-d_{\mathrm{EDT}}^{2}\right) / d_{\mathrm{EDT}}^{2}$. This means that the rim area is proportional to the crater area but further experimental investigation is required. For the measured crater profile, the maximum crater depth $h_{\mathrm{EDT}}=5 \mu \mathrm{m}, d_{\mathrm{EDT}}=60 \mu \mathrm{m}, D_{\mathrm{EDT}}=100 \mu \mathrm{m}, f_{\mathrm{d}}=0.6$ and $K_{\mathrm{d}}=1.78$.

If a new EDT event is close to the previous event, partly overlapping craters appear in the rim region, also referred as conjoined event as shown in Figure 6.9a. It has been observed that the preferred distance of conjoined event centres appears to be about $\left(d_{\mathrm{EDT}}+D_{\mathrm{EDT}}\right) / 2$ [105]. In the algorithm the radius $R_{\text {conj }}$ is therefore defined as $\left(d_{\mathrm{EDT}}+D_{\mathrm{EDT}}\right) / 2$ [105], which means that if the centre of new EDT event falls within the distance $R_{\text {conj }}$ of any previous EDT event centre, the centre is moved so as to have centre to centre offset of $R_{\text {conj }}$. The following procedure as described in [105] is implemented to generate EDT roll surface.

1. Choose a random location of an EDT event.

2. If the location is within the distance $R_{\text {conj }}$ of the previous EDT event, update the conjoined EDT event location such that:

(a) The centre of the updated location is exactly $R_{\text {conj }}$ away from the previous nearest EDT event.

(b) From all possible new locations which satisfy condition (a) choose a location closest to original random location.

3. If the original random location is outside the distance $R_{\text {conj }}$ of any previous EDT event, the original location is chosen.

4. The height data at the chosen EDT event location is determined using Equation (6.2). For partially overlapping events, use superposition of height data.

5. Repeat this procedure for a required EDT event density to generate the EDT roll surface.

The random locations of EDT events are determined using the Matlab random number generator. The algorithm is implemented in the Matlab software.

\subsubsection{Roughness transfer model}

The sheet surface resembles the negative imprint of the texture roll topography. The correlation between the sheet surface and roll texture 
increases with an increase in rolling force [105]. Wentink et al. [105] used a bearing area (BA) approach for roughness transfer. In this approach, the roll surface is pressed until a bearing area (contact area) approaches a desired value. This approach is acceptable for low elongation of a sheet during skin pass rolling and limited slip in the roll bite. During skin pass rolling, the elongation in GI sheet is usually $<2 \%$ so slip in the roll bite can be assumed negligible. The bearing area depends on applied rolling force and sheetroll materials. Wentink et al. [105] compared the surface topographies of measured sheet surface and generated sheet surface at different values of BA and confirmed that the required BA is directly proportional to the rolling force. However, they concluded that for a practical rolling situation, the model leads to a realistic surface roughness and topography for contact BA $\approx 50 \%$. Therefore, in this study, the BA approach is used with a contact $\mathrm{BA}=50 \%$. The measured untextured GI sheet $\left(\mathrm{Sq}_{\mathrm{wp}}=0.5 \mu \mathrm{m}\right)$ is used on which the negative of the EDT roll surface is printed to generate the EDT surface. Figure 6.10 shows the generated EDT roll surface and sheet surface. The surface height distribution of the EDT surface is usually non-Gaussian, as shown in Chapter 2 (Figures 2.9-2.12), similarly to the generated EDT surface. Furthermore, Figure 6.11 shows the comparison of a measured EDT surface and generated EDT surface topographies. The key difference is that
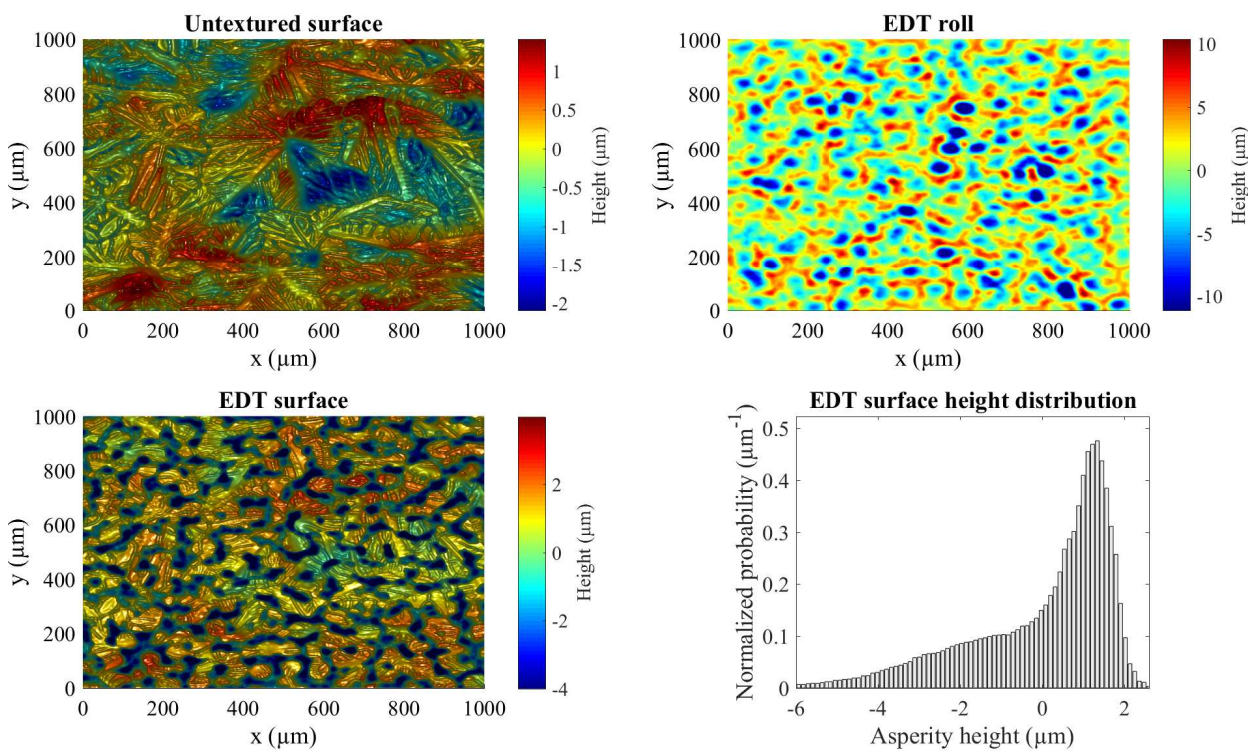

Figure 6.10 Surface topographies of initial untextured sheet, generated EDT roll and EDT surface (and its height distribution). 
(a) Measured EDT surface

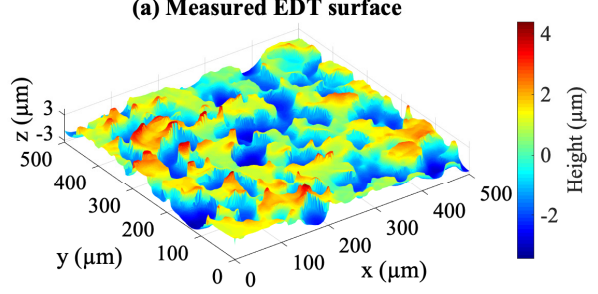

(b) Generated EDT surface

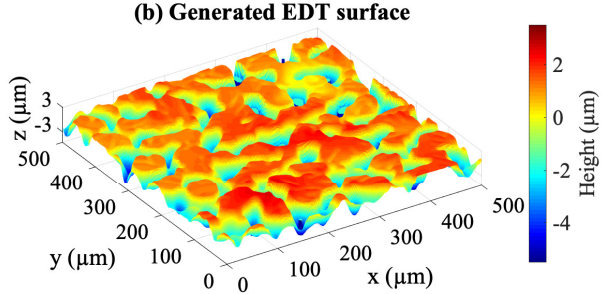

Figure 6.11 (a) A measured EDT surface $(\mathrm{Sa}=1.3 \mu \mathrm{m}, \mathrm{Sq}=1.5 \mu \mathrm{m})$ and (b) A generated EDT surface $(\mathrm{Sa}=1.4 \mu \mathrm{m}, \mathrm{Sq}=1.7 \mu \mathrm{m})$ with $h_{\mathrm{EDT}}=4 \mu \mathrm{m}, d_{\mathrm{EDT}}=60 \mu \mathrm{m}, D_{\mathrm{EDT}}=100 \mu \mathrm{m}$ and $\rho_{\mathrm{EDT}}=1000$.

in a real surface the rise of material at the edge of indented valleys can be observed, which is not accounted for in the current model.

\subsection{Effect of EDT surface parameters on friction}

The size of EDT craters on the roll surface can be controlled within close limits by controlling pulse profile, peak current, voltage and distance between electrode and roll surface [94]. The roughness and surface topography of roll surface depend on the number of EDT events per unit area (EDT event density). In the current study, EDT surfaces are generated using a method described in Section 6.4 for a range of crater parameters and event densities, as shown in Table 6.2. The ranges are chosen such that the resulting EDT surfaces have realistic surface roughness $(\mathrm{Sa}<3.0 \mu \mathrm{m})$. The measured untextured GI sheet with surface roughness $\mathrm{Sq}=0.5 \mu \mathrm{m}$ is used on which the texture from the EDT roll is embossed. Similarly to the study of LT surfaces, the COF of EDT surfaces is determined using the virtual

Table 6.2 Texture parameters for EDT surface DOE.

\begin{tabular}{lll}
\hline Parameter & Values & Unit \\
\hline Untextured sheet surface roughness $\left(\mathrm{Sq}_{\mathrm{wp}}\right)$ & 0.5 & $\mu \mathrm{m}$ \\
Crater inner diameter $\left(d_{\mathrm{EDT}}\right)$ & $40,60,80$ & $\mu \mathrm{m}$ \\
Crater depth $\left(h_{\mathrm{EDT}}\right)$ & $3,4,5$ & $\mu \mathrm{m}$ \\
EDT event density $\left(\rho_{\mathrm{EDT}}\right)$ & $500,750,1000$ & $\mathrm{~mm}^{-2}$ \\
$f_{\mathrm{d}}$ & 0.6 & \\
$K_{\mathrm{d}}$ & 1.78 & \\
\hline
\end{tabular}


strip-draw test. All the input parameters of simulations are the same as in the LT surface study. The friction look-up table including the flow factors is generated for each surface of $2 \times 2 \mathrm{~mm}$ area and is then used in FE simulations.

\subsubsection{EDT surface: results and discussion}

The COF results of all generated surfaces at different tool roughnesses and lubricant amounts are shown in Figure 6.12. Figures 6.12a to 6.12c show COF results at different tool roughnesses and a lubricant amount of $0.2 \mathrm{~g} / \mathrm{m}^{2}$ for which a boundary lubrication regime prevails. Similarly to LT surfaces, the effect of tool roughness is clearly visible. It is also noticed that COF shows a decreasing trend with an increase in EDT crater diameter. This is because with an increase in crater diameter, the negative of crater on untextured surface leaves bigger patches of virgin (untextured) surface

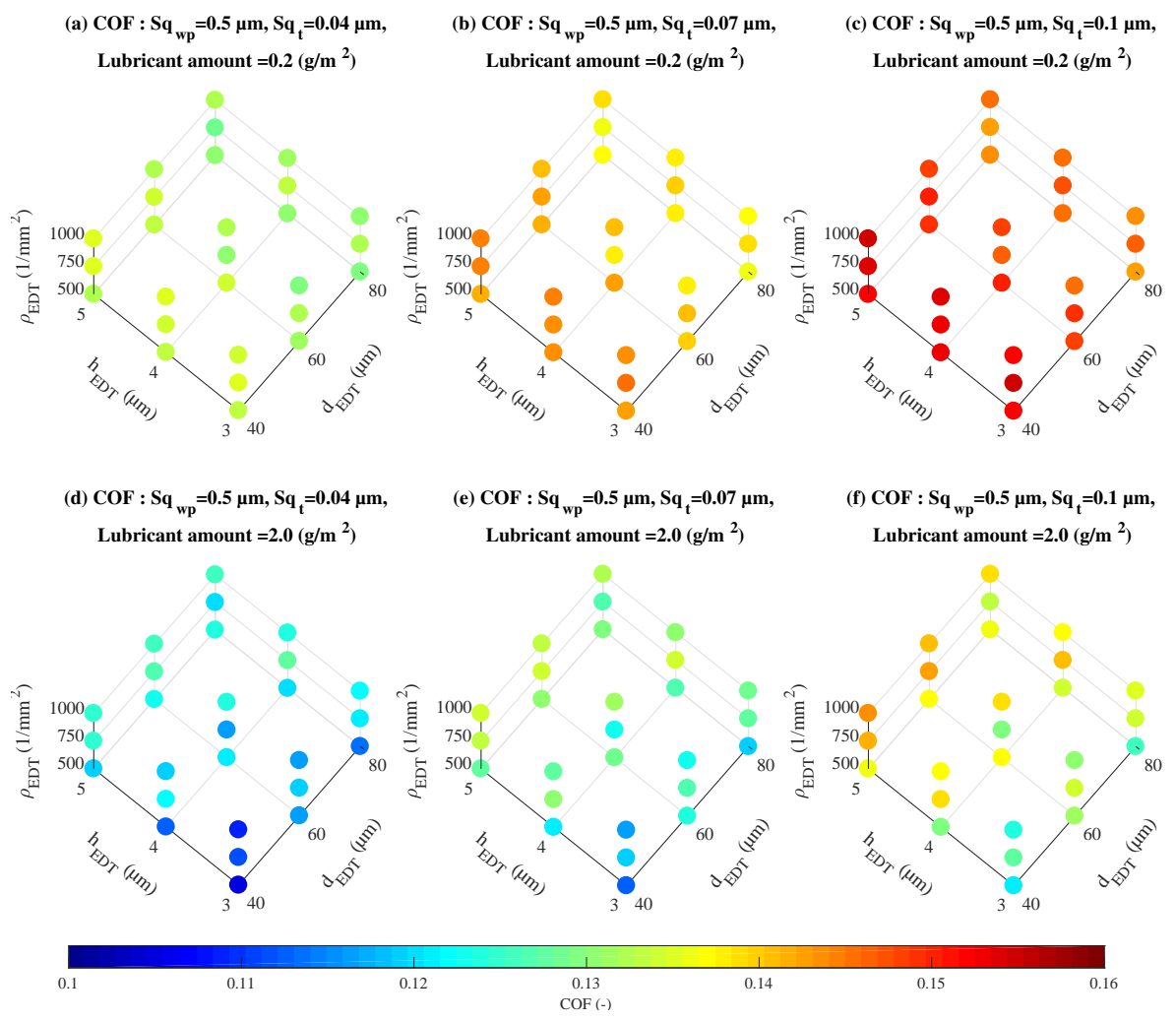

Figure 6.12 COF of EDT surfaces for different texture parameters. 
(a)

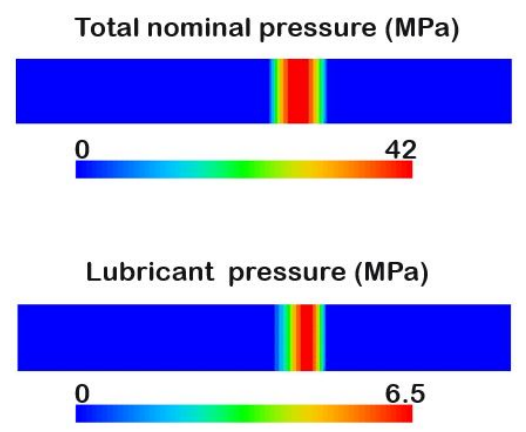

(b) Total nominal pressure (MPa)

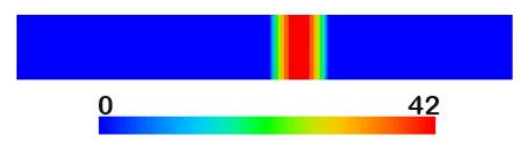

Lubricant pressure (MPa)

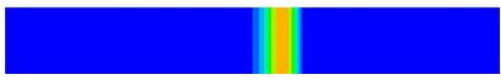

6.5

Figure 6.13 Nominal contact pressure and lubricant pressure for generated EDT surfaces at lubricant amount of $2.0 \mathrm{~g} / \mathrm{m}^{2}$ (a) $S a=0.82 \mathrm{\mu m}$, $h_{E D T}=3 \mu \mathrm{m}, \quad d_{E D T}=60 \mu \mathrm{m}, \quad \rho_{E D T}=500 . \quad$ (b) $S a=1.34 \mu \mathrm{m}$, $h_{E D T}=5 \mu \mathrm{m}, d_{E D T}=60 \mu \mathrm{m}, \rho_{E D T}=500$.

with low roughness $(\mathrm{Sq}=0.5 \mu \mathrm{m})$. The tool asperities interact with EDT surface at these patches. Therefore, the contact patches formed between the tool-sheet metal are bigger. According to the multi-asperity friction model as described in Section 4.3.2, the fitted elliptical paraboloid through penetrated tool asperities on the contact patch is bigger and smoother. The attack angle of the fitted shape with respect to sliding direction is low, resulting in low COF [1]. The influence of EDT event density and crater depth (in boundary lubrication regime) on the $\mathrm{COF}$ is not noticeable.

Figures $6.12 \mathrm{~d}$ to $6.12 \mathrm{f}$ show COF results at different tool roughnesses and a lubricant amount of $2.0 \mathrm{~g} / \mathrm{m}^{2}$. The effect of the lubricant amount is significant. It can also be observed that the effect of lubricant (developed lubricant pressure) is not the same for all surfaces in the mixed lubrication regime. This is because the wedge effect (first RHS term in average Reynolds equation, see Equation (5.3)) and flow factors depend on surface texture, which influence the lubricant pressure. For example, Figure 6.13 shows that for EDT surfaces of distinct surface textures, the developed lubricant pressure is different.

The change in COF due to a change in tool roughness is shown in Figure 6.14 at constant lubricant amount of $0.2 \mathrm{~g} / \mathrm{m}^{2}$ and $2.0 \mathrm{~g} / \mathrm{m}^{2}$ for all generated EDT surfaces. The surfaces show a trend in COF variation. The variation in COF decreases with an increase in crater diameter. 


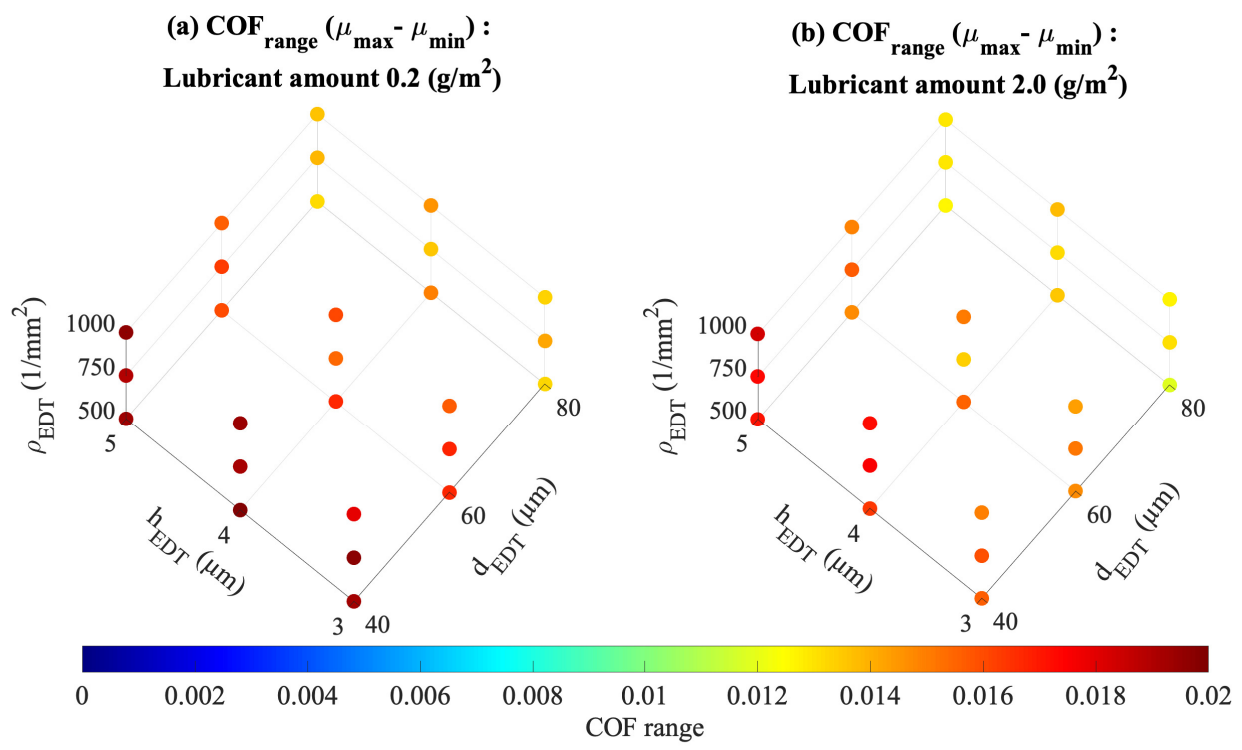

Figure 6.14 EDT surface: range of COF with respect to tool roughness at lubricant amounts of (a) $0.2 \mathrm{~g} / \mathrm{m}^{2}$ (b) $2.0 \mathrm{~g} / \mathrm{m}^{2}$.

\subsection{Robust friction behaviour: A case study}

To further confirm the influence of texture parameters on robust friction behaviour, a component level case study is performed. The deep drawing FE simulations of a cross-die product are performed using generated EDT surfaces with different texture parameters. Here, the robustness in friction is assessed with respect to evolution in tool roughness. GI sheets with a

Table 6.3 EDT surfaces used for case study.

\begin{tabular}{lllll}
\hline Parameter & Surface 1 & Surface 2 & Surface 3 & Unit \\
\hline Crater inner dia. $\left(d_{\mathrm{EDT}}\right)$ & 80 & 60 & 40 & $\mu \mathrm{m}$ \\
Crater outer dia. $\left(D_{\mathrm{EDT}}\right)$ & 133 & 100 & 67 & $\mu \mathrm{m}$ \\
Crater depth $\left(h_{\mathrm{EDT}}\right)$ & 3 & 3 & 4 & $\mu \mathrm{m}$ \\
EDT event density $\left(\rho_{\mathrm{EDT}}\right)$ & 500 & 750 & 1000 & $\mathrm{~mm}^{-2}$ \\
Surface roughness $(\mathrm{Sa})$ & 1.06 & 1.00 & 1.02 & $\mu \mathrm{m}$ \\
\hline
\end{tabular}


coating thickness of $7 \mu \mathrm{m}$ and DX54 substrate are used. For comparison, three different generated EDT surfaces that have similar surface roughness are considered. The surfaces are selected based on the results from the previous section. The texture parameters of chosen EDT surfaces are given in Table 6.3. For the selected texture parameters, surface 1 with larger crater diameter (Table 6.3) is expected to have less variation due to change in tool roughness compared to surfaces 2 and 3. Strip-draw test simulations showed that with increasing crater diameter the robustness in friction is enhanced (Figure 6.14).

The details of the cross-die FE simulation, geometry of tooling and blank can be found in Section 5.5. Material properties of DX54 substrate can be found in Section 4.5. The FE simulation process parameters are given in Table 6.4. All tools are assumed rigid and modelled with the same surface topography as used in Sections 6.3 and 6.5. Two tool surface roughness levels and two lubricant amounts are used. Therefore, four simulations are performed for each EDT surface. The tool roughness is changed by scaling the height data of the measured tool surface. The forming limit diagram (FLD) is constructed for each simulation at a punch stroke of $75 \mathrm{~mm}$. The difference in safety margin determined using FLDs at different tool roughnesses is used as a basis to deduce conclusions about the robust friction behaviour.

Figure 6.15 shows FLDs constructed using FE simulation results for each EDT surface. Figure 6.15a shows the difference in FLDs of all three surfaces at a tool roughness of $\mathrm{Sq}_{\mathrm{t}}=0.1 \mu \mathrm{m}$ at a constant lubricant amount of $0.2 \mathrm{~g} / \mathrm{m}^{2}$. The difference in FLDs is not significant but it is clear that surface

Table 6.4 Parameters of cross-die simulations.

\begin{tabular}{ll}
\hline Blank material & Steel DX54-GI \\
Blank size & $260 \times 260 \mathrm{~mm}$ \\
& Sheet thickness $=1.0 \mathrm{~mm}$ \\
Lubricant & Fuchs Anticorit PLS100T \\
& Amount $=0.2$ and $2.0 \mathrm{~g} / \mathrm{m}^{2}$ \\
& Dynamic viscosity $\left(\eta_{40^{\circ}}\right)=90 \mathrm{mPas}$ \\
& Density $\left(\rho_{25^{\circ}}\right)=0.896 \mathrm{~g} / \mathrm{cm}^{3}$ \\
Blank holder force $\left(F_{\text {bhf }}\right)$ & $120 \mathrm{kN}$ \\
Punch velocity $\left(v_{\text {punch }}\right)$ & $60 \mathrm{~mm} / \mathrm{s}$ \\
Punch stroke & $75 \mathrm{~mm}$ \\
\hline
\end{tabular}


(a) $\mathrm{Sq}_{\mathrm{t}}=0.1 \mu \mathrm{m}$,

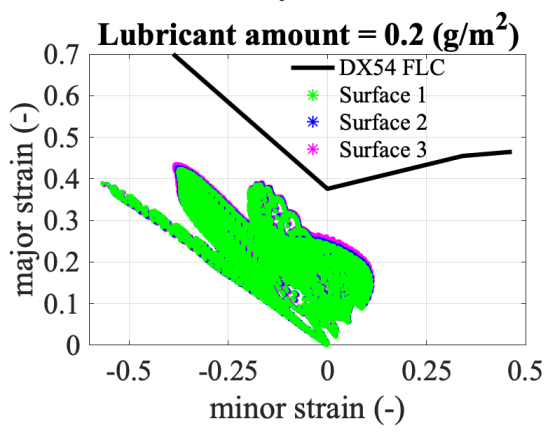

(c) $\mathrm{Sq}_{\mathrm{t}}=0.1 \mu \mathrm{m}$,

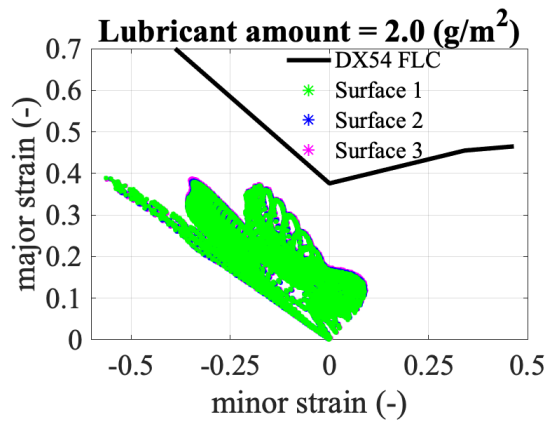

(b) $\mathrm{Sq}_{\mathrm{t}}=0.25 \mu \mathrm{m}$,

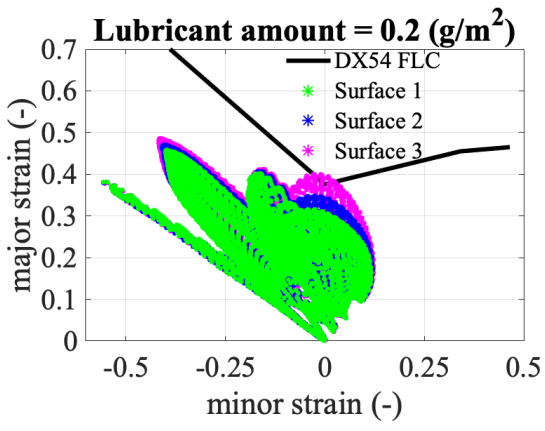

(d) $\mathrm{Sq}_{\mathrm{t}}=0.25 \mu \mathrm{m}$,

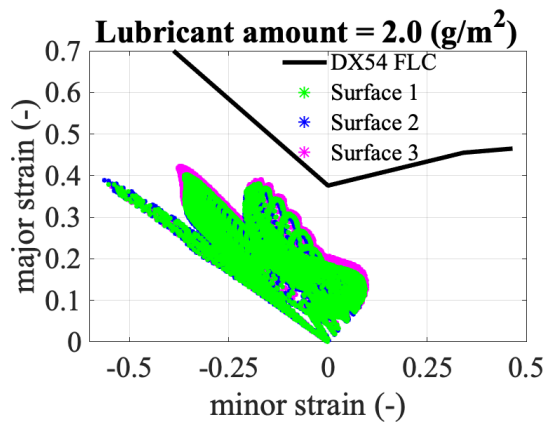

Figure 6.15 Sensitivity of tool roughness and lubricant amount on FLD of EDT surfaces.

3 has a slightly higher COF than surfaces 1 and 2 . When the tool roughness is increased to $0.25 \mu \mathrm{m}$ (Figure 6.15b), surface 3 goes beyond the forming limit. Looking at the difference in FLDs with respect to two different tool roughnesses, it can be concluded that the COF can significantly affect FLD. The safety margin for surface 3 with low crater diameter is much smaller than that for surface 1 with a larger crater diameter. This suggests that surface 1 is the most robust and surface 3 is the least robust among the chosen sheet surfaces with respect to tool roughness. At a high lubricant amount, the change in safety margin with an increase in tool roughness is much less than for the results at a low lubricant amount. This is because at a lubricant amount of $2.0 \mathrm{~g} / \mathrm{m}^{2}$ a mixed lubrication regime exists for all surfaces, which means that due to a developed lubricant pressure the contribution of solid to solid direct asperity shear force at tool-sheet contacts is less significant than in the case of $0.2 \mathrm{~g} / \mathrm{m}^{2}$ lubricant amount. 
It is interesting to note that the change in safety margin of all surfaces do not differ much in the mixed lubrication regime but still surface 1 shows the most robust behaviour. This case study confirms that surface texture parameters influence the robustness in friction.

\subsection{Summary and conclusions}

In this study, the influence of different surface texture parameters on friction is studied. LT and EDT surfaces are generated for a given set of texture parameters. The rise in COF due to an increase in tool roughness is less in the mixed lubrication regime than in the boundary lubrication regime for both LT and EDT surfaces. The influence of lubricant amount is bigger than the texture parameters. However, the type of lubrication regime (boundary or mixed) depends on texture parameters because they influence the amount of lubricant required for a mixed lubrication regime. The sensitivity study on LT surfaces suggests that the influence of texture parameters on the COF is not so noticeable for a low lubricant amount for which a boundary lubrication regime exists. At a high lubricant amount, a mixed lubrication regime exists for some surfaces resulting in a low $\mathrm{COF}$. The robustness of the COF with respect to tool roughness is estimated at different lubricant amounts. For LT surfaces, the results show that generally the surfaces are more robust in a mixed lubrication regime than a boundary lubrication regime. For EDT surfaces, the COF shows a decreasing trend with an increase in EDT crater diameter. The influence of other parameters (density and crater depth) on the COF is not noticeable. Similarly to LT surfaces, the effect of lubricant amount is significant. Furthermore, it is observed that the EDT surfaces become more robust with respect to tool roughness with an increase in crater diameter. To further validate the relation of crater diameter on robustness, cross-die simulations are performed using three different EDT surfaces with different crater diameters. The difference in safety margin determined from FLDs due to a change in tool roughness confirms that EDT surfaces with a large crater diameter are more robust. Furthermore, surfaces show more robust behaviour in the mixed lubrication regime than in the boundary lubrication regime. 



\section{Chapter 7}

\section{Conclusions and recommendations}

The current research work can be divided into three main topics (1) asperity flattening models (Chapters 2, 3 \& 4) (2) boundary and mixed lubrication regime friction models (Chapters $4 \& 5$ ) and (3) friction behaviour of textured surfaces (Chapter 6). Detailed conclusions are discussed at the end of each of those chapters. In this chapter, the most important conclusions and recommendations are discussed for each topic.

\section{(1) Asperity flattening models}

\section{Conclusions and discussion :}

Accurate estimation of the real area of contact is vital for reliable modelling of friction. Therefore, understanding the asperity flattening mechanisms under different loading conditions is important. In this research, asperity flattening models for coated sheets are developed for normal loading, sliding and combined normal loading and bulk strain. The advantage of the developed normal load flattening model is that it accounts for coating and substrate material behaviour and does not require model calibration, unlike the previous model [8]. However, the model requires a contact pressure database which is generated using FE analysis of single asperities of specific coating-substrate materials and coating thickness.

An experimental setup was developed to investigate the effect of combined normal loading and bulk strain on the real area of contact. The results show that the real area of contact increases significantly with 
longitudinal strain. The real area of contact increases with coating thickness (soft coating on hard substrate) and decreases with surface roughness. The surface texture also influences the asperity deformation. For instance, for surfaces of similar roughnesses, the real area of contact is higher for surfaces with higher mean peak spacing.

Sliding experiments are also performed for a range of nominal pressures. The results show that the real area of contact increases by a factor between 2-3 than for normal loading alone.

\section{Recommendations :}

In the flattening models, material anisotropy of zinc coating is not considered. Material anisotropy ought to be considered for a more accurate estimation of asperity deformations.

Currently, the real area of contact is determined based on the local peak in the surface height distribution function of the deformed surface. This method assumes that the tool surface is flat and the elastic recovery of deformed asperities is negligible. However, in real situations, the tool surface is not perfectly flat (forming tools) and the elastic recovery depends on the amount of asperity deformation. This method can introduce errors in measurement of the real area of contact. To account for these effects, advanced measurement techniques such as ultrasound [107] or fluorescence microscopy [108] may be used for more accurate measurements.

The experimental setup developed during this research is applicable for combined normal loading and uniaxial strain. However, in actual forming situations, biaxial straining, compression and sheet surface roughening due to free surface straining exist. Hence, further research is required for thorough experimental investigation for such loading conditions and to include these effects in the model.

\section{(2) Boundary and mixed lubrication regime friction models}

\section{Conclusions and discussion :}

A friction model for coated sheets is developed in the boundary and mixed lubrication regimes. The model accounts for the influence of contact loads, measured surface topographies of the tool and the sheet, coating and substrate material behaviour on friction. A novel single asperity ploughing model of a 3D elliptical paraboloid shape is used to determine the shear 
force at local contact locations, from which the coefficient of friction (COF) is estimated. The asperity geometry and its orientation with respect to the sliding direction are considered [41]. During ploughing, the deformed sheet material piles up in front of the asperity, resulting in higher ploughing force. The material pile-up effect is included in the model as well. It is shown that this effect plays an important role in model accuracy. The model predicts a decreasing trend in COF with an increase in nominal contact pressure which correlates well with the results from lab-scale friction experiments.

In the mixed lubrication regime, the average Reynolds equation including flow factors is solved on the global FE domain to determine the lubricant pressure. It was demonstrated that the flow factors depend on the surface texture and therefore influence the lubricant pressure and friction. Consequently, the flow factors are determined on the measured rough surfaces. The coupled boundary and mixed lubrication friction model is successfully implemented in FE code for forming simulations. The model results correlate very well with the experiments. This demonstrates the applicability of the model for forming simulations for more accurate formability studies and the design of forming tools.

\section{Recommendations :}

During asperity ploughing, if the asperities are aligned on the same ploughing track then the effect of ploughing is reduced because asperity ploughing in the same track do not displace substrate material. These effects are not considered in the current model and needs further research. A possible approach is to identify asperities ploughing on the same track based on their relative positions and geometry. Based on the ploughing depth of these aligned asperities, a volume of substrate material ploughed by each asperity can be determined which can be used to compensate the effect of asperity alignment for a more accurate estimation of COF.

Currently, the friction look-up table is generated in a fixed dominant sliding direction (sheet drawing direction) at the tool-sheet metal interface. However, in a realistic forming situation the local sliding direction can vary. A sliding direction dependent look-up table may be used to account for this.

In the mixed lubrication regime, the lubricant squeeze effect is assumed negligible. This is valid for low contact pressures and quasi-static processes such as deep drawing at low punch velocity but as the punch velocity increases, this effect can be significant and should be considered.

The friction model is validated at component level using experiments with respect to parameters such as the punch force vs. displacement, strain- 
field and real area of contact. Additional validation parameters should be explored for thorough validation: for example, thickness distribution of deformed sheet, lubricant pressure using pressure sensors and lubricant film thickness. A novel experimental method of fluorescence microscopy [109] can be used to visualize the lubricant layer.

\section{(3) Friction behaviour of textured surfaces}

\section{Conclusions and discussion :}

The influence of surface texture parameters on friction is studied for LT and EDT surfaces. For this purpose, surface generation algorithms for LT and EDT surfaces are implemented. In the boundary lubrication regime, the influence of the texture parameters on COF is low for LT surfaces. For EDT surfaces, the COF shows a decreasing trend with an increase in EDT crater diameter. Also, the robustness of friction with respect to tool roughness enhances with an increase in EDT crater diameter. In general, friction is more robust in the mixed lubrication regime than in the boundary lubrication regime.

\section{Recommendations :}

In this research, the EDT surface generation algorithm first proposed by Wentink et al. [105] is used. The algorithm is based on the idea of transferring the negative imprint of EDT roll topography on the sheet surface. However during skin pass rolling the indentation of sheet surface by peaks on the roll surface displaces material on the edges of valleys. It has been observed that the displaced material distributes non-uniformly and tends to rise more on the edges of valleys. This effect needs to be modelled to generate more realistic EDT surfaces and to study their influence on friction behaviour. 


\section{Appendix A}

\section{Linear friction test: GI sheet - sapphire}

This appendix presents the summary of linear sliding experiments to determine the coefficient of friction between polished sapphire and a GI sample. The coefficient of friction is required as an input for FE simulations in Section 3.3.

\section{Friction experiments using linear friction tester}

To determine the coefficient of friction between sapphire and a GI sample, a linear friction tester is used, as shown in Figure A.1. GI sheet sample 1 in Table 3.1 is used. A circular GI sheet sample of $50 \mathrm{~mm}$ diameter is fixed in the workpiece holder B. A mirror-finished sapphire convex lens of $75 \mathrm{~mm}$ radius of curvature and $20 \mathrm{~mm}$ diameter is glued to the tool holder, which is lowered onto the sample at a desired normal load. Normal load of $2 \mathrm{~N}$ and $4 \mathrm{~N}$ are used, resulting in a nominal contact pressure of 30-55 MPa which is of the same order as used in the bulk strain experiments. The Hertz equation [110] for contact between elastic sphere (sapphire lens) and elastic flat (sample surface) is used to estimate the mean contact pressure. Normal load is applied using a force-controlled piezo actuator connected to a PID feedback control loop. After the desired normal load is applied, a workpiece table is moved at a speed $3 \mathrm{~mm} / \mathrm{min}$. The friction forces are measured by a piezo sensor from which the coefficient of friction is determined as shown in Figure A.1. An estimated average coefficient of friction for sapphire-GI sample combination at $2 \mathrm{~N}$ and $4 \mathrm{~N}$ normal load is 0.083 . 

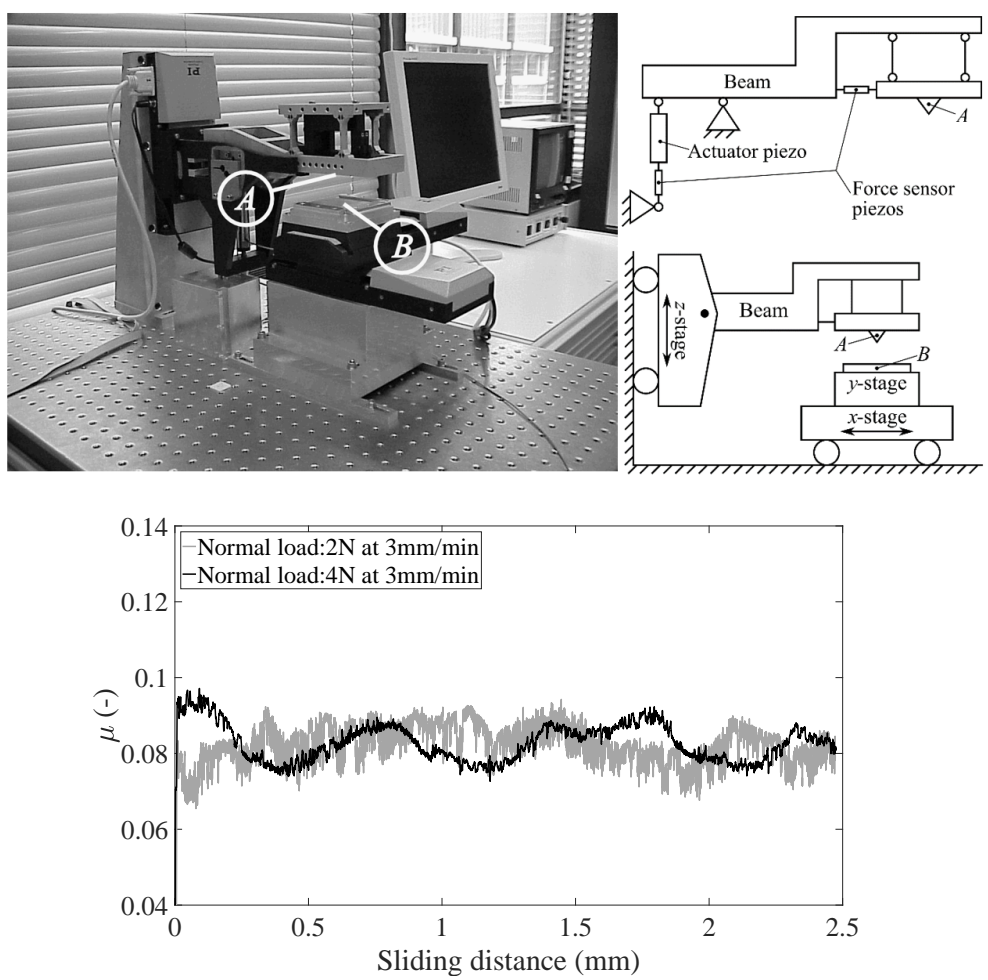

Figure A.1 (top) Linear friction tester. (bottom) Coefficient of friction between GI sample and sapphire. 


\section{Research deliverables}

The key deliverables related to this research project are listed here.

\section{Journal publications}

1. M.P. Shisode, J. Hazrati, T. Mishra, M.B. de Rooij and A.H. van den Boogaard, "Semi-analytical contact model to determine the flattening behavior of coated sheets under normal load" Tribology International, 146, 106182, 2020.

2. M.P. Shisode, J. Hazrati, T. Mishra, M.B. de Rooij and A.H. van den Boogaard, "Evolution of real area of contact due to combined normal load and sub-surface straining in sheet metal" (Accepted in Friction).

3. M.P. Shisode, J. Hazrati, T. Mishra, M.B. de Rooij, C.H.L.J. ten Horn, J. van Beeck and A.H. van den Boogaard, "Modeling boundary friction of coated sheets in sheet metal forming" Tribology International, 153, 106554, 2020.

4. M.P. Shisode, J. Hazrati, T. Mishra, M.B. de Rooij and A.H. van den Boogaard, "Mixed lubrication friction model including surface texture effects for sheet metal forming" (Under review).

5. M.P. Shisode, J. Hazrati, T. Mishra, M.B. de Rooij and A.H. van den Boogaard, "Design of EDT surface texture for robust friction behavior" (In preparation).

\section{Conference Proceedings}

1. M.P. Shisode, J. Hazrati, T. Mishra, M.B. de Rooij and A.H. van den Boogaard, "Multi-scale contact modeling of coated steels for sheet 
metal forming applications" Key Engineering Materials, Vol. 767, Trans Tech Publications Ltd, 2018.

2. M.P. Shisode, J. Hazrati, T. Mishra, M.B. de Rooij and A.H. van den Boogaard, "Multi-scale Friction Modeling of Coated Steels for Sheet Metal Forming Applications" The $13^{\text {th }}$ International Conference on Numerical Methods in Industrial Forming Processes (NUMIFORM), Portsmouth, USA, 2019.

3. M.P. Shisode, J. Hazrati, T. Mishra, M.B. de Rooij and A.H. van den Boogaard, "Modeling Mixed Lubrication Friction for Sheet Metal Forming Applications" Procedia Manufacturing, 47, 586-590, 2020.

\section{Presentations in conferences}

1. International Conference on Tribology in Manufacturing Processes (ICTMP), Elsinore, Denmark, 2018.

2. International Deep Drawing Research Group (IDDRG) conference, Enschede, The Netherlands, 2019.

3. International Conference on Numerical Methods in Industrial Forming Processes (NUMIFORM), Portsmouth, USA, 2019.

4. M2i conference, Meeting Materials, The Netherlands, 2019.

5. International Conference on Material Forming (ESAFORM), virtual conference organized by BTU Cottbus - Senftenberg, Germany, 2020.

\section{Poster contribution in conferences}

1. M2i conference, Meeting Materials, The Netherlands, 2016, 2017, 2018, 2019.

2. Engineering Mechanics Symposium, The Netherlands, 2016, 2017, $2018,2019$.

\section{Awards}

- Best poster award, Engineering Mechanics Symposium, The Netherlands, 2019. 


\section{Acknowledgements}

This thesis is a collective effort of many people who have contributed directly or indirectly. Therefore, it is my great pleasure to acknowledge several people who have challenged, supported and stuck with me along the way in shaping this thesis.

I would like to express my deepest gratitude and profound respect to my promoter Prof. Ton van den Boogaard. I owe you a big thank you for giving me this opportunity. Thank you for your technical support, enthusiasm and encouragement at all stages of this research work. I will cherish our bi-monthly discussions.

My sincere thanks to my daily supervisor Dr. Javad Hazrati. You have been instrumental in guiding me through this wonderful journey. I am deeply indebted to your invaluable assistance during the writing phase of my thesis and publications. Your critical attitude, attention to small details and technical expertise really helped to make a better thesis.

My heartiest gratitude to the members of my graduation committee: Prof. dr. ir. T. Tinga, Prof. dr. ir. M.B. de Rooij, Prof. dr. J. P. Ponthot, Prof. dr. ir.-ing. A. Brosius \& Dr. ir. C.H.L.J. ten Horn. I would also like to thank the chair of my defence committee, Prof. dr. ir. H.F.J.M. Koopman.

I gratefully acknowledge the support from people at the Materials Innovation Institute (M2i) and industrial partner TATA Steel. You were the backbone of this research project. A special thanks to Jeroen van Beeck, Carel ten Horn, Pieter Baart, Matthijs Toose, Marco Appelman and Menno de Bruine from Tata Steel R\&D for your technical guidance and assistance during the experiments. I also would like to thank Mr. Jan-Dirk Kamminga from M2i for your enthusiasm in my research work and valuable comments during the progress meetings.

I would like to extend my appreciation to all my colleagues in the NSM 
group. I would particularly like to mention the bi-weekly DiekA meetings. Being part of these meetings was in itself a great learning experience. Thanks Ton, Geijs, Javad, Semih, Jos, Antonella, Boukje, Shahrzad, Omid, Erkan, Frans, Ali, Sikander, Nachiket, Greg, Shakil, Zulfiqar, Mahdi, Björn for your constructive criticisms on my presentations and for providing your valuable suggestions. My special thanks go to Boukje and Jenny for helping me to write the thesis summary in Dutch. Your help is much appreciated. Thank you to my thesis reading committee members Ton, Javad and Shakil for your comments and suggestions. Sikander, Ali, thank you for your help during my experiments. I will cherish the time I spent with all of you in coffee breaks, EM conferences, M2i conferences, EM courses and other activities. I must admit that the hour after our coffee breaks was the most productive time of the day for me. I would like to extend my warm thanks to my current officemates Mahdi and Zulfiqar for making our office a comfortable place and former office mates Jos, Omid and Chao for your indispensable help especially during my first year.

Special thanks to Prof. Matthijn de Rooij and Tanmaya Mishra. You were an integral part of this journey. I really appreciate your co-operation throughout this research work and I learned a lot from you. This was indeed a well-managed collaborative research project between the group of Nonlinear Solid Mechanics (NSM) and the group of Surface Technology and Tribology (STT). Thanks Matthias Feinaeugle and Hasib Mustafa for our discussions on laser texturing.

A warm thanks to Debbie and Tjerkje for your help in my onboarding and administrative tasks. Nico and Axel, thank you for your help in software and hardware related issues. Thomas Zijlstra, Eric de Vries, Bert Vos, Leo Tiemersma and Nick Helthuis for giving me equipment trainings and help during experiments.

My special thanks to Abhijeet and Apurva, Nachiket and Ketakee, and Ayanshi who is the new addition in our group. Your company made me feel home here. I will cherish the time we spent together in group vacations and Diwali, Holi celebrations. I am sure our friendship will go a long way.

Thanks to all the people in the corridor for making the place dynamic and fun to be in. You have been such wonderful colleagues. Thank you Yigitcan, Dona, Julie and Daphné for the great memories during our stay at Matenweg.

I express my deepest thanks and gratitude to my parents, sisters and 
brothers-in-law for all your love, support and unwavering belief in me. I know at times it was hard to stay away physically from all of you but I appreciate your understanding. I am forever indebted to you for all you have done for me.

Finally, I wholeheartedly express my love, affection and gratitude to my wife Akshada. Writing a PhD thesis was a tedious task but your company and support made it a joyful experience. This work would not have been possible without your support and love. Most of all, thank you for being my best friend.

Meghshyam Prabhakar Shisode

October 2020 



\section{Bibliography}

[1] J. Hol, V.T. Meinders, M.B. de Rooij, and A.H. van den Boogaard. Multi-scale friction modeling for sheet metal forming: The boundary lubrication regime. Tribology International, 81:112-128, 2015.

[2] X. Ma, M.B. de Rooij, and D.J. Schipper. A load dependent friction model for fully plastic contact conditions. Wear, 269(11-12):790-796, 2010 .

[3] J. Hol, M.V.C. Alfaro, M.B. de Rooij, and V.T. Meinders. Advanced friction modeling for sheet metal forming. Wear, 286:66-78, 2012.

[4] J.A. Greenwood and J.B.P. Williamson. Contact of nominally flat surfaces, Proceedings of the Royal Society of London. Mathematical and Physical Sciences, Series A, 294:21, 1996.

[5] A.W. Bush, R.D. Gibson, and T.R. Thomas. The elastic contact of a rough surface. Wear, 35(1):87-111, 1975.

[6] W. R. Chang, I. Etsion, and D. B. Bogy. An elastic-plastic model for the contact of rough surfaces. Journal of Tribology, 109(2):257-263, 1987.

[7] Y. Zhao, D.M. Maietta, and L. Chang. An asperity microcontact model incorporating the transition from elastic deformation to fully plastic flow. Journal of Tribology, 122(1):86-93, 2000.

[8] J.D. Westeneng. Modelling of contact and friction in deep drawing processes. PhD thesis, University of Twente, 2001.

[9] D. Tabor. The hardness of solids. Review of physics in technology, 1(3):145, 1970. 
[10] L. Pei, S. Hyun, J.F. Molinari, and M.O. Robbins. Finite element modeling of elasto-plastic contact between rough surfaces. Journal of the Mechanics and Physics of Solids, 53(11):2385-2409, 2005.

[11] S. Cai and B. Bhushan. Three-dimensional sliding contact analysis of multilayered solids with rough surfaces. Journal of Tribology, 129(1):40-59, 2007.

[12] Z. Chen, R. Goltsberg, and I. Etsion. A universal model for a frictionless elastic-plastic coated spherical normal contact with moderate to large coating thicknesses. Tribology International, 114:485-493, 2017.

[13] W. Chang. An elastic-plastic contact model for a rough surface with an ion-plated soft metallic coating. Wear, 212(2):229-237, 1997.

[14] H. Mulki and T. Mizuno. Contact mechanics of zinc-coated steel sheets. Wear, 199(2):260-267, 1996.

[15] M.P. Shisode, J. Hazrati, T. Mishra, M.B. de Rooij, and A.H. van den Boogaard. Multi-scale contact modeling of coated steels for sheet metal forming applications. In Key Engineering Materials, volume 767, pages 223-231. Trans Tech Publ.

[16] B. Bhushan and S. Venkatesan. Effective mechanical properties of layered rough surfaces. Thin solid films, 473(2):278-295, 2005.

[17] E. Puchi-Cabrera, M.H. Staia, and A. Lost. Modeling the composite hardness of multilayer coated systems. Thin Solid Films, 578:53-62, 2015 .

[18] A.M. Korsunsky, M.R. McGurk, S.J. Bull, and T.F. Page. On the hardness of coated systems. Surface and Coatings Technology, 99(12):171-183, 1998.

[19] J. Halling and R.D. Arnell. Ceramic coatings in the war on wear. Wear, 100(1-3):367-380, 1984.

[20] J. Pullen and J.B.P. Williamson. On the plastic contact of rough surfaces. Proceedings of the Royal Society of London. A. Mathematical and Physical Sciences, 327(1569):159-173, 1972. 
[21] H. Vegter, H. Mulder, P. van Liempt, and J. Heijne. Work hardening descriptions in simulation of sheet metal forming tailored to material type and processing. International Journal of Plasticity, 80:204-221, 2016.

[22] G.M. Song, W.G. Sloof, Y.T. Pei, and J.T.M. De Hosson. Interface fracture behavior of zinc coatings on steel: Experiments and finite element calculations. Surface and Coatings Technology, 201(7):43114316, 2006.

[23] Y.T. Pei, G.M. Song, W.G. Sloof, and J.T.M. de Hosson. A methodology to determine anisotropy effects in non-cubic coatings. Surface and Coatings Technology, 201(16-17):6911-6916, 2007.

[24] M.B. de Rooij, G. van der Linde, and D.J. Schipper. Modelling material transfer on a single asperity scale. Wear, 307(1-2):198-208, 2013.

[25] J. Hol. Multi-scale friction modeling for sheet metal forming. PhD thesis, University of Twente, 2013.

[26] N. Bay and T. Wanheim. Real area of contact and friction stress at high pressure sliding contact. Wear, 38(2):201-209, 1976.

[27] N. Bay. Friction stress and normal stress in bulk metal-forming processes. Journal of Mechanical Working Technology, 14(2):203-223, 1987.

[28] T. Wanheim, N. Bay, and A.S. Petersen. A theoretically determined model for friction in metal working processes. Wear, 28(2):251-258, 1974.

[29] M.P. Shisode, J. Hazrati, T. Mishra, M.B. de Rooij, and A.H. van den Boogaard. Semi-analytical contact model to determine the flattening behavior of coated sheets under normal load. Tribology International, page 106182, 2020.

[30] C.M. Wichern, B.C. de Cooman, and C.J. van Tyne. Surface roughness of a hot-dipped galvanized sheet steel as a function of deformation mode. Journal of Materials Processing Technology, 160(3):278-288, 2005. 
[31] C.M. Wichern, B.C. de Cooman, and C.J. van Tyne. Surface roughness changes on a hot-dipped galvanized sheet steel during deformation at low strain levels. Acta Materialia, 52(5):1211-1222, 2004 .

[32] Z.G. Wang, Y. Yoshikawa, T. Suzuki, and K. Osakada. Determination of friction law in dry metal forming with DLC coated tool. CIRP Annals, 63(1):277-280, 2014.

[33] C.V Nielsen, P.A.F. Martins, and N. Bay. Modelling of real area of contact between tool and workpiece in metal forming processes including the influence of subsurface deformation. CIRP Annals, 65(1):261-264, 2016.

[34] M.P.F. Sutcliffe. Surface asperity deformation in metal forming processes. International Journal of Mechanical Sciences, 30(11):847868, 1988.

[35] W.R.D. Wilson and S. Sheu. Real area of contact and boundary friction in metal forming. International Journal of Mechanical Sciences, 30(7):475-489, 1988.

[36] H. Ike and A. Makinouchi. Effect of lateral tension and compression on plane strain flattening processes of surface asperities lying over a plastically deformable bulk. Wear, 140(1):17-38, 1990.

[37] T. Mishra, M.B. de Rooij, M.P. Shisode, J. Hazrati, and D.J. Schipper. Characterization of interfacial shear strength and its effect on ploughing behaviour in single-asperity sliding. Wear, 436:203042, 2019 .

[38] M.B. de Rooij. Tribological aspects of unlubricated deep drawing processes. PhD thesis, University of Twente, 1998.

[39] J.M. Challen and P.L.B. Oxley. An explanation of the different regimes of friction and wear using asperity deformation models. Wear, 53(2):229-243, 1979.

[40] J.M. Challen and P.L.B. Oxley. Slip-line fields for explaining the mechanics of polishing and related processes. International Journal of Mechanical Sciences, 26(6-8):403-418, 1984. 
[41] T. Mishra, M.B. de Rooij, M.P. Shisode, J. Hazrati, and D.J. Schipper. An analytical model to study the effect of asperity geometry on forces in ploughing by an elliptical asperity. Tribology International, 137:405-419, 2019.

[42] D. Tabor. Junction growth in metallic friction: the role of combined stresses and surface contamination. Proceedings of the Royal Society of London. Series A. Mathematical and Physical Sciences, 251(1266):378-393, 1959.

[43] T. Kayaba and K. Kato. Experimental analysis of junction growth with a junction model. Wear, 51(1):105-116, 1978.

[44] J.S. McFarlane and D. Tabor. Relation between friction and adhesion. Proceedings of the Royal Society of London. Series A. Mathematical and Physical Sciences, 202(1069):244-253, 1950.

[45] W.C. Emmens. Tribology of flat contacts and its application in deep drawing. PhD thesis, University of Twente, 1997.

[46] S. Lo and S. Tsai. Real-time observation of the evolution of contact area under boundary lubrication in sliding contact. Journal of Tribology, 124(2):229-238, 2002.

[47] J.S. Courtney-Pratt and E. Eisner. The effect of a tangential force on the contact of metallic bodies. Proceedings of the Royal Society of London. Series A. Mathematical and Physical Sciences, 238(1215):529-550, 1957.

[48] A. Ovcharenko, G. Halperin, and I. Etsion. In situ and real-time optical investigation of junction growth in spherical elastic-plastic contact. Wear, 264(11-12):1043-1050, 2008.

[49] T. Mishra, M.B. de Rooij, M.P. Shisode, J. Hazrati, and D.J. Schipper. A material point method based ploughing model to study the effect of asperity geometry on the ploughing behaviour of an elliptical asperity. Tribology International, 142:106017, 2020.

[50] T. Mishra, M.B. de Rooij, M.P. Shisode, J. Hazrati, and D.J. Schipper. Characterization of interfacial shear strength and its effect on ploughing behaviour in single-asperity sliding. Wear, 436:203042, 2019 . 
[51] T. Mishra, G.C. Ganzenmüller, M.B. de Rooij, M.P. Shisode, J. Hazrati, and D.J. Schipper. Modelling of ploughing in a singleasperity sliding contact using material point method. Wear, 418:180190, 2019.

[52] H. Vegter and A.H. van den Boogaard. A plane stress yield function for anisotropic sheet material by interpolation of biaxial stress states. International Journal of Plasticity, 22(3):557-580, 2006.

[53] A.H. van den Boogaard and J. Huétink. Simulation of aluminium sheet forming at elevated temperatures. Computer Methods in Applied Mechanics and Engineering, 195(48-49):6691-6709, 2006.

[54] W.R.D. Wilson. Friction and lubrication in bulk metal-forming processes. Journal of Applied Metalworking, 1(1):7-19, 1978.

[55] H.G. Elrod. Thin-film lubrication theory for Newtonian fluids with surfaces possessing striated roughness or grooving. Journal of Lubrication Technology, 95(4):484-489, 1973.

[56] H. Christensen. Stochastic models for hydrodynamic lubrication of rough surfaces. Proceedings of the Institution of Mechanical Engineers, 184(1):1013-1026, 1969.

[57] H. Christensen and K. Tonder. The hydrodynamic lubrication of rough bearing surfaces of finite width. Journal of Lubrication Technology, 93(3):324-329, 1971.

[58] K. Tønder and H. Christensen. Waviness and roughness in hydrodynamic lubrication. Proceedings of the Institution of Mechanical Engineers, 186(1):807-812, 1972.

[59] N. Patir and H.S. Cheng. An average flow model for determining effects of three-dimensional roughness on partial hydrodynamic lubrication. Journal of Lubrication Technology, 100(1):12-17, 1978.

[60] N. Patir and H.S. Cheng. Application of average flow model to lubrication between rough sliding surfaces. Journal of Lubrication Technology, 101(2):220-229, 1979.

[61] J.H. Tripp. Surface roughness effects in hydrodynamic lubrication: The flow factor method. Journal of Lubrication Technology, 105(3):458-463, 1983. 
[62] S. Lo. A study on flow phenomena in mixed lubrication regime by porous medium model. ASME Journal of Tribology, 116:640-647, 1994.

[63] F. Dörr and M. Liewald. Determination of flow factors for the semianalytical prediction of friction coefficients. Production Engineering, 6(1):19-27, 2012.

[64] H.G. Elrod. A general theory for laminar lubrication with Reynolds roughness. Journal of Lubrication Technology, 101(1):8-14, 1979.

[65] C. Wu and L. Zheng. An average Reynolds equation for partial film lubrication with a contact factor. Journal of Tribology, 111(1):188191, 1989.

[66] W.R.D. Wilson and D. Chang. Low speed mixed lubrication of bulk metal forming processes. Journal of Tribology, 118(1):83-89, 1996.

[67] W.R.D. Wilson and N. Marsault. Partial hydrodynamic lubrication with large fractional contact areas. Journal of Tribology, 120(1):16-20, 1998.

[68] J.F. Booker and K.H. Huebner. Application of finite element methods to lubrication: an engineering approach. Journal of Lubrication Technology, 94(4):313-323, 1972.

[69] Y. Hu and W.K. Liu. An ALE hydrodynamic lubrication finite element method with application to strip rolling. International Journal for Numerical Methods in Engineering, 36(5):855-880, 1993.

[70] T. Yang and S. Lo. A finite element analysis of full film lubricated metal forming process. Tribology International, 37(8):591-598, 2004.

[71] J. Hol, V.T. Meinders, H.J.M. Geijselaers, and A.H. van den Boogaard. Multi-scale friction modeling for sheet metal forming: The mixed lubrication regime. Tribology International, 85:10-25, 2015.

[72] B.J. Hamrock, S.R. Schmid, and B.O. Jacobson. Fundamentals of fluid film lubrication. CRC press, 2004.

[73] S. Lo. On the effects of roughness orientation - a mapping and double scale analysis of flow factors. ASME Journal of Tribology, 114:747$754,1992$. 
[74] F. Sahlin, R. Larsson, A. Almqvist, P.M. Lugt, and P. Marklund. A mixed lubrication model incorporating measured surface topography. part 1: theory of flow factors. Proceedings of the Institution of Mechanical Engineers, Part J: Journal of Engineering Tribology, 224(4):335-351, 2010.

[75] N. Patir. Effects of surface roughness on partial film lubrication using an average flow model based on numerical simulation. PhD thesis, Northwestern University, 1978.

[76] J.L. Teale and A.O. Lebeck. An evaluation of the average flow model for surface roughness effects in lubrication. Journal of Lubrication Technology, 102:360-366, 1980.

[77] L. Lunde and K. Tonder. Pressure and shear flow in a rough hydrodynamic bearing, flow factor calculation. Journal of Tribology, 119:549-555, 1997.

[78] Y. Hu and L. Zheng. Some aspects of determining the flow factors. ASME Journal of Tribology, 111:525-531, 1989.

[79] S.R. Harp and R.F. Salant. An average flow model of rough surface lubrication with inter-asperity cavitation. Journal of Tribology, 123(1):134-143, 2001.

[80] S. Xiong and Q.J. Wang. Steady-state hydrodynamic lubrication modeled with the Payvar-Salant mass conservation model. Journal of Tribology, 134(3), 2012.

[81] I. Etsion. Modeling of surface texturing in hydrodynamic lubrication. Friction, 1(3):195-209, 2013.

[82] K. Tønder. Numerical investigation of the lubrication of doubly periodic unit roughnesses. Wear, 64(1):1-14, 1980.

[83] P. Payvar and R.F. Salant. A computational method for cavitation in a wavy mechanical seal. Journal of Tribology, 114(1):199-204, 1992.

[84] S. Patankar. Numerical heat transfer and fluid flow. CRC press, 1980.

[85] R. Zhou, J. Cao, Q.J. Wang, F. Meng, K. Zimowski, and Z.C. Xia. Effect of EDT surface texturing on tribological behavior of aluminum sheet. Journal of Materials Processing Technology, 211(10):16431649, 2011. 
[86] Y. Cho, T. Kim, and Y. Koo. Effect of kurtosis on the flow factors using average flow model. JSME International Journal Series C Mechanical Systems, Machine Elements and Manufacturing, 47(1):429-434, 2004.

[87] M.P. Shisode, J. Hazrati, T. Mishra, M.B. de Rooij, C.H.L.J. ten Horn, J. van Beeck, and A.H. van den Boogaard. Modeling boundary friction of coated sheets in sheet metal forming applications. Accepted in Tribology International, 2020.

[88] J. van Beeck, T. Chezan, and T. Khandeparkar. Advanced tribomechanical modelling of sheet metal forming for the automotive industry. MSEE, 418(1):012096, 2018.

[89] G.F. Batalha and M.S. Filho. Quantitative characterization of the surface topography of cold rolled sheets - new approaches and possibilities. Journal of Materials Processing Technology, 113(13):732-738, 2001.

[90] M. Vermeulen and J. Scheers. Micro-hydrodynamic effects in EBT textured steel sheet. International Journal of Machine Tools and Manufacture, 41(13-14):1941-1951, 2001.

[91] J. Scheers, M. Vermeulen, C. de Mare, and K. Meseure. Assessment of steel surface roughness and waviness in relation with paint appearance. International Journal of Machine Tools and Manufacture, 38(5-6):647-656, 1998.

[92] S. Mezghani, H. Zahouani, and J. Piezanowski. Multiscale characterizations of painted surface appearance by continuous wavelet transform. Journal of Materials Processing Technology, 211(2):205-211, 2011.

[93] O. Elkoca. A study on the characteristics of electrical discharge textured skin pass mill work roll. Surface and Coatings Technology, 202(12):2765-2774, 2008.

[94] J. Simao, D.K. Apinwall, M.L.H. Wise, and K. Subari. Surface texture transfer in simulated tandem and temper mill rolling using electrical discharge textured rolls. Journal of Materials Processing Technology, 56(1-4):177-189, 1996. 
[95] D. Du, Y.F. He, B. Sui, L.J. Xiong, and H. Zhang. Laser texturing of rollers by pulsed Nd: Yag laser. Journal of Materials Processing Technology, 161(3):456-461, 2005.

[96] H. Mustafa, D.T.A. Matthews, and G.R.B.E. Römer. Influence of the pulse duration at near-infrared wavelengths on the laser-induced material removal of hot-dipped galvanized steel. Journal of Laser Applications, 32(2):022015, 2020.

[97] D. Bijani, E.L. Deladi, A. Akchurin, M.B. de Rooij, and D.J. Schipper. The influence of surface texturing on the frictional behaviour of parallel sliding lubricated surfaces under conditions of mixed lubrication. Lubricants, 6(4):91, 2018.

[98] I. Etsion and L. Burstein. A model for mechanical seals with regular microsurface structure. Tribology Transactions, 39(3):677-683, 1996.

[99] A. Kovalchenko, O. Ajayi, A. Erdemir, G. Fenske, and I. Etsion. The effect of laser surface texturing on transitions in lubrication regimes during unidirectional sliding contact. Tribology International, 38(3):219-225, 2005.

[100] L. Galda, P. Pawlus, and J. Sep. Dimples shape and distribution effect on characteristics of Stribeck curve. Tribology International, 42(10):1505-1512, 2009.

[101] M. Jonasson, T. Pulkkinen, L. Gunnarsson, and E. Schedin. Comparative study of shotblasted and electrical-discharge-textured rolls with regard to frictional behavior of the rolled steel sheet surfaces. Wear, 207(1-2):34-40, 1997.

[102] X. Liu, M. Liewald, and D. Becker. Effects of rolling direction and lubricant on friction in sheet metal forming. Journal of Tribology, 131(4), 2009.

[103] H. Mustafa, M. Mezera, D.T.A. Matthews, and G.R.B.E. Römer. Effect of surface roughness on the ultrashort pulsed laser ablation fluence threshold of zinc and steel. Applied Surface Science, 488:1021,2019 .

[104] M. Qiu, A. Delic, and B. Raeymaekers. The effect of texture shape on the load-carrying capacity of gas-lubricated parallel slider bearings. Tribology Letters, 48(3):315-327, 2012. 
[105] D.J. Wentink, D.T.A. Matthews, N.M. Appelman, and E.M. Toose. A generic model for surface texture development, wear and roughness transfer in skin pass rolling. Wear, 328:167-176, 2015.

[106] M. Nitschke. Roll texturing and roll grinding as a basis for modern surface structures in automotive cold mill flat products. SEAISI Quarterly, 33(1):65-72, 2004.

[107] K. Hodgson, R.S. Dwyer-Joyce, and B.W. Drinkwater. Ultrasound as an experimental tool for investigating engineering contacts. Tribologia, 19(4):9-17, 2000.

[108] D. Petrova, B. Weber, C. Allain, P. Audebert, D. Bonn, and A.M. Brouwer. Fast 3d microscopy imaging of contacts between surfaces using a fluorescent liquid. ACS Applied Materials \& Interfaces, 10(48):40973-40977, 2018.

[109] D. Petrova, B. Weber, C. Allain, P. Audebert, C.H. Venner, A.M. Brouwer, and D. Bonn. Fluorescence microscopy visualization of the roughness-induced transition between lubrication regimes. Science Advances, 5(12):eaaw4761, 2019.

[110] H. Hertz. About the contact of elastic solid bodies (Über die Berührung fester elastischer Körper). J Reine Angew Math, 5:12-23, 1881. 
